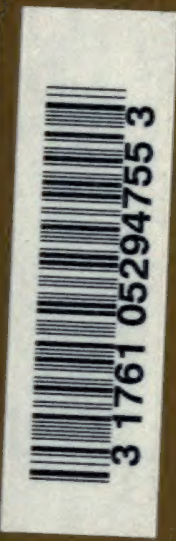


Digitized by the Internet Archive in 2008 with funding from Microsoft Corporation 


$\mathrm{H}_{4}$

CHEMICAL PHYSIOLOGY 
By the same Author.

A TEXT-BOOK OF CHEMICAL PHYSIOLOGY AND PATHOLOGY.

With 104 Illustrations. 8 vo. 288.

LONGMANS, GREEN, \& CO., 39 Paternoster Row

London, New York, and Bombay. 


\section{THE ESSENTIR\&S}

PHYSIOLOG Y"

FOR THE USE OF STUDENTS

BY

W. D. HALLIBURTON, M.D., F.R.S.

FELLOW OF THE ROYAL COLLEGE OF PHYSICIANS

PROFESSOR OF PHYSIOLOGY IN KING'S COLLBGE, LONDON

AUTHOR OF 'TEXT-BOOK OF CHEMICAL PHYSIOLOGY AND PATHOLOGY'

FOURTH EDITION

LONGMANS, GREEN, AND CO. 39 PATERNOSTER ROW, LONDON NEW YORK AND BOMBAY 1901 


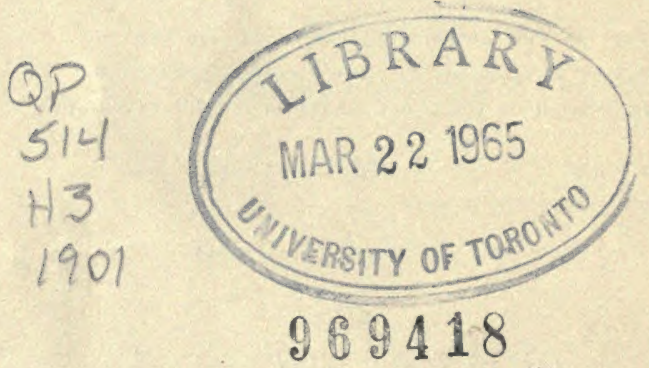




\section{PREFACE}

\section{To \\ THE FOURTH EDITION}

THE general arrangement and plan of this book remain the same as in previous editions. The subject matter has been brought up to date.

I have endeavoured to keep the work within a moderate compass, but, with the advance of the science, even its essentials expand.

The principal additions now introduced are new sections relating to the chemistry of nervous tissues and of the purine compounds and to the important subject of osmosis. The description of the phenomena of polarised light has also been considerably expanded.

I have to thank Dr. H. Willoughby LyLe, who has again assisted me in reading proof-sheets and preparing the Index.
W. D. HALLIBURTON.

KnNG's CoLt.Ege: May 1901. 



\section{CONTENTS}

INTRODUCTION .

\section{ELEMENTARY COURSE}

Lissor

I. The CaRbohtdrates and Fats . . . . . . . 9

II. The Protemos . . . . . . . . . . . 19

III. The Proteids (continued) . . . . . . . 20

IV. FOODB.$+ \div$. . . . . . . . 33

V. SAITVA + . . . . . . . . . . . 44

VI. Peptic Digestion . . . . . . . . . . 52

ViI. Pancreatic Digegtios . . . . . . . . . 60

VIII. BHE . . . . . . . . . . . . 69

IX. THE BloOd . . . . . . . . . . . 81

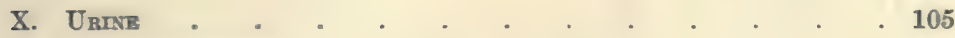

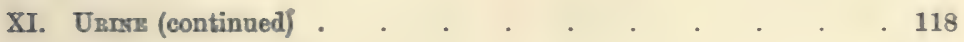

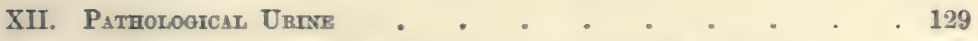

Scheme for Detecting Physological Prosmate Prescipless o 134

\section{ADVANCED COURSE}

IxTRODECTION .

Lpssox

XIII. Carbohidrates . . . . . . . . . . 140

XIV. Action of Malt tpon Stakch . . . . . . . . 143

XV. Crtstaluifation of Egg Albumin . . . . . . . 144

XVI. Coagulation of Míli . . . . . . . . . 115

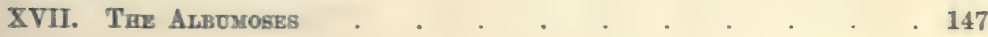


XVIII. Digestion

XIX. HEMOGLOBIN AND ITS DERTVATIVES . . . . . . . 151

XX. SERUM . . . . . . . . . . . . 155

XXI. Colgutation of Blood . . . . . . . . . . . 157

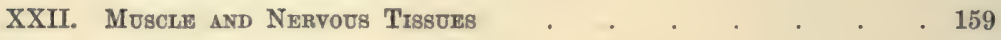

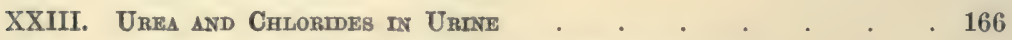

XXIV. Estmation of Phosphate and Sulphates in Urine . . . 171

XXV. Uric Acid and Creatinine * . . . . . . . . . . 174

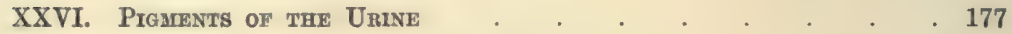

\section{APPENDIX}

HЕYACYTOMETER . . . . . . . . . . . . . . 181

HIEMOGLOBINOMETERS . . . . . . . . . . . . . 183

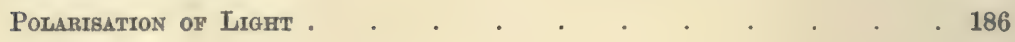

Pollarimeters . . . . . . . . . . . . . . . . . 190

The Spectro-Polarimeter . . . . . . . . . . . . 193

Relation between Circular Polarisation and Chemical Constitutron • 194

Mercuriat Atr PUMpg . . . . . . . . . . . 195

ANALYSIS OF GASES . . . . . . . . . . . . . . . 198

Kjeldahl's Method of Estmating Nitrogen . . . . . . . . 199

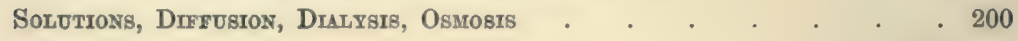

INDEX * . . . . . . . . . . . . . 209 


\section{LIST OF ILLUSTRATIONS}

YTG.

1. Dextrosin Orystals

2. Ivostre Crystals . Frey 12

3. Muh-gogar Crystals Frey 13

4. Section of Pra, showng \$tarch Gratas Yco, after Sachs 15

5. Fat Cerus - Schäfer 16

6. Stmplu Wanm Bath 20

7. Duluser 23

8. Dialyger 23

9. Dhagrat of a Cext - Schäfer 29

10. Мrik - $Y e 0 \quad 36$

11. Cotostrum Composches . Heidenhain 36

12. Autzont of Serous Gland - Langley 46

13. Mucots Cents - Langley 46

14. Sobmagmiary Glavid Heidenhain 46

15. Yrabt Crats . Yeo's Physiology 47

16. Schzomrycetes After Zopf $\quad 48$

17. Bactulog Axthracis Koch 49

18. Cardic Guavd Klein 53

19. Prlome Gland Ebstein 53

20. Cardiac Glayd - Langley 54 21. Alveolus of Paxcreas . . . . . . . Kïhne and Lea 61 22. Lruche Cristats . . . . . . . . . Kuhne 61 23. Tyrosnve Crystaus. . . . . . . . Frey 66

24. Hzмatordis Crystals . . . . . . Frey 70

25. Cholegrern Chystafs. . . . . . . Frey 73 
FIG.

PAGE

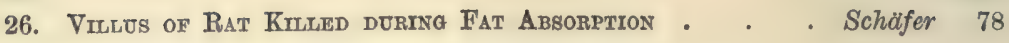

27. Mocods Membrane of Frog's Intestine during Fat

Absorption * . . . . . . . . Schäfer 78

28 Fibrin Fruaments and Blood Tablets . . . . . Schäfer 83

29. Action of Reagents on Blood Conperoless . . . . Schäfer 88

30. Oxthamoglobin Crystals . . . . Q Quain's Anatomy 89

31. H正m Crystals . . . . . . . . . Preyer 91

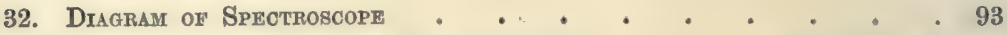

33. Figure of Spectroscope and Accessories . . . McKendrick 93

34. Arrangement of Prisms in Direct-vision Spectroscope Gscheidlen 94

35. Stand for Dtrect-vision Spectroscope . . . . . . 95

36. Agsorption Spectra . . . . . . . . Rollet 95

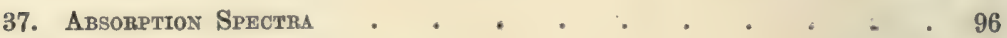

38. Dupré's Urea Apparatus . . . . . . . Gamgee 106

39. URINOMETER . . . . . . . . . McKendrick 108

40. Urea Crystatis . . . . . . . . . Frey 108

41. Urea Nitrate axd Oxalate . . . . . . Frey 110

42. Triple Phosphate Crxstals . . . . . . . Frey 117

43. Uric Acid Crystals . . . . . . . Frey 119

44. Hippuric Act Crystals . . . . . . . . Frey 123

45. Creatine Crystats . . . . . . . . . Frey 124

46. Creatring Crystals . . . . . . . . Frey 124

47. Acid Sodium Urate . . . . . . . . Frey 126

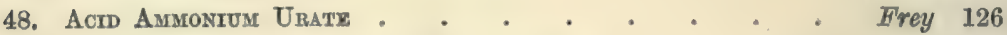

49. Envelope Cristals of Calcium Oxamate . . . . Frey 126

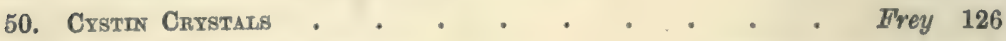

51. Triple Phosphate Crystals . . . . Bryant's Surgery 127

52. Calcium Phosphate Crystals . . . . Bryant's Surgery 127

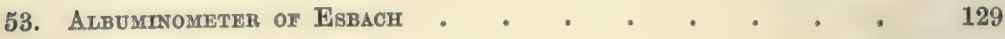

54. Two Burettess on Stand . . . . . . . Sutton 130

55. Hot-air Oven with Gas Regulator . . . . Gscheidlen 140

56. Osazone Crystals . . . . . . Coloured plate to face 141

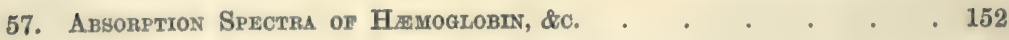

58. Pgotographic Spectrum oz Hemoglobin and Oxyhzmogrobin Gamgee 153 
FIG.

$\Delta G \mathbf{B}$

59. Photographic Spectrey of Oxihzmoglobe and Methemo- Gamgee 153

60. Ceastrifugar Machene 157

61. Arsorption Spectra of Myohemates 160

62. A Destcator

Gscheidlen 161

63. Absorption Spectra of Urtiary Ptguests After Hopkins 179

64. Gowers' HaNACYTOMETER 181

65. OLIFER's HæMacyToMeter 182

66. Gowers' HæxмogLobnometer . 183

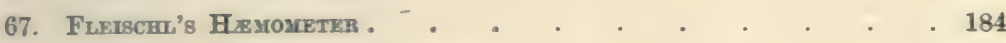

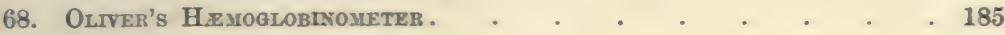

69. Model to Inlustrate Polarised Lieht • • • . . . 187

70. Modél to Ihllustrate Polariagd Light • • . . . . 187

71. Model to Inlustrate Polartied Light • • . . . . 188

72. Diagram to Explang Polartsation of Light . . . . . 189

73. Dugram to Explaty Polarisation of Light • . . . . 190

74. SOLFIL's SACCHARIMETEB . . . . . . . • . 191

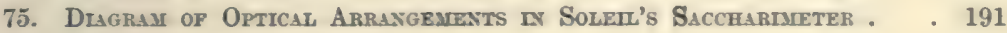

76. Lacreant's Polnkmimter . . . . . . . . . 192

77. Spectro-pothrimeter of von FletschL. . . . . . . 193

78. Diagram of Asmametric Carbon Atours . . . . . . 195

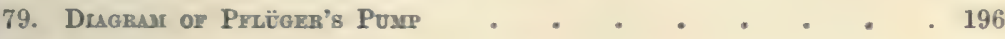

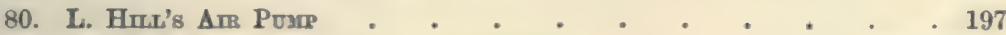

81. WALLER's Apparatus yor GAS AxaLysts • • . . Waller 198

82. KJELDAнL's MzTHоD • • . . Waller, after Argutinsky 199

83. Diagram to Illugtrate Osarosis . . . . . . . . 203 



\section{ESSENTIALS \\ OF \\ CHEMICAL PHYSIOLOGY}

\section{INTRODUCTION}

Chemical Physiology or Physiological Chemistry, as it is sometimes termed, deals with the chemical composition of the body and with the chemical changes it undergoes; it deals also with the composition of the food which enters, and the excretions which leave, the body.

When a chemist examines liring things he is placed at a disadvantage when compared with an anatomist; for the latter can with the microscope examine cells, organisms, and structures in the living condition. The chemist, on the other hand, cannot at present state anything positive about the chemical structure of living matter, because the reagents he uses will destroy the life of the tissue he is examining. There is, however, no such disadvantage when he examines non-living matter, like food and urine, and it is therefore in the analysis of such substances that chemical physiology has made very important advances, and the knowledge so obtained is of the greatest practical interest to the student and practitioner of medicine.

The animal organism is in its earliest embryonic state a single cell; as development progresses it becomes an adherent mass of simple cells. In the later stages various tissues become differentiated from each other by the cells becoming grouped in different ways, by alterations in the shape of the cells, by deposition of intercellular matter between the cells, and by chemical changes in the living matter of the cells themselves. Thus in some situations the cells are grouped into the various epithelial linings; in others the 
cells become elongated, and form muscular fibres; in the connective tissues we have a preponderating amount of intercellular material, which may become permeated with fibres, or be the seat of the deposition of calcareous salts, as in bone. Instances of chemical changes in the cells themselves are seen on the surface of the body, where the superficial layers of the epidermis become horny (i.e. filled with the chemical substance called keratin); in the mucous salivary glands, where the cells become filled with mucin, which they subsequently extrude; and in adipose tissue, where they become filled with fat.

In spite of these changes, the variety of which produces the great complexity of the adult organism, there are many cells which still retain their primitive structure; notable among these are the white corpuscles of the blood.

A cell may be defined as a mass of living material containing in its interior a more solid structure called the mucleus. The nucleus exercises a controlling influence over the nutrition and subdivision of the cell.

The living substance is usually pervaded with granules; one of these minute particles called the centrosome exercises an attractive influence on the granules and fibrils of the protoplasm in its neighbourhood, and the appearance so produced is called the attraction sphere. The attraction sphere becomes especially prominent, and divides into two when the cell is about to divide; this usually precedes the division of the nucleus.

Living material is called protoplasm, and protoplasm is characterised by (1) its power of movement (seen in amœboid movement, ciliary movement, muscular movement); (2) its power of assimilation, that is, it is able to convert into protoplasm the nutrient material or food which is ingested; (3) its power of growth-this is a natural consequence of its power of assimilation; (4) its power of reproduction-this is a variety of growth; and (5) its power to excrete, to give out waste materials, the products of its other activities.

Of all the signs of life, those numbered 2 and 5 in the foregoing list are the most essential. Living material is in a continual state of unstable chemical equilibrium, building itself up on the one hand, breaking down on the other; the term used for the sum total of these intra-molecular rearrangements is metabolism. The chemical substances in the protoplasm which are the most important from this point of view are the complex nitrogenous compounds called Proteids. So far as is at present known, proteid material is never absent from 
living substance, and is never present in anything else than that which is alive or has been formed by the agency of living cells. It may therefore be stated that Proteid Metabolism is the most essential characteristic of vitality.

The chemical structure of protoplasm can only be investigated after the protoplasm has been killed. The substances it yields are (1) Water; protoplasm is semi-fluid, and at least three-quarters of its weight, often more, are due to water. (2) Proteids. These are the most constant and abundant of the solids. A proteid or albuminous substance consists of carbon, hydrogen, nitrogen, oxygen, with sulphur and phosphorus in small quantities only. In nuclein, a proteid-like substance obtained from the nuclei of cells, phosphorus is more abundant. The proteid obtained in greatest abundance from the cell-protoplasm is nucleo-proteid, that is a compound of proteid with varying amounts of nuclein. White of egg is a familiar instance of an albuminous substance or proteid, and the fact (which is also familiar) that this sets into a solid on boiling will serve as a reminder that the greater number of the proteids found in nature have a similar tendency to coagulate under the influence of heat and other agencies. (3) Various other substances occur in smaller proportions, the most constant of - which are lecithin, a phosphorised fat ; cholesterin, a monatomic alcohol; and inorganic salts, especially phosphates and chlorides of calcium, sodium, and potassium.

It will be seen from this rapid survey of the composition of the body how many are the substances which it is necessary we should study ; the food from which it is built up is also complex, for animals do not possess to such an extent as plants do the power of building up complex from simple materials.

We may now proceed to an enumeration of the chemical constituents of the animal body, and group them in a systematic way.

The substances out of which the body is built consist of chemical elements and of chemical compounds, or unions of these elements.

The elements found in the body are carbon, hydrogen, njtrogen, oxygen, sulphur, phosphorus, fluorine, chlorine, iodine, silicon, sodium, potassium, calcium, magnesium, lithium, iron, and occasionally manganese, copper, and lead.

Of these very few occur in the free state. Oxygen (to a small extent) and nitrogen are found dissolved in the blood-plasma; hydrogen is formed by putrefaction in the alimentary canal. With some few exceptions such as these, the elements enumerated above are found combined with one another to form compounds. 
The compounds, or, as they are generally termed in physiology, the proximate principles, found in the body are divided into-

(1) Mineral or inorganic compounds.

(2) Organic compounds, or compounds of carbon.

The inorganic compounds present are water, various acids (such as hydrochloric acid in the gastric juice), ammonia (as in the urine), and numerous salts, such as calcium phosphate in bone, sodium chloride in blood and urine, and many others.

The organic compounds are more numerous; they may be subdivided into-

1. Various groups of alcohols and organic acids, and their derivatives, such as the fats and carbohydrates.

2. Various derivatives of ammonia, amides, amines, urea, \&c.

3. Aromatic bodies, or derivatives of benzene.

4. Proteids, the most important of all, and substances allied toproteids like the albuminoids, pigments, and ferments.

A more convenient practical method of grouping the proximate principles of the body and of food is the following :-

Inorganic . $\quad$ Organic $\left\{\begin{array}{c}\text { Nitrogenous } \\ \text { Non-nitrogenous }\end{array}\right.$

Water.

Salts-e.g.chlorides and phosphates of sodium and calcium.

Proteids-e.g. albumin, myosin.

Albuminoids-e.g. gelatin, keratin.

Simpler nitrogenous bodies-e.g. lecithin, creatine, urea.

Fats-e.g. butter, fats of adipose tissue.

Carbohydrates-e.g. sugar, starch.

Simple organic bodies - e.g. alcohol, cholesterin, vegetable acids, and salts, lactic acid.

Many of the substances enumerated above only occur in small quantities. The most important are the inorganic substances, water and salts; and the organic substances, proteids, carbohydrates, and fats. It is necessary in our subsequent study of the principles of chemical physiology that we should always keep in mind this simple classification; the subdivision of organic substances into proteids, fats, and carbohydrates forms the starting point, the A B C, as one might say, of chemical physiology.

I will conclude this introductory chapter by giving a list of the apparatus and reagents necessary for a practical study of the subject, and some tables which it will be often found convenient to refer to.

The following set of reagents conveniently contained in 4 to $6 \mathrm{oz}$. glass stoppered bottles should be provided for each two students :-

Sulphuric acid, concentrated.

$\begin{array}{lll}\prime & \quad 25 \text { per cent. } \\ . . & . . & 0 \cdot 1 \quad .\end{array}$


Nitric acid, concentrated.

Fuming nitric acid.

Hydrochloric acid, concentrated.

Acetic" acid, glacial. $0-2$ per cent. ${ }^{.}$

", 20 per cont.

Glyoxylic acid.

Caustic potash, 20 per cent.

Ammonia.

" $\quad 0.1 \quad$,

Sodium carbonate, 1 per cent.

Ammonium sulphide solution.

Ammonium sulphate, saturated solution.

Silver nitrate, 1 per cent.

Barium ehloride, saturated solution.

Ammonium molybdate solution.

Millon's reagent. ${ }^{2}$

Solution of ferrocyanide of potassium.

" litmus.

" sodium phosphate.

Methylated spirit.

iodine in potassium iodide.

Ether.

Esbach's reagent. ${ }^{3}$

Solution of copper sulphate, 1 per cent.

Fehling's solution.

The following additional reagents will be required by those taking the advanced course:-

Solution of mercuric chloride.

" potassium ferricyanide.

Sodium carbonate, saturated solution.

" chloride, saturated solution.

" $\quad$ 10-per-cent, solution.

Magnesium sulphate, saturated solution.

Lime water.

Baryta mixture. 4

Sodium acetate solution. ${ }^{5}$

Phosphoric acid, 0.5 per cent.

Absolute alcohol.

In addition to these, there should be kept in stock in the laboratory, to be given out for the lessons in which they are used, the following:-

Solid sodium chloride.

" magnesium sulphate.

1 Made by adding 994 c.c. of water to 6 c.c. of the concentrated hydrochloric acid of the British Pharmacopoeia.

2 Mercury is dissolved in its own weight of strong nitric acid. The solution so obtained is diluted with twice its volume of water. The decanted clear liquid is Millon's reagent.

${ }^{3}$ Ten grammes of picric acid and 20 grammes of eitric acid are dissolved in 800 to 900 c.c. of boiling water, and then sufficient water added to make up a litre.

- Made by mixing 1 volume of barium nitrate solution with 2 of barium hydrate solution, both saturated in the cold.

${ }^{5}$ Prepared as follows :- Sodium acetate, 100 grammes; water, 900 c.c.; glacial acetic acid, 100 c.c. 
Solid ammonium sulphate.

" sodio-magnesium sulphate.

Standard solution of uranium acetate or nitrate for estimating phosphates. ${ }^{1}$

Standard solution of mercuric nitrate for estimating urea.
99
99
silver
"
"
Caustic soda, 40 per cent.
Bromine.
Solution of potassium bichromate.
Phenyl hydrazine hydrochloride.
Solid sodium acetate.
Phospho-tungstic acid.
Glacial phosphoric acid.

Each student should be provided with-

A Bunsen burner.

1 dozen test-tubes in test-tube stand.

2 or 34 -oz. flasks.

2 flat porcelain dishes.

2 or 44-oz. beakers.

2 small glass funnels and a funnel stand.

A glass stirring rod and a small pipette.

1 burette.

An iron tripod with wire gauze.

Filter papers and litmus papers.

A 100-c.c. cylindrical measuring glass.

A thermometer marked in degrees Centigrade.

A urinometer.

A tin can on a stand to be used as a water-bath.

Apparatus which is not so frequently used, such as that employed in generating carbonic anhydride, carbonic oxide, or sulphuretted hydrogen, may be given out as required. The laboratory should also possess a good balance, with its accessories, water and air baths, kept at various temperatures, retorts, and analytical apparatus generally. The microscope, polarimeter, spectroscope, dialyser, are also frequently employed in chemico-physiological investigations.

\section{WEIGHTS AND MEASURES}

The weights and measures usually employed in science are those of the metric system, but as in this country the practical physician still largely uses English grains and ounces, we may compare the two systems in the following way :-

Weights

(English System.)
1 grain $=0.0648$ gramme
1 ounce $=487.5$ grains $=28.3595$ grammes
$1 \mathrm{lb},=16 \mathrm{oz} .=7,000$ grains $=453.5925$ "

The scruple $=20$ grains $=1 \cdot 296$ gramme, and the drachm $=60$ grains $=3.888$ grammes, are retained in use, but neither is an aliquot part of the ounce; though for practical purposes an ounce is considered to consist of 8 drachms.

' Instructions how to make standard solutions will be given in the lessons where they are used. 
(Metric System.)

1 milligramme $=$
1 centigramme $=$
1 decigramme $=$
1 gramme
1 decagramme $=10$
1 hectogramme $=100$
1 kilogramme $=1,000$

$\begin{aligned} 0.001 \text { gramme } & =0.015432 \text { grain } \\ 0.01 \quad & =154323 " \\ 0.1 \quad & =1.543235 \text { " } \\ \text { grammes } & =154.3235 \text { grains } \\ " & =1543.235 \\ " & =15432.35 \\ & =21 \mathrm{~b} .3 \mathrm{oz} .119 .8,\end{aligned}$

Measures of Length

(English System.)

1 inch $=25^{\circ} 4$ millimetres

1 foot $=12$ inches $=304 \cdot 8$ millimetres

(Motric System.)

The standard of length is the metre; subdivisions and multiples of which, with the prefixes milli-, centi-, and deci-, on the one hand, and deca-, hecto-, and kilo-, on the other, have the same relation to the metre as the subdivisions and multiples of the gramme, in the table just given, have to the gramme, thus: .

$$
\begin{aligned}
& 1 \text { millimetre }=0.001 \text { metre }=0.03937 \text { inch } \\
& 1 \text { centimetre }=0.01 \quad, \quad=0.3937, ", \\
& 1 \text { decimetre }=0.1 \quad, \quad=3.93707 \text { inches } \\
& 1 \text { metre }
\end{aligned}
$$

\section{Measures of Capacity}

(English System.)

$\begin{array}{ll}1 \text { minim } & =0.059 \text { cubic centimetre } \\ 1 \text { fluid drachm = } 60 \text { minims } & =3.549 \text { cubic centimetres } \\ 1 \text { fluid ounce }=8 \text { fluid drachms } & =28.398 \\ 1 \text { pint }=20 \text { fluid ounces } & =567.936 \\ 1 \text { gallon }=8 \text { pints } & =4.54837 \text { litres }\end{array}$

(Metric System.)

In the metric system the measures of capacity are intimately connected with the measures of length; we thus have cubic millimetres, cubic centimetres, and so forth. The standard of capacity is the litre, which is equal to 1,000 cubic centimetres ; and each cubic centimetre is the rolume of 1 gramme of distilled water at $4^{\circ} \mathrm{C} .{ }^{1}$

1 cubic centimetre (generally written c.c.) $=16.931$ minims.

1 litre $=1,000$ c.c. $=1$ pint 15 oz. 2 drs. $11 \mathrm{~m} .=35 \cdot 2154$ fluid ounces.

1 cubic inch $=16 \cdot 386$ c.c.

\section{THERMOMETRIC SCALES}

The seale most frequently used in this country is the Fahrenheit scale; in this the freezing-point of water is $32^{\circ}$, and the boiling-point $212^{\circ}$. On the Continent the Réaumur scale is largely employed, in which the freezing.

$14^{\circ} \mathrm{C}$. is the temperature at which water has the greatest density. For practical purposes measures are more often constructed so that a cubic centimetre holds a gramme of water at $16^{\circ} \mathrm{C}$., which is about the average temperature of rooms. The true cubic centimetre contains only 0.999 gramme at $16^{\circ} \mathrm{C}$. 
point is $0^{\circ}$, and the boiling-point $80^{\circ}$. In scientific work the Centigrade scale has almost completely taken the place of these; in this system the freezing-point is $0^{\circ}$, and the boiling-point $100^{\circ}$.

To convert degrees Fahrenheit into degrees Centigrade, subtract 32 and multiply by $\frac{5}{9}$, or $\mathrm{C}=(\mathrm{F}-32)_{9}^{5}$. Conversely, degrees Centigrade may be converted into degrees Fahrenheit by the following formula: $\mathrm{F}=\frac{9}{5} \mathrm{C}+32$.

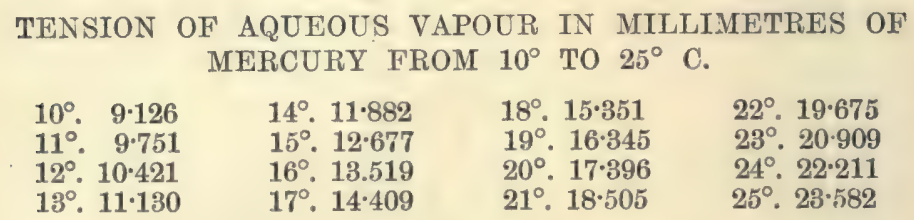

TABLE OF THE DENSITY OF WATER AT TEMPERATURES BETWEEN $0^{\circ}$ AND $30^{\circ} \mathrm{C}$.

$\begin{array}{rrrr}0^{\circ} \cdot 0 \cdot 99988 & 8^{\circ} \cdot 0 \cdot 99988 & 16^{\circ} \cdot 0 \cdot 99900 & 24^{\circ} \cdot 0 \cdot 99738 \\ 1^{\circ} \cdot 0 \cdot 99993 & 9^{\circ} \cdot 0 \cdot 99982 & 17^{\circ} \cdot 0 \cdot 99884 & 25^{\circ} \cdot 0 \cdot 99714 \\ 2^{\circ} \cdot 0 \cdot 99997 & 10^{\circ} \cdot 0 \cdot 99974 & 18^{\circ} \cdot 0 \cdot 99866 & 26^{\circ} \cdot 0 \cdot 99689 \\ 3^{\circ} \cdot 0 \cdot 99999 & 11^{\circ} \cdot 0 \cdot 99965 & 19^{\circ} \cdot 0 \cdot 99847 & 27^{\circ} \cdot 0 \cdot 99662 \\ 4^{\circ} \cdot 1 \cdot 00000 & 12^{\circ} \cdot 0 \cdot 99955 & 20^{\circ} \cdot 0 \cdot 99827 & 28^{\circ} \cdot 0 \cdot 99635 \\ 5^{\circ} \cdot 0 \cdot 99999 & 13^{\circ} \cdot 0 \cdot 99942 & 21^{\circ} \cdot 0 \cdot 99806 & 29^{\circ} \cdot 0 \cdot 99607 \\ 6^{\circ} \cdot 0 \cdot 99997 & 14^{\circ} \cdot 0 \cdot 99930 & 22^{\circ} \cdot 0 \cdot 99785 & 30^{\circ} \cdot 0 \cdot 99579 \\ 7^{\circ} \cdot 0 \cdot 99994 & 15^{\circ} \cdot 0 \cdot 99915 & 23^{\circ} \cdot 0 \cdot 99762 & \end{array}$

\section{.SYMBOLS AND ATOMIC WEIGHTS OF THE PRINCIPAL}

\begin{tabular}{|c|c|c|c|c|c|c|c|c|}
\hline Aluminium & $\mathrm{Al}$ & $27 \cdot 02$ & Fluorine & $\mathbf{F}$ & $19 \cdot 1$ & Phosphorus & $\mathrm{P}$ & $30 \cdot 96$ \\
\hline Antimony & $\mathrm{Sb}$ & $120 \cdot 0$ & Gold & $\mathrm{Au}$ & $197 \cdot 0$ & Platinum & Pt & $194 \cdot 3$ \\
\hline Arsenic & $\mathrm{As}$ & $74 \cdot 9$ & Hydrogen & $\mathrm{H}$ & $1 \cdot 0$ & Potassium & $\mathrm{K}$ & 39.04 \\
\hline Barium & $\mathrm{Ba}$ & $136 \cdot 8$ & Iodine & $I$ & $126 \cdot 53$ & Silver & $\mathrm{Ag}$ & $107 \cdot 66$ \\
\hline Bismuth & $\mathrm{Bi}$ & $208 \cdot 0$ & Iron & $\mathrm{Fe}$ & $55 \cdot 9$ & Silicon & $\mathrm{Si}$ & $28: 3$ \\
\hline Boron & B & $10 \cdot 9$ & Lead & $\mathrm{Pb}$ & $206 \cdot 4$ & Sodium & $\mathrm{Na}$ & $23 \cdot 0$ \\
\hline Bromine & $\mathrm{Br}$ & $79 \cdot 75$ & Magnesium & $\mathrm{Mg}$ & $24 \cdot 0$ & Strontium & $\mathrm{Sr}$ & $87 \cdot 3$ \\
\hline Cadmium & $\mathrm{Cd}$ & $112 \cdot 0$ & Manganese & $\mathrm{Mn}$ & $55 \cdot 0$ & Sulphur & s & $31 \cdot 98$ \\
\hline Calciuma & $\mathrm{Ca}$ & $39 \cdot 9$ & Mercury & $\mathrm{Hg}$ & $199 \cdot 8$ & Tin & $\mathrm{Sn}$ & $118 \cdot \xi$ \\
\hline Carbon & C & $12 \cdot 0$ & Nickel & $\mathrm{Ni}$ & $58 \cdot 6$ & & & \\
\hline $\begin{array}{l}\text { Chlorine } \\
\text { Copper }\end{array}$ & $\begin{array}{l}\mathrm{Cl} \\
\mathrm{Cu}\end{array}$ & $\begin{array}{l}35 \cdot 45 \\
63 \cdot 2\end{array}$ & $\begin{array}{l}\text { Nitrogen } \\
\text { Oxygen }\end{array}$ & $\begin{array}{l}N \\
O\end{array}$ & $\begin{array}{l}14.0 \\
16.0\end{array}$ & $\begin{array}{l}\text { Tungster } \\
\text { Zinc }\end{array}$ & $\begin{array}{l}\text { Wn } \\
\mathrm{Zn}\end{array}$ & 117 \\
\hline
\end{tabular}




\section{ELEMENTARY COURSE}

\section{LESSON I \\ THE CARBOHYDRATES AND FATS}

1. Note the general appearance of the specimens of grape sugar or dextrose, cane sugar, dextrin, and starch which are given round.

2. Put some of each into cold water. Starch is insoluble; dextrose, cane sugar, and dextrin dissolve after a time, but more readily in hot water.

3. Trommer's test for dextrose.-Put a few drops of copper sulphate solution into a test-tube, then solution of dextrose, and then strong caustic potash. On adding the caustic potash a precipitate is first formed, which, owing to the presence of the sugar, rapidly redissolres, forming a blue solution. On boiling this a yellow or red precipitate (cuprous hydrate or oxide) forms.

Fehling's test for dextrose.-Fehling's solution is a mixture of copper sulphate, caustic soda, and Rochelle salt of a certain strength. It is used for estimating dextrose quantitatively (see Lesson XII.). It may be used as a qualitative test also. Boil some Fehling's solution; if it remains clear iti; in good condition; add to it an equal rolume of solntion of dextrose and boil again. Reduction, resulting in the formation of cuprous hydrate or oxide, takes place as in Trommer's test.

4. Cane Sugar.-(a) The solution of cane sugar when mixed with copper sulphate and eaustic potash gires a blue solution. But on boiling no reduction occurs.

(b) Take some of the cane sugar solution and boil it with a few drops of 25-per-cent. sulphuric acid. This converts it into equal parts of dextrose and levulose. It then gives Trommer's or Fehling's test in the typical way.

(c) Boil some of the cane sugar solntion with an equal volume of concentrated hydrochloric acid. A deep red solution is formed. Dextrose, lactose, and maltose do not give this test.

5. Starch.-(a) Examine microseopically the scrapings from the surface of a freshly cut potato. Note the appearance of the starch grains with their concentric markings.

(b) On boiling starch with water an opalescent solution is formed, which, if strong, gelatinises on cooling.

(c) Add iodine solution. An intense blue colour is produced, which disappears on heating, and if not heated too long reappears on cooling. N.B.-Prolonged heating drives off the iodine, and consequently no blue colour returns after cooling.

(d) Conversion into dextrin and dextrose. To some starch solution in a flask add a few drops of 25-per-cent. sulphuric acid, and boil for 15 minutes. Take some of the liquid, which is now clear, and show the presence of dextrin and dextrose. 
6. Dextrin.-Add iodine solution to solution of dextrin, and a reddishbrown solution is produced. The colour disappears on heating and reappears on cooling.

7. Glycogen.-Solution of glycogen is given round: $(a)$ it is opalescent like that of starch.

(b) With iodine it gives a brown colour very like that given by dextrin. The colour disappears on heating and reappears on cooling.

(c) By boiling with 25-per-cent. sulphuric acid for 15 to 20 minutes it is converted into grape sugar.

8. Lard is given round as an example of a fat. (a) It is insoluble in water.

(b) By boiling with potash it yields a solution of soap.

(c) Add to this solution a few drops of 25-per-cent. sulphuric acid. On heating a layer of fatty acid collects on the surface.

(d) Shake up some lard with ether. It dissolves, leaving little or no residue.

\section{CARBOHYDRATES}

The carbohydrates are found chiefly in vegetable tissues, and many of them form important foods. Some carbohydrates are, however, found in or formed by the animal organism. The most important of these are glycogen, or animal starch; dextrose; and lactose, or milk sugar.

They may be for the greater part arranged into three groups, according to their empirical formulæ. The names and formulæ of these groups, and the most important members of each, are as follows :-

\begin{tabular}{|c|c|c|}
\hline $\begin{array}{l}\text { 1. Monosacecharides or Glucoses, } \\
\mathrm{C}_{6} \mathrm{H}_{32} \mathrm{U}_{6}\end{array}$ & $\begin{array}{l}\text { 2. Disaccharides, Sucroses, or } \\
\text { Succhinaroses, } \\
\mathrm{O}_{12} \mathrm{H}_{2 \mathrm{~g}} \mathrm{O}_{1 \mathrm{n}}\end{array}$ & $\begin{array}{l}\text { 3. Polysaccharides or Amyloses. } \\
\qquad\left(\mathrm{C}_{6} \mathrm{H}_{10} \mathrm{O}_{5}\right)_{n}\end{array}$ \\
\hline $\begin{array}{l}\text { + Dextrose } \\
\text { - Levulose } \\
\text { + Galactose }\end{array}$ & $\begin{array}{l}\text { + Cane sugar } \\
\text { + Lactose } \\
\text { + Maltose }\end{array}$ & $\begin{array}{l}\text { + Starch } \\
+ \text { Glycogen } \\
+ \text { Dextrin } \\
\text { Cellulose } \\
\text { Gums }\end{array}$ \\
\hline
\end{tabular}

The + and - signs in the above list indicate that the substances to which they are prefixed are dextro- and levo-rotutory respectively as regards polarised light. ${ }^{1}$

The carbohydrates may be conveniently defined as compounds of carbon, hydrogen, and oxygen, the two last-named elements being in the proportion in which they occur in water. This definition is, however, only a rough one, and if pushed too far would include

' For a description of polarised light and polarimeters see Appendix. This and the other matter in the Appendix are placed there for convenience, not beenuse they are unimportant. Students are therefore urged to refer to and carefully study these subjects. 
sereral substances like acetic acid, lactic acid, and inosite, which are not carbohydrates.

The formulæ given above are merely empirical; and there is no doubt that the quantity $n$ in the starch group is variable, and often large; hence the name polysaccharides that is given to the group. Research has, moreover, shown that the glucoses are either aldehydes or ketones of hexatomic alcohols having the general formula $\mathrm{C}_{6} \mathrm{H}_{8}(\mathrm{OH})_{6}$. Thus dextrose is the aldehyde of sorbite, levulose the ketone of mannite, and galactose the aldehyde of dulcite. The amyloses may be regarded as the anhydrides of the glucoses $\left[n \mathrm{C}_{6} \mathrm{H}_{12} \mathrm{O}_{6}\right.$ $\left.-n \mathrm{H}_{2} \mathrm{O}=\left(\mathrm{C}_{6} \mathrm{H}_{10} \mathrm{O}_{5}\right)_{n}\right]$. The sucroses are condensed glucoses-i.e. they are formed by the combination of two molecules of glucose with the loss of one molecule of water $\left(\mathrm{C}_{6} \mathrm{H}_{12} \mathrm{O}_{6}+\mathrm{C}_{6} \mathrm{H}_{12} \mathrm{O}_{6}-\mathrm{H}_{2} \mathrm{O}\right.$ $\left.=\mathrm{C}_{12} \mathrm{H}_{22} \mathrm{O}_{11}\right)$; hence the term disaccharide. The following are the chief facts in relation to each of the principal carbohydrates :-

\section{MONOSACCHARIDES}

Dextrose or Grape Sugar.-This carbohydrate is found in fruits, honey, and in minute quantities in the blood $(0.12$ per cent.) and numerous tissues, organs, and fluids of the body. It is the form of sugar found in large quantities in the blood and urine in the disease known as diabetes.

Dextrose is soluble in hot and cold water and in alcohol. It is crystalline (see fig. 1), but not so sweet as cane sugar. When heated with strong potash certain complex acids are formed which have a yellow or brown colour. This constitutes Moore's test for sugar. In alkaline solutions dextrose reduces salts of silver,

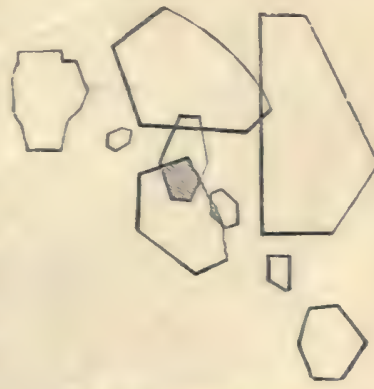

Fic. 1.-Dextrose crystals. bismuth, mercury, and copper. The reduction of cupric to cuprous oxide constitutes Trommer's test, which has been already described at the head of the lesson. On boiling it with an alkaline solution of picric acid, a dark red opaque solution due to reduction of the picric to picramic acid is produced. Another important property of grape sugar is that under the influence of yeast it is converted into alcohol and carbonic acid $\left(\mathrm{C}_{6} \mathrm{H}_{12} \mathrm{O}_{6}=2 \mathrm{C}_{2} \mathrm{H}_{6} \mathrm{O}+2 \mathrm{CO}_{2}\right)$.

Dextrose may be estimated by the fermentation test, by the polarimeter, and by the use of Fehling's solution. The last method is the most important; it rests on the same principles as Trommer's 
test, and we shall study it and other methods of estimating sugar in connection with diabetic urine (see Lesson XII.).

Levulose.-When cane sugar is treated with dilute mineral acids it undergoes a process known as inversion-i.e. it takes up water and is converted into equal parts of dextrose and levulose. The previously dextro-rotatory solution of cane sugar then becomes levorotatory, the levo-rotatory power of the levulose being greater than the dextro-rotatory power of the dextrose formed. Hence the term inversion. Similar hydrolytic changes are produced by certain ferments, such as the invert ferment of the intestinal juice.

Pure levulose can be crystallised, but so great is the difficulty of obtaining crystals of it that one of its names was uncrystallisable sugar. Small quantities of levulose have been found in blood, urine, and muscle. It has been recommended as an article of diet in diabetes in place of ordinary sugar; in this disease it does not appear to have the harmful effect that other sugars produce. Levulose gives the same general reactions as dextrose.

Galactose is formed by the action of dilute mineral acids

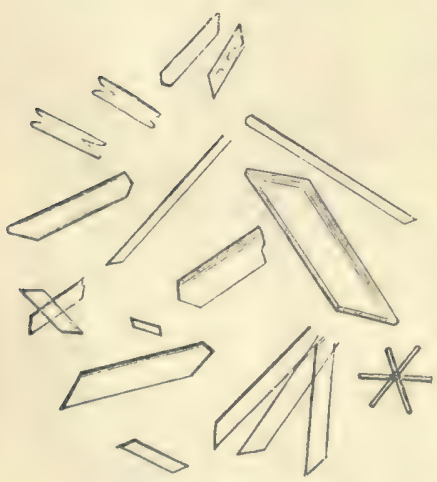

Fic. 2.-Inosite crystals. or inverting ferments on laciose or milk sugar. It resembles dextrose in being dextro-rotatory, in reducing cupric hydrate in Trommer's test, and in being directly fermentable with yeast. When oxidised by means of nitric acid it, however, yields an acid called mucic acid $\left(\mathrm{C}_{6} \mathrm{H}_{10} \mathrm{O}_{8}\right)$, which is only sparingly soluble in water. Dextrose when treated this way yields an isomeric acid-i.e. an acid with the same empirical formula, called saccharic acid, which is readily soluble in water.

Inosite, or muscle sugar, is found in muscle, kidney, liver, and other parts of the body in small quantities. It is also largely found in the vegetable kingdom. It is a crystallisable substance (see fig. 2) and has the same formula $\left(\mathrm{C}_{6} \mathrm{H}_{12} \mathrm{O}_{6}\right)$ as the glucoses. It is, however, not a sugar. It gives none of the sugar tests, and careful analysis has shown it has quite a different chemical constitution from the true sugars. It belongs to the aromatic series, and is only included here for convenience.

\section{DISACCHARIDES}

Cane Sugar.-This sugar is generally distributed throughout the vegetable kingdom in the juices of plants and fruits, especially the 
sugar cane, beetroot, mallow, and sugar maple. It is a substance of great importance as a food. After abundant ingestion of cane sugar traces may appear in the urine, but the greater part undergoes inversion in the alimentary canal.

Pure cane sugar is crystalline and dextro-rotatory. It holds cupric. hydrate in solution in an alkaline liquid-that is; with Trommer's test it gives a blue solution. But no reduction occurs on boiling. After inversion it is strongly reducing.

Inversion may be brought about readily by boiling with dilute mineral acids, or by means of an inverting ferment, such as that occurring in the succus entericus or intestinal juice. It then takes up water and is split into equal parts of dextrose and levulose (see p. 12).

$$
\underset{\text { [cane sigar] }}{\mathrm{C}_{12} \mathrm{H}_{22} \mathrm{O}_{11}}+\underset{\text { [destrose] }}{\mathrm{H}_{2} \mathrm{O}}=\underset{\text { [levulose] }}{\mathrm{C}_{6} \mathrm{H}_{12} \mathrm{O}_{6}}
$$

With yeast, cane sugar is first inverted by means of a special soluble ferment produced by the yeast cells, and then there is an alcoholic fermentation of the glucoses so formed.

Lactose, or milk sugar, occurs in milk. It has also been described as occurring in the urine of women in the early days of lactation or after weaning.

It crystallises in rhombic prisms (see fig. 3). It is much less soluble in water than cane sugar or dextrose, and has only a slightly sweet taste. It is insoluble in alcohol and ether; aqueous solutions are dextro-rotatory.

Solutions of lactose give Trommer's test, but when the reducing power is tested quantitatively by Fehling's solution it is found to be a less powerful reducing agent than dextrose. If it required seven parts of a solution of dextrose to reduce a given

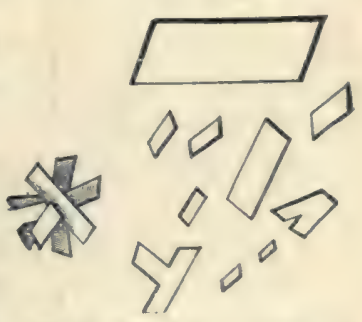

Fiti. 3.-Mfilk-sugar erystals. quantity of Fehling's solution, it would require ten parts of a solution of lactose of the same strength to reduce the same quantity of Fehling's solution.

Lactose, like cane sugar, can be hydrolysed by the same agencies as those already enumerated in connection with cane sugar. The glucoses formed are dextrose and galactose.

$$
\mathrm{C}_{12} \mathrm{H}_{22} \mathrm{O}_{11}+\mathrm{H}_{2} \mathrm{O}=\underset{\text { [lactose] }}{\mathrm{C}_{6} \mathrm{H}_{12} \mathrm{O}_{6}}+\underset{\text { [gertrose] }}{\mathrm{C}_{6} \mathrm{H}_{12} \mathrm{O}_{6}}
$$

With yeast it is first inverted, and then alcohol is formed. This, however, occurs slowly. 
With the lactic-acid organisms which bring about the souring of milk the lactic-acid fermentation is produced. This may also occur as the result of the action of putrefactive bacteria in the alimentary canal. The two stages of the lactic-acid fermentation are represented by the following equations:-

$$
\begin{gathered}
\mathrm{C}_{12} \mathrm{H}_{22} \mathrm{O}_{11}+\mathrm{H}_{2} \mathrm{O}=\underset{\text { [lactic acid] }}{4 \mathrm{C}_{3} \mathrm{H}_{6} \mathrm{O}_{3}} \\
\text { [lactose] } \\
4 \mathrm{C}_{3} \mathrm{H}_{6} \mathrm{O}_{3}=\underset{\text { [butyric acid] }}{2 \mathrm{C}_{4} \mathrm{H}_{8} \mathrm{O}_{2}}+4 \mathrm{CO}_{2}+4 \mathrm{H}_{2} \\
\text { [lactic acid] }
\end{gathered}
$$

Maltose is the chief end product of the action of malt diastase on starch, and is also formed as an intermediate product in the action of dilute sulphuric acid on the same substance. It is also the chief sugar formed from starch by the diastatic ferments contained in the saliva (ptyalin) and pancreatic juice (amylopsin). ${ }^{1}$ It can be obtained in the form of acicular crystals ; it is strongly dextro-rotatory. It gives Trommer's test; but its reducing power, as measured by Fehling's solution, is one-third less than that of dextrose.

By prolonged boiling with water, or, more readily, by boiling with a dilute mineral acid, or by means of an inverting ferment, such as occurs in the intestinal juice, it is converted into dextrose.

$$
\underset{\text { [maltose] }}{\mathrm{C}_{12} \mathrm{H}_{22} \mathrm{O}_{11}}+\mathrm{H}_{2} \mathrm{O}=\underset{\text { [dextrose] }}{2 \mathrm{C}_{6} \mathrm{H}_{12} \mathrm{O}_{6}}
$$

It undergoes readily the alcoholic fermentation.

The three important physiological sugars (dextrose, lactose, and maltose) may be distinguished from one another by their relative reducing action on Fehling's solution $(1 \cdot 0: 0 \cdot 71: 0 \cdot 63)$, or by the phenyl-hydrazine test described in Lesson XIII.

\section{POLYSACCHARIDES.}

Starch is widely diffused through the vegetable kingdom. It occurs in nature in the form of microscopic grains, varying in size and appearance, according to their source. Each consists of a central spot (hilum) round which more or less concentric envelopes of starch proper or granulose alternate with layers of cellulose. Cellulose has very little digestive value, but starch is a most important food.

Starch is insoluble in cold water; it forms an opalescent solution in boiling water, which if concentrated gelatinises on cooling. Its most characteristic reaction is the blue colour it gives with iodine.

On heating starch with dilute mineral acids dextrose is formed.

1 An isomeric sugar called iso-maltose (see Lesson XIII.) is also formed under these circumstances. 
By the action of diastatic ferments, maltose is the chief end product. In both cases dextrin is an intermediate stage in the process.

Before the formation of dextrin the starch solution loses its opalescence, a substance called soluble starch or amidulin being formed. This, like native starch, gives a blue colour with iodine. Although the molecular weight of starch is unknown, the formula for soluble starch is probably $\left(\mathrm{C}_{6} \mathrm{H}_{10} \mathrm{O}_{5}\right)_{200}$. Equations that represent the formation of sugars and dextrins from this are very complex, and are at present hypothetical.

Dextrin is the name given to the intermediate products in the hydration of starch, and two chief varieties are distinguished-erythro-dextrin, which gives a reddish-brown colour with iodine; and achroö-dextrin, which does not.

It is readily soluble in water, but

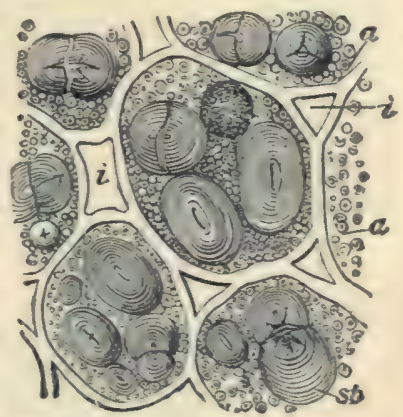

Fir: 4.--Section of pea showing starch and aleurone grains embedided in the protoplasm of the cells : $a$, aleurone grains : $s t$, starch grains; $i$. intercellular spaces. (Yeo, after Sachs.) insoluble in alcohol and ether. It is gummy and amorphous. It does not give Trommer's test, nor does it ferment with yeast. It is dextro-rotatory. By hydrating agencies it is converted into glucose.

Glycogen, or animal starch, is found in liver, muscle, and colourless blood corpuscles. It is also abundant in all embryonic tissues.

Glycogen is a white tasteless powder, soluble in water, but it forms, like starch, an opalescent solution. It is insoluble in alcohol and ether. It is dextro-rotatory. With Trommer's test it gives a blue solution, but no reduction occurs on boiling.

With iodine it gives a reddish or port-wine colour, very similar to that given by erythro-dextrin. Dextrin may be distinguished from glycogen by (1) the fact that it gives a clear, not an opalescent, solution with water; and (2) it is not precipitated by basic lead acetate as glycogen is. It is, however, precipitated by basic lead acetate and ammonia. (3) Glycogen is precipitated by 55 per cent. of alcohol ; the dextrins require 85 per cent. or more.

Cellulose.-This is the colourless material of which the cell-walls and woody fibres of plants are composed. By treatment with strong mineral acids it is, like starch, converted into glucose, but with much greater difficulty. The various digestive ferments have little or no action on cellulose; hence the necessity of boiling starch 
before it is taken as food. Boiling bursts the cellulose envelopes of the starch grains, and so allows the digestive juice to get at the starch proper. Cellulose is found in a few animals, as in the test or outer investments of the Tunicates.

For further information regarding the earbohydrates see Lesson XIII.

\section{THE FATS}

Fat is found in small quantities in many animal tissues. It is, however, found in large quantities in three situations, viz. bone marrow, adipose tissue, and milk. The consideration of the fat in milk is postponed to Lesson IV.

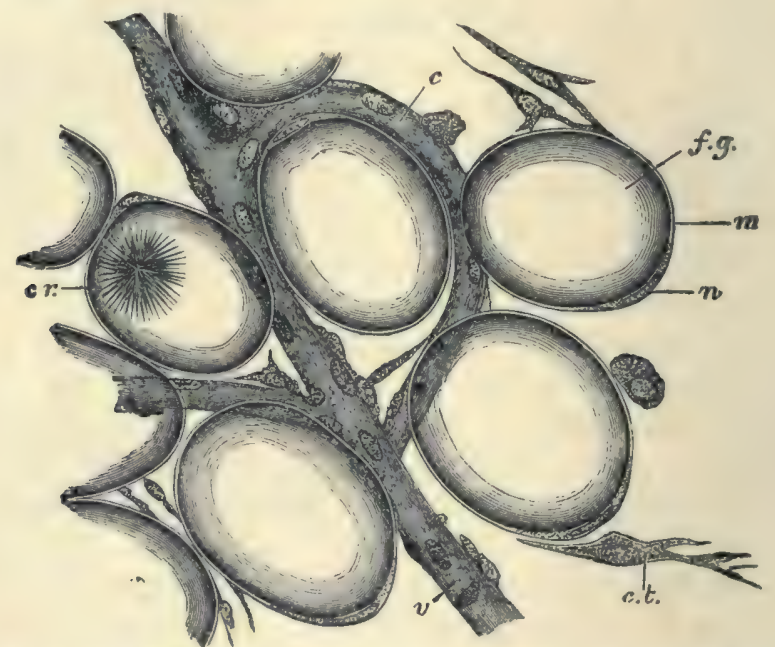

Tit. 5. - $\Lambda$ few cells from the margin of a fat lobule ; $f . q$. fat globule distending fat cell : $n$, nucleus : $m$, membranous envelope of the cell : $c r$., bunch of erystals within a fat cell ; $c$, eapillary vessel : $r$, venule; c. t., connective tissue cell. The fibres of the connective tissue are not represented.

The contents of the fat cells of adipose tissue are fluid during life, the normal temperature of the body $\left(37^{\circ} \mathrm{C}\right.$., or $99^{\circ} \mathrm{F}$.) being considerably above the melting-point $\left(25^{\circ} \mathrm{C}\right.$.) of the mixture of the fats found there. These fats are three in number, and are called palmitin, stearin, and olein. They differ from one another in chemical composition and in certain physical characters, such as melting-point and solubilities. Olein melts at $-5^{\circ} \mathrm{C}$., palmitin at $45^{\circ} \mathrm{C}$., and stearin at $53-66^{\circ} \mathrm{C}$. Thus, it is olein which holds the other two dissolved at the body temperature. Fats are all soluble in hot alcohol, ether, and chloroform, but insoluble in water.

Chemical Constitution of the Fats.-The fats are compounds of 
fatty acids with glycerin, and may be termed glycerides or glyceric ethers. The term hydrocarbon, applied to them by some authors, is wholly incorrect.

The fatty acids form a series of acids derived from the monatomic alcohols by oxidation. Thus, to take ordinary ethyl alcohol, $\mathrm{C}_{2} \mathrm{H}_{5} \mathrm{HO}$, the first stage in oxidation is the removal of two atoms of hydrogen to form aldehyde, $\mathrm{CH}_{3}$. $\mathrm{COH}$ : on further oxidation an atom of oxygen is added to form acetic acid, $\mathrm{CH}_{3}$. $\mathrm{COOH}$.

A similar acid can be obtained from all the other alcohols thus :-

From methyl alcohol $\mathrm{CH}_{3} \cdot \mathrm{HO}$, formic acid $\mathrm{H} . \mathrm{COOH}$ is obtained

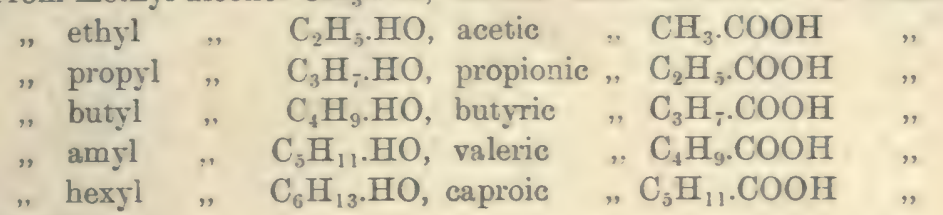

and so on.

Or in general terms:-

From the alcohol with formula $\mathrm{C}_{n} \mathrm{H}_{2 n-1}$. $\mathrm{HO}$ the acid with formula $\mathrm{C}_{n-1} \mathrm{H}_{2 n-1} \cdot \mathrm{CO} . \mathrm{OH}$ is obtained. The sixteenth term of this series has the formula $\mathrm{C}_{15} \mathrm{H}_{31} \cdot \mathrm{CO} . \mathrm{OH}$, and is called palmitic acid; the eighteenth has the formula $\mathrm{C}_{17} \mathrm{H}_{35} \cdot \mathrm{CO} . \mathrm{OH}$, and is called stearic acid. Each acid, as will be seen, consists of a radicle, $\mathrm{C}_{n-1} \mathrm{H}_{2 n-1} \mathrm{CO}$, united to hydroxyl (HO).

Oleic acid, however, is not a member of the fatty acid series proper, but belongs to a somewhat similar series of acids known as the acrylie series, of which the general formula is $\mathrm{C}_{n-1} \mathrm{H}_{2 n-3} \mathrm{COOH}$. It is the eighteenth term of the series, and its formula is $\mathrm{C}_{17} \mathrm{H}_{33} \cdot \mathrm{CO} . \mathrm{OH}$.

Glycerin or Glycerol is a triatomic alcohol, $\mathrm{C}_{3} \mathrm{H}_{5}(\mathrm{OH})_{3}$-i.e. three atoms of hydroxyl united to a radicle glyceryl $\left(\mathrm{C}_{3} \mathrm{H}_{5}\right)$. The hydrogen in the hydroxyl atoms is replaceable by other organic radicles. As an example take the radicle of acetic acid called acetyl $\left(\mathrm{CH}_{3} \cdot \mathrm{CO}\right)$. The following formulæ represent the derivatives that can be obtained by replacing one, two, or all three hydroxyl hydrogen atoms in this way :-
$\mathrm{C}_{3} \mathrm{H}_{5} \cdot\left\{\begin{array}{l}\mathrm{OH} \\ \mathrm{OH} \\ \mathrm{OH}\end{array}\right.$
$\mathrm{C}_{3} \mathrm{H}_{5}$ 罗等
[xilycerin]
O. $\mathrm{CH}_{3} \cdot \mathrm{CO}$
[monoacetin]

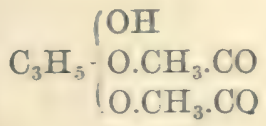
[diacetin]
(O.CH$\cdot . \mathrm{CO}$
$\mathrm{C}_{3} \mathrm{H}_{5}: \mathrm{O}^{-\mathrm{CH}_{3}} \cdot \mathrm{CO}$

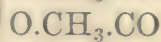
[Griscetin]

Triacetin is a type of a neutral fat; stearin, palmitin, and olein ought more properly to be called tristearin, tripalmitin, and triolein 
respectively. Each consists of glycerin in which the three atoms of hydrogen in the hydroxyls are replaced by radicles of the fatty acid. This is represented in the following formulæ :-

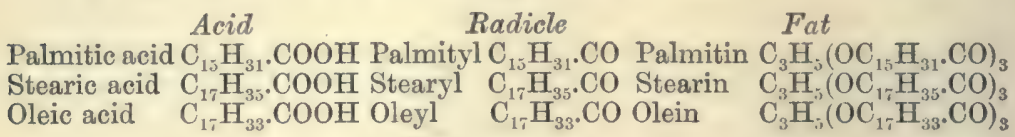

Decomposition Products of the Fats.-The fats split up into the substances out of which they are built up.

Under the influence of superheated steam, mineral acids, and in the body by means of certain ferments (for instance, the fat-splitting ferment steapsin of the pancreatic juice), a fat combines with water and splits into glycerin and the fatty acid. The following equation represents what occurs in a fat, taking tripalmitin as an example :-

$$
\begin{aligned}
& \mathrm{C}_{3} \mathrm{H}_{5}\left(\mathrm{O} . \mathrm{C}_{15} \mathrm{H}_{31} \mathrm{CO}\right)_{3}+3 \mathrm{H}_{2} \mathrm{O}=\mathrm{C}_{3} \mathrm{H}_{5}(\mathrm{OH})_{3}+3 \mathrm{C}_{35} \mathrm{H}_{31} \mathrm{CO} . \mathrm{OH} \\
& \text { [palmitin } \rightarrow \text { fat] } \\
& \text { [glycerin] [palmitic acid- } \mathrm{a} \text { fatty acid] }
\end{aligned}
$$

In the process of saponification much the same sort of reaction occurs, the final products being glycerin and a compound of the base with the fatty acid, which is called a soap. Suppose, for instance, that potassium hydrate is used; we get-

$$
\underset{\text { [palmitin }-\mathrm{a} \text { fat] }}{\mathrm{C}_{3} \mathrm{H}_{5}\left(\mathrm{O} . \mathrm{C}_{15} \mathrm{H}_{31} \mathrm{CO}\right)_{3}+3 \mathrm{KHO}=\mathrm{C}_{3} \mathrm{H}_{5}(\mathrm{OH})_{3}+3 \mathrm{C}_{15} \mathrm{H}_{31} \mathrm{CO} . \mathrm{OK}}
$$

Emulsification.-Another change that fats undergo in the body is very different from saponification. It is a physical rather than a chemical change; the fat is broken up into very small globules, such as is seen in the natural emulsion-milk.

Lecithin $\left(\mathrm{C}_{42} \mathrm{H}_{84} \mathrm{NPO}_{9}\right)$.- This is a very complex fat, which yields on decomposition not only glycerin and a fatty (stearic) acid, but phosphoric acid, and an alkaloid $\left[\mathrm{N} .\left(\mathrm{CH}_{3}\right)_{3} \mathrm{C}_{2} \mathrm{H}_{6} \mathrm{O}_{2}\right.$ ] called choline in addition. Lecithin is found to a great extent in the nervous system, ${ }^{1}$ and to a small extent in bile. Together with cholesterin, a crystallisable, monatomic alcohol $\left(\mathrm{C}_{27} \mathrm{H}_{45} \cdot \mathrm{HO}\right)$, which we shall consider more at length in connection with the bile, it is found in small quantities in the protoplasm of all cells.

1 See further under Nervous Tissues, Lesson XXII. 


\section{LESSON II}

\section{THE PROTEIDS}

1. Tests for Proteids. - The following tests are to be tried with a mixture of one part of white of egg to ten of water. (Egg-white contains a mixture of albumin and globulin.)

(a) Heat Congulation.-Faintly acidulate with a few drops of 2-per-cent. acetic acid and boil. The proteid is rendered insoluble (coagulated proteid).

(b) Precipitation with Nitric Acid.-The addition of strong nitric acid to the original solution also produces a white precipitate.

(c) Xanthoproteic Reaction.--On boiling the white precipitate produced by nitric acid it turns vellow; after cooling add ammonia; the yellow becomes orange.

(d) Millon's Test.-Millon's reagent (which is a mixture of the nitrates of mercury containing excess of nitric acid; see p. 5) gives a white precipitate, which turns brick-red on boiling.

(e) After the addition of a few drops of 20 -per-cent. acetic acid, potassium ferrocyanide gives a white precipitate.

(f) Piotrowsihi's test.-Add a drop of a 1-per-cent. solution of cupric sulphate to the original solution and then eaustic potash, and a violet solution is obtained.

Repeat experiment $(f)$ with a solution of commercial peptone, and note that a rose-red solution is obtained. This is called the biuret reaction.

(g) Adamkievicz's Reaction (Hopkins's modification).-Add the albumin solution to dilute glyoxylic acid, and then strong sulphuric acid; an intense violet colour is obtained. Most commercial specimens of glacial acetic acid contain glyoxrlic acid and may be used in place of pure glyoxylic acid in this test.

2. Action of Neutral Salts.- (a) Saturate the solution of egg-white with magnesium sulphate by adding crystals of the salt and grinding it up thoroughly in a mortar. A white precipitate of egg-globulin is produced. Filter. The filtrate contains egg-albumin. The precipitate of the globulin is very small.

(b) Half saturate the solution of egg-white with ammonium sulphate. This may be done br adding to the solution an equal volume of a saturated solution of ammonium sulphate. The precipitate produced consists of the globulin; the albumin remains in solution.

(c) Completely saturate another portion with ammonium sulphate by adding crystals of the salt and grinding in a mortar-a precipitate is produced of both the globulin and albumin. Filter. The filtrate contains no proteid.

(d) Repeat the last experiment $(c)$ with a solution of commercial peptone. A precipitate is produced of the albumoses or proteoses it contains. Filter. The filtrate contains the true peptone. This gires the biuret reaction (see above), but large excess of strong potash must be added on account of the presence of ammonium sulphate. Ammonium sulphate precipitates all proteids except peptone. 


\section{IIESSON III}

\section{THE PROTEIDS (continued)}

1. Action of Acids and Alkalis on Albumin.-Take three test-tubes and label them $\mathrm{A}, \mathrm{B}$, and $\mathrm{C}$.

In each place an equal amount of diluted egg-white, similar to that used in the last lesson.

To $A$ add a few drops of 0.1-per-cent. solution of caustic potash.

To $B$ add the same amount of $0 \cdot 1$-per-cent. solution of calnstic potash.

To $\mathrm{C}$ add a rather larger amount of $0 \cdot 1$-per-cent. sulphuric acid.

Put all three into the warm bath ${ }^{2}$ at about the temperature of the body $\left(36-40^{\circ}\right.$ C. $)$.

After five minutes remove test-tube $\mathbf{A}$, and boil. The proteid is no

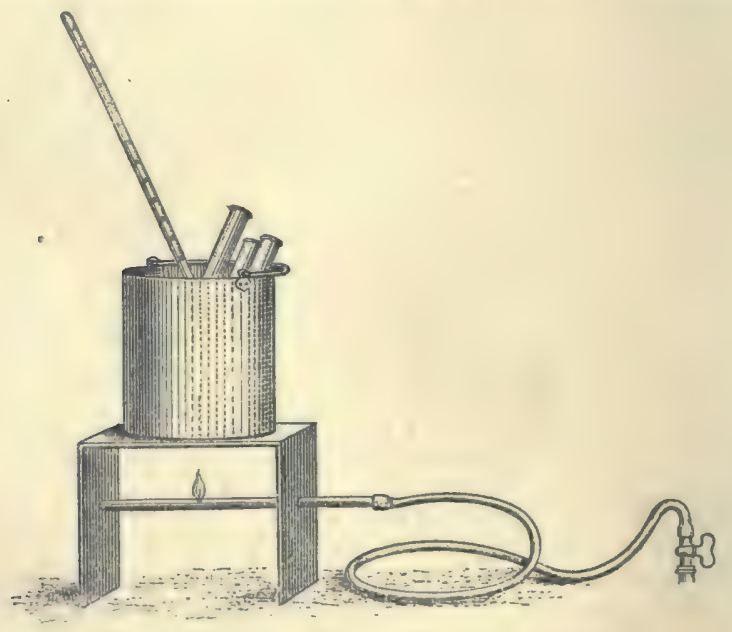

Fı. 6. - Simple warm bath, as described in footnote.

longer coagulated by heat, having been converted into alkali-albumin. After cooling, colour with litmus solution and neutralise with $0 \cdot 1$-per-cent. acid. At the neutral point a precipitate is formed which is soluble in excess of either acid or alkali.

Next remove B. This also now contains alkali-albumin. Add to it a fow

1 A convenient form of warm bath suitable for class purposes may be made by placing an ordinary tin pot half full of water over $a$ bent piece of iron which acts as a warm stage as in the figure. The stage is kept warm by a small gas flame. Such a warm bath may be placed between every two or three students. 
irops of sodium phosphate, colour with litmus. and neutralise as before. Note that the alkali-albumin now requires more acid for its precipitation than in $\mathrm{A}$, the acid which is first added converting the sodium phosphate into acid sodium phosphate.

Now remove $\mathrm{C}$ from the bath. Boil it. Again there is no coagulation, the proteid having been converted into acid-albumin, or syntonin. After cooling, colour with litmus and neutralise with 0-1-per-cent. alkali. At the neutral point a precipitate is formed, soluble in excess of acid or alkali. (Acid-albumin is formed more slowly than alkali-albumin, so it is best to leave this experiment to the last.)

2. Take some gelatin and dissolve it in hot water. On cooling, the solution sets into a jelly (gelatinisation).

Take a dilute solution of gelatin, and try all the proteid tests with it enumerated on p. 19. Carefully note down your results.

3. Add a few drops of acetic acid to some saliva. A stringy precipitate of mucin is formed.

4. A tendon has been soaked for a few days in lime water. The fibres are not dissolved, but they are loosened from one another owing to the solution of the interstitial or ground substance by the lime water. Take some of the lime-water extract and add acetic acid. A precipitate of mucin is obtained. The fibres themselves consist of collagen, which vields gelatin on boiling. Vitreous humour or the Whartonian jelly of the umbilical cord is much richer in ground substance than tendon, and, if treated in the same way, a much larger yield of mucin is obtained.

The Proteids are the most important substances that occur in animal and vegetable organisms; none of the phenomena of life occur without their presence; and though it is impossible to state positively that they occur as such in living protoplasm, they are invariably obtained by subjecting living structures to analytical processes.

Proteids are highly complex compounds of carbon, hydrogen, oxygen, nitrogen, and sulphur occurring in a solid viscous condition or in solution in nearly all parts of the body. The different members of the group present differences in chemical and physical properties. They all possess, however, certain common chemical reactions and are united by a close genetic relationship.

The various proteids differ a good deal in elementary composition. Hoppe-Seyler gires the following percentages :-

$\begin{array}{lccccc} & \text { C } & \text { H } & \text { N } & \text { S } & \text { O } \\ \text { From } & 51.5 & 6.9 & 15 \cdot 2 & 0.3 & 20.9 \\ \text { To } & 54.5 & 7 \cdot 3 & 17 \cdot 0 & 2.0 & 23.5\end{array}$

We are, horrever, not acquainted with the constitutional formula of proteid substances. There have been many theories on the subject, but practically all that is known with certainty is that many different substances may be obtained by the decomposition of proteids. How they are built up into the proteid molecule is unknown 
The decompositions that occur in the body are, moreover, different from those which can be made to occur in the laboratory; hence the conclusion that living protoplasm differs somewhat from the nonliving proteid material obtainable from it.

(1) In the body. Carbonic acid, water, and urea ${ }^{1}$ are the chief final products. Glycocine, leucine, creatine, uric acid, ammonia, \&c., are probably intermediate products. Carbohydrates (glycogen) and fats may also originate from proteids.

(2) Outside the body. Various strong reagents break up proteids into ammonia, carbonic acid, amines, fatty acids, amido-acids like leucine, arginine, and glycocine, and aromatic compounds like tyrosine.

\section{TESTS FOR PROTEIDS}

Solubilities.-All proteids are insoluble in alcohol and ether. Some are soluble in water, others insoluble. Many of the latter are soluble in weak saline solutions. Some are insoluble, others soluble in concentrated saline solutions. It is on these varying solubilities that proteids are classified.

All proteids are soluble with the aid of heat in concentrated mineral acids and alkalis. Such treatment, however, decomposes as well as dissolves the proteid. Proteids are also soluble in gastric and pancreatic juices; but here, again, they undergo a change, being converted into a hydrated variety of proteid of smaller molecular: weight called peptone. The intermediate substances formed in this process are called proteoses or albumoses. Commercial peptone contains a mixture of proteoses and true peptone.

Heat Coagulation.-Many of the proteids which are soluble in water or saline solutions are rendered insoluble when those solutions are heated. This is true for most of the proteids that occur in nature. The solidifying of white of egg when heated is a familiar instance of this. The temperature of heat coagulation differs in different proteids: thus myosinogen and fibrinogen coagulate at about $56^{\circ} \mathrm{C}$.; serum albumin and serum globulin at about $75^{\circ} \mathrm{C}$.

The proteids which are coagulated by heating their solutions come for the most part into two classes-the albumins and the globulins. The full distinction between these we shall see immediately. We may, however, state here that the albumins are soluble in distilled water; the globulins are not, but require salts to hold them in solution.

' Recent research has shown that urea can be also obtained from proteids by analytical methods outside the body (see under URINE). 
Indiffusibility.-The proteids (peptones excepted) belong to the class of substances called colloids by Thomas Graham; that is, they pass with difficulty, or not at all, through animal membranes. In the construction of dialysers, vegetable parchment is very largely used (see figs. 7 and 8 ).

Proteids may thus be separated from diffusible (crystalloid) substances like salts, but the process is a somewhat tedious one. If some serum or white of egg is placed in a dialyser, and distilled water outside, the greater amount of the salts passes into the water through the membrane; the two proteids, albumin and globulin,

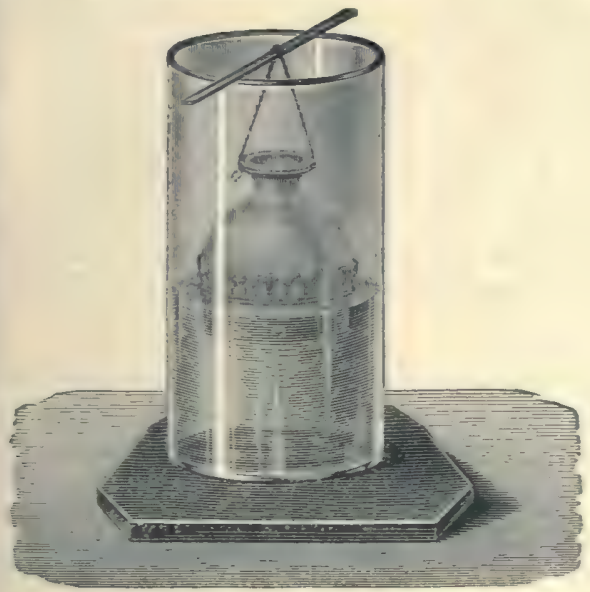

Fig. T-Dialyser. The lower opening of the bell jar suspendet in water is tiglitl 5 corerel with parcliment paper. The fluil to be dialysen is placerl within this ressel; the crystalloids pass out into the distilled water outside through the parchment paper.

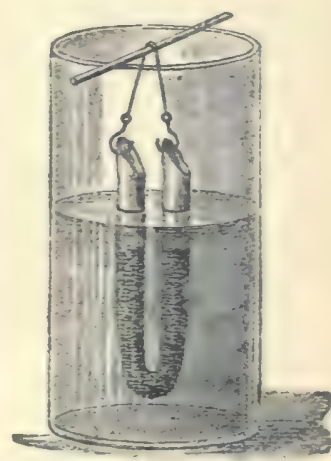

Fir. 8.-In this form of dialyser the substance to be dialysed is placed within the piece of tubing stispenilerl in the larger resel of water. The tubing is masle of parchment paper.

remain inside. The globulin is, however, precipitated, as the salts which previously kept it in solution have been removed.

The terms ' diffusion' and 'dialysis' should be distinguished from each other.

If water is carefully poured on the surface of a solution of any substance, this substance gradually spreads through the water, and the composition of the mixture becomes uniform in time. The time occupied is short for substances like sodium chloride, and long for substances like albumin. The phenomenon is called diffusion. If the solutions are separated by a membrane the term 'dialysis' is employed. The word osmosis is properly restricted to the passage of water through membranes, and ean be best studied when semi-permeable membranes are employed. See fully article Oswosis in Appendix.

Crystallisation.-Hæmoglobin, the red pigment of the blood, is a proteid substance, and is crystallisable (for further details, see THE BLOoD). Like other proteids it has an enormously large molecule; 
though crystalline, it is not crystalloid in Graham's sense of that term. Blood pigment is not the only crystallisable proteid. Long ago crystals of proteid (globulin or vitellin) were observed in the aleurone grains of many seeds, and in the similar proteid occurring in the egg-yolk of some fishes and amphibians. By appropriate methods these have been separated and re-crystallised. Further, egg-albumin itself has been crystallised. If a solution of white of egg is diluted with half its volume of saturated solution of ammonium sulphate, the globulin present is precipitated and is removed by filtration. The filtrate is now allowed to remain some days at the temperature of the air, and as it becomes more concentrated from evaporation, minute spheroidal globules and finally minute needles, either aggregated or separate, make their appearance (Hofmeister). Crystallisation is much more rapid and perfect if a little acetic or sulphuric acid is added (Hopkins). Serum albumin (from horse and rabbit) has also been similarly crystallised (Gürber).

Action on Polarised Light.-All the proteids are levo-rotatory, but the amount of rotation they produce varies with the kind of proteid. See Appendix.

Colour Reactions.-The principal colour reactions: (1) the xanthoproteic; (2) Millon's; (3) the violet colour with copper sulphate and caustic potash, have been already given in the heading to this lesson. The first two colour reactions depend on the presence of an aromatic radicle in the proteid molecule. Peptones behave differently from the native proteids in this last test. They give a rose-red colour instead of a violet, if only a trace of copper sulphate is used. The albumoses act in this respect like the peptones. This rose-red colour is also given by the substance called biuret; ${ }^{1}$ hence the test is called the biuret reaction.

Precipitants of Proteids.-Proteids are precipitated by a large number of reagents; the peptones and albumoses are exceptions in many cases, and will be considered separately afterwards (see Lesson VI.).

Solutions of the proteids are precipitated by-

1. Strong acids, like nitric acid.

2. Picric acid.

3. Acetic acid and potassium ferrocyanide.

4. Acetic acid and excess of neutral salts like sodium sulphate. thus :-

1 Biuret is formed by heating solid urea; ammonia passes off and leaves biuret.

$$
\begin{aligned}
& 2 \mathrm{CON}_{2} \mathrm{H}_{1}-\mathrm{NH}_{3}=\mathrm{C}_{2} \mathrm{O}_{2} \mathrm{~N}_{3} \mathrm{H}_{5} \\
& \text { [urea], [ammonla] [bluret]. }
\end{aligned}
$$


5. Salts of the heary metals, like copper sulphate, mercuric chloride, lead acetate, silver nitrate, \&c.

6. Tannin.

7. Alcohol.

8. Saturation with certain neutral salts, such as ammonium sulphate.

It is necessary that the words coagulation and precipitation should, in connection with the proteids, be carefully distinguished. The term coagulation is used when an insoluble proteid (coagulated proteid) is formed from a soluble one. This may occur-

1. When the proteid is heated-heat coagulation.

2. Under the influence of a ferment; for instance, when a curd is formed in milk by rennet or a clot in shed blood by the fibrin ferment - ferment coagulation.

3. When an insoluble precipitate is produced by the addition of certain reagents (nitric acid, picric acid, tannin, \&c.).

There are, however, other precipitants of proteids in which the precipitate formed is readily soluble in suitable reagents, like saline solution, and the proteid continues to show its typical reactions. This precipitation is not coagulation. Such a precipitate is produced by saturation with ammonium sulphate. Certain proteids, called globulins, are more readily precipitated by such means than others. Thus, serum globulin is precipitated by half-saturation with ammonium sulphate. Full saturation with ammonium sulphate precipitates all proteids but peptone. The globulins are precipitated by certain salts like sodium chloride and magnesium sulphate, which do not precipitate the albumins. The precipitation of proteids by salts in this way is conveniently termed 'salting out.'

The precipitation produced by alcohol is peculiar in that after a time it becomes a coagulation. Proteid freshly precipitated by alcohol is readily soluble in water or saline media; but after it has been allowed to stand some weeks under alcohol it becomes more and more insoluble. Albumins and globulins are most readily rendered insoluble by this method; albumoses and peptones are apparently never rendered insoluble by the action of alcohol. This fact is of value in the separation of these proteids from others.

\section{CLASSIFICATION OF PROTEIDS}

Proteids may be of animal or vegetable origin, and both animal and vegetable proteids may be subdivided in the same way. We shall, however, be chiefly concerned with the animal proteids. 
If we use the term 'proteid' in the widest sense, the first main subdivision of these substances is into

A. The simple proteids.

B. The compound or conjugated proteids.

c. The albuminoids.

D. The protamines. These substances are regarded by Kossel as the simplest proteids, and though it is doubtful whether this view will be ultimately accepted, it will be convenient to consider them here.

We may now take these four classes one by one.

\section{A. The Simple Proteids}

Class I. Albumins.-These are soluble in water, in dilute saline solutions, and in saturated solutions of sodium chloride and magnesium sulphate. They are, however, precipitated by saturating their solutions with ammonium sulphate. Their solutions are coagulated by heat, usually at $70-73^{\circ} \mathrm{C}$. The following are instances :-

(a) Serum albumin. (b) Egg albumin. (c) Lact-albumin (see MILK).

Class II. Globulins.-These are insoluble in water, soluble in dilute saline solutions, and insoluble in concentrated solutions of neutral salts like sodium chloride, magnesium sulphate, and ammonium sulphate. A globulin dissolved in a dilute saline solution may therefore be precipitated-

1. By removing the salt-by dialysis (see p. 23).

2. By increasing the amount of salt. The best salts to employ are ammonium sulphate (half saturation) or magnesium sulphate (complete saturation).

The globulins are coagulated by heat; the temperature of heat coagulation varies considerably. The following are instances:-

(a) Fibrinogen

(b) Serum globulin (paraglobulin); in blood plasma.

(c) Egg globulin in white of egg.

(d) Myosinogen in muscle.

(e) Crystallin in the crystalline lens.

If we compare together these two important classes of proteids, we find that they all give the same general tests, that all are coagulated by heat, but that they differ in solubilities. This difference in solubility may be stated in tabular form as follows :- 


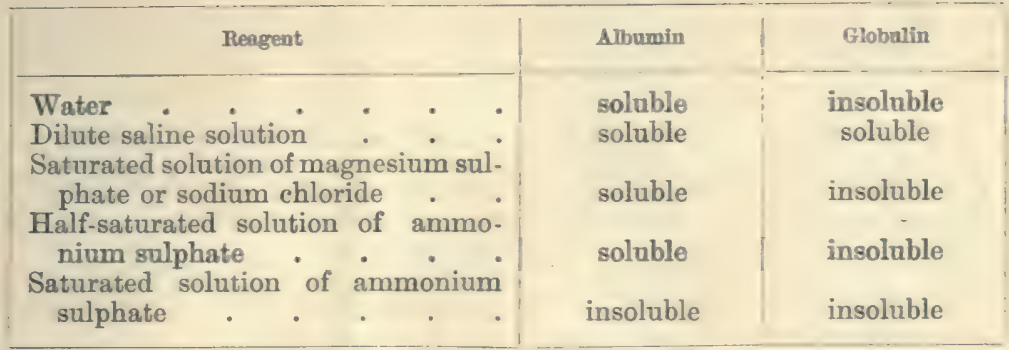

Class III. Proteoses, These products of digestion will be studied Class IV. Peptones $\int$ in Lessons VI. and VII.

Class V. Coagulated Proteids.-There are two principal subdivisions of these :-

(a) Proteids in which coagulation has been produced by heat; they are insoluble in water, saline solutions, weak acids, and weak alkalis ; soluble after prolonged boiling in concentrated mineral acids ; dissolved by gastric and pancreatic juices, they give rise to peptones.

(b) Proteids in which coagulation has been produced by ferments :-

i. Fibrin (see Blood). ii. Myosin (see Muscle). iii. Casein (see MiLK).

Directions for testing for and separating proteids will be found at the end of this elementary course.

\section{Albuminates}

Albuminates are compounds of proteid (albumin or globulin) with mineral substances. Thus, if a solution of copper sulphate is added to a solution of albumin, a precipitate of copper albuminate is obtained. Similarly, by the addition of other salts of the heavy metals, other metallic albuminates are obtainable.

The albuminates which are obtained by the action of dilute acids and alkalis on either albumins or globulins are of considerable physiological interest because they are formed during digestion, and it is to these we shall chiefly confine our attention. The general properties of the acid-albumin, or syntonin, and the alkali-albumin which are thereby respectively formed will be gathered from the practical exercise which stands at the head of this lesson. They are insoluble in pure water, but are soluble in either acid or alkali, and are precipitated by neutralisation unless disturbing influences like the presence of sodium phosphate are present. It may also be added that, like globulins, they are precipitated by saturation with such 
neutral salts as sodium chloride and magnesium sulphate. If dissolved in acid or alkali, they are not coagulated by heat.

A variety of alkali albumin (probably a compound containing a large quantity of alkali) may be formed by adding strong potash to undiluted white of egg. The resulting jelly is called Lieberkühn's jelly. A similar jelly is formed by adding strong acetic acid to undiluted egg-white.

The halogens (chlorine, bromine, and iodine) also form albuminates, and may be used for the precipitation of proteids.

\section{B. The Compound Proteids}

The compound proteids are compounds of albuminous substances with other organic materials, which are as a rule also of complex nature.

They may be divided into the following groups :-

1. Hæmoglobin and its allies. These are compounds of proteid with an iron-containing pigment, and will be fully considered under BLOOD.

2. Gluco-proteids. These are compounds of proteids with members of the carbohydrate group. This class includes the mucins, and substances allied to the mucins, called mucoids.

Dr. Pavy has shown that a small quantity of a similar carbohydrate can be split off from various other proteids, which we have already classified as simple proteids.

Mucin is a widely distributed substance, occurring in epithelial cells, or shed out by them (mucus, mucous glands, goblet cells); and in connective tissue where it forms the chief constituent of the ground substance or intercellular material.

The mucin obtained from different sources varies in composition and reactions. There are probably several mucins; they all agree in the following points :-

(a) Physical character. Viscid and tenacious.

(b) Precipitability from solutions by acetic acid; they all dissolve in dilute alkalis like lime water.

(c) They are all compounds of a proteid with a carbohydrate provisionally called animal gum, which by treatment with dilute mineral acid can be hydrated into a reducing but non-fermentable sugar, the nature of which is at present uncertain.

The mucoids differ from the mucins either in being non-precipitable from alkaline solutions by acetic acid, or in being readily soluble in excess of acetic acid. One of these, called oro-mucoid, is found in 
white of egg, and others called pseudo-mucin and para-mucin are sometimes found in the fluid of ovarian cysts, and dropsical effusions.

3. Nucleins and nucleo-proteids.-These are compounds of proteid with a complex organic acid called nucleic acid, which contains phosphorus.

Nucleo-proteids.-Compounds of proteids with nuclein. They are found in the nuclei and protoplasm of cells. Caseinogen of milk and vitellin of egg-yolk are similar substances. In physical charactors they often closely simulate mucin; in fact, the substance called mucin in the bile is in some animals a nucleo-proteid. They may be distinguished from mucin by the fact that they yield on gastric digestion not only peptone but also an insoluble residue of nuclein which is soluble in alkalis, is precipitable by acetic acid from such a solution, and contains a high percentage (10-11) of phosphorus.

Some of the nucleo-proteids also contain iron, and it is probable that the normal supply of iron to the body is contained in the nucleoproteids, or hæmatogens (Bunge), of plant and animal cells.

The relationship of nucleo-proteids to the coagulation of the blood is described under BLood.

Nucleo-proteids may be prepared from cellular structures like testis, thymus, kidney, \&c., by two methods :-

1. Wooldridge's method.-The organ is minced and soaked in water for twenty-four hours. Acetic acid added to the aqueous extract precipitates the nucleo-proteid, or, as Wooldridge called it, tissue fibrinogen.

2. Sodium chloride method. - The minced organ is ground up in a mortar with solid sodium chloride; the resulting viscous mass is poured into excess of distilled water, and the nucleo-proteid rises in strings to the top of the water.

The solvent usually employed for a nucleo-proteid, whichever method it is prepared by, is a 1-per-cent. solution of sodium carbonate.

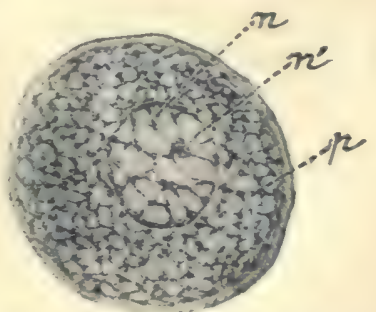

Fi:- 9.-Diagram of a cell : $\mu$, protoplasm composed of spou viop̧lasm and hyaloplasm : $n$, nuthens with intranuclear network of ehromatin or nuclein; and $n^{\prime}$, nuelerins. (Echiifer.)

Nuclein is the chief constituent of cell-nuclei. Its physical characters are something like mucin, but it differs chemically in containing a high percentage of phosphorus. Nuclein is identical with the chromatin of histologists (see fig. 9).

On decomposition nuclein yields a complex organic acid called 
nucleic acid, together with a variable amount of proteid. Nucleic acid on decomposition yields phosphoric acid and various bases of the xanthine group. Some forms of nuclein, called pseudo-nuclein, such as are obtained from casein and vitellin, differ from the true nucleins in not yielding these xanthine or, as they are sometimes termed, alloxuric or purine bases.

Further particulars concerning the alloxuric bases will be given under URIC ACID, to which they are closely related.

The following diagrammatic way of representing the decomposition of nucleo-proteid will assist tise student in remembering the relationships of the substances we have just been considering:-

Nucleo-Proteid

subjected to gastric digestion yields

Proteid converted into peptone, which goes into solution.

Nuclein, which remains as an insoluble residue. If this is dissolved in alkali and then hydrochloric acid added it yields

Proteid-convertedinto acid albumin in solution.

A precipitate consisting of nucleic acid. If this is heated in a sealed tube with hydrochloric acid, it yields a number of imperfectly known substances like thymic acid and in some cases a reducing sugar. But the best known and constant products of its decomposition are

Phosphoric acid.

Purine bases, viz:

Adenine

Hypoxanthine

Guanine

Xanthine

The nuclein obtained from the nuclei or heads of the spermatozoa consists of nucleic acid without any proteid admixture. In fishes' spermatozoa, however, the nucleic acid is united to protamine, the chemical properties of which we shall be considering immediately. 


\section{The Albuminoids}

The albuminoids form a heterogeneous group of substances which, though similar to the proteids in many particulars, differ from them in certain other points. The principal members of the group are the following:-

1. Collagen, the substance of which the white fibres of connective tissue are composed. Some observers regard it as the anhydride of gelatin.

2. Ossein.-This is the same substance derived from bone: ${ }^{1}$

3. Gelatin. -This substance is produced by boiling collagen with water. It possesses the peculiar property of setting into a jelly when a solution made with hot water cools. It gives most of the proteid colour tests. Many observers state, however, that it contains no sulphur. On digestion it is like proteid converted into peptone-like substances, and is readily absorbed. Though it will replace in diet a certain quantity of proteid, acting as what is called a 'proteidsparing' food, it cannot altogether take the place of proteid as a food. Animals fed on gelatin instead of proteid waste rapidly. Chondrin, the very similar substance obtained from hyaline cartilage, appears to be a mixture of gelatin with mucinoid materials.

4. Elastin.-This is the substance of which the yellow or elastic fibres of connective tissue are composed. It is a very insoluble material. The sarcolemma of muscular fibres and certain basement membranes are very similar.

5. Keratin, or horny material, is the substance found in the surface layers of the epidermis, in hairs, nails, hoofs, and horns. It is very insoluble, and chiefly differs from proteids in its high percentage of sulphur. A similar substance, called neurokeratin, is found in neuroglia and nerve fibres. In this connection it is interesting to note that the epidermis and the nervous system are both formed from the same layer of the embryo- the epiblast.

6. Chitin and similar substances found in the exo-skeleton of many invertebrates.

1 In round numbers the solid matter in bone contains two-thirds inorganic or earthy matter, and one-third organic or animal matter. The inorganic constituents are calcium phosphate ( 84 per cent. of the ash), calcium carbonate (13 per cent.), and smaller quantities of calcium chloride, calcium fluoride, and magnesium phosphate. The organic constituents are ossein (this is the most abundant), elastin from the membranes lining the Haversian canals, lacunæ, and canaliculi, and proteids and nuclein from the bone corpuscles. There is also a small quantity of fat even after removal of all the marrow. Dentine is like bone chemically, but the proportion of earthy matter is rather greater. Enamiel is the hardest tissue in the body; the mineral matter is like that found in bone and dentine; but the organic matter is so small in quantity as to be practically non-existent. (Tomes.) Enamel is epiblastic, not mesoblastic like bone and dentine. 


\section{The Protamines}

These are basic substances which are combined with nuclein in the heads of the spermatozoa of certain fishes. They resemble proteids in many of their characters-e.g. they give Piotrowski's reaction and some of the other tests for proteids. They are regarded by Kossel as the simplest proteids. On hydrolytic decomposition, they first yield substances analogous to the peptones, which are called protones, and then they split up into simpler materials which are mainly bases containing six atoms of carbon, and called in consequence the hexone bases. These bases have the following names and formulæ:-

$\begin{array}{ll}\text { Histidine } & \mathrm{C}_{6} \mathrm{H}_{9} \mathrm{~N}_{3} \mathrm{O}_{2} \\ \text { Arginine } & \mathrm{C}_{6} \mathrm{H}_{14} \mathrm{~N}_{4} \mathrm{O}_{2} \\ \text { Lysine } & \mathrm{C}_{6} \mathrm{H}_{14} \mathrm{~N}_{2} \mathrm{O}_{2}\end{array}$

Protamines differ in their composition according to their source, and yield these products in different proportions. Thus salmine (the protamine from the salmon) has the empirical formula $\mathrm{C}_{30} \mathrm{H}_{57} \mathrm{~N}_{17} \mathrm{O}_{6}$, and sturine (from the sturgeon) $\mathrm{C}_{36} \mathrm{H}_{69} \mathrm{~N}_{19} \mathrm{O}_{7}$.

A good deal of work still remains to be done at these substances, but the five which have hitherto been most fully worked at are salmine, sturine, scombrine (from the mackerel), cyclopterine (from Cyclopterus lumpus), and clupeine (from the herring).

Of these salmine and clupeine appear to be identical; the principal products of the decomposition of salmine, clupeine, and scombrine are arginine, amido-valerianic acid, and a small quantity of an unknown residue.

Sturine yields these same products with lysine, and histidine in addition.

Cyclopterine yields the same products as sturine, with the addition of an aromatic substance.

The more complex proteids and albuminoids yield hexone bases, and so Kossel considers that all these substances contain a protamine nucleus. The more complex proteids, however, yield many other products of decomposition in addition to these bases, of which leucine $\left(\mathrm{C}_{6} \mathrm{H}_{13} \mathrm{NO}_{2}\right)$ and tyrosine $\left(\mathrm{C}_{9} \mathrm{H}_{11} \mathrm{NO}_{3}\right)$, an aromatic substance, may be specially mentioned. Cyclopterine, which also yields an aromatic substance, is thus an important chemical link between the other protamines and the proteids proper. It is interesting to note how many of these decomposition products contain six carbon atoms, and it reminds one that in the sugars obtained from starch there are also six atoms of carbon. 


\section{LESSON IV}

\section{FOODS}

A. Milk. 1. Examine a drop of milk with the microscope.

2. Note the specific gravity of fresh milk with the lactometer; compare this with the specific gravity of milk from which the cream has been removed (skimmed milk). The specific gravity of skimmed milk is higher owing to the removal of the lightest constituent-the cream.

3. The reaction of fresh milk is neutral or slightly alkaline.

4. Warm some milk in a test-tube to the temperature of the bods, and and a few drops of rennet. After standing, a curd is formed from the conversion of caseinogen, the chief proteid in milk, into casein. The casein entangles the fat globules. The liquid residue is termed whey. No curdling is produced if the rennet solution is previously boiled, because heat kills ferments.

5. Take some milk to which 0.2 per cent. of potassium oralate has been added; warm to $40^{\circ} \mathrm{C}$. and add rennet. No curdling takes place because the oxalate has precipitated the calcium salts which are necessary in the coagulation process.

Take a second specimen of oxalated milk and add a few drops of 2-percent. solution of calcium chloride, and then rennet; curdling or coagulation takes place if the mixture is kept warm in the usual way.

6. To another portion of warm milk diluted with water add a few drops of 20-per-cent. acetic acid. A lumpy precipitate of caseinogen entangling the fat is formed.

7. Filter off this precipitate, and in the filtrate test for lactose or milk sugar by Trommer's test (see Lesson I.) ; for lact-albumin by boiling, or by Millon's reagent (see Lesson II.) ; and for earthy (that is, calcium and magnesium) phosphates by ammonia, which precipitates these phosphates. Phosphates mav also be detected by adding nitric acid and ammonium molybdate and boiling; a yellow crystalline precipitate is formed.

8. Fat (butter) may be extracted from the precipitate by shaking it with ether; on exaporation of the ethereal extract the fat is left behind, forming a greasy stain on paper. The presence of fat may also be demonstrated by the black colour produced by the addition of osmic acid to the milk.

9. Caseinogen, like globulins, is precipitated by saturating wilk with sodium chloride or magnesium sulphate. and by half saturation with ammonium sulphate, but differs from the globulins in not being coagulated by heat. The precipitate produced by saturation with salt floats to the surface with the entangled fat, and the clear salted whey is seen below after an hour or two.

B. Flour.-Mix some wheat flour with a little water into a stiff dough. Wrap this up in a piece of muslin and knead it under a tap or in a capsule of water. The starch grains come through the holes in the muslin (identify by iodine test), and an elastic sticky mass remains behind. This is a proteid called gluten. Suspend a fragment of gluten in water; add nitric acid and boil ; it turns rellow; cool and add ammonia ; it turns orange (xanthoproteic reaction). Boil another fragment with Millon's reagent; it turns a brick-red colour. 
C. Bread contains the same constituents as flour, except that some of the starch has been converted into dextrin and dextrose during baking (most flours, however, contain a small quantity of sugar). Extract breadcrust with cold water, and test the extract for dextrin (iodine test) and for dextrose (Trommer's test). If hot water is used, starch also passes into solution.

D. Meat.-This is our main source of proteid food. Cut up some lean meat into fine shreds and grind these up with salt solution. Filter and test for proteids.

\section{THE PRINCIPAL FOOD-STUFFS}

We can now proceed to apply the knowledge we have obtained of the proteids, carbohydrates, and fats to the investigation of some important foods. We do not actually use as food the various organic proximate principles in the pure condition; it is necessary that in a suitable diet these should be mixed in certain proportions, and in nature we find them already mixed for us. The chief proximate principles in food are:-
1. Proteids
2. Carbohydrates organic.
3. Fats
4. Water
5. Salts inorganic.

In milk and in eggs, which form the exclusive foods of young animals, all varieties of these proximate principles are present in suitable proportions. Hence they are spoken of as perfect foods. Eggs, though a perfect food for the developing bird, contain too little carbohydrate for a mammal. In most vegetable foods carbohydrates are in excess, while in animal food, like meat, the proteids are predominant. In a suitable diet these should be mixed in proper proportions, which must vary for herbivorous and carnivorous animals. We must, however, limit ourselves to the omnivorous animal, man.

A healthy and suitable diet must possess the following characters :-

1. It must contain the proper amount and proportion of the various proximate principles.

2. It must be adapted to the climate, to the age of the individual, and to the amount of work done by him.

3. The food must contain not only the necessary amount of proximate principles, but these must be present in a digestible form. As an instance of this many vegetables (peas, beans, lentils) contain even more proteid than beef and mutton, but are not so nutritious, as they are less digestible, much passing off in the fæces unused.

The nutritive value of a diet depends chiefly on the amount of carbon and nitrogen it contains in a rearlily digestible form. A man doing a moderate amount of work will eliminate, chiefly from the 
lungs in the form of carbonic acid, from 250 to 280 grammes of carbon per diem. During the same time he will eliminate, chiefly in the form of urea in the urine, about 15 to 18 grammes of nitrogen. These substances are derived from the metabolism of the tissues, and various forms of energy, work and heat being the chief, are simultaneously liberated. During muscular exercise the output of carbon greatly increases; the increased excretion of nitrogen is not nearly so marked. Taking, then, the state of moderate exercise, it is necessary that the waste of the tissues should be replaced by fresh material in the form of food; and the proportion of carbon to nitrogen should be the same as in the excretions : 250 to 15 , or 166 to 1 . The proportion of carbon to nitrogen in proteid is, however, 53 to 15 , or 3.5 to 1 . The extra supply of carbon must come from non-nitrogenous foods - viz. fat and carbohydrate.

Moleschott gives the following daily diet :-

Proteid 120 grammes.

Fat 90 ,

Carbohydrate 333 , ,

Ranke's diet closely resembles Moleschott's ; it is-

Proteid 100 grammes.

Fat 100 ,

Carbohydrate 250 ,

In preparing diet tables, such adequate diets as those just given should be borne in mind. The following dietary (from G. N. Stewart) will be seen to be rather more liberal, bat may be taken as fairly typical of what is usually consumed by an adult man in the twenty-four hours, doing an ordinary amount of work.

\begin{tabular}{|c|c|c|c|c|c|c|c|c|c|}
\hline \multirow{2}{*}{ Food-stuff } & \multirow{2}{*}{\multicolumn{3}{|c|}{ Quantity }} & \multicolumn{6}{|c|}{ Grammes of } \\
\hline & & & & $\begin{array}{c}\text { Nitro- } \\
\text { gen }\end{array}$ & $\begin{array}{l}\text { Car- } \\
\text { boul }\end{array}$ & $\begin{array}{l}\text { Pro- } \\
\text { teids }\end{array}$ & Fats & $\begin{array}{l}\text { Carbo- } \\
\text { hydrates }\end{array}$ & salts \\
\hline Lean meat & 250 & $\begin{array}{l}\text { Metric } \\
\text { gystem } \\
\text { grammes }\end{array}$ & Raglish & 8 & 33 & 55 & 8.5 & 0 & 4 \\
\hline Bread & 500 & grammes & 18 & 6 & 112 & 40 & $7 \cdot 5$ & 245 & $6 \cdot 5$ \\
\hline Milk . & 500 & , & $\frac{3}{4}$ pint & 3 & 35 & 20 & 20 & 25 & $3 \cdot 5$ \\
\hline Butter & 30 & " & $1 \mathrm{oz}$ & 0 & 20 & 0 & 27 & 0 & 0.5 \\
\hline $\begin{array}{c}\text { Fat with } \\
\text { meat }\end{array}$ & 30 & , & 1 & 0 & 22 & 0 & 30 & 0 & 0 \\
\hline Potatoes. & 450 & ". & $16 "$ & 1.5 & 47 & 10 & 0 & 95 & $4 \cdot 5$ \\
\hline Oatmeal . & 75 & ", & 3 & 1.7 & 30 & 10 & 4 & 48 & 2 \\
\hline & & & & $20 \cdot 2$ & 299 & 135 & 97 & 413 & 21 \\
\hline
\end{tabular}




\section{MILK}

Milk is often spoken of as a 'perfect food,' and it is so for infants. For those who are older it is so voluminous that unpleasantly large quantities of it would have to be taken in the course of the day to insure the proper supply of nitrogen and carbon. Moreover for adults it is relatively too rich in proteid and fat. It also contains too little iron (Bunge); hence children weaned late become anæmic.

The microscope reveals that it consists of two parts : a clear fluid and a number of minute particles that float in it. These consist of minute oil globules, varying in diameter from 0.0015 to 0.005 millimetre.

The milk secreted during the first few days of lactation is called colostrum. It contains very little caseinogen, but large quantities of globulin instead. Microscopically, cells from the acini of the
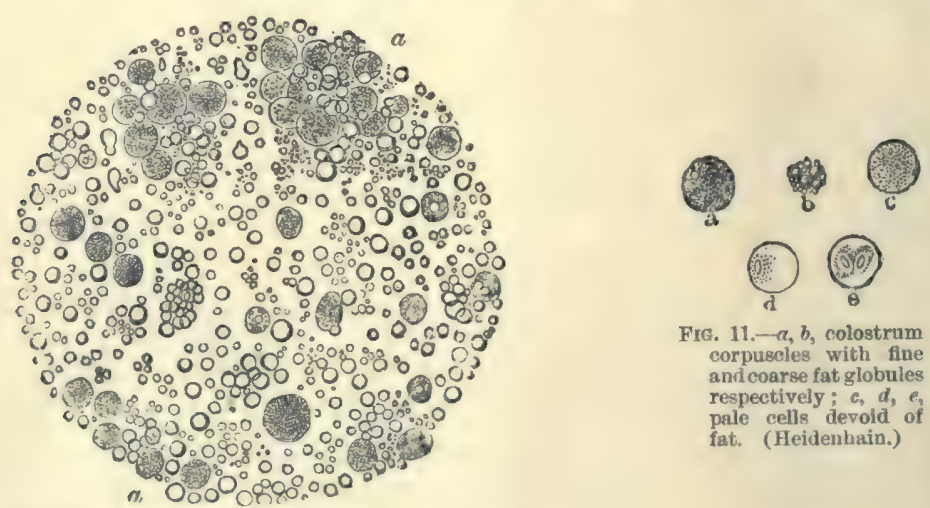

FrG. 11.- $a, b$, colostrum corpuscles with fine and coarse fat globules respectively ; $c_{2} d, e_{2}$ pale cells devold of fat. (Heidenhain.)

Fic. 10.-Microscopic appearance of milk in the early stage of lactation, showing colostrum corpuscles in addition to fat globules. (Yeo.)

mammary gland are seen, which contain fat globules in their interior; they are called colostrum corpuscles.

Reaction and Specific Gravity.-The reaction of fresh cow's milk and of human milk is generally neutral or slightly alkaline. In carnivora the milk is acid. All milk readily turns acid or sour as the result of fermentative change, part of its lactose being transformed into lactic acid (see p. 37). The specific gravity of milk is usually ascertained with the hydrometer. That of normal cow's milk varies from 1028 to 1034 . When the milk is skimmed the specific gravity rises, owing to the removal of the light constituent, the fat, to 1033 to 1037. In all cases the spacific gravity of water with which other substances are compared is taken as 1000 . 
Composition.-Frankland gires the following table, contrasting the milk of woman, ass, and cow:-

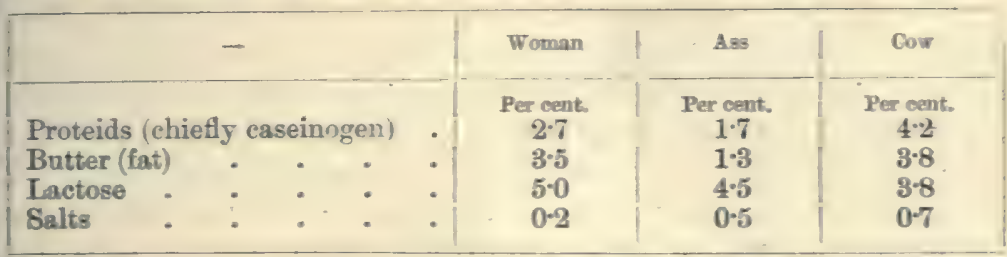

Hence, in feeding infants on cow's milk, it will be necessary to dilute it, and add sugar to make it approximately equal to natural human milk.

The Proteids of Milk. -The principal proteid in milk is called caseinogen; this is the one which is coagulated by rennet to form casein. Cheese consists of easein with the entangled fat. The other proteid in milk is an albumin. It is present in small quantities only ; it differs in some of its properties (specific rotation, coagulation temperature, and solubilities) from serum-albumin; it is called lactalbumin.

The Coagulation of Milk-Rennet is the agent usually employed for this purpose: it is a ferment secreted by the stomach, especially by sucking animals, and is generally obtained from the calf.

The curd consists of the casein and entangled fat: the liquid residue called whey contains the sugar, salts, and albumin of the milk. There is also a small quantity of a new proteid called wheyproteid, which differs from caseinogen by not being convertible into casein. It is produced by the decomposition of the caseinogen molecule during the process of curdling.

The curd formed in human milk is more finely divided than that in cow's milk; hence it is more digestible. In feeding children and invalids on cow's milk, the lumpy condition of the curd may be obviated by the addition of lime water or barley water to the milk.

Considerable discussion has taken place as to whether the caseinogen of human milk may not be a different proteid from that of cow's milk, especially in relation to the amount and manner of combination of its phosphorus. The differences, however, appear to be explicable on the hypothesis that they are due to rariations in the amounts of calcium salts and of citric acid which are present.

Caseinogen itself may be precipitated by acids such as acetic acid or by saturation with neutral salts like sodium chloride. This, however, is not coagulation, but precipitation. The precipitate may be collected and dissolved in lime water; the addition of rennet then 
produces coagulation in this solution, provided that a sufficient amount of calcium salts is present.

The addition of rennet produces coagulation in milk, provided that a sufficient amount of calcium salts is present. If the calcium salts are precipitated by the addition of potassium oxalate, rennet causes no formation of casein. The process of curdling in milk is a double one ; the first action due to rennet is to produce a change in caseinogen; the second action is that of the calcium salt, which precipitates the altered caseinogen as casein. In blood also, calcium salts are necessary for coagulation, but there they act in a different way, namely, in the production of fibrin-ferment (see Coagulation of BLOOD).

Caseinogen is often compared to alkali-albumin. The latter, however, does not clot with rennet, and is, unlike caseinogen, readily soluble in excess of acids. Caseinogen is not a globulin, though it is, like globulins, precipitated by neutral salts. It differs from a globulin in not being coagulated by heat. It is a nucleo-proteid: that is, a compound of a proteid with the proteid-like but phosphorusrich material called nuclein (see p. 29).

The Fats of Milk.-The chemical composition of the fat of milk (butter) is very like that of adipose tissue. It consists chiefly of palmitin, stearin, and olein. There are, however, smaller quantities of fats derived from fatty acids lower in the series, especially butyrin and caproin. The relation between these varies somewhat, but the proportion is roughly as follows:-Olein, $\frac{3}{7}$; palmitin, $\frac{1}{3}$; stearin, $\frac{1}{6}$; butyrin, caproin, and caprylin, $\frac{1}{17}$. The old statement that each fat globule is surrounded by a membrane of caseinogen has been shown to be incorrect. Milk also contains small quantities of lecithin, a phosphorised fat; of cholesterin, an alcohol which resembles fat in its solubilities (see BILE), and a yellow fatty pigment or lipochrome.

Milk Sugar or Lactose.-This is a saccharose $\left(\mathrm{C}_{12} \mathrm{H}_{22} \mathrm{O}_{11}\right)$. Its properties have already been described in Lesson I. p. 13.

Souring of Milk.-When milk is allowed to stand, the chief change which it is apt to undergo is a conversion of a part of its lactose into lactic acid. This is due to the action of micro-organisms, and would not occur if the milk were contained in closed sterilised vessels. Equations showing the change produced are given on p. 14. When souring occurs, the acid which is formed precipitates a portion of the caseinogen. This must not be confounded with the formation of casein from caseinogen which is produced by rennet. There are, however, some bacterial growths which produce true coagulation like rennet. 
Alcoholic Fermentation in Milk. - When yeast is added to milk, the sugar does not readily undergo the alcoholie fermentation. Other somewhat similar fungoid growths are, however, able to produce the change, as in the preparation of koumiss; the milk sugar is first inverted, that is dextrose and galactose are formed from it (see p. 13), and it is from these sugars that alcohol and carbonic acid originate.

The Salts of Milk.-The chief salt present is calcium phosphate; a small quantity of magnesium phosphate is also present. The other salts are chiefly chlorides of sodium and potassium.

\section{EGGS}

In this country the eggs of hens and ducks are those particularly selected as foods. The shell is made of calcareous matter, especially calcium carbonate. The white is composed of a richly albuminous fluid enclosed in a network of firmer and more fibrous material. The amount of solids is 13.3 per cent.; of this 12.2 is proteid in nature. The proteids are albumin, with smaller quantities of egg-globulin (see p. 26) and ovo-mucoid (p. 28). The remainder is made up of sugar ( 0.5 per cent.), traces of fats, lecithin and cholesterin, and 0.6 per cent. of inorganic salts. The yolk is rich in food materials for the development of the future embryo. In it there are two varieties of yolk-spherules, one kind yellow and opaque (due to admixture with fat and a yellow lipochrome), and the other smaller, transparent and almost colourless: these are proteid in nature, consisting of the nucleo-proteid called vitellin (pp. 29,30). Small quantities of sugar, lecithin, cholesterin, and inorganic salts are also present.

The nutritive value of eggs is high, as they are so readily digestible; but the more an egg is cooked the more insoluble do its proteid constituents become.

\section{MEAT}

This is composed of the muscular and connective (including adipose) tissues of certain animals. The flesh of some animals is not eaten; in some cases this is a matter of fashion; some flesh, like that of the carnivora, is stated to have an unpleasant taste; and in other cases (e.g. the horse) it is more lucrative to use the animal as a beast of burden.

Meat is the most concentrated and most easily assimilable of nitrogenous foods. It is our chief source of nitrogen. Its chief solid constituent is proteid, and the principle proteid is myosin. In addition to the extractives and salts contained in muscle, there is always 
a certain percentage of fat, eren though all visible adipose tissue is dissected off. The fat-cells are placed between the muscular fibres, and the amount of fat so situated varies in different animals. It is particularly abundant in pork; hence the indigestibility of this form of flesh: the fat prevents the gastric juice from obtaining ready access to the muscular fibres.

The following table gives the chief substances in some of the principal meats used as food.

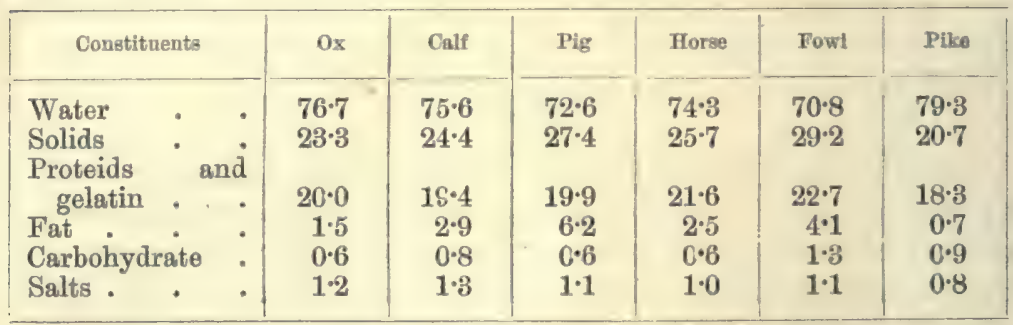

The large percentage of water in meat should be particularly noted; if a man wished to take his daily minimum of 100 grammes of proteid entirely in the form of meat, it would be necessary for him to consume about 500 grammes (i.e. a little more than $1 \mathrm{lb}$.) of meat per diem.

\section{FLOUR}

The best wheat flour is made from the interior of wheat grains, and contains the greater proportion of the starch of the grain and most of the proteid. Whole flour is made from the whole grain minus the husk, and thus contains not only the white interior but also the harder and browner outer portion of the grain. This outer region contains a somewhat larger proportion of the proteids of the grain. Whole flour contains 1 to 2 per cent. more proteid than the best white flour, but it has the disadvantage of being less readily digested. Brown flour contains a certain amount of bran in addition; it is still less digestible, but is useful as a mild laxative, the insoluble cellulose mechanically irritating the intestinal canal as it passes along.

The best flour contains very little sugar. The presence of sugar indicates that germination has commenced in the grains. In the manufacture of malt from barley this is purposely allowed to go on.

When mixed with water, wheat flour forms a sticky adhesive mass called dough. This is due to the formation of gluten, and the forms of grain poor in gluten cannot be made into dough (oats, rice, 
sc.). Gluten does not exist in the flour as such, but is formed on the addition of water from the pre-existing soluble proteids (e.g. globulins) in the flour.

The following table contrasts the composition of some of the more important vegetable foods :-

\begin{tabular}{|c|c|c|c|c|c|c|c|c|c|}
\hline \multicolumn{3}{|c|}{ Constituents } & Wheat & Barley & Oats & Rice & Leutils & Peas & Potatoes \\
\hline Water & . & . & $13 \cdot 6$ & $13 \cdot 8$ & 124 & $13 \cdot 1$ & $12 \cdot 5$ & $14 \cdot 8$ & $76 \cdot 0$ \\
\hline Proteid & . & - & $12 \cdot 4$ & $11 \cdot 1$ & $10 \cdot 4$ & $7 \cdot 9$ & $24 \cdot 8$ & $23 \cdot 7$ & $2 \cdot 0$ \\
\hline Fat. & . & . & $1 \cdot 4$ & $2 \cdot 2$ & $5 \cdot 2$ & 0.9 & 1.9 & $1 \cdot 6$ & 02 \\
\hline Starch & - & . & $67 \cdot 9$ & $64 \cdot 9$ & $57 \cdot 8$ & 76.5 & $54 \cdot 8$ & $49 \cdot 3$ & $20 \cdot 6$ \\
\hline Cellulose. & . & . & $2 \cdot 5$ & $5 \cdot 3$ & $11 \cdot 2$ & 0.6 & $3 \cdot 6$ & $7 \cdot 5$ & 0.7 \\
\hline Mineral salts & . & - & $1 \cdot 8$ & $2 \cdot 7$ & $3 \cdot 0$ & $1 \cdot 0$ & $2 \cdot 4$ & $3 \cdot 1$ & $1 \cdot 0$ \\
\hline
\end{tabular}

Ve see from this table-

1. The great quantity of starch always present.

2. The small quantity of fat; that bread is generally eaten with butter is a popular recognition of this fact.

3. Proteid, except in potatoes, is pretty abundant, and especially so in the pulses (lentils, peas, \&c.). The proteid in the pulses is not gluten, but consists of vitellin and globulin-like substances.

In the mineral matters in vegetables, salts of potassium and magnesium are, as a rule, more abundant than those of sodium and calcium.

\section{BREAD}

Bread is made by cooking the dough of wheat flour mixed with yeast, salt, and flavouring materials. A ferment in the flour acts at the commencement of the process when the temperature is kept $a_{0}$ little over that of the body, and forms dextrin and sugar from the starch, and then the alcoholic fermentation, due to the action of the yeast, begins. The bubbles of carbonic acid, burrowing passages through the bread, make it light and spongy. This enables the digestive juices subsequently to soak into it readily and affect all parts of it. During baking the gas and alcohol are expelled from the bread, the yeast is killed, and a crust forms from the drying of the outer portions of the dough.

White bread contains, in 100 parts, 7 to 10 of proteid, 55 of carbohydrates, 1 of fat, 2 of salts, and the rest water.

\section{COOKING OF FOOD}

The cooking of foods is a development of civilisation, and much relating to this subject is a matter of education and taste rather than 
of physiological necessity. Cooking, however, serves many useful ends :-

1. It destroys all parasites and danger of infection. This relates not only to bacterial growths, but also to larger parasites, such as tapeworms and trichinæe.

2. In the case of vegetable foods it breaks up the starch grains, bursting the cellulose and allowing the digestive juices to come into contact with the granulose.

3. In the case of animal foods it converts the insoluble collagen of the universally distributed connective tissues into the soluble gelatin. The loosening of the fibres is assisted by the formation of steam between them. By thus loosening the binding material, the more important elements of the food, such as muscular fibres, are rendered accessible to the gastric and other juices. Meat before it is cooked is generally kept a certain length of time to allow rigor mortis to pass off.

Of the two chief methods of cooking, roasting and boiling, the former is the more economical, as by its means the meat is first surrounded with a coat of coagulated proteid on its exterior, which keeps in the juices to a great extent, letting little else escape than the dripping (fat). Whereas in boiling, unless both bouillon and bouilli are used, there is considerable waste. Cooking, especially boiling, renders the proteids more insoluble than they are in the raw state, but this is counterbalanced by the other advantages that cooking possesses.

Beef Tea. - In making beef tea and similar extracts of meat it is necessary that the meat should be placed in cold water, and this is gradually and carefully warmed. In cooking a joint it is usual to put the meat into boiling water at once, so that the outer part is coagulated, and the loss of material minimised.

An extremely important point in this connection is that beef tea and similar meat extracts should not be regarded as foods. They are valuable as pleasant stimulating drinks for invalids, but they contain very little of the nutritive material of the meat, their chief constituents, next to water, being the salts and extractives (creatine, creatinine, lactic acid, \&c.) of flesh.

Many invalids restricted to a liquid diet get tired of milk, and imagine that they get sufficient nutriment by taking beef tea instead. It is very important that this erroneous idea should be corrected. One of the greatest difficulties that a physician has to deal with in these cases is the distaste which many adults evince for milk. It is essential that this should be obviated as far as possible by preparing the milk in different ways to avoid monotony. Some can take koumiss; but a less expensive variation may be introduced in the 
shape of junkets, which, although well known in the West of England, are comparatively unknown in other parts. The preparation of a junket consists in adding to warm milk in a bowl or dish a small quantity of essence of rennet (Clark's essence is very good for this purpose) and flavouring material according to taste. The mixture is then put aside, and in a short time the milk sets into a jelly (coagulation of casein), which may then be served with or without cream.

Soup contains the extractives of meat, a small proportion of the proteids, and the principal part of the gelatin. The gelatin is usually increased by adding bones and fibrous tissue to the stock. It is the presence of this substance which causes the soup when cold to gelatinise.

\section{ACCESSORIES TO FOOD}

Among these must be placed alcohol, the value of which within moderate limits is not as a food but as a stimulant; condiments (mustard, pepper, ginger, curry powder, \&c.), which are stomachic stimulants the abuse of which is followed by dyspeptic troubles; and tea, coffee, cocoa, and similar drinks. These are stimulants chiefly to the nervous system; tea, coffee, maté (Paraguay), guarana (Brazil), cola nut (Central Africa), bush tea (South Africa), and a few other plants used in various countries all owe their chief property to an alkaloid called theine or caffeine $\left(\mathrm{C}_{8} \mathrm{H}_{10} \mathrm{~N}_{4} \mathrm{O}_{2}\right)$; cocoa to the closely related alkaloid, theobromine $\left(\mathrm{C}_{7} \mathrm{H}_{8} \mathrm{~N}_{4} \mathrm{O}_{2}\right)$; coca to cocaine. These alkaloids are all poisonous, and used in excess, even in the form of infusions of tea and coffee, produce over-excitement, loss of digestive power, and other disorders well known to physicians. Coffee differs from tea in being rich in aromatic matters; tea contains a bitter principle, tannin. To avoid the injurious solution of too much tannin, tea should only be allowed to infuse (draw) for a few minutes. Cocoa is not only a stimulant but a food as well; it contains about 50 per cent. of fat, and 12 per cent. of proteid. But cocoa as usually taken in the form of an infusion does not contain much of these food substances.

Green vegetables are taken as a palatable adjunct to other foods, rather than for their nutritive properties. Their potassium salts are, however, abundant. Cabbage, turnips, and asparagus contain 80 to 92 water, 1 to 2 proteid, 2 to 4 carbohydrates, and 1 to 1.5 cellulose per cent. The small amount of nutriment in most green foods accounts for the large meals made by, and the vast capacity of the alimentary canal of herbivorous animals. 


\section{LESSON $V$}

\section{SALIVA}

1. To a little saliva in a test-tube add acetic acid. Mucin is precipitated in stringy flakes.

2. Filter some fresh saliva to separate cells and mucus, and apply the xanthoproteic or Millon's test to the filtrate; the presence of proteid is shown.

3. Put some 0.5-per-cent. starch solution into two test-tubes. Add some filtered saliva to one of them, and put both in the water-bath at $40^{\circ} \mathrm{C}$. After five minutes remove them and test both fluids with iodine and Trommer's test. The saliva will be found to have converted the starch into dextrin and sugar (maltose).

4. The presence of potassium sulphocyanide (KCNS) in saliva may be shown by the red colour given by a drop of ferric chloride. This colour is discharged by mercuric chloride.

5. The reaction of saliva is alkaline to litmus paper.

The saliva is the first digestive juice to come in contact with the food: it is secreted by three pairs of salivary glands, the parotid, submaxillary, and sublingual. The secretions from these differ somewhat in composition, but they are mixed in the mouth, the secretion of the minute mucous glands of the mouth and a certain number of epithelial cells and débris being added to it. The socalled 'salivary corpuscles' are derived either from the glands themselves or from the tonsils.

The secretion of saliva is a reflex action; the taste or smell of food excites the nerve endings of the afferent nerves (glossopharyngeal and olfactory); the efferent or secretory nerves are contained in the chorda tympani (a branch of the seventh cranial nerve) which supplies the submaxillary and sublingual, and in a branch of the glossopharyngeal which supplies the parotid. The sympathetic branches which supply the blood vessels with constrictor nerves contain in some animals secretory fibres also.

The parotid gland is called a serous or albuminous gland; before secretion the cells of the acini are swollen out with granules; after secretion has occurred the cells shrink, owing to the granules having been shed out to contribute to the secretion (see fig. 12). 
The submaxillary and sublingual glands are called mucous glands: their secretion contains mucin. Mucin is absent from parotid saliva. The granules in the cells are larger than those of the parotid gland; they are composed of mucinogen, the precursor of mucin (see fig. 13).

In a section of a mucous gland prepared in the ordinary way the mucinogen granules are swollen out, and give a highly refracting appearance to the mucous acini (see fig. 14).

\section{COMPOSITION OF SALIVA}

On microscopic examination of mixed saliva is few epithelial scales from the mouth and salivary corpuscles from the salivary glands are seen. The liquid is transparent, slightly opalescent, of slimy consistency, and may contain lumps of nearly pure mucin. On standing it becomes cloudy owing to the precipitation of calcium carbonate, the carbonic acid which held it in solution as bicarbonate escaping.

Of the three forms of saliva which contribute to the mixture found in the mouth, the sublingual is richest in solids ( 2.75 per cent.). The submaxillary saliva comes next $(2 \cdot 1$ to 2.5 per cent.). When artificially obtained by stimulation of nerves in the dog the salivit obtained by stimulation of the sympathetic is richer in solids than that obtained by stimulation of the chorda tympand. The parotid saliva is poorest in total solids $(0.3$ to 0.5 per cent.), and contains no mucin. Mixed saliva contains in man an average of about 0.5 per cent. of solids : it is alkaline in reaction, due to the salts in it; and has a specific gravity of 1002 to 1006 .

The solid constituents dissolved in saliva may be elassified thus :-

Organic

(a. Mucin : this may be precipitated by acetic acid.

b. Ptyalin : an amylolytic ferment.

c. Proteid : of the nature of a globulin.

d. Potassium sulphocyanide.

Inorganic $\left\{\begin{array}{l}e . \text { Sodium chloride: the most abundant salt. } \\ f . \text { Other salts: sodium carbonate, calcium phosphate } \\ \text { and carbonate: magnesium phosphate; potassium } \\ \text { chloride. }\end{array}\right.$

\section{THE ACTION OF SALIVA}

The action of saliva is twofold, physical and chemical.

The physical use of saliva consists in moistening the mucous membrane of the mouth, assisting the solution of soluble substances 
in the food, and in virtue of its mucin lubricating the bolus of food to facilitate swallowing.
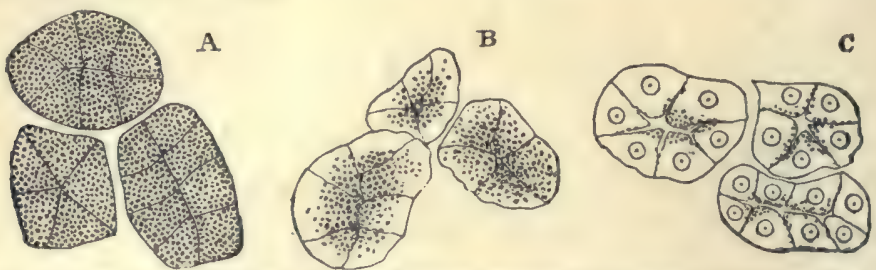

FIG. 12.-Alveoli of serous gland : A, loaded before secretion; B, after a short period of active secretion; C, after a prolonged period. (Langley.)
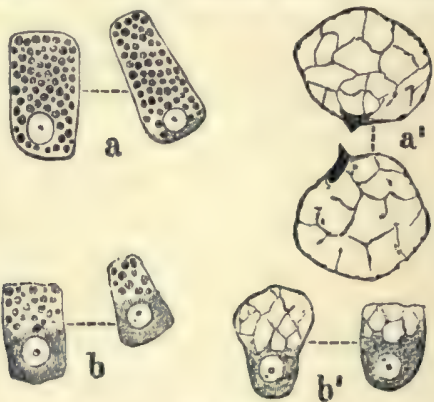

Fid. 13.-Mucous cells from a fresh submaxillary gland of $\log : a$, loailed with mucinogen granules before secretion: $b$, after secretion : the granules are fewer, especially at the attached border of the cell : $a^{\prime}$ and $b^{\prime}$ represent cells in a loaded and discharged eondition respectively which have been irrigated with water or dilute acid. The mucous granules are swollen into a trunsparent mass of mucin traversed by a network of protoplasmic cell-substance. (Foster, after Langley.)

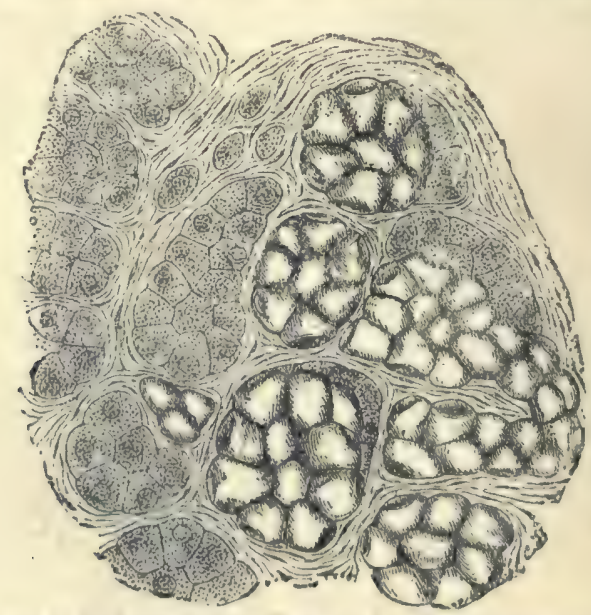

F1木. 14. - Section of part of the human submaxillary gland (Heidenhain.) To the right is n group) of mucous aiveoli, to the left a group of serous alveoli.

The chemical action of saliva is due to its active principle, ptyalin. This substance belongs to the class of unorganised ferments 
or enzymes, and to that special class of unorganised ferments which are called amylolytic (starch splitting) or diastatic (resembling diastase, the similar ferment in germinating barley and other grains). A general description of ferments will be found at the end of this lesson.

The starch is first split into dextrin and maltose; the dextrin is subsequently converted into maltose also: this occurs more quickly with erythro-dextrin, which gives a red colour with iodine, than with the other variety of dextrin called achroö-dextrin, which gives no colour with iodine. Brown and Morris give the following equation :-

$$
\begin{aligned}
& 10\left(\mathrm{C}_{6} \mathrm{H}_{10} \mathrm{O}_{5}\right)_{1}+4 n \mathrm{H}_{2} \mathrm{O} \\
& \text { [stanch] [water] } \\
& =4 n \mathrm{C}_{12} \mathrm{H}_{22} \mathrm{O}_{11}+\left(\mathrm{C}_{6} \mathrm{H}_{10} \mathrm{O}_{5}\right)_{n}+\left(\mathrm{C}_{6} \mathrm{H}_{10} \mathrm{O}_{5}\right)_{n} \\
& \text { [maltose] [achroos-dextrin] [erythro-dertrin] }
\end{aligned}
$$

Ptyalin acts in a similar way, but more slowly on glycogen; it has no action on cellulose; hence it is inoperative on uncooked starch grains, for in these the cellulose layers are intact.

Ptyalin acts best at about the temperature of the body $\left(35-40^{\circ}\right)$, and in a neutral medium; a small amount of alkali makes but little difference; a very small amount of acid stops its activity. The conversion of starch into sugar by saliva in the stomach continues for 15 to 30 minutes; the hydrochloric acid which is poured out by the gastric glands first neutralises the saliva and combines with the proteids in the food; but immediately free hydrochloric acid appears the ptyalin is destroyed, so that it does not resume work even when the semi-digested food once more becomes alkaline in the duodenum.

\section{FERMENTS}

The word fermentation was first applied to the change of sugar into alcohol and carbonic acid by means of yeast. The evolution of carbonic acid causes frothing and bubbling; hence the term 'fermentation.' The agent yeast which produces this is called the ferment. Microscopic investigation shows that yeast is composed of minute rapidly growing unicellular organisms (torulæ) belonging to the fungus group of plants.

The souring of milk, the transformation of urea into ammonium carbonate in decomposing

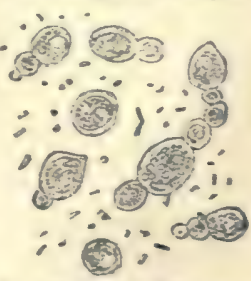

Fig. 15. Cells of $\tau$ he reast plant in process of building, between which are some bacteria (Yeo's 'Physiology."). urine, and the formation of rinegar (acetic acid) frcm alcohol are produced by the growth of very similar organisms. The complex series 
of changes known as putrefaction which are accompanied by the formation of malodorous gases and which are produced by the growth of various forms of bacteria, also come into the same category.

That the change or fermentation is produced by these organisms is shown by the fact that it occurs only when the organisms are present, and stops when they are removed or killed by a high tem-

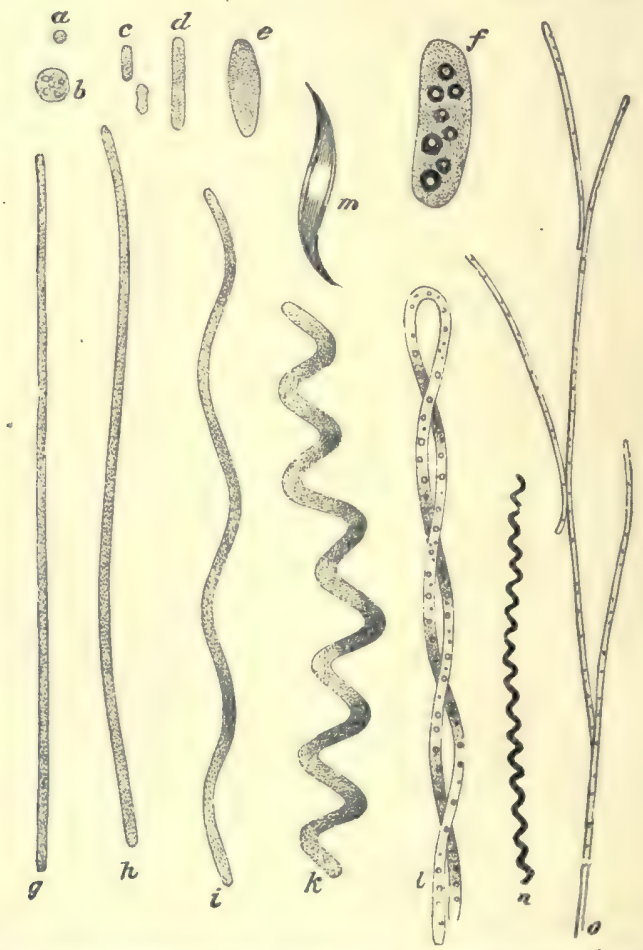

Fu, 16,-Typical forms of Schizomycetes (after $\%$ opf ) : $\pi$, micronecus : $b$, macrococous; $c$, bacterium : $d$, bacillns ; $e$, chlostridimm : $t$, Monas Okenii : $l$, leptothrix ; $h, i$, vibrio ; $k$, spirillum ; $l$, spirulina ; $m$, spiromonas ; $n$, spirochæete ; 0 , eladothrix.

perature or by certain substances (carbolic acid, mercuric chloride, \&c.) called antiseptics. The organisms probably produce fermentative effects by shedding out soluble ferments or enzymes.

The 'germ theory' of disease explains the infectious diseases by considering that the change in the system is of the nature of fermentation, and, like the others we have mentioned, produced by microbes ; the transference of the bacteria or their spores from one person to another constitutes infection. The poisons produced by the growing bacteria appear to be either alkaloidal (ptomaines) or proteid in 
nature. The existence of poisonous proteids is a very remarkable thing, as no chemical differences can be shown to exist between them and those which are not poisonous, but which are useful as foods. Snake venom is an instance of a very virulent poison of proteid nature.

There is another class of chemical transformations which at first sight differ very considerably from all of these. They, however, resemble these fermentations in the fact that they occur independently of any apparent change in the agents that produce them. The agents that produce them are not living organisms, but chemical substances, the result of the activity of living cells. The change of starch into sugar by the ptyalin of the saliva is an instance.

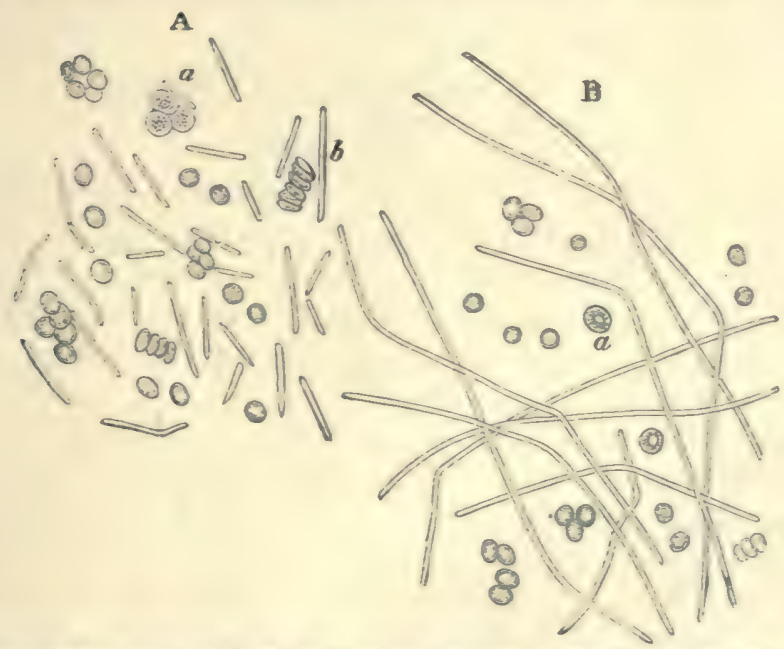

FIG. 17.-Bacilhs anthracis, the agent that proiluees anthrax or spleuic fever (Koch): A, bacilli, mingled with blood corpuscles from the bloorl of guinea-pig. some of the bacilli diviling: $\mathrm{B}$, the same after three hours' cnlture in a drop of aqueous humour. They grow oui into long leptothrixlike flaments, which subseunently livitle up, and spores are developed in the segments.

Ferments may therefore be divided into two classes :-

1. The organised ferments-torulæ, bacteria, \&c.

2. The unorganised ferments or enzymes-like ptyalin.

Each may be again subdivided according to the nature of the chemical change produced.

In digestion, the study of which we are just commencing, it is the unorganised ferments with the action of which we have chiefly to deal. The unorganised ferments may be classified as follows:-

(a) Amylolytic-those which change amyloses (starch, glycogen) into sugars. Examples: ptyalin, diastase, amylopsin. 
(b) Proteolytic-those which change proteids into proteoses and peptones. Examples: pepsin, trypsin.

(c) Steatolytic or lipolytic-those which split fats into fatty acids and glycerin. An example, steapsin, is found in pancreatic juice.

(d) Inversive-those which convert saccharoses (cane sugar, maltose, lactose) into glucose. Examples: invertin of intestinal juice and of yeast cells.

(e) Coagulative-those which convert soluble into insoluble proteids. Examples : rennet, fibrin ferment, myosin ferment.

Most ferment actions are hydrolytic - i.e. water is added to the material acted on, which then splits into new materials. This is seen by the following examples :-

1. Conversion of cellulose into carbonic acid and marsh gas (methane) by putrefactive organisms.

$$
\begin{aligned}
& \left(\mathrm{C}_{6} \mathrm{H}_{10} \mathrm{O}_{5}\right) n+n \mathrm{H}_{2} \mathrm{O}=3 n \mathrm{CO}_{2}+3 n \mathrm{CH}_{4} \\
& \text { [cellulose] [water] [carbonio [methane] } \\
& \text { acid] }
\end{aligned}
$$

2. Inversion of cane sugar by the unorganised ferment invertin :-

$$
\underset{\text { [oane sugar] }}{\mathrm{C}_{12} \mathrm{H}_{22} \mathrm{O}_{11}}+\underset{\text { [water] }}{\mathrm{H}_{2} \mathrm{O}=\mathrm{C}_{6} \mathrm{H}_{12} \mathrm{O}_{6}}+\underset{\text { [extrose] }}{\mathrm{C}_{6} \mathrm{H}_{12} \mathrm{O}_{6}}
$$

It appears also that some enzymes are oxygen carriers and produce oxidation. They are termed oxidases. Very little is known of these at present.

A remarkable fact concerning the ferments is that the substances they produce in time put a stop to their activity; thus in the case of the organised ferments the alcohol produced by yeast, the phenol, cresol, \&c., produced by putrefactive organisms from proteids, first stop the growth of, and ultimately kill, the organisms which produce them. In the case of the unorganised ferments, the products of their activity hinder and finally stop their action, but on the removal of these products the ferments resume work.

This fact suggested to Croft Hill the question whether ferments will act in the reverse manner to their usual action; and in the case of one ferment, at any rate, he found this to be the case. Inverting ferments, as we have just seen, usually convert a disaccharide into monosaccharides. One of these inverting ferments, called maltase, coverts maltose into dextrose. If, however, the ferment is allowed to act on strong solutions of dextrose, it converts a small proportion of that sugar back into maltose again. 'Reversible action' has since this been shown to occur in the case of other enzymes.

Ferments act best at a temperature of about $40^{\circ} \mathrm{C}$. Their 
activity is stopped, but the ferments are not destroyed, by cold; it is stopped and the ferments killed by too great heat. A certain amount of moisture and oxygen is also necessary; there are, however, certain micro-organisms that act without free oxygen; these are called anaërobic, in contradistinction to those which require oxygen, and which are therefore called aërobic.

The chemical nature of the enzymes is very difficult to investigate; they are substances that elude the grasp of the chemist to a great extent. So far, however, research has taught us that they are either proteid in nature or are substances closely allied to the proteids.

The distinction between organised ferments and enzymes is more apparent than real; for the micro-organisms exert their action by enzymes that they secrete. By crushing reast cells Buchner has succeeded in obtaining from them an enzyme that produces alcoholic fermentation. 


\section{LESSON VI}

\section{PEPTIC DIGESTION}

\section{Half fill four test-tubes-}

A with water. B with 0.2-per-cent. hydrochloric acid. C with 0.2per-cent. hydrochloric acid. D with solution of white of egg ( 1 to 10 of water).

2. To A add a few drops of glycerin extract of stomach ${ }^{1}$ (this contains pepsin) and a piece of a solid proteid like fibrin.

To $B$ also add pepsin solution and a piece of fibrin.

To $\mathrm{C}$ add only a piece of fibrin.

To $\mathrm{D}$ add a few drops of pepsin solution and fill up the tube with 0.2 -percent. hydrochlorio acid. fully.

3. Put the tubes into the water-bath at $40^{\circ} \mathrm{C}$, and observe them care-

In A the fibrin remains unaltered.

In $\mathrm{B}$ it becomes swollen, and gradually dissolves.

In $\mathrm{C}$ it becomes swollen, but does not dissolve.

4. After half an hour examine the solution in test-tube B.

(a) Colour some of the liquid with litmus and neutralise with dilute alkali. Acid-albumin, syntonin, or parapeptone is precipitated.

(b) Take another test-tube, and put into it a drop of 1-per-cent. solution of copper sulphate; empty it out so that the merest trace of copper sulphate remains adherent to the wall of the tube; then add the solution from testtube $\mathrm{B}$ and a few drops of strong caustic potash. A pink colour (biuret reaction) is produced. This should be carefully compared with the violet tint given by unaltered albumin.

(c) To a third portion of the fluid in test-tube B add a drop of nitric acid; albumoses or propeptones are precipitated. This precipitate dissolves on heating and reappears on cooling.

5. Repeat these three tests with the digested white of egg in test-tube D.

6. Examine an artificial gastric digestion which has been kept a week. Note the absence of putrefactive odour; in this it contrasts very forcibly with an artificial pancreatic digestion under the same circumstances.

\section{THE SECRETION OF GASTRIC JUICE}

The juice secreted by the glands in the mucous membrane of the stomach varies in composition in the different regions, but the mixed gastric juice, as it may be termed, is a solution of a proteolytic ferment called pepsin in a saline solution, which also contains a little free hydrochloric acid.

' Benger's liquor pepticus may be used instead of the glycerin extract of atomach. 


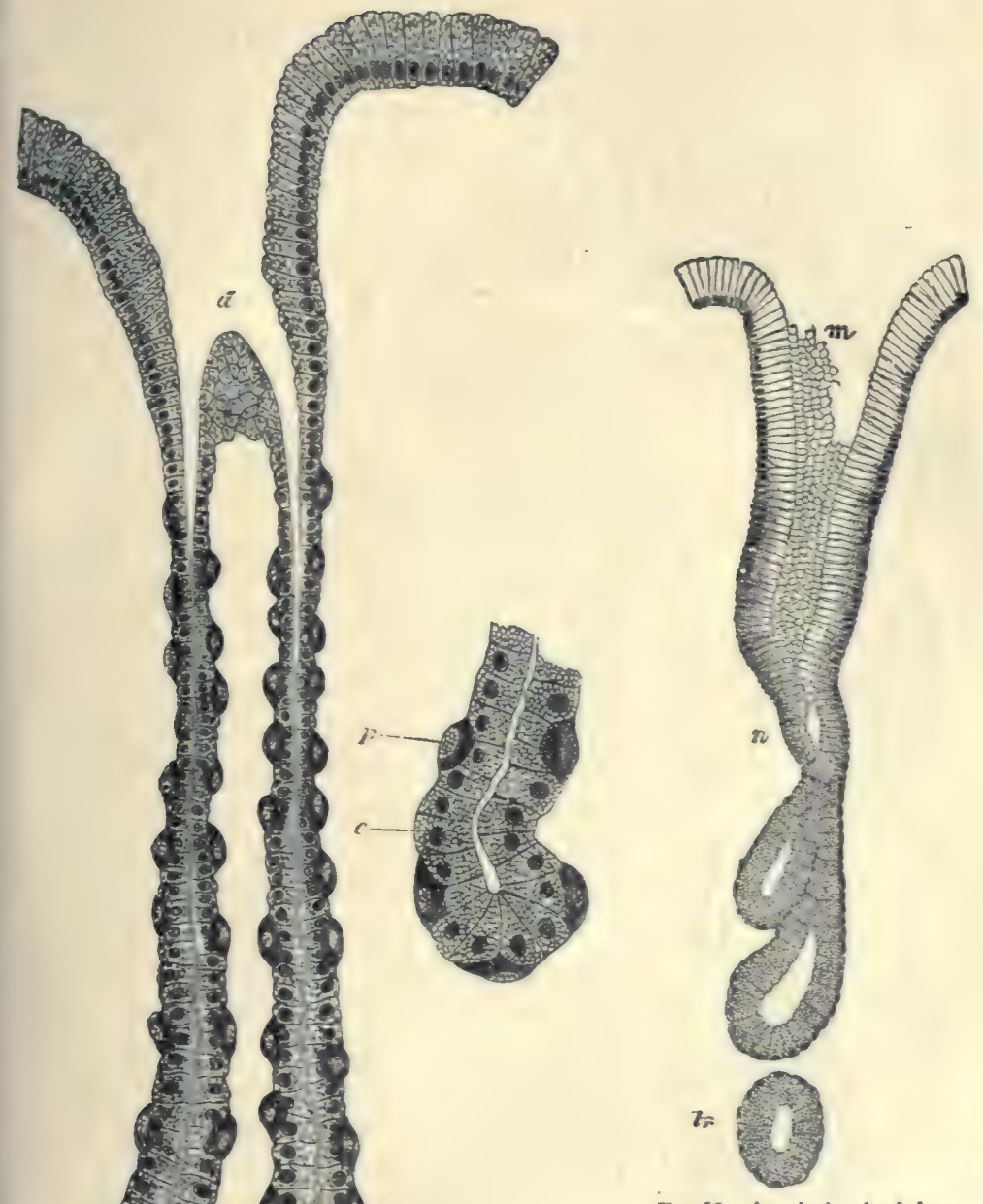

F10. 19.-A prloric gland from a section of the dog's stomach (Ebstein): $m$, mouth : $n$, nock: $t r$, a deep portion of tubule cut transverselv.

Fic. 18. A earliae glaul from the dog's stomach (Klein) : $d$, thet or mouth of the gland : $b$, base or fundus of one of its tubules; on the right the base of a tubnle is more highly magnified; $c$ central cell ; $p$, parietal cell. 
The gastric juice can be obtained during the life of an animal by means of a gastric fistula. Gastric fistulæ have also been made in human beings, either by accidental injury or by surgical operations. The most celebrated case is that of Alexis St. Martin, a young Canadian who received a musket wound in the abdomen in 1822. Observations made on him by Dr. Beaumont formed the startingpoint for our correct knowledge of the physiology of the stomach and its secretion.

We now make artificial gastric juice by mixing weak hydrochloric

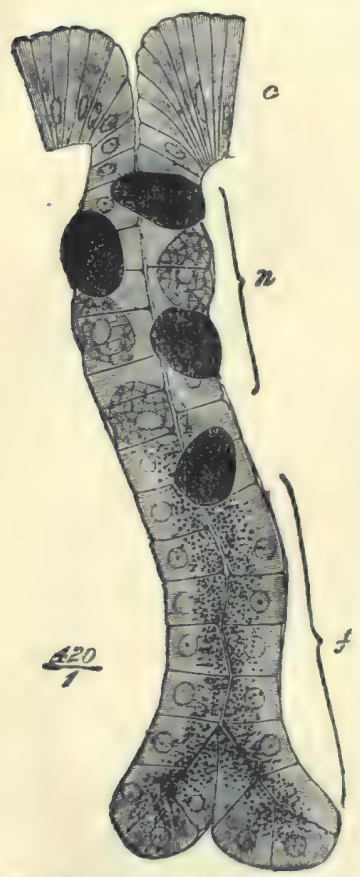

FIG. 20.-A cariliue gland of simple form from the bat's stomach. Osmic aold preparation (Lang. ley): $c$, columnar epithelium of the surface; $n$, neck of the gland, with central and parietal cells : $f$, base or fundus, oceupied only by principal or central cells, which exhibit the granules aceumulated towaris the lumen of the glamil. acid $(0 \cdot 2$ per cent.) with a glycerin or aqueous extract of the stomach of a recently killed animal. This artificial juice acts like the normal juice.

Two kinds of glands are distinguished in the stomach, which differ from each other in their position, in the character of their epithelium, and in their secretion. The cardiac glands are those situated in the cardiac half of the stomach: their ducts are short, their tubules long in proportion. The latter are filled with polyhedial cells, only a small lumen being left; they are more closely granular than the corresponding cells in the pyloric glands. They are called principal or central cells. Between them and the basement membrane of the tubule are other cells which stain readily with aniline dyes. They are called parietal or oxyntic (i.e. acid-forming), cells. - The pyloric glands, in the pyloric half of the stomach, have long ducts and short tubules lined with cubical cells. There are no parietal cells.

The central cells of the cardiac glands and the cells of the pyloric glands are loaded with granules. During secretion they discharge their granules, those that remain being chiefly situated near the lumen, leaving in each cell a clear outer zone (see fig. 20). These are the cells that secrete the pepsin. Like secreting cells generally, they select certain materials from the lymph that bathes them; these materials are worked up by the protoplasmic activity of the 
cells into the secretion, which is then discharged into the lumen of the gland. The most important substance in a digestive secretion is the ferment. In the case of a gastric juice this is pepsin. We can trace an intermediate step in this process by the presence of the granules. The granules are not, however, composed of pepsin, but of a mother-substance which is readily converted into pepsin. We shall find a similar ferment precursor in the cells of the pancreas, and the term zymogen is applied to these ferment percursors. The zymogen in the gastric cells is called pepsinogen. The rennetferment or rennin that causes the curdling of milk is distinct from pepsin, and is preceded by another zymogen; it is, however, formed by the same cells.

The parietal cells undergo merely a change of size during secretion; at first they are somewhat enlarged, and after secretion they shrink. They are also called oxyntic cells, because it is believed that they secrete the hydrochloric acid of the juice. Heidenhain succeeded in making in one dog a cul-de-sac of the fundus, in another of the pyloric region of the stomach; the former secreted a juice containing both acid and pepsin; the latter, parietal cells being absent, secreted a viscid alkaline juice containing pepsin. The formation of a free acid from the alkaline blood and lymph is an important but puzzling problem. There is no doubt that it is formed from the chlorides of the blood and lymph, and of the many theories advanced as to how this is done, Maly's is, on the whole, the most satisfactory. He considers that the acid originates by the interaction of the calcium chloride with the disodium hydrogen phosphate of the blood, thus:-

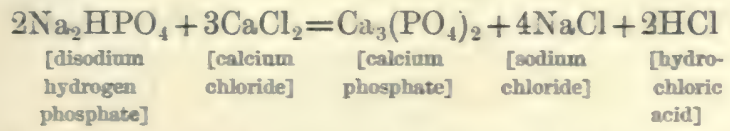

or more simply by the interaction of sodium chloride and sodium dihydrogen phosphate, as is shown in the following equation:-

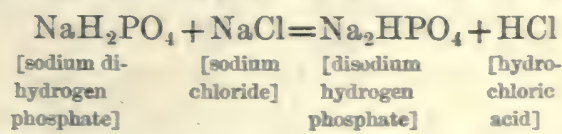

The sodium dihydrogen phosphate in the above equation is probably derived from the interaction of the disodium hydrogen phosphate and the carbonic acid of the blood, thus :-

$$
\mathrm{Na}_{2} \mathrm{HPO}_{4}+\mathrm{CO}_{2}+\mathrm{H}_{2} \mathrm{O}=\mathrm{NaHCO}_{3}+\mathrm{NaH}_{2} \mathrm{PO}_{4}
$$

But, as Professor Gamgee has pointed out, these reactions can 
hardly be considered to occur in the blood generally but rather in the oxyntic cells, which possess the necessary selective powers in reference to the saline constituents of the blood, and the hydrochloric acid, as soon as it is formed, passes into the secretion of the gland in consequence of its high power of diffusion.

\section{COMPOSITION OF GASTRIC JUICE}

The following table gives the percentage composition of the gastric juice of man and the dog:-

\begin{tabular}{|c|c|c|c|c|}
\hline \multicolumn{3}{|c|}{ Constituents } & \multirow{2}{*}{$\begin{array}{l}\text { Human } \\
99 \cdot 44\end{array}$} & \multirow{2}{*}{$\frac{\text { Dog }}{97 \cdot 30}$} \\
\hline Water & . & . $\cdot$ & & \\
\hline $\mathrm{HCl}$. & : & : & $0 \cdot 20$ & $0 \cdot 30$ \\
\hline $\mathrm{CaCl}_{2}$. & . & . & 0.006 & 0.06 \\
\hline $\mathrm{NaCl}$. & . & . & 0.14 & $0 \cdot 25$ \\
\hline $\mathrm{KCl}$. & . & . & 0.05 & $0 \cdot 11$ \\
\hline $\mathrm{NH}_{4} \mathrm{Cl}$ & . & . & - & 0.05 \\
\hline $\mathrm{Ca}_{3}\left(\mathrm{PO}_{4}\right)_{2}$ & . & . & & $0 \cdot 17$ \\
\hline $\mathrm{Mg}_{3}\left(\mathrm{PO}_{4}\right)_{2}$ & . & . & 0.01 & 0.02 \\
\hline $\mathrm{FePO}$ & - & . & & 0.008 \\
\hline
\end{tabular}

One sees from this how much richer in all constituents the gastric juice of the dog is than that of man. Carnivorous animals have always a more powerful gastric juice than other animals: they have more work for it to do; but the great contrast seen in the table is, no doubt, partly due to the fact that the persons from whom it has been possible to collect gastric juice have been invalids. In the foregoing table one also sees the great preponderance of chlorides over other salts: apportioning the total chlorine to the various metals present, that which remains over must be combined with hydrogen to form the free hydrochloric acid of the juice.

Pepsin stands apart from nearly all other ferments by requiring an acid medium in order that it may act. Probably a compound of the two substances called pepsin-hydrochloric acid is the really active agent. Other acids may take the place of hydrochloric acid, but none act so well. Lactic acid is often found in gastric juice: this appears to be derived by fermentative processes from the food.

Some recent very valuable work performed by Pawlow on dogs has enabled him not only to show that the secretory fibres for the gastric glands are contained in the vagus or pneumogastric nerves, but also to obtain a gastric juice free from any admixture with saliva 
or food. The main facts in relation to this pure juice are as follows:- It is clear and colourless; it has a specific grarity of 1003 to 1006. It is feebly dextro-rotatory, gives no biuret reaction, but gives the ordinary proteid reactions. It contains from 0.4 to 0.6 per cent. of hydrochloric acid. It is strongly proteolytic, and inrerts cane sugar. When cooled to $0^{\circ} \mathrm{C}$. it deposits a fine precipitate of pepsin; this settles in layers, and the layers first deposited contain most of the acid, which is loosely combined with and carried down by the pepsin. Pepsin is also precipitable by saturation with ammonium sulphate (Kühne). Elementary analysis gave the following results :-

\begin{tabular}{|c|c|c|}
\hline \multicolumn{3}{|c|}{ old- } \\
\hline Carbon. & $50-73$ & er cent. \\
\hline Hydrogen & - $\quad 7-23$ & \\
\hline Chlorine . & . 1.01 to $1 \cdot 17$ & ," \\
\hline Sulphur . & $\begin{array}{lll}\text {. } & \text {. } 0-98\end{array}$ & \\
\hline Nitrogen. & not es & imated \\
\hline Oxygen . & the rer & ainder. \\
\hline
\end{tabular}

Precipitated by $\mathrm{Am}_{2} \mathrm{So}_{4}$
$50 \cdot 37$
6.88
0.89
$1 \cdot 34$

$14 \cdot 55$ to $15 \cdot 0$

the remainder.

More recently Pawlow has by a very ingenious surgical operation succeeded in the dog in separating off from the stomach a diverticulum which pours its secretion through an opening in the abdominal wall. The following are his main results :-

1. Increase in the quantity of food given causes an increase in the amount of gastric juice secreted.

2. The juice is most abundant in the early periods of digestion, but it continues to be secreted in declining quantity as long as any food remains to be dealt with. When there is no food given there is no juice. But sham feeding or chewing will cause it to flow.

3. The amount of pepsin secreted is similarly proportional to the needs of the animal.

4. The larger the proportion of proteid in the diet, the more abundant and active is the juice secreted.

\section{THE ACTION OF GASTRIC JUICE}

The principal actions of the gastric juice have been already practically studied : the action of pepsin in converting the proteids. of the food into the diffusible peptones is its chief action. The curdling of milk by rennet will be found described in Lesson IV.

There is a still further action-that is, the gastric juice is antiseptic; putrefactive processes do not normally occur in the stomach, and the organisms that produce such processes, many of which are swallowed with the food, are in great measure destroyed, and thus the body is protected from them. The acid is the agent in the juice that possesses this power. 
The formation of peptones is a process of hydrolysis; peptones may be formed by other hydrating agencies like superheated steam and heating with dilute mineral acids. There are certain intermediate steps in this process; the intermediate substances are called propeptones or proteoses. The word 'proteose' is the best to employ: it includes the albumoses (from albumin), globuloses (from globulin), vitelloses (from vitellin), \&c. Similar substances are also formed from gelatin (gelatoses) and elastin (elastoses).

Another intermediate step in gastric digestion is called parapeptone: this is acid-albumin or syntonin. In classifying the products of digestion it will be convenient to take albumin as our example, but we must remember that globulin, myosin, and all the other proteids form corresponding products. The products of digestion may be classified according to the order in which they are formed as follows:-

1. Parapeptone or acid-albumin.

\section{Propeptone}

(a) Proto-albumose

$\{$ (b) Hetero-albumose

(c) Deutero-albumose
The primary albumoses, i.e. those which are formed first.

\section{Peptone.}

It is very doubtful whether all the albumin passes through the acid-albumin stage.

Peptones.-These are the final products of the action of gastric juice on native proteids.

They are soluble in water, are not coagulated by heat, and are not precipitated by nitric acid, copper sulphate, ammonium sulphate, and a number of other precipitants of proteids. They are precipitated but not coagulated by alcohol. They are also precipitated by tannin, picric acid, potassio-mercuric iodide, phospho-molybdic acid, and phospho-tungstic acid.

They give the biuret reaction (rose-red, with a trace of copper sulphate and caustic potash or soda).

Peptone is readily diffusible through animal membranes. The utility of the formation of diffusible substances during digestion is obvious.

Proteoses.-These are the intermediate products in the hydrolysis of native proteids into peptones.

They are not coagulated by heat; they are precipitated but not coagulated by alcohol; like peptone they give the biuret reaction. They are precipitated by nitric acid, the precipitate being soluble on 
heating, and reappearing when the liquid cools. This last is a distinctive property of proteoses. They are slightly diffusible.

The following table will give us at a glance the chief characters of peptones and proteoses in contrast with those of native proteids like albumin and globulin :-

\begin{tabular}{|c|c|c|c|c|c|c|}
\hline $\begin{array}{l}\text { Tariety of } \\
\text { proteisl }\end{array}$ & $\begin{array}{l}\text { Action of } \\
\text { heat }\end{array}$ & $\begin{array}{l}\text { Aetion of } \\
\text { alcoliol }\end{array}$ & $\begin{array}{l}\text { Action of } \\
\text { nitrie aeid }\end{array}$ & $\begin{array}{l}\text { Action of } \\
\text { ammonium } \\
\text { sulphate }\end{array}$ & $\begin{array}{l}\text { Action of } \\
\text { curyer } \\
\text { sulphate } \\
\text { aul eaustie } \\
\text { potash }\end{array}$ & $\begin{array}{l}\text { Diffusi- } \\
\text { bility }\end{array}$ \\
\hline Albumin & Coagulateıl & $\begin{array}{l}\text { Precipitated, } \\
\text { then congu- } \\
\text { lated }\end{array}$ & $\begin{array}{l}\text { Precipitated } \\
\text { in the cold; } \\
\text { not readily } \\
\text { soluble on } \\
\text { heating }\end{array}$ & $\begin{array}{l}\text { Precipitated } \\
\text { by complete } \\
\text { saturation }\end{array}$ & $\begin{array}{l}\text { Fiolet } \\
\text { colonr }\end{array}$ & sil \\
\hline Globalin & Ditto & $\begin{array}{c}\text { Ditto } \\
\text { : }\end{array}$ & Ditto & $\begin{array}{l}\text { Precipitated } \\
\text { by half satu- } \\
\text { ration; also } \\
\text { precipitated } \\
\text { by satura- } \\
\text { tion with } \\
\text { MgSO. }\end{array}$ & Ditto & Ditto \\
\hline $\begin{array}{l}\text { Protenses } \\
\text { (albu- } \\
\text { moses) }\end{array}$ & $\begin{array}{l}\text { Dot coagu- } \\
\text { lateil }\end{array}$ & $\begin{array}{l}\text { Precipitated, } \\
\text { but nut co- } \\
\text { agalated }\end{array}$ & $\begin{array}{l}\text { Precipicaterl } \\
\text { in the cold; } \\
\text { readily so- } \\
\text { luble on } \\
\text { heatiug : } \\
\text { the precipi- } \\
\text { tate reap- } \\
\text { pears on } \\
\text { cooling }{ }^{3}\end{array}$ & $\begin{array}{l}\text { Preeipilated } \\
\text { ly saturation }\end{array}$ & $\begin{array}{l}\text { Rose-red } \\
\text { colour } \\
\text { (biuret } \\
\text { reaction) }\end{array}$ & Slight \\
\hline Peptones & $\begin{array}{l}\text { Sot coagu- } \\
\text { lated }\end{array}$ & $\begin{array}{l}\text { Precipitated, } \\
\text { but not co- } \\
\text { agulated }\end{array}$ & $\begin{array}{l}\text { Not precipi- } \\
\text { tated }\end{array}$ & $\begin{array}{l}\text { Sot preeipi- } \\
\text { tated }\end{array}$ & $\begin{array}{l}\text { Rose-red } \\
\text { colonx } \\
\text { (binret } \\
\text { reaction) }\end{array}$ & Great \\
\hline
\end{tabular}

The difference between the different proteoses is mainly one of solubility. The primary proteoses (proto- and hetero-) are precipitated by saturation with magnesium sulphate or sodium chloride. Deuteroproteose is not; it is, however, precipitated by saturation with ammonium sulphate. Proto- and deutero- proteoses are soluble in water; hetero-proteose is not; it requires a salt to hold it in solution.

To sum up: the main action of the gastric juice is upon the proteids of the food, converting them into more soluble and diffusible products. The fats are not chemically altered in the stomach; their proteid envelopes are, however, dissolved, and the solid fats are melted. Starch is unaffected; but cane sugar is inverted. The inversion of cane sugar is largely due to the hydrochloric acid of the juice, and is frequently assisted by inverting ferments contained in the vegetable food swallowed.

I In the case of deutero-albumose this reaction only occurs in the presence of excess of salt. 


\section{LESSON VII}

\section{PANCREATIC DIGESTION}

1. A 1-per-cent. solution of sodium carbonate, to which a little glycerin extract of pancreas ${ }^{1}$ has been added, forms a good artificial pancreatic fluid.

2. Half fill three test-tubes with this solution.

A. To this add half its bulk of diluted egg-white (1 in 10).

B. To this add a piece of fibrin.

C. Boil this; cool; then add fibrin.

3. Put all into the water-bath at $40^{\circ} \mathrm{C}$. After half an hour, test A and B for alkali-albumin by neutralisation, for albumoses by nitric acid, and for albumoses and peptone by the biuret reaction.

4. Note in $\mathrm{B}$ that the fibrin does not swell up and dissolve, as in gastric digestion, but that it is eaten away from the edges to the interior.

5. In $\mathrm{C}$ no digestion occurs, as the ferments have been destroyed by boiling.

6. Take a solution of starch, equal quantities in three test-tubes.

I). To this add a few drops of glycerin extract of pancreas (without the sodium carbonate).

E. To this add a few drops of bile.

F. To this add both bile and pancreatic extract.

7. Put these into the water-bath, and test small portions of each every half-minute by the iodine reaction. It disappears first in $\mathrm{F}$; then in $\mathrm{D}$; while $\mathrm{E}$ undergoes no change. Test $\mathrm{D}$ and $\mathrm{F}$ for maltose by Fehling's solntion.

8. Shake up a few drops of olive oil with artificial pancreatic juice (extract of pancreas and sodium carbonate). A milky fluid (emulsion) is formed, from which the oil does not readily separate on standing.

9. The foregoing experiments illustrate the action that pancreatic juice has on all three classes of organic food.

i. On Proteids.-Fibrin, albumin, \&c. are converted into proteoses and peptone by the ferment trypsin in an alkaline medium.

ii. On Carbohydrates.-Starch is converted into sugar (maltose) by the ferment amylopsin, especially in presence of bile.

iii. On Fats. - These are emulsified. In the body they are also split into fatty acid and glycerin by the ferment steapsin; but this cannot be shown with the artificial juice, as steapsin is not soluble in glycerin.

The pancreas is a compound racemose gland, like the parotid. There are, however, histological points of difference between them. The secretory nerve fibres are contained in the vagus (Pawlow). Microscopic examination of the gland cells in different stages of

' Benger's liquor pancreaticus diluted with two or three times its volume of 1-per-cent. sodium carbonate may be used instead. 
activity reveals changes comparable to those already described in the case of salivary and gastric cells. Granules indicating the presence of a zymogen which is called trypsinogen (that is, the precursor of trypsin, the most important ferment of the pancreatic juice) crowd the cells before secretion: these are discharged during secretion, so that in an animal whose pancreas has been powerfully stimulated to secrete, as by the administration of pilocarpine, the granules are seen only at the free border of the cells (see fig. 21).

As in the case of gastric juice, experiments on the pancreatic secretion are usually performed with an artificial juice, made by mixing a weak alkaline solution (1-per-cent. sodium carbonate) with an extract of pancreas. The pancreas should be kept some time
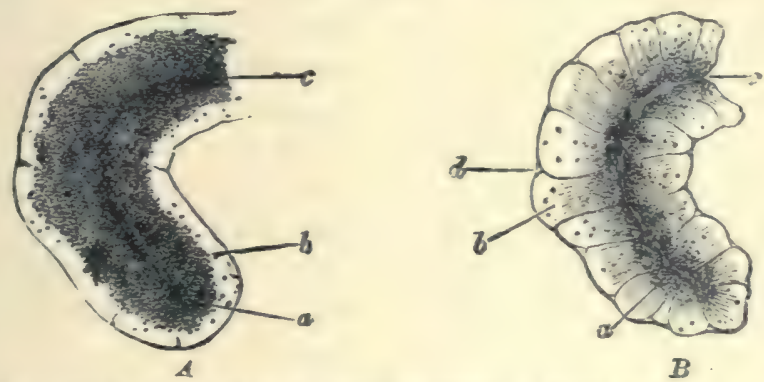

Fic. 21. -Part of an alreolus of the rabbit"s pancrea: : $A$, before discharge: B. after . (From Foster, after Killune and Iea.)

before the extract is made, or treated with dilute acid so as to ensure that the transformation of trypsinogen into trypsin has taken place.

Quantitative analysis of human pancreatic juice gives the following results :-

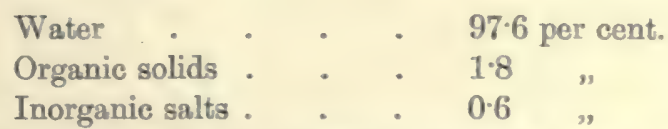

Dog's pancreatic juice is considerably richer in solids.

The organic substances in pancreatic juice are-

(a) Ferments. These are the most important both quantitatively and functionally. They are four in number :-

i. Trypsin, a proteolytic ferment.

ii. Amylopsin or pancreatic diastase, an amylolytic ferment.

iii. Steapsin, a fat-splitting ferment.

iv. A milk-curdling ferment.

(b) A small amount of proteid matter, coagulable by heat.

(c) Traces of leucine, tyrosine, xanthine, and soaps. 
The inorganic substances in pancreatic juice are-

Sodium chloride, which is the most abundant, and smaller quantities of potassium chloride, and phosphates of sodium, calcium, and magnesium. The alkalinity of the juice is due to phosphates and carbonates, especially of sodium.

\section{ACTION OF PANCREATIC JUICE}

The action of pancreatic juice, which is the most powerful and important of all the digestive juices, may be described under the headings of its four ferments.

1. Action of Trypsin.--Trypsin acts like pepsin, but with certain differences, which are as follows :-

(a) It acts in an alkaline, pepsin in an acid medium.

(b) It acts more rapidly than pepsin; deutero-proteoses can be detected as intermediate products in the formation of peptone. Primary (i.e. proto- and hetero-) proteoses have not been found; the action is apparently too rapid to admit of their detection.

(c) An albuminate of the nature of alkali-albumin is formed in place of the acid-albumin of gastric digestion.

(d) It acts more powerfully on certain albuminoids (such as elastin) which are difficult of digestion in gastric juice. Collagen, however, is not digested.

(e) Acting on solid proteids like fibrin, it eats them away from the surface to the interior; there is no preliminary swelling as in gastric digestion.

(f) Trypsin acts further than pepsin, on prolonged action partly decomposing the peptone which has left the stomach into simpler products, of which the most important are leucine and tyrosine.

Besides leucine and tyrosine, smaller quantities of aspartic acid [amido-succinic acid, $\mathrm{C}_{2} \mathrm{H}_{3}\left(\mathrm{NH}_{2}\right)(\mathrm{COOH})_{2}$ ], glutamic acid [amidopyrotartaric acid, $\mathrm{C}_{3} \mathrm{H}_{5}\left(\mathrm{NH}_{2}\right)(\mathrm{COOH})_{2}$, lysine, arginine, ammonia, and a substance of doubtful nature called tryptophan are also formed; tryptophan gives a reddish-violet colour with chlorine or bromine water.

Kühne considered that the peptones which leave the stomach may be arranged into two classes: (1) hemipeptone, which is split by the prolonged action of pancreatic juice into the substances (leucine, tyrosine, \&c.) just enumerated ; and (2) antipeptone, which resists this further action.

This theory held the field for many years, but recent researches have shown that it has little or no foundation in fact.

We know that the action of proteolytic enzymes is by the process 
of hydrolysis to split the heavy proteid molecule into smaller and smaller molecules; first we get proteoses, then peptones, and finally simple substances like leucine and tyrosine: the formation of leucine, tyrosine, \&c., does not occur to any great extent in normal digestion, for these simple materials are of little or no nutritive value. The substance formerly called antipeptone is really not a peptone at all. Siegfried showed it is a substance of low molecular weight, and according to him it is identical with a substance he had previously separated from muscle, and called carnic acid $\left(\mathrm{C}_{10} \mathrm{H}_{15} \mathrm{~N}_{3} \mathrm{O}_{5}\right)$. Further work by Kutscher has shown that Siegfried is probably wrong in regarding antipeptone as a single substance, but that it is in reality a mixture of several substances of which he has separated out the hexone bases arginine and histidine (see p. 32) and aspartic acid. At any rate antipeptone is not on the same level as the true peptones, which are capable of utilisation by the organism, but is in the same category as leucine and tyrosine and similar materials of low molecular weight.

These facts can all be easily accounted for on the supposition that a variable fraction of the proteid molecule is broken off with comparative ease, and appears as leucine, tyrosine, and other amido-acids. This is more easily performed by the more powerful tryptic enzyme than by the comparatively feeble agent pepsin. Pepsin, however, is not entirely inactive in this direction, for although leucine and tyrosine cannot as a rule be found in a gastric digestion, yet there are analogous substances of low molecular weight (aspartic acid and the hexone bases) which were incorrectly grouped together by the earlier workers as a peptone (antipeptone).

2. Action of Amylopsin. - The conversion of starch into maltose is the most powerful and rapid of all the actions of the pancreatic juice. It is much more powerful than saliva, and will act even on unboiled starch. The absence of this ferment in the pancreatic juice of infants is an indication that milk, and not starch, is their natural diet.

3. Action on Fats.-The action of pancreatic juice on fats is a double one: it forms an emulsion, and it decomposes the fats into fatty acids and glycerin by means of its fat-splitting ferment steapsin. The fatty acids unite with the alkaline bases to form soaps (saponification). The chemistry of this is described on p. 18. The fat-splitting power of pancreatic juice cannot be studied with a glycerin extract, as steapsin is not soluble in glycerin: either the fresh juice or a watery extract of pancreas must be used.

The formation of an emulsion may be studied in this way. Shake 
up olive oil and water together, and allow the mixture to stand; the finely divided oil globules soon separate from and float on the surface of the water; but if a colloid matter like albumin or gum is first mixed with the water, the oil separates more slowly. A more permanent emulsion is formed by an alkaline fluid, and especially when a small amount of free fatty acid is being continually liberated ; the acid combines with the alkali to form a soap; the soap was formerly stated to form a thin layer on the outside of each oil globule, which prevented them running together again. This is not now regarded as correct; the oil globules are prevented from running together because of differences in the surface tension between them and the surrounding fluid. Pancreatic fluid possesses, however, all the necessary qualifications for forming an emulsion:-i. It is alkaline; ii. It is viscous from the presence of proteid; iii. It has the power of liberating free acids.

4. Milk-curdling Ferment.-The addition of pancreatic extracts to milk causes clotting, which differs in some of its details from the curdling produced by rennin; but this action can hardly ever be called into play, as the milk upon which the juice has to act has been already curdled by the rennin of the stomach.

\section{INTESTINAL DIGESTION}

The pancreatic juice does not act alone on the food in the intestines. There are, in addition, the bile, the succus entericus (secreted by the crypts of Lieberkühn), and bacterial action to be considered.

The bile, as we shall find, has little or no digestive action by itself, but combined with pancreatic juice it assists the latter in all its actions. In our practical exercises we have already seen this is true for the digestion of starch. It is also true for the digestion of proteid, and very markedly so for the digestion of fat. Occlusion of the bile-duct by a gall-stone or by inflammation prevents bile entering the duodenum. Under these circumstances the freces contain a large amount of undigested fat. In some animals the bile contains a ferment which is able to convert starch into sugar. The chief value of the bile in digestion is to act as a solvent of fats and fatty acids. This property it owes to the bile salts.

The succus entericus has no action on fats or proteids, but it appears to have to some extent the power of converting starch into sugar ; its most important action, however, is due to a ferment it contains called invertin, which inverts saccharoses-that is, it converts cane sugar and maltose into glucose. The original use of the 
term 'inversion' has been explained on p. 12. It may be extended to include the similar hydrolysis of other saccharoses, although there may be no formation of levorotatory substances. There are probably several inverting ferments in the succus entericus, one of which acts on cane sugar, one on maltose, and one on milk sugar.

Bacterial Action.-The gastric juice is an antiseptic; the-pancreatic juice is not. A feebly alkaline fluid like pancreatic juice is just the most suitable medium for bacteria to flourish in. Even in an artificial digestion the fluid is very soon putrid, unless special precautions to exclude or kill bacteria are taken. It is often difficult to say where pancreatic action ends and bacterial action begins, as many of the bacteria that grow in the intestinal contents, having reached that situation in spite of the gastric juice, act in the same way as the pancreatic juice. Some form sugar from starch, others peptone, leucine, and tyrosine from proteids, while others, again, break up fats. There are, however, certain actions that are entirely due to these putrefactive organisms.

i. On carbohydrates. The most frequent fermentation they set up is the lactic acid fermentation: this may go further and result in the formation of carbonic acid, hydrogen, and butyric acid (see p. 14). Cellulose is broken up into carbonic acid and methane. This is the chief cause of the gases in the intestine, the amount of which is increased by vegetable food.

ii. On fats. In addition to acting like steapsin, lower acids (valeric, butyric, \&c.) are produced. The formation of acid products from fats and carbohydrates gives to the intestinal contents an acid reaction. Recent researches show that the contents become acid much higher up in the small intestine than was formerly considered to be the case. These organic acids do not hinder.pancreatic digestion to any appreciable extent.

iii. On proteids. Fatty acids and amido-acids, especially leucine and tyrosine, are produced; but these putrefactive organisms have a special action in addition, producing substances having an evil odour, like indole, skatole, and phenol. There are also gaseous products in some cases.

If excessive, putrefactive processes are harmful ; if within normal limits, they are useful, helping the pancreatic juice and, further, preventing the entrance into the body of poisonous products. It is possible that, in digestion, poisonous alkaloids are formed. Certainly this is so in one well-known case. Lecithin, a material contained in small quantities in many foods, and in large quantities in egg-yolk and brain, is broken up by the pancreatic juice into glycerin, phos- 
phoric acid, stearic acid, and an alkaloid called choline. We are, however, protected from the poisonous action of choline by the bacteria, which break it up into carbonic acid, methane, and ammonia.

\section{LEUCINE AND TYROSINE}

These two substances have been frequently mentioned in the preceding pages. As types of the decomposition products of proteids they are important, though probably only small quantities are normally formed during digestion.

They belong to the group of amido-acids. On p. 17 we have given a list of the fatty acids; if we replace one of the hydrogen

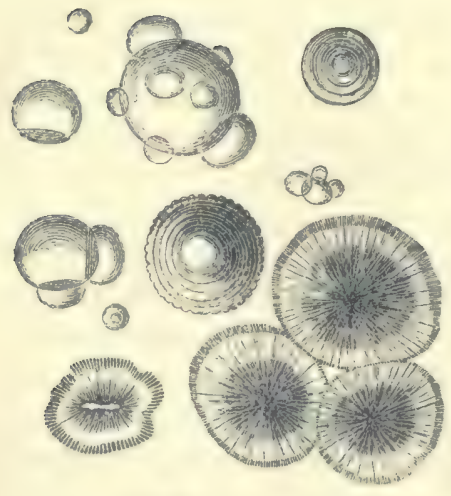

FIG. 22.-Leucine crystals.

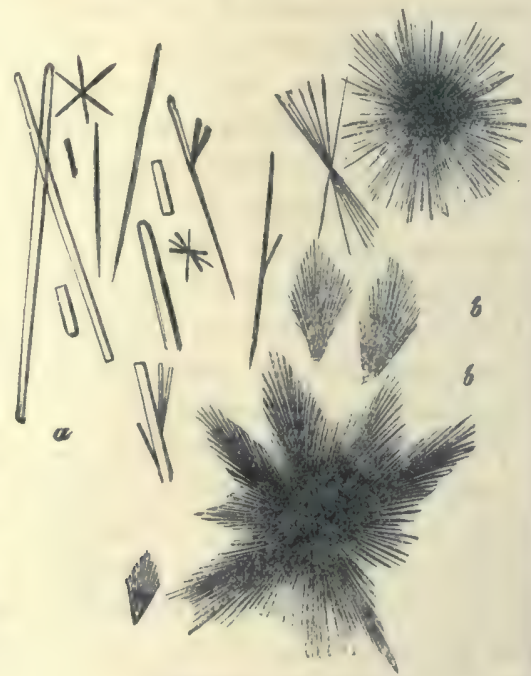

Fic. 23.-Tyrosine crystals.

atoms in a fatty acid by amidogen $\left(\mathrm{NH}_{2}\right)$, we obtain what is called an amido-acid. Take acetic acid : its formula is $\mathrm{CH}_{3} . \mathrm{COOH}$; replace one $\mathrm{H}$ by $\mathrm{NH}_{2}$, and we get $\mathrm{CH}_{2} \cdot \mathrm{NH}_{2} \cdot \mathrm{COOH}$, which is amido-acetic acid or glycocine. If we take caproic acid-a term a little higher in the series-its formula is $\mathrm{C}_{5} \mathrm{H}_{11} . \mathrm{COOH}$; amido-caproic acid is $\mathrm{C}_{5} \mathrm{H}_{10} \cdot \mathrm{NH}_{2} \cdot \mathrm{COOH}$, which is also called leucine. There are, however, several isomeric amido-caproic ácids. It was thought until quite recently that leucine was the amido-acid of normal caproic acid, but it has been shown to be a-amido-iso-butylacetic acid. The difference in the structure of these two compounds may be represented by the following graphic formulæ: 


Normal
acid. $\left\{\begin{array}{lr}\mathrm{CH}_{3} & \text { Iso-butyl } \\ \mathrm{CH}_{2} & \begin{array}{l}\mathrm{CH}_{3} \mathrm{CH}_{3} \\ \mathrm{CH}_{2}\end{array} \\ \mathrm{CH}_{2} & \text { acetic acid } \\ \mathrm{CH} . \mathrm{NH}_{2} & \mathrm{CH} \\ \mathrm{COOH} . & \mathrm{CH}\end{array}\right.$

Tyrosine is a little more complicated, as it is not only an amido-acid, but also contains an aromatic radicle. Propionic acid has the formula $\mathrm{C}_{2} \mathrm{H}_{5} \cdot \mathrm{COOH}$; amido-propionic acid is $\mathrm{C}_{2} \mathrm{H}_{4} \cdot \mathrm{NH}_{2} \cdot \mathrm{COOH}$, and is called alanine. If another $\mathrm{H}$ in this is replaced by oxyphenyl $\left(\mathrm{C}_{6} \mathrm{H}_{4} \cdot \mathrm{OH}\right)$, we get $\mathrm{C}_{5} \mathrm{H}_{3} \cdot \mathrm{NH}_{2} \cdot \mathrm{C}_{6} \mathrm{H}_{4} \mathrm{OH} \cdot \mathrm{COOH}$, which is oxyphenylamido-propionic acid, or tyrosine. Figs. 22 and 23 represent the erystalline forms of leucine and tyrosine.

\section{EXTIRPATION OF THE PANCREAS}

Complete removal of the pancreas in animals and diseases of the pancreas in man produce a condition of diabetes, in addition to the loss of pancreatic action in the intestines. Grafting the pancreas from another animal into the abdomen of the animal from which the pancreas has been removed relieves the diabetic condition.

How the pancreas acts otherwise than in producing the pancreatic juice is not known. It must, however, have other functions related to the general metabolic phenomena of the body, which are disturbed by removal or disease of the gland. This is an illustration of a universal truth-viz. that each part of the body does not merely do its own special work, but is concerned in the great eycle of changes which is called general metabolism. Interference with any organ upsets not only its specific function, but causes disturbances through the body generally. The interdependence of the circulatory and respiratory systems is a well-known instance. Removal of the thyroid gland upsets the whole body, producing widespread changes known as myxœdema. Removal of the testis produces not only a loss of the spermatic secretion, but changes the whole growth and appearance of the animal. Removal of the greater part of the kidneys produces rapid wasting and the breaking down of the tissues to form an increased quantity of urea. The precise way in which these glands are related to the general body processes is, however, a subject of which we know as yet very little. The theory at present most in farour is that certain glands produce an internal secretion, which leares the gland via the lymph, and is then distributed to minister to parts elsewhere. Removal of such glands as the thyroid 
or suprarenal produces disease or death because this internal secretion can no longer be formed. In the case of the pancreas, Professor Schäfer has propounded the theory that the external secretion of the pancreas (that is, pancreatic juice) is formed by the cells lining the acini, and that the internal secretion, stoppage of which in some way leads to diabetes, is produced in the curious islets of epithelium-like cells scattered through the organ, and which the reader will find described in works on histology. 


\section{LESSON VIII}

\section{$B I L E$}

1. Ox bile is given round. Observe its colour, taste, smell, and reaction to litmus paper.

2. Acidulate a little bile with 20 -per-cent. acetic acid. A stringy precipitate of a mucinoid substance is obtained. Filter this off and boil the filtrate; no proteid coagulable by heat is present.

3. Add a few drops of bile to $(a)$ acid-albumin prepared as described in Lesson III., and (b) solution of proteoses to which half its volume of $0 \cdot 2$-per-cent. hydrochloric acid has been added. A precipitate occurs in each case. Bile salts precipitate the unpeptonised proteid which leaves the stomach.

4. Pettenkofer's Test for Bile Salts.-To a thin film of bile in a capsule add a drop of solution of cane sugar and a drop of concentrated sulphuric acid. A purple colour is produced. This occurs more quickly on the application of heat. The test may also be performed as follows:- Shake up some bile and cane sugar solution in a test-tube until a froth is formed. Pour concentrated sulphuric acid gently down the side of the tube ; it produces a purple colour in the froth.

5. Gmelin's Test for Bile Pigments.-On to a little fuming nitric acid (i.e. nitric acid containing nitrous acid in solution) in a test-tube pour gently a little bile. Notice the succession of colours-green, blue, red, and rellow -at the junction of the two liquids. This test may also be performed in a capsule. Place a drop of fuming nitric acid in the middle of a thin film of bile; it becomes surrounded by rings of the above-mentioned colours.

6. Examine crystals of cholesterin microscopically.

7. To a few cholesterin crystals add a drop of iodine solution and a drop of concentrated sulphuric acid. A play of colours (red, green, blue) is produced. Other tests for cholesterin are described on p. 74 .

Bile is the secretion of the liver which is poured into the duodenum; it has been collected in living animals by means of a biliary fistula; the same operation has occasionally been performed in human beings. After death the gall bladder yields a good supply of bile which is more concentrated than that obtained from a fistula.

Bile is being continuously poured into the intestine, but there is an increased discharge immediately on the arrival of food in the duodenum; there is a second increase in secretion a few hours later.

Though the chief blood supply of the liver is by a vein (the portal vein), the amount of blood in the liver varies with its needs, being increased during the periods of digestion. This is due to the fact 
that in the area from which the portal vein collects blood-stomach, intestine, spleen, and pancreas - the arterioles are all dilated, and the capillaries are thus gorged with blood. Further, the active peristalsis of the intestine and the pumping action of the spleen are additional factors in driving more blood onwards to the liver.

The bile is secreted from the portal blood at a much lower pressure than one finds in glands, such as the salivary glands, the blood supply of which is arterial. Heidenhain found that the pressure in the bile duct of a dog averaged $15 \mathrm{~mm}$. of mercury, which is about double that in the portal vein.

The second increase in the flow of bile-that which occurs some hours after the arrival of the semi-digested food (chyme) in the intestine - appears to be due to the effect of the digestive products carried by the blood to the liver stimulating the hepatic cells to activity; this is supported by the fact that proteid food increases the quantity of bile secreted, whereas fatty food which is absorbed, not by the portal vein, but by the lacteals, has no such effect.

The chemical processes by which the constituents of the bile are

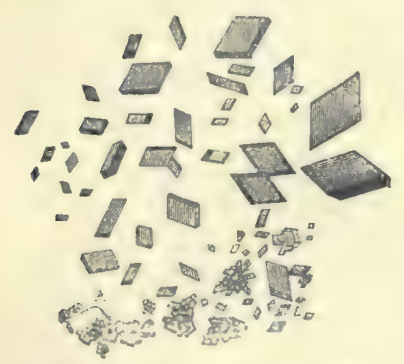

FrG. 24.-Hæmatoidin crystals. formed are obscure. We, however, know that the biliary pigment is produced by the decomposition of hæmoglobin. Bilirubin is, in fact, identical with the ironfree derivative of hæmoglobin called hæmatoidin, which is found in the form of crystals in old blood-clots such as occur in the brain after cerebral hæmorrhage (see fig. 24).

An injection of hæmoglobin into the portal vein, or of substances like water which liberate hæmoglobin from the red blood corpuscles, produces an increase of bile pigment. If the spleen takes any part in the elaboration of bile pigment, it does not proceed so far as to liberate hæmoglobin from the corpuscles. No free hrmoglobin is discoverable in the blood plasma in the splenic vein.

The amount of bile secreted is differently estimated by different observers; the amount secreted daily in man appears to vary from 500 c.c. to 1 litre (1,000 c.c.).

\section{THE CONSTITUENTS OF BILE}

The constituents of the bile are the bile salts proper (taurocholate and glycocholate of soda), the bile pigments (bilirubin, biliverdin), a mueinoid substance, small quantities of fats, soaps, cholesterin, 
lecithin, urea, and mineral salts, of which sodium chloride and the phosphates of iron, calcium, and magnesium are the most important.

Bile is a yellowish, reddish-brown, or green fluid, according to the relative preponderance of its two ehief pigments. It has a musklike odour, a bitter-sweet taste, and a neutral or faintly alkaline reaction.

The specific gravity of human bile from the gall bladder is 1026 to 1032 ; that from a fistula, 1010 to 1011 . The greater concentration of gall-bladder bile is partly but not wholly explained by the addition to it from the walls of that cavity of the mucinoid material.

The amount of solids in bladder bile varies from 9 to 14 per cent., in fistula bile from 1.5 to 3 per cent. The following table shows that this low percentage of solids is almost entirely due to want of bile salts. This can be accounted for in the way first suggested by Schiff-that there is normally a bile circulation going on in the body; a large quantity of the bile salts that passes into the intestine is first split up, then reabsorbed and again secreted. Such a circulation would obviously be impossible in cases where all the bile is discharged to the exterior.

The following table gives some important analyses of human bile :-

\begin{tabular}{|c|c|c|c|}
\hline Constitrents & $\begin{array}{l}\text { Fistula bile } \\
\text { (healthy woman. } \\
\text { Copewan and } \\
\text { Winston) }\end{array}$ & $\begin{array}{c}\text { Pistula bile (case } \\
\text { of cancer. Yeo and } \\
\text { Herroun) }\end{array}$ & $\begin{array}{l}\text { Normal bile } \\
\text { (Freriehs) }\end{array}$ \\
\hline \multirow{4}{*}{$\begin{array}{l}\text { Sodium glycocholate } \\
\text { Sodium taurocholate } \\
\text { Cholesterin, lecithin, fat } \\
\text { Mucinoid material. } \\
\text { Pigment. } \\
\text { Inorganic salts }\end{array}$} & $0 \cdot 6280$ & $0 \cdot 165$ & $9 \cdot 14$ \\
\hline & 0.0990 & $0 \cdot 038$ & $1 \cdot 18$ \\
\hline & 0.1725 & 0.148 & $2 \cdot 98$ \\
\hline & $0 \cdot 4510$ & 0.878 & 0.78 \\
\hline \multirow{3}{*}{$\begin{array}{l}\text { Total solids } \\
\text { Water (by difference) }\end{array}$} & $1 \cdot 4230$ & 1.284 & $14 \cdot 08$ \\
\hline & $98 \cdot 5570$ & $98 \cdot 716$ & 85.92 \\
\hline & $100 \cdot 0000$ & $100 \cdot 000$ & $100^{\circ} 00$ \\
\hline
\end{tabular}

Bile Mucin.-There has been considerable diversity of opinion as to whether bile mucin is really mucin. The most recent work in Hammarsten's laboratory shows that differences occur in different animals. Thus in the ox there is very little true mucin, but a great amount of nucleo-proteid; in human bile, on the other hand, there is very little if any nucleo-proteid : the mucinoid material present there is really mucin. (On the general characters of Mucin and NucceoProtems see pp. 28 and 29.) 
The Bile Salts.-The bile contains the sodium salts of complex amido-acids called the bile acids. The two acids most frequently found are glycocholic and taurocholic acids. The former is the more abundant in the bile of man and herbivora; the latter in carnivorous animals, like the dog. The most important difference between the two acids is that taurocholic acid contains sulphur, and glycocholic acid does not.

Glycocholic acid $\left(\mathrm{C}_{26} \mathrm{H}_{43} \mathrm{NO}_{6}\right)$ is by the action of dilute acids and alkalis, and also in the intestine, hydrolysed and split into glycocine or amido-acetic acid and cholalic acid.

$$
\begin{aligned}
& \mathrm{C}_{26} \mathrm{H}_{43} \mathrm{NO}_{6}+\mathrm{H}_{2} \mathrm{O}=\mathrm{CH}_{2} \cdot \mathrm{NH}_{2} \cdot \mathrm{COOH}+\mathrm{C}_{24} \mathrm{H}_{40} \mathrm{O}_{5} \\
& \text { [glyeocholic acid] }
\end{aligned}
$$

[glycooine]

[oholalic aoid]

The glycocholate of soda has the formula $\mathrm{C}_{26} \mathrm{H}_{42} \mathrm{NaNO}_{6}$.

Taurocholic acid $\left(\mathrm{C}_{26} \mathrm{H}_{45} \mathrm{NO}_{7} \mathrm{~S}\right)$ similarly splits into taurine or amido-ethyl-sulphonic acid and cholalic acid.

$$
\mathrm{C}_{26} \mathrm{H}_{45} \mathrm{NO}_{7} \mathrm{~S}+\mathrm{H}_{2} \mathrm{O}=\mathrm{C}_{2} \mathrm{H}_{4} \cdot \mathrm{NH}_{2} \cdot \mathrm{HSO}_{3}+\underset{\text { [taurine] }}{\mathrm{C}_{24} \mathrm{H}_{40} \mathrm{O}_{5}}
$$

The taurocholate of soda has the formula $\mathrm{C}_{26} \mathrm{H}_{44} \mathrm{NaNO}_{7} \mathrm{~S}$.

The colour reaction called Pettenkofer's reaction, described in the practical exercises at the head of this lesson, is due to the presence of cholalic acid. The sulphuric acid acting on sugar forms a small quantity of a substance called furfuraldehyde, in addition to other products. The furfuraldehyde gives the purple colour with cholalic acid.

The Bile Pigments.-The two chief bile pigments are bilirubin and biliverdin. Bile which contains chiefly the former (such as dog's bile) is of a golden or orange-yellow colour, while the bile of many herbivora, which contains chiefly biliverdin, is either green or bluish green. Human bile is generally described as containing chiefly bilirubin, but there have been some cases described in which biliverdin was in excess. The bile pigments show no absorption bands with the spectroscope ; their origin from the blood pigment has already been stated (p. 70).

Bilirubin has the formula $\mathrm{C}_{16} \mathrm{H}_{18} \mathrm{~N}_{2} \mathrm{O}_{3}$ : it is thus an iron-free derivative of hæmoglobin. The iron is apparently stored up in the liver cells, perhaps for future use in the manufacture of new hæmoglobin. The bile contains only a trace of iron.

Biliverdin has the formula $\mathrm{C}_{16} \mathrm{H}_{18} \mathrm{~N}_{2} \mathrm{O}_{4}$ (i.e. one atom of oxygen more than in bilirubin): it may occur as such in bile; it may be formed by simply exposing red bile to the oxidising action of the atmosphere; or it may be formed as in Gmelin's test by the more vigorous oxidation produced by fuming nitric acid. 
Gmelin's test consists of a play of colours-green, blue, red, and finally yellow, produced by the oxidising action of fuming nitric acid (that is, nitric acid containing nitrous acid in solution). The end or yëllow product is called choletelin, $\mathrm{C}_{16} \mathrm{H}_{18} \mathrm{~N}_{2} \mathrm{O}_{6}$.

Hydrobilirubin.-If a solution of bilirubin or biliverdin in dilute alkali is treated with sodium amalgam or allowed to putrefy, a brownish pigment is formed called hydrobilirubin, $\mathrm{C}_{32} \mathrm{H}_{44} \mathrm{~N}_{4} \mathrm{O}_{7}$. With the spectroseope it shows a dark absorption band between $b$ and $\mathrm{F}$, and $a$ fainter band in the region of the $\mathrm{D}$ line.

Urobilin.-Hydrobilirubin isinteresting because a similar substance is formed from the bile pigment by reduction processes in the intestine, and constitutes stercobilin, the pigment of the fæces. Some of this is absorbed and ultimately leaves the body in the urine as one of its pigments called urobilin. A small quantity of urobilin is sometimes found preformed in the bile. The identity of urobilin and stercobilin has been frequently disputed, but the recent work of Garrod and Hopkins has confirmed the old statement that they are the same substance with different names. Urobilin has a well-marked absorption band in the region of the $\mathrm{F}$ line, and when partially precipitated from an alkaline solution by acidification, it also shows an absorption band in the region of the $\mathrm{E}$ line. Hydrobilirubin differs from urobilin in containing much more nitrogen in its molecule ( $9 \cdot 2$ instead of 4.1 per cent.), and is probably a product of less complete reduction than urobilin. (See further Lesson XXVI.)

Cholesterin.-This substance is contained not only in bile, but very largely in nervous tissues. Like lecithin, it is an abundant constituent of the white substance of Schwann. It is found also in blood corpuscles. In bile it is normally present in small quantities only, but it may occur in excess, and so form the concretions known as gallstones, which are generally more or less tinged with bilirubin.

Though its solubilities remind one of a fat, cholesterin is not a fat. It is, in fact, chemically speaking, a monatomic alcohol. Its formula is $\mathrm{C}_{27} \mathrm{H}_{45} \cdot \mathrm{HO}$.

From alcohol or ether containing water

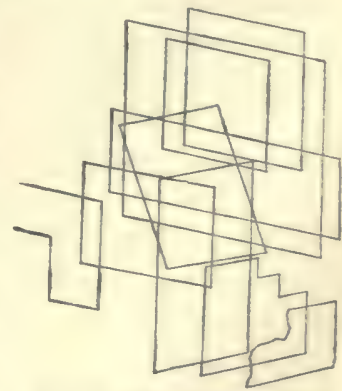

Fig. 25. - Cholesterin erystals. it crystallises in the form of rhombic tables, which contain a molecule of water of crystallisation: these are easily recognised under the microscope (fig. 25). It gives the following tests :- 
1. With iodine and concentrated sulphuric acid the crystals give a play of red, green, and blue.

2. Heated with sulphuric acid and water $(5: 1)$ the edges of the crystals turn red.

3. A solution of cholesterin in chloroform, gently shaken with an equal amount of concentrated sulphuric acid, turns red, and ultimately purple, the subjacent acid acquiring a green fluorescence. (Salkowski's reaction.)

'The mode of origin of cholesterin in the body has not been clearly made out. Whether it is formed in the tissues generally, in the blood, or in the liver, is not known; nor has it been determined conclusively that it is derived from albuminous or nervous matter. It is also doubtful if we are to regard it as a waste substance of no use to the body, as its presence in the blood-corpuscles, in nervous matter, in the egg, and in vegetable grains, points to a possible function of a histogenetic or tissue-forming character.' (McKendrick.)

A substance called iso-cholesterin, isomeric with ordinary cholesterin, is found in the fatty secretion of the skin (sebum); it is largely contained in the preparation called lanoline made from sheep's-wool fat. It does not give Salkowski's reaction with chloroform and sulphuric acid just described.

\section{THE USES OF BILE}

One of the most remarkable facts concerning the bile is its apparently small use in the digestion of food. It is doubtless, to a large extent, excretory. Some state that in some animals it has a slight action on fats and carbohydrates, but it appears to be rather a coadjutor to the pancreatic juice (especially in the digestion of fat) than to have any independent digestive activity (see p. 64).

Bile is said to be a natural antiseptic, lessening the putrefactive processes in the intestine. This is also very doubtful. Though the bile salts are weak antiseptics, the bile itself is readily putrescible, and the power it has of diminishing putrescence in the intestine is due chiefly to the fact that by increasing absorption it lessens the amount of putrescible matter in the bowel.

When the bile meets the chyme the turbidity of the latter is increased, owing to the precipitation of unpeptonised proteid. This is an action due to the bile salts, and it has been surmised that this conversion of the chyme into a more viscid mass is to hinder somewhat its progress through the intestines; it clings to the intestinal wall, thus allowing absorption to take place. The neutralisation of the acid gastric juice by the bile also allows the alkalinity of the pancreatic 
juice to have full play. Bile is a solvent of fatty acids, and assists the absorption of fat (see p. 80).

\section{THE FATE OF THE BILIARY CONSTITUENTS}

We have seen that fistula bile is poor in solids as compared with normal bile, and that this is explained on the supposition that the normal bile circulation is not occurring-the liver cannot excrete what it does not receive back from the intestine. Schiff was the first to show that if the bile is led back into the duodenum, or even if the animal is fed on bile, the percentage of solids in the bile excreted is at once raised. It is on these experiments that the theory of a bile circulation is mainly founded. The bile circulation relates, however, chiefly, if not entirely, to the bile salts : they are found but sparingly in the fæces; they are only represented to a slight extent in the urine : hence it is calculated that seven-eighths of them are re-absorbed from the intestine. Small quantities of cholalic acid, taurine, and glycocine are found in the frees; the greater part of these products of the decomposition of the bile salts is taken by the portal vein to the liver, where they are once more synthetised into the bile salts. Some of the taurine is absorbed and excreted as tauro-carbamic acid $\left(\mathrm{C}_{2} \mathrm{H}_{4} \mathrm{NHCO} . \mathrm{NH}_{2} \mathrm{HSO}_{3}\right)$ in the urine. Some of the absorbed glycocine may be excreted as urea or uric acid. The cholesterin and mucus are found in the fæces; the pigment is changed into stercobilin, a substance like hydrobilirubin. Some of the stercobilin is absorbed, and leares the body as the urinary pigment, urobilin.

\section{THE FECES}

The fæces are alkaline in reaction, and contain the following substances:-

1. Water: in health from 68 to 82 per cent.; in diarrhœa it is more abundant still.

2. Undigested food; that is, if food is taken in excess, some escapes the action of the digestive juices. On a moderate diet unaltered proteid is never found.

3. Indigestible constituents of the food : cellulose, keratin, mucin, chlorophyll, gums, resins, cholesterin.

4. Constituents digestible with difficulty : uncooked starch, tendons, elastin, various phosphates, and other salts of the alkaline earths.

5. Products of decomposition of the food: indole, skatole, phenol, acids such as fatty acids, lactic acid, \&c. ; hæmatin from hæmoglobin ; insoluble soaps like those of calcium and magnesium. 
6. Bacteria of all sorts and débris from the intestinal wall ; cells, nuclei, mucus, \&c.

7. Bile residues : mucus, cholesterin, traces of bile acids and their products of decomposition, stercobilin from the bile pigment. ${ }^{1}$

\section{MECONIUM}

Meconium is the name given to the greenish-black contents of the intestine of new-born children. It is chiefly concentrated bile, with débris from the intestinal wall. The pigment is a mixture of bilirubin and biliverdin; it is not stercobilin.

\section{ABSORPTION}

Food is digested in order that it may be absorbed. It is absorbed in order that it may be assimilated-that is, become an integral part of the living material of the body.

Having now considered the action of digestive juices, we can study the absorption which follows. In the mouth and œsophagus the thickness of the epithelium and the quick passage of the food through these parts reduce absorption to a minimum. Absorption takes place more rapidly in the stomach: the small intestine with its folds and villi to increase its surface is, however, the great place for absorption ; and although the villi are absent from the large intestine, absorption occurs there also, but to a less extent.

Foods such as water and soluble salts like sodium chloride are absorbed unchanged. The organic foods, however, are considerably changed, colloid materials like starch and proteid being converted respectively into the diffusible materials sugar and peptone.

There are two channels of absorption, the blood vessels (portal capillaries) and the lymphatic vessels or lacteals.

Absorption, however, is no mere physical process of diffusion and filtration. We must also take into account the fact that the cells through which the absorbed substances pass are living, and in virtue of their vital activity not only select materials for absorption, but also change those substances while in contact with them. These cells are of two kinds-(1) the columnar epithelium that covers the surface; and (2) the lymph cells in the lymphoid tissue beneath. It is now generally accepted that of the two the former, the columnar epithelium, is the more importanv. When these cells are removed or rendered inactive by sodium fluoride, absorption practically ceases, though the opportunities for simple filtration or diffusion would be by such means increased.

' Stercobilin may originate also from the hæmatin of the food. (MacMunn.) 
Absorption of Carbohydrates.--Though the sugar formed from starch by ptyalin and amylopsin is maltose, that found in the blood is glucose. Under normal circumstances little if any is absorbed by the lacteals. The glucose is formed from the maltose by the succus entericus, and perhaps also by the vital action of the epithelial cells. Cane sugar and milk sugar are also converted into glucose before absorption.

The carbohydrate food which enters the blood as glucose is taken to the liver, and there stored up in the form of glycogen-a reserve store of carbohydrate material for the future needs of the body. Glycogen, however, is found in animals which take no carbohydrate food. It must, then, be formed by the protoplasmic activity of the liver cells from their proteid constituents. The carbohydrate store leaves the liver in the blood of the hepatic vein as glucose (dextrose) once more.

The above is a brief statement of the glycogenic functions of the liver as taught by Claude Bernard, and accepted by the majority of physiologists. It has always been strongly contested by Dr. Pavy, who has in a recently published book revived the question. Dr. Pavy's theory is that the glycogen formed in the liver from the sugar of the portal blood is never during life reconverted into sugar, but is used in the formation of other substances like fat and proteid ; in support of this he has shown that proteids contain a carbohydrate radicle. He denies that the post-mortem formation of sugar from glycogen that occurs in an excised liver is a true picture of what occurs during life.

Absorption of Proteids.-A certain amount of soluble proteid is absorbed unchanged. Thus, after taking a large number of eggs, egg albumin is found in the urine. Patients fed per rectum derive nourishment from proteid food, though proteolytic ferments are not present in this part of the intestine.

Most proteid, however, is normally absorbed as peptone and proteose (albumose). Peptones and proteoses are absent from the blood under all circumstances, even from the portal blood during the most active digestion. In other words, during absorption the epithelial cells change the products of proteolysis (peptones and proteoses) back once more into native proteids (albumin and globulin).

The greater part of the proteid absorbed passes into the blood; a little into the lymph vessels also; but this undergoes the same change.

When peptone (using the word to include the proteoses also) is injected into the blood stream, poisonous effects are produced, the coagulability of the blood is lessened, the blood pressure falls, 
secretion ceases, and in the dog 0.3 gramme of 'peptone' per kilogramme of body weight is sufficient to kill the animal.

The epithelial cells of the alimentary canal thus protect us from

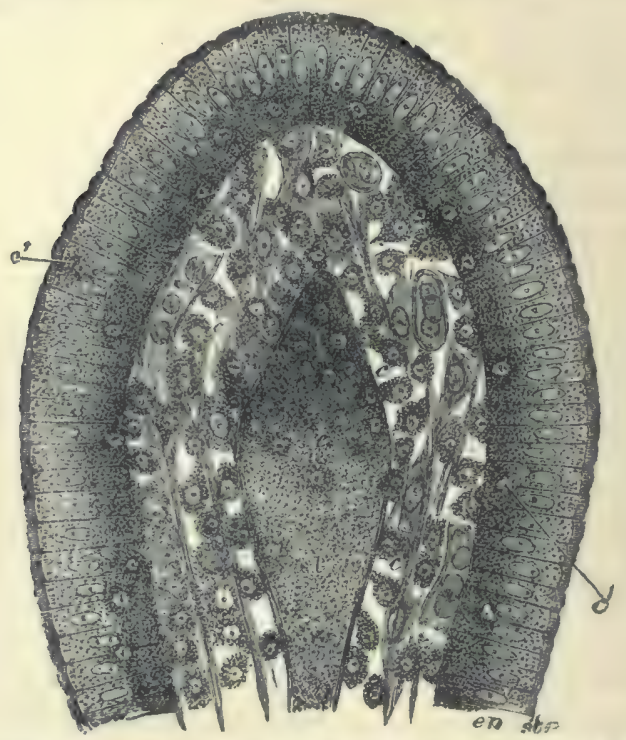

FIr. 26,- Section of the villus of a rat killed during fat-absorption (E. A. Schläfer): ep, epithelium; str, striated border ; $c$, lymph cells : $c^{\prime}$. lyurli cells in the epithelium ;

$l$, central lacteal containing disintegrating lymph cells.

those poisonous effects by converting the harmful peptone into the useful albumin and globulin.

Absorption of Fats. - The fats undergo in the intestine two changes : one a physical change (emulsification), the other a chemi-

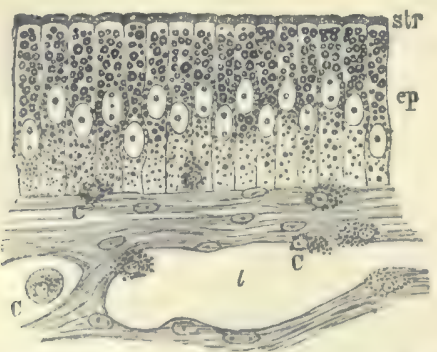

Fis. 27, - Nucous membraue of frog's istestine durieur fat

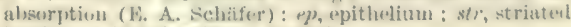
buriter : $c$, lyuph cells: 1 , liteterul. cal change (saponification). The lymphatic vessels are the great channels for fat absorption, and their name, lacteals, is derived from the milk-like appearance of their contents (chyle) during the absorption of fat.

The way in which the minute fat globules pass from the intestine into the lacteals has been the subject of much 
controversy. The course they take may be studied by killing animals at varying periods after a meal of fat, and making osmic acid microscopic preparations of the villi. Figs. 26 and 27 illustrate the appearances observed by Professor Schäfer.

The columnar epithelium cells become first filled with fatty globules of varying size, which are generally larger near the free border. The globules pass down the cells, the larger ones breaking up into smaller ones during the journey; they are then transferred to the amoboid cells of the lymphoid tissue beneath: these ultimately penetrate into the central lacteal, where they either disintegrate or discharge their cargo into the lymph stream. The globules are by this time divided into immeasurably small ones, the molecular basis of chyle. The chyle enters the blood stream by the thoracic duct, and after an abundant fatty meal the blood plasma is quite milky; the fat droplets are so small that they circulate without hindrance through the capillaries. The fat in the blood after a meal is eventually stored up in connective tissue cells of adipose tissue. It must, howerer, be borne in mind that the fat of the body is not exclusively derived from the fat of the food, but it may originate also both from proteid and from carbohydrate.

As, howerer, the fat globules were never seen penetrating the striated border of the epithelial cells, there was a great difficulty in understanding how they reached the interior of these cells; the cells will not take up other particles, and it appears certain that they do not in the higher animals protrude pseudopodia from their borders (this, however, does occur in the endoderm of some of the lower invertebrates).

Recent research has in a great measure solred this difficulty. In the first place particles may be present in the epithelium and lymphoid cells while no fat is being absorbed. These particles are protoplasmic in nature, as they stain with reagents that stain protoplasmic granules; they however also stain darkly with osmic acid, and so are apt to be mistaken for fat. There is, however, no doubt that the particles found during fat absorption are composed of fat. There is also no doubt that the epithelial cells have the power of again forming fat out of the fatty acids and glycerin into which it has been broken up in the intestine. Munk, who has performed a large number of experiments on the subject, showed that the splitting of fats into glycerin and fatty acids occurs to a much greater extent than was formerly supposed; these substances being soluble pass readily into the epithelium cells; and these cells perform the synthetic act of building them into fat once more; the fat so formed 
appears in the form of small globules, surrounding or becoming mixed with the protoplasmic granules that are ordinarily present. Another remarkable fact which he made out is that after feeding an animal on fatty acids the chyle contains fat. The necessary glyceriu must have been formed by protoplasmic activity during absorption. The more recent work of Moore and Rockwood has shown that fat is absorbed entirely as fatty acid or soap; and that preliminary emulsification, though advantageous for the formation of these substances, is not essential.

We thus see how with increase of knowledge, due to improved methods of research, a complete change has come over the ideas which physiologists have held regarding this subject. It is not so many years ago, that the physical chango-emulsification-which fats undergo in the intestine, was considered to be more important than the chemical changes-fat-splitting and caponification. In fact the small amount of chemical change which was supposed to occur was regarded as quite subordinate, and of value merely in assisting the process of emulsification. We now know that the exact converse is the truth; the chemical change is the important process, and emulsification the subordinate one.

Bile aids the digestion of fat, in virtue of its being a solvent of fatty acids, and it probably assists fat absorption by reducing the surface tension of the intestinal contents; membranes moistened with bile allow fatty materials to pass through them more readily than would otherwise be the case. In cases of disease in which bile is absent from the intestines, a large proportion of the fat in the food passes. into the fæces. 


\section{LESSON IX}

\section{THE BLOOD}

\section{Blood Plasma}

1. The coagulation of the blood has been prevented in specimen $\mathrm{A}$ by the addition of neutral salt (an equal rolume of saturated sodium-sulphate solution, or a quarter of its volume of saturated magnesium-sulphate solution). The corpuscles hare settled, and the supernatant salted plasma has been siphoned off.

2. The coagulation of the blood in specimen $B$ has been prevented by the addition of an equal volume of a 0.4 -per-cent. solution of potassium oxalate in normal saline solntion.

3. Put a small quantity of $\mathrm{A}$ into three test-tubes and dilute each with about ten times its volume of liquid:

A 1. With distilled water.

A 2. With solution of fibrin ferment containing a little calcium chloride. ${ }^{2}$

A 3. With the same.

4. Put $\mathrm{A} 1$ and $\mathrm{A} 2$ into the water-bath at $40^{\circ} \mathrm{C}$.; leave $\mathrm{A} 3$ at the temperature of the air. A 1 coagulates slowly or not at all; A 2 coagulates rapidly; A 3 coagulates less rapidly than A 2.

5. Add to some of $\mathrm{B}$ a few drops of dilute ( 2 per cent.) calcium chloride solution: it coagulates, and more quickly, if the temperature is $40^{\circ} \mathrm{C}$.

\section{Blood Serum}

Blood serum is the fluid residue of the blood after the separation of the clot; it is blood plasma minus fibrin. The general appearance of fibrin obtained by whipping fresh blood will already be familiar to the student, as he has used it in experiments on digestion (Lessons VI. and VII.).

Serum has a yellowish tinge due to serum lutein, but as generally obtained it is often contaminated with a small amount of oxyhæmoglobin, and solooks reddish. It contains proteids (giving the general tests already studied in Lesson II.), extractives, and salts in solution. The proteids are serum albumin and serum globulin. The fibrin ferment is also a proteid-like sub. stance. It is present in only small quantities, and in the following experiments is precipitated with serum globulin.

1 This lesson may conveniently be divided into two, the first dealing with plasma and serum, and the second with hæmoglobin.

" An easy way of preparing an impure but efficient solution of fibrin ferment is to take 5 c.c. of blood serum and dilute it with a litre of distilled water. A partial precipitation of globulin takes place, and carries down the ferment with it. After a few hours pour off the supernatant fluid and dissolve the precipitate in half a litre of tap water to which a few drops of 2 per cent. solution of calcium chloride have been added. This solution ean be then given round to the class as fibrin ferment. 
Separation of the serum proteids.-(a) Dilute serum with fifteen times its volume of water. It becomes cloudy owing to the partial precipitation of serum globulin. Add a few drops of 2 per cent. acetic acid; the precipitate becomes more abundant, but dissolves in excess of the acid.

(b) Pass a stream of carbonic acid through serum diluted with twenty times its bulk of water. A partial precipitation of serum globulin occurs.

(c) Saturate some serum with magnesium sulphate by adding crystals of the salt and grinding in a mortar. A precipitate of serum globulin is produced.

(d) Half saturate the serum with ammonium sulphate by adding to it an equal volume of a saturated solution of the salt. Serum globulin is precipitated.

(e) Completely saturate the serum with ammonium sulphate by adding crystals of the salt and grinding in a mortar; a precipitate is produced of both the globulin and the albumin. Filter through a dry filter paper; the filtrate contains no proteid.

\section{Hæmoglobin}

6. Direct the spectroseope to the window and carefully focus Fraunhofer's lines. Note especially D in the yellow, and E, the next well-marked line, in the green.

7. Direct the spectroscope to a luminous gas flame: these lines are absent. Place a little sodium chloride in the flame. Notice the bright yellow line in the position of the $\mathrm{D}$ line.

8. Take a series of six test-tubes of about equal size. Fill the first with diluted defibrinated ox-blood ( 1 part of blood to 31 of water); then fill the second tube with the same mixture diluted with an equal bulk of water (1 in 64); half fill the third tube with this and fill up the tube with an equal bulk of water ( 1 in 128), and so on. The sixth tube will contain 1 part of blood to 1,024 of water, and will be nearly colourless.

9. Into another series of six test-tubes put a few drops of ammonium sulphide; then pour in some of the contents of each of the first series and warm very gently.

10. Examine the tubes with the spectroscope and map out on a chart the typical absorption bands of oxyhrmoglobin in the first series, and of (reduced) hæmoglobin in the second series. Notice that in the more dilute specimens of hæmoglobin the bands are no longer seen, whereas those of oxyhæmoglobin in specimens similarly diluted are still visible.

11. Take a tube which shows the single band of reduced hæmoglobin and shake it with the air; the bright red colour returns to it, and it shows spectroseopically the two bands of oxyhæmoglobin for a short time. Continue watching the two bands, and note that they fade and are replaced by a single band as reduction again occurs.

12. Mix a drop of defibrinated rat's blood on a slide with a drop of water, or mount it in a drop of Canada balsarn. Examine the crystals of oxyhrmoglobin as they form.

13. Smear a little blood, obtained by pricking the finger, on a slide and allow it to dry; cover, and run glacial acetic acid under the cover glass, and boil. Examine microscopically for the dark brown crystals of hæmin.

\section{COAGULATION OF BLOOD}

Microscopic investigation of vertebrate blood shows that it consists of a fluid which holds in suspension large numbers of solid bodiesthe red and the white corpuscles and the blood tablets. 
After blood is shed it rapidly becomes viscous and then sets into a solid red jelly. The jelly soon contracts and squeezes out a strawcoloured fluid called the serum, in which the shrunken clot ultimately floats.

With the microscope, filaments of fibrin are seen forming a network throughout the plasma, many radiating from small clumps of blood tablets. It is the formation of fibrin which is the essential act of eoagulation: this entangles the corpuscles and forms the clot. Fibrin is formed from the plasma, and may be obtained free from corpuscles when blood plasma is allowed to clot, the corpuscles having previously been removed. It may be also obtained from blood by whipping it with a bunch of twigs; the fibrin adheres to the twigs and entangles but few corpuscles. These may be removed by

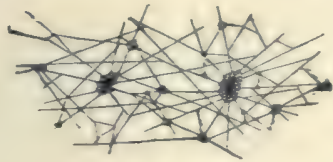

A.

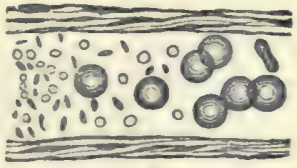

B

Fig. 28.-Fibriu filaments anil bloon tablets: A, network of fibrin shown after washing away the corpuscles from a preparation of blowl that has been allowed to clot. Many of the filametit: raliate from small clumps of blood tahlets; B (from Osier), blool corpuseles and blool tabiets within a small vein.

washing with water. Serum is plasma minus fibrin. The relation of plasma, serum, and clot can be seen at a glance in the following scheme of the constituents of the blood:-

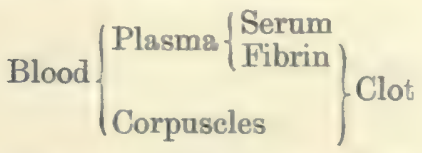

It may be roughly stated that in 100 parts by weight of blood $60-65$ parts consist of plasma and 35-40 of corpuscles.

The buffy coat is seen when blood coagulates slowly, as in horse's blood. The red corpuscles sink more rapidly than the white, and the upper stratum of the clot (buffy coat) consists mainly of fibrin and white corpuscles.

Coagulation is hastened by-

1. A temperature a little over that of the body.

2. Contact with foreign matter.

3. Injury to the vessel walls.

4. Agitation.

5. Addition of calcium salts. 
6. Injection of nucleo-proteid produces intravascular clotting. Very minute doses, however, produce the opposite effect-namely delay of coagulation.

Coagulation is hindered or prevented by-

1. A low temperature. In a vessel cooled by ice, coagulation may be prevented for an hour or more.

2. The addition of a large quantity of neutral salts like sodium sulphate or magnesium sulphate.

3. Contact with the living vascular walls.

4. Contact with oil.

5. Addition of a soluble oxalate (e.g. potassium oxalate): this precipitates the calcium necessary for coagulation as insoluble calcium oxalate.

6. Injection of commercial peptone (which consists chiefly of proteoses) into the circulation of the living animal.

7. Addition of leech extract. This acts in virtue of a proteose it contains.

The theory generally received which accounts best for the coagulation of the blood is that of Hammarsten, and it may be briefly stated as follows:-

When blood is within the vessels one of the constituents of the plasma, a proteid of the globulin class called fibrinogen, exists in a soluble form.

When the blood is shed the fibrinogen molecule is split into two parts : one part is a globulin, which remains in solution, the other is the insoluble material fibrin.

This change is brought about by the activity of a special unorganised ferment called the fibrin ferment.

This ferment does not exist in healthy blood contained in healthy blood vessels, but is one of the products of the disintegration of the white corpuscles and blood tablets that occurs when the blood leaves the vessels or comes into contact with foreign matter.

To this may be added, as the result of recent research, that a soluble calcium salt is essential for the formation of the ferment; that the fibrin ferment belongs to the class of nucleo-proteids; that other nucleo-proteids (Wooldridge's tissue-fibrinogens, see p. 29) obtained from most of the cellular organs of the body produce intravascular clotting when injected into the circulation of a living animal.

The fibrin ferment may very conveniently be called thrombin. Like other ferments it is preceded by a mother substance or zymogen which may be called prothrombin; the action of calcium salts is to 
convert prothrombin into thrombin. We may therefore represent the process of clotting in the following tabular way.

In the plasma a proteid substance exists, called Frbrinogen.

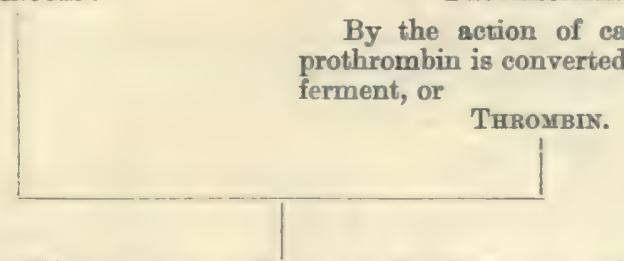

Thrombin acts on fibrinogen in such a way that two new substances are formed.

One of these is unimportant, viz. a globulin (fibrino-globulin) which remains in solution. Its amount is very small.

\section{THE PLASMA AND SERUM}

The liquid in which the corpuscles float may be obtained by employing one or other of the methods already described for preventing the blood from coagulating. The corpuscles, being heavy, sink, and the supernatant plasma can then be removed by a pipette or siphon; the separation can be effected more thoroughly by the use of a centrifugal machine (see fig. 60, Lesson XXI.).

On counteracting the influence which has prevented the blood from coagulating, the plasma then itself coagulates. Thus plasma obtained by the use of cold clots on warming gently; plasma which has been decalcified by the action of a soluble oxalate clots on the addition of a calcium salt; plasma obtained by the use of a strong solution of salt coagulates when this is diluted by the addition of water, the addition of fibrin ferment being necessary in most cases; where coagulation occurs without the addition of fibrin ferment, no doubt some is present from the partial disintegration of the corpuscles which has already occurred. Pericardial and hydrocele fluids resemble pure plasma very closely in composition. As a rule, however, they contain few or no white corpuscles, and do not clot spontaneously, but after the addition of fibrin ferment or liquids like serum that contain fibrin ferment they always yield fibrin.

Pure plasma may be obtained from horse's veins by what is known as the 'living test-tube' experiment. If the jugular vein is ligatured in two places, so as to include a quantity of blood within it, then 
removed from the animal and hung in a cool place, the blood will not coagulate for many hours. The corpuscles settle, and the supernatant plasma can be removed with a pipette.

The plasma is alkaline, yellowish in tint, and its specific gravity is about 1026 to 1029 .

Its chief constituents may be enumerated as follows:1,000 parts of plasma contain-

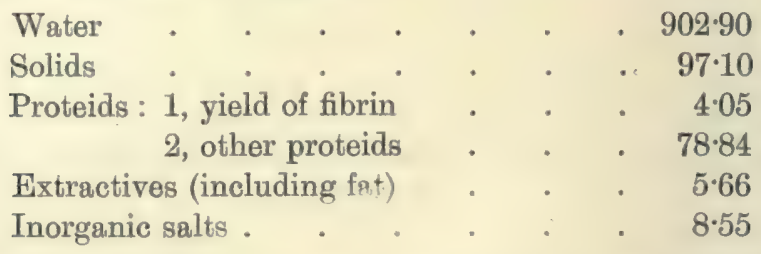

In round numbers plasma contains 10 per cent. of solids, of which 8 per cent. are proteid in nature. The small quantity of fibrinogen as indicated by the amount of fibrin formed should be carefully noted.

Serum contains the same three classes of constituents-proteids, extractives, and salts. The extractives and salts are the same in the two liquids. The proteids differ, as is shown in the following table :-

Proteids of Plasma

\section{Fibrinogen}

Serum globulin

Serum albumin

\section{Proteids of Serum}

Serum globulin

Serum albumin

Fibrin ferment (nucleo-proteid)

Fibrino-globulin

The gases of the plasma and serum are small quantities of oxygen, nitrogen, and carbonic acid. The greater part of the oxygen of the blood is combined in the red corpuscles with hæmoglobin; the carbonic acid is chiefly combined as carbonates (see Respiration).

We may now consider one by one the various constituents of the plasma and serum.

A. Proteids-Fibrinogen.-This is the substance acted on by fibrin ferment. It yields, under this action, an insoluble product called fibrin, and a soluble proteid of the globulin class.

Fibrinogen is a globulin. It differs from serum globulin, and may be separated from it by the fact that half-saturation with sodium chloride precipitates it. It coagulates by heat at the low temperature of $56^{\circ} \mathrm{C}$. As judged from the yield of fibrin, it is the least abundant of the proteids of the plasma (see table on upper part of this page).

Serum globulin and serum albumin.-These substances are considered in the practical exercises at the head of this lesson: see also 
Lesson II. Both serum globulin and serum albumin probably consist of more than one proteid substance (see Lesson XX.).

Fibrin ferment.-Schmidt's method of preparing it is to take serum and add excess of alcohol. This precipitates all the proteids, fibrin ferment included. After some weeks the alcohol is poured off; the serum globulin and serum albumin have been by this means rendered insoluble in water; an aqueous extract is, however, found to contain fibrin ferment, which is not so easily coagulated by alcohol as the other proteids are. A simpler method of preparing fibrin ferment in an impure but efficient form is given in the footnote on p. 81 .

B. Bxtractives.-These are non-nitrogenous and nitrogenous. The non-nitrogenous are sugar ( $0 \cdot 12$ per cent.), fats, soaps, cholesterin ; and the nitrogenous are urea $(0.02$ to 0.04 per cent.), and still smaller quantities of uric acid, creatine, creatinine, xanthine, and hypoxanthine.

C. Salts.-The most abundant salt is sodium chloride: it constitutes between 60 and 90 per cent. of the total mineral matter. Potassium chloride is present in much smaller amount. It constitutes about 4 per cent. of the total ash. The other salts are phosphates and sulphates.

Schmidt gives the following table :-

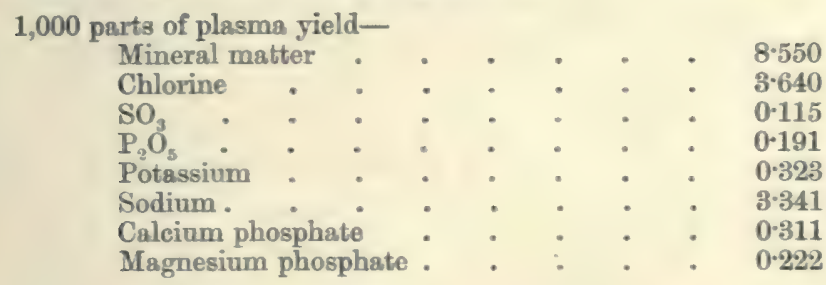

\section{THE WHITE BLOOD CORPUSCLES}

These corpuscles are typical animal cells. Their nucleus consists of nuclein, their cell-protoplasm yields proteids belonging to the nucleo-proteid and globulin groups. The nucleo-proteid obtained from them is the zymogen of the fibrin ferment, the addition of a calcium salt converting it into the ferment. The protoplasm of these cells often contains small quantities of fat and glycogen.

\section{THE RED BLOOD CORPUSCLES}

The red blood corpuscles are much more numerous than the white, averaging in $\operatorname{man} 5,000,000$ per cubic millimetre, or 400 to 500 red to each white corpuscle. The method of enumerstion of the corpuscles is described in the Appendix. 
They vary in size and structure in different groups of vertebrates. In mammals they are biconcave (except in the camel tribe, where they are biconvex) non-nucleated discs, in man averaging $\frac{1}{3200}$ inch in diameter; during fotal life nucleated red corpuscles are, however, found. In birds, reptiles, amphibians, and fishes they are biconvex oval discs with a nucleus: they are largest in the amphibia.

Water causes the corpuscles to swell up, and dissolves out the red pigment (oxyhæmoglobin), leaving a globular colourless stroma.

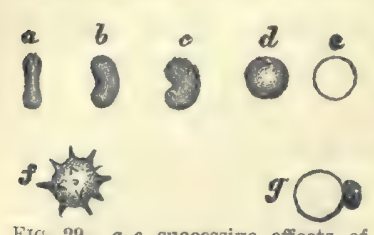

Frg. 29,-a-e, successive effects of water on a red bloor corpuscle; $f$, a red corpuscle crenated by salt solution; $g$, action of tannin on a red corpuscle. Salt solution causes the corpuscles to shrink : they become crenated or wrinkled. The action of water and salt solution suggests the existence of a membrane on the surface of the corpuscles through which osmosis takes place, but the existence of such a membrane is still a matter of discussion. If there is no actual membrane, the outer denser portion of the stroma plays the rôle of one during osmotic phenomena. Dilute alkalis $(0 \cdot 2$ per cent. potash) dissolve the corpuscles. Dilute acids (1 per cent. acetic acid) act like water, and in nucleated corpuscles render the nucleus distinct. Tannic acid causes a discharge of hæmoglobin from the stroma, but this is immediately altered and precipitated. It remains adherent to the stroma as a brown globule, consisting probably of hæmatin. Boric acid acts similarly, but in nucleated red corpuscles the pigment collects chiefly round the nucleus, which may then be extruded from the corpuscles.

Composition.-1,000 parts of red corpuscles contain-

Water

Solids $\left\{\begin{array}{l}\text { organic } \\ \text { inorganic }\end{array}\right.$
- 688 parts

. 303.88 "

$8 \cdot 12$,

100 parts of dried corpuscles contain-

Proteid

Hæmoglobin

Lecithin

Cholesterin .
- 5 to 12 parts

. 86,94 . ,

. $1 \cdot 8$

. $0 \cdot 1$
"

part

The proteid present appears to be identical with the nucleoproteid of white corpuscles. The mineral matter consists chiefly of chlorides of potassium and sodium, and phosphates of calcium and magnesium. In man potassium chloride is more abundant than sodium chloride; this, however, does not hold good for all animals. 
Oxygen is contained in combination with the hæmoglobin to form oxyhæmoglobin. The corpuscles also contain a certain amount of carbonic acid (see Respiration, at the end of this lesson).

The pigment of the red corpuscles.-The pigment is by far the most abundant and important of the constituents of the red corpuscles. It is a substance which gives the reactions of a proteid, but differs from most other proteids in containing the element iron; it is also readily crystallisable.

It exists in the blood in two conditions: in arterial blood it is combined loosely with oxygen, is of a bright red colour, and is called oxyhrmoglobin; the other condition is the deoxygenated or reduced hæmoglobin (better called simply hæmoglobin). This is found in the blood after asphyxia. It also occurs in all venous blood-that is, blood which is returning to the heart after it has supplied the tissues with oxygen. Venous blood, however, always contains a considerable quantity of oxyhæmoglobin also. Hæmoglobin is the oxygen-carrier of the body, and it may be called a respiratory pigment.

Crystals of oxyhæmoglobin may be obtained with readiness from the blood of such animals as the rat, guinea-pig, or dog; with difficulty from other animals, such as man, ape, and most of the common mammals. The following methods are the best :-

1. Mix a drop of defibrinated blood of the rat on a slide with a drop of water; put on a cover glass; in a few minates the corpuscles are rendered colourless, and then the oxyhæmoglobin crystallises out from the solution so formed.

2. Microscopical preparations may also be made by Stein's method, which consists in using Canada balsam instead of water in the above experiment.

3. On a larger scale the crystals may be obtained by mixing the blood with one-sixteenth of its volume of

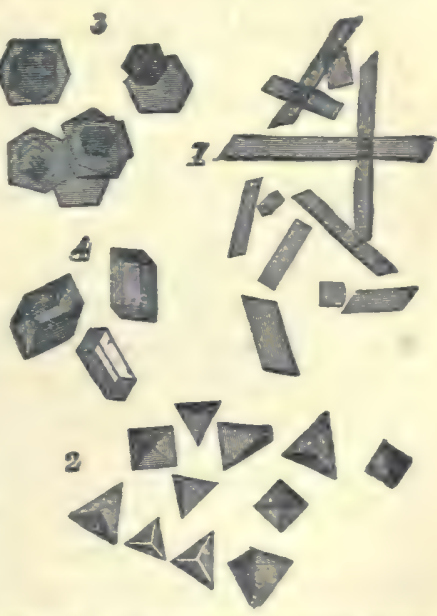

FIG. 30. - Oxyhæmoglobin ervstals magnified : 1, from human blood: 2, from the guinea-pig ; 3, squirrel ; 4 , hamster.

ether; the corpuscles dissolve and the blood assumes a laky appearance. After a period, varying from a few minutes to days, abundant crystals are deposited.

The accompanying figures represent the form of the crystals so obtained. 
In nearly all animals the crystals are rhombic prisms; but in the guinea-pig they are rhombic tetrahedra (four-sided pyramids); in the squirrel, hexagonal plates; and in the hamster, rhombohedra and hexagonal plates.

The crystals also contain a varying amount of water of crystallisation: this may in part explain their different crystalline forms and solubilities.

Different observers have analysed hæmoglobin. They find carbon, hydrogen, nitrogen, oxygen, sulphur, and iron. The percentage of iron is 0.4 . The amounts of the other elements are variously given, but, roughly, they are the same as in the proteids. We know at present as little of the chemical structure of hæmoglobin as of the proteids generally.

Oxyhæmoglobin may be estimated in the blood (1) by the amount of iron in the ash, or (2) by certain colorimetric methods which are described in the Appendix.

On adding an acid or alkali to hæmoglobin, it is broken up into two parts, a proteid called globin, an $\mathbb{I}$ a brown pigment called hamatin, which contains all the iron of the original substance.

Globin is a somewhat unique proteid. It is coagulable by heat, soluble in dilute acids, and precipitable from such solutions by ammonia. It closely resembles a substance previously separated from red corpuscles by Kossel and termed by him histone (Schulz).

Hæmatin is not crystallisable; according to Hoppe-Seyler its formula is $\mathrm{C}_{34} \mathrm{H}_{35} \mathrm{~N}_{4} \mathrm{FeO}_{5}$; other observers give different formulæ. It presents different spectroseopic appearances in acid and alkaline solutions, which we shall study more fully in the advanced course. It also yields several products under the influence of certain reagents, which we shall also again consider in the advanced course. For the present, we will mention only two of these, hæmin and hæmatoporphyrin.

Hæmin is of great importance, as the obtaining of this substance in a crystalline form is the best chemical test for blood. Hæmin crystals, sometimes called, after their discoverer, Teichmann's crystals, are composed of the hydrochloride of hæmatin. They may be prepared for microscopic examination by boiling a fragment of dried blood with a drop of glacial acetic acid on a slide; on cooling, dark brown plates and prisms belonging to the triclinic system, often in star-shaped clusters and with rounded angles (fig. 31), separate out.

In the case of an old blood-stain it is necessary to add a crystal 
of sodium chloride in addition. Fresh blood contains sufficient sodium chloride in itself.

The action of the acetic acid is (1) to split the hæmoglobin into hæmatin and globin; and (2) to erolve hydrochloric acid from the sodium chloride. The hæmatin unites with the hydrochloric acid, and thus hæmin is formed. The formula for hæmin is $\mathrm{C}_{35} \mathrm{H}_{35} \mathrm{~N}_{4} \mathrm{FeClO}_{4}$ (Mörner).

Hæmatoporphyrin is iron-free hæmatin; it may be prepared by mixing blood with strong sulphuric acid: the iron is taken out as ferrous sulphate. This substance is also found sometimes in nature: it occurs in certain invertebrate pigments, and may also be found in certain forms of pathological urine. It shows wellmarked spectroscopic bands, and so is not identical with the ironfree derivative of hæmoglobin called hæmatoidin which is formed

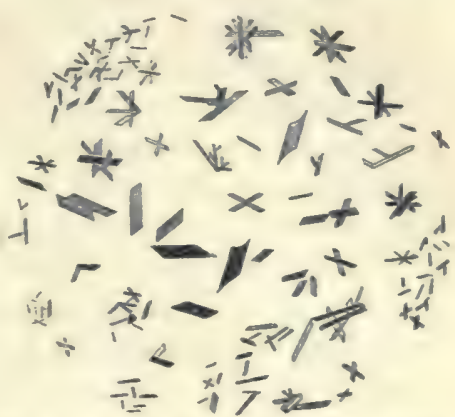

FIG. 31. -Hamin errstals magnified. (Preyer.) in extravasations of blood in the body (see p. 70). The two substances are possibly isomeric.

\section{COMPOUNDS OF HÆMOGLOBIN WITH GASES}

Hæmoglobin forms at least four compounds with gases :-

With oxygen

With carbonic oxide.

With nitric oxide.
(1. Oxyhæmoglobin.

12. Methremoglobin.

3. Carbonic oxide hæmoglobin.

4. Nitric oxide hæmoglobin.

These compounds have similar crystalline forms: each probably consists of a molecule of hæmoglobin combined with one of the gas in question. They part with the combined gas somewhat readily, and are arranged in order of stability in the above list, the least stable first.

Oxyhæmoglobin is the compound that exists in arterial blood. Many of its properties have been already mentioned. The oxygen linked to the hæmoglobin, which is removed by the tissues through which the blood circulates, may be called the respiratory oxygen of homoglobin. The processes that occur in the lungs and tissues, resulting in the oxygenation and deoxygenation respectively of the hæmoglobin, may be imitated outside the body, using either blood or 
pure solutions of hæmoglobin. The respiratory oxygen can be removed, for example, in the Torricellian vacuum of a mercurial airpump, or by passing a neutral gas like hydrogen through the blood, or by the use of reducing agents like ammonium sulphide or Stokes's reagent. ${ }^{1}$ One gramme of hæmoglobin will combine with $1 \cdot 34$ c.c. of oxygen.

If any of these methods for reducing oxyhrmoglobin is used, the bright red (arterial) colour of oxyhæmoglobin changes to the purplish (venous) tint of hæmoglobin. On once more allowing oxygen to come into contact with the hæmoglobin, as by shaking the solution with the air, the bright arterial colour returns.

These colour-changes may be more accurately studied with the spectroscope, and the constant position of the absorption bands seen constitutes an important test for blood pigment. It will be first necessary to describe briefly the instrument used.

The Spectroscope.-When a ray of white light is passed through a prism, it is refracted or bent at each surface of the prism; the whole ray is, however, not equally bent, but it is split into its constituent colours, which may be allowed to fall on a screen. The band of colours beginning with the red, passing through orange, yellow, green, blue, and ending with violet, is called a spectrum: this is seen in nature in the rainbow. It may be obtained artificially by the glass prism or prisms of a spectroscope.

The spectrum of sunlight is interrupted by numerous dark lines crossing it vertically, called Fraunhofer's lines. These are perfectly constant in position, and serve as landmarks in the spectrum. The more prominent are $\mathrm{A}, \mathrm{B}$, and $\mathrm{C}$, in the red; $\mathrm{D}$, in the yellow ; $\mathrm{E}, b$, and $\mathrm{F}$, in the green; $\mathrm{G}$ and $\mathrm{H}$, in the violet. These lines are due to certain volatile substances in the solar atmosphere. If the light" from burning sodium or its compounds is examined spectroscopically, it will be found to give a bright yellow line, or rather two bright yellow lines very close together. Potassium gives two bright red lines and one violet line; and the other elements, when incandescent, give characteristic lines, but none so simple as sodium. If now the flame of a lamp be examined, it will be found to give a continuous spectrum like that of sunlight in the arrangement of its colours, but unlike it in the absence of dark lines; but if the light from the lamp be made to pass through sodium vapour before it reaches the spectroscope, the bright yellow light will be found

'Stokes's reagent must always be freshly prepared : it is a solution of ferrous sulphate to which a little tartaric acid has been added, and then ammonia till the reaction is alkaline. 
absent, and in its place a dark line, or rather two dark lines very close together, occupying the same position as the two bright lines of the sodium spectrum. The sodium vapour thus absorbs the same

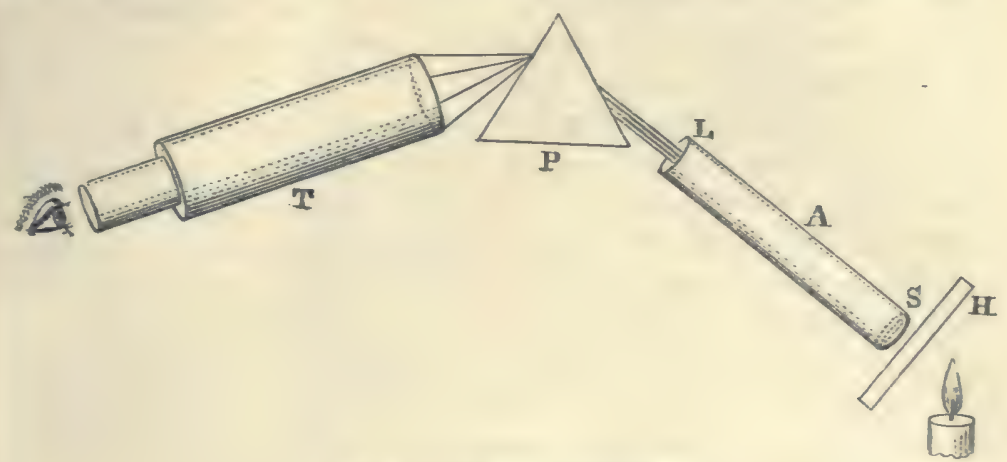

FiG. 32.-Diagram of spectroseope.

rays as those which it itself produces at a higher temperature. Thus the $\mathrm{D}$ line, as we term it, in the solar spectrum is due to the presence

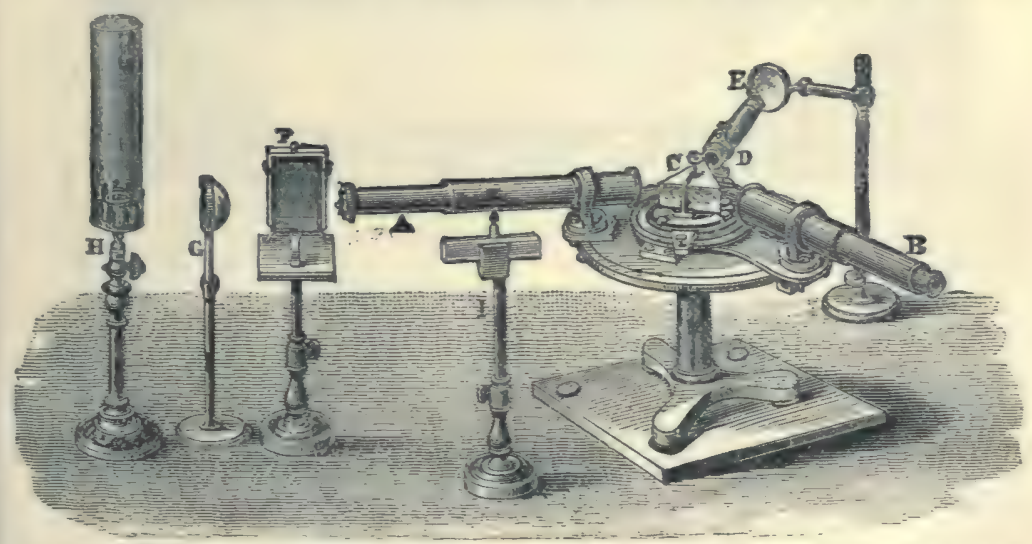

FIG. 33.-Spectroscope : A, collimator with adjustable slít at one (left) end and collimating leus at the other (right) end ; B, telescope moving on graluated are dirided into degrees; C. prism or combination of prisms : D, tube for seale: E. mirror for illuminating seale; F, vessel with parallel glass sides for holding fluid. shown with the flat side towards the reader; I, long speetroscope bottle for examining a deep layer of fluid: H, Argand burner: G. condenser for concentrating the light from $\mathbf{H}$ on the slit. (From a photograph taken by Dr. MacMunn for McKendrick's 'Physiology.')

of sodium vapour in the solar atmosphere. The other dark lines are similarly accounted for by other elements.

The large form of spectroscope (fig. 32) consists of a tube A, called the collimator, with a slit at the end $\mathrm{S}$, and a convex lens at the end $\mathrm{L}$. The latter makes the rays of light passing through the slit from the 
source of light parallel: they fall on the prism $\mathrm{P}$, and then the spectrum so formed is focussed by the telescope $\mathrm{T}$.

The third tube, D, seen in the next figure (fig. 33), carries a small transparent scale of wave lengths, as in accurate observations the position of any point in the spectrum is given in the terms of the corresponding wave-lengths.

If we now interpose between the source of light and the slit $\mathrm{S}$ a piece of coloured glass ( $\mathrm{H}$ in fig. 32 ), or a solution of a coloured substance contained in a vessel with parallel sides (the hæmatoscope of Hermann, F in fig. 33), the spectrum is found to be no longer continuous, but is interrupted by a number of dark shadows, or absorption bands, corresponding to the light absorbed by the coloured medium. Thus a solution of oxyhæmoglobin of a certain strength gives two bands between the $\mathrm{D}$ and $\mathrm{E}$ lines; hæmoglobin gives only one; and other red solutions, though to the naked eye similar to. oxyhæmoglobin, will give characteristic bands in other positions.

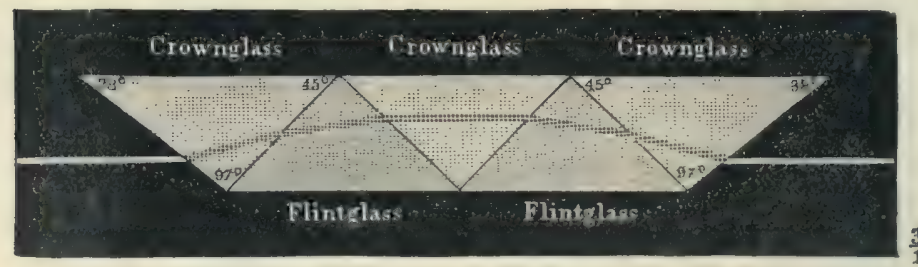

FIG. 34.-Arrangement of prisms in direct-vision spectroscope.

A convenient form of small spectroscope is the direct-vision spectroscope, in which, by an arrangement of alternating prisms of crown and flint glass, placed as in fig. 34, the spectrum is observed by the eye in the same line as the tube furnished with the slit-indeed slit and prisms are both contained in the same tube.

Such small spectroscopes may be used for class purposes, and may for convenience be mounted on a stand provided with a gasburner and a receptacle for the test-tube (see fig. 35 ).

In the examination of the spectrum of small coloured objects, a combination of the microscope and direct-vision spectroscope, called the micro-spectroscope, is used.

Fig. 36 illustrates a method of representing absorption spectra diagrammatically. The solution was examined in a layer 1 centimetre thick. The base line has on it at the proper distances the chief Fraunhofer lines, and along the right-hand edges are 
spectrum 2). There are two distinct absorption bands between the $\mathrm{D}$ and $\mathrm{E}$ lines; the one nearest to $\mathrm{D}$ (the $a$ band) is narrower, darker, and has better defined edges than the other (the fo band). As will be seen on looking at fig. 36, a solution of oxyhæmoglobin of concentration greater than 0.65 per cent. and less than 0.85 per cent. (examined in a cell of the usual thickness of 1 centimetre) gives one thick band overlapping both $\mathrm{D}$ and $\mathrm{E}$, and a stronger solution only lets the red light through between $\mathrm{C}$ and $\mathrm{D}$. A solution which gives the two characteristic bands must therefore be a very dilute one. The one band ( $\gamma$ band) of hæmoglobin (fig. 37, spectrum 3 ) is not so

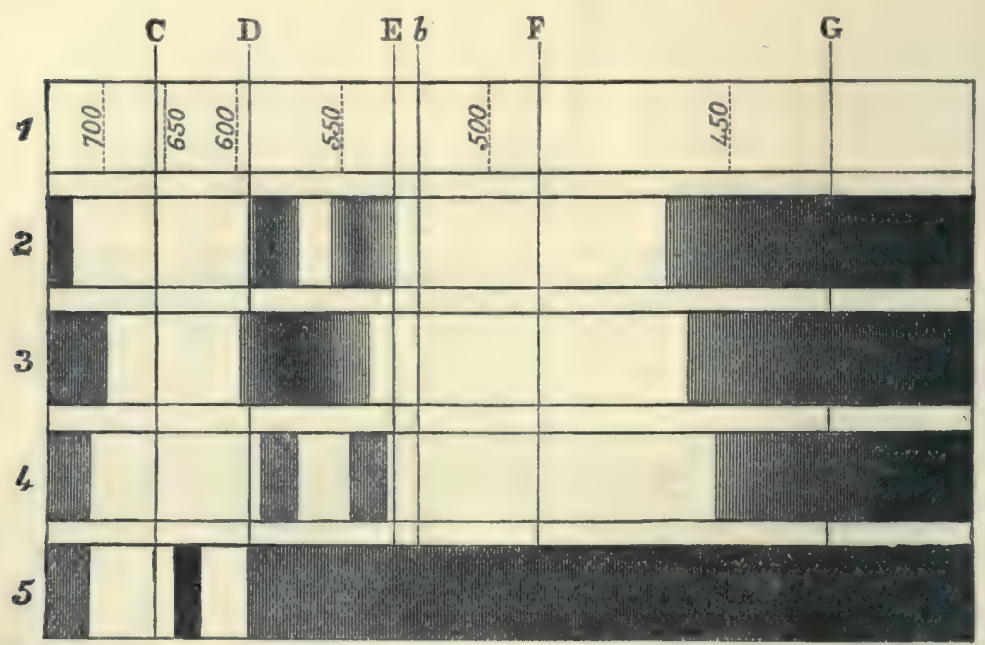

FIG. 37.-1, Solar spectrum: 2, spectrum of oxyhæmoglobin $(0.37$ per cent. solution $): 3$, spectrum of hæunglobin; 4, spectrum of CO-hæmoglobin ; 5 , spectrum of methæmoglofin (conceutrated solution).

well defined as the $a$ or $\beta$ bands. On dilution it fades rapidly, so that in a solution of such strength that both bands of oxyhæmoglobin would be quite distinct the single band of hæmoglobin has disappeared from view. The oxyhæmoglobin bands can be distinguished in a solution which contains only one part of the pigment to 10,000 of water, and even in more dilute solutions which seem to be colourless the $a$ band is still visible.

Methæmoglobin.-This may be produced artificially by adding such reagents as potassium ferricyanide or amyl nitrite to a solution of oxyhæmoglobin ; it may also occur in certain diseased conditions in the urine; it is therefore of considerable practical importance. It can be crystallised, and is found to contain the same amount of 
oxygen as oxyhæmoglobin, only combined differently. The oxygen is not removable by the air-pump, nor by a stream of a neutral gas like hydrogen. It can, however, by reducing agents like ammonium sulphide, be made to yield hæmoglobin. Methæmoglobin is of a brownish-red colour, and gives a characteristic absorption band in the red between the $\mathrm{C}$ and $\mathrm{D}$ lines (fig. 37, spectrum 5).

The ferricyanide of potassium or sodium not only eauses the conversion of oxyhæmoglobin into methæmoglobin, but if the reagent is added to blood which has been previously laked by the addition of twice its volume of water there is an evolution of oxygen. If a small amount of sodium carbonate or ammonia is added as well to prevent the evolution of any carbonic acid, and the oxygen is collected and measured, it is found that all the oxygen previously combined in oxyhæmoglobin is discharged. This is at first sight puzzling, because, as just stated, methæmoglobin contains the same amount of oxygen that is present in oxyhæmoglobin. What occurs is that after the oxygen is discharged from oxyhæmoglobin, an equal quantity of oxygen takes its place from the reagents added. The oxygen atoms of the methæmoglobin must be attached to a different part of the hæmatin group from the oxygen atoms of the oxyhæmoglobin, sc that the hæmatin group when thus altered loses its power of combining with oxygen and carbonic oxide to form compounds which are dissociable in a vacuum.

Dr. Haldane, to whom we owe these interesting results, gives the following provisional equation to represent what occurs :-

$$
\begin{aligned}
& \mathrm{HbO}_{2}+4 \mathrm{Na}_{3} \mathrm{Cy}_{6} \mathrm{Fe}+4 \mathrm{NaHCO}_{3}=\mathrm{HbO}_{2}+4 \mathrm{Na}_{4} \mathrm{Cy}_{6} \mathrm{Fe} . \\
& \begin{array}{c}
\text { [oxyhrmo- } \\
\text { globin] }
\end{array} \begin{array}{c}
\begin{array}{c}
\text { sodium ferri- } \\
\text { cyanide] }
\end{array} \\
\text { [sodium bicar- } \\
\text { bonate] }
\end{array} \begin{array}{c}
\text { [methsemo- } \\
\text { globin] }
\end{array} \begin{array}{c}
\text { [sodium ferro- } \\
\text { cyanide] }
\end{array} \\
& +4 \mathrm{CO}_{2}+2 \mathrm{H}_{2} \mathrm{O}+\mathrm{O}_{2} \text {. } \\
& \text { [carbonic [water] [oxygen] }
\end{aligned}
$$

Carbonic Oxide Hæmoglobin may be readily prepared by passing a stream of carbonic oxide or coal gas through blood or through a solution of oxyhæmoglobin. It has a peculiar cherry-red colour. Its absorption spectrum is very like that of oxyhæmoglobin, but the two bands are slightly nearer the violet end of the spectrum (fig. 37, spectrum 4). Reducing agents, like ammonium sulphide, do not change it; the gas is more firmly combined than the oxygen in oxyhæmoglobin. CO-hæmoglobin forms crystals like those of oxyhæmoglobin : it resists putrefaction for a very long time.

Carbonic oxide is given off during the imperfect combustion of carbon such as occurs in charcoal stoves: this acts as a powerful 
poison by combining with the hæmoglobin of the blood, and thus interfering with normal respiratory processes. The colour of the blood and its resistance to reducing agents are in such cases characteristic.

Nitric 0xide Hæmoglobin.-When ammonia is added to blood, and then a stream of nitric oxide passed through it, this compound is formed. It may be obtained in crystals isomorphous with oxy-and CO-hæmoglobin. It also has a similar spectrum. It is even more stable than CO-hæmoglobin; it has little practical interest, but is of theoretical importance as completing the series.

Bohr has advanced a theory that hrmoglobin forms a compound with earbonic dioxide, and that there are numerous oxyhæmoglobins containing different amounts of oxygen, but his views have not been accepted.

Very dilute solutions of hæmoglobin and its derivatives show an absorption band in the ultra-violet region in addition to those just described in the visible regions of the spectrum (see more fully Advanced Course).

\section{CHEMISTRY OF RESPIRATION}

The consideration of the blood, and especially of its pigment, is so closely associated with respiration that a brief account of that process follows conveniently here.

The lungs consist essentially of numerous little hollow sacs in the walls of which is a close plexus of capillary blood vessels. These air sacs, or alveoli, communicate with the external air by the trachea, bronchi, and bronchial tubes. Inspiration is due to a muscular effort that enlarges the thorax, the closed cavity in which the lungs are situated. Owing to the atmospheric pressure the lungs become distended. The atmospheric air does not, however, actually penetrate beyond the bronchial tubes; the gases which get into the smallest tubes and air sacs do so mainly by diffusion. Expiration is ordinarily brought about by the elastic rebound of the lungs and chest walls, and is only a muscular effort when forced: but even the most vigorous expiratory effort is unable to expel the alveolar air. This air and the blood in the capillaries are only separated by the thin capillary and alveolar walls. The blood parts with its excess of carbonic acid and watery vapour to the alveolar air; the blood at the same time receives from the alveolar air the oxygen which renders it arterial.

The intake of oxygen is the commencement, and the output of carbonic acid the end, of the series of changes known as respiration. The intermediate steps take place all over the body, and constitute what is known as internal or tissue respiration. The exchange of gases which,occurs in the lungs is sometimes called in contradistinc- 
tion external respiration. We have already seen that oxyhæmoglobin is only a loose compound, and in the tissues it parts with its oxygen. The oxygen does not necessarily undergo immediate union with carbon to form carbonic acid, and with hydrogen to form water, but in most cases, as in muscle, is held in reserve by the tissue itself. Ultimately, however, these two oxides are formed : they are the chief products of combustion. Certain other products which represent the combustion of nitrogenons material (urea, uric acid, \&c.) ultimately leave the body by the urine. All these substances pass into the venous blood, and the gaseous products, carbonic acid, and a portion of the water find an outlet by the lungs.

Inspired and Expired Air.-The composition of the inspired and the expired air may be compared in the following table:-

\begin{tabular}{|c|c|c|c|}
\hline- & & Inspired or atmospheric Air & Bxpired Air \\
\hline $\begin{array}{l}\text { Oxygen } \\
\text { Nitrogen : } \\
\text { Carbonic acid } \\
\text { Watery vapour. } \\
\text { Temperature. }\end{array}$ & : & $\begin{array}{c}20.96 \text { vols. per cent. } \\
79 " \\
0-04 " \\
\text { variable" } \\
n\end{array}$ & $\begin{array}{l}16.03 \text { vols. per cent. } \\
79 " \\
4.4 \text { " " } " \\
\text { saturated" } \\
\text { that of body }\left(37^{\circ} \text { C. }\right)\end{array}$ \\
\hline
\end{tabular}

The nitrogen remains unchanged. The recently discovered gases, argon, crypton, \&c., are in the above table reckoned in with the nitrogen. They are, hawerer, only present in minute quantities. The chief change is in the proportion of oxygen and carbonic acid. The loss of oxygen is about 5 , the gain in carbonic acid $4 \frac{1}{2}$. If the inspired and expired airs are carefully measured at the same temperature and barometric pressure, the volume of expired air is thus rather less than that of the inspired. The conrersion of oxygen into carbonic acid would not cause any change in the rolume of the gas, for a molecule of oxygen $\left(\mathrm{O}_{2}\right)$ would give rise to a molecule of carbonic acid $\left(\mathrm{CO}_{2}\right)$, which would occupy the same volume (Avogadro's law). It must, however, be remembered that carbon is not the only element which is oxidised. Fats contain a number of atoms of hydrogen which during metabolism are oxidised to form water ; a certain small amount of oxygen is also used in the formation of urea. Carbohydrates contain sufficient oxygen in their own molecules to oxidise their hydrogen; hence the apparent loss of oxygen is least when a vegetable diet (that is, one consisting largely of starch and other carbohydrates) is taken, and greatest when much fat and proteid are eaten. The quotient $\mathrm{CO}_{2}$ given off is called the respiratory quotient. 
Normally it is $\frac{4.5}{5}=0.9$, but this varies considerably with diet, as just stated. It varies also with muscular exercise, when the output of carbonic acid is much increased both absolutely and relatively to the amount of oxygen used up.

Gases of the Blood.-From 100 volumes of blood about 60 volumes of gas can be removed by the mercurial air-pump (see Appendix). The average composition of this gas from dog's blood is-

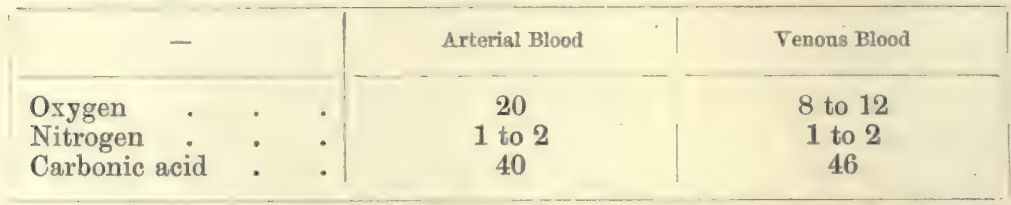

The nitrogen in the blood is simply dissolved from the air just as water would dissolve it: it has no physiological importance. The other two gases are present in much greater amount than can be explained by simple solution; they are, in fact, chiefly present in loose chemical combinations. Less than one volume of the oxygen and about two of carbonic acid are present in simple solution in the plasma.

Oxygen in the Blood.-The amount of gas dissolved in a liquid varies with the pressure of the gas; double the pressure and the amount of gas dissolved is doubled. Now this does not occur in the case of oxygen and blood; very nearly the same amount of oxygen is dissolved whatever be the pressure. We thus have a proof that oxygen is not merely dissolved in the blood, but is in chemical union: and the fact that the oxygen of oxyhæmoglobin can be replaced by equivalent quantities of other gases, like carbonic oxide, is a further proof of the same statement. The tension or partial pressure of oxygen in the air of the alveoli is less than that in the atmosphere, but greater than that in venous blood; hence oxygen passes from the alveolar air into the blood; the oxygen immediately combines with the hæmoglobin, and thus leaves the plasma free to absorb more oxygen; and this goes on until the hæmoglobin is entirely, or almost entirely, saturated with oxygen. The reverse change occurs in the tissues where the partial pressure of oxygen is lower than in the plasma, or in the lymph that bathes the tissue elements; the plasma parts with its oxygen to the lymph, the lymph to the tissues; the oxyhæmoglobin then undergoes dissociation to supply more oxygen to the plasma and lymph, and this in turn to the tissues once more. This goes on until the oxyhæmoglohin loses a great portion of its store of oxygen, but even in asphyxia it does not lose all. 
The following values are given by Fredericq for the tension of oxygen in percentages of an atmosphere. His experiments were made on dogs:-

\begin{tabular}{|c|c|c|c|c|c|c|}
\hline External air . & • & & $\cdot$ & • & & $20 \cdot 96$ \\
\hline Alveolar air & - & - & • & - & • & 18 \\
\hline Arterial blood & * & - & • & - & - & 14 \\
\hline Tissues . & . & . & . & . & . & 0 \\
\hline
\end{tabular}

The arrow shows the direction in which the gas passes.

The methods of obtaining the gases of the blood and analysing them are deseribed in the Appendix. When the gases are being pumped off from the blood, rery little oxygen comes off until the pressure is greatly reduced, and then, at a certain point, it is suddenly disengaged. This shows it is not in simple solution, but is united chemically to the hæmoglobin as oxyhæmoglobin, which is dissociated when the pressure is extremely low.

The aridity of the tissues for oxygen is shown by Ehrlich's experiments with methylene blue and similar pigments. Methylene blue is more stable than oxyhæmoglobin; but if it is injected into the circulation of a living animal, and the animal killed a few minutes later, the blood is found dark blue, but the organs colourless. On exposure to oxygen the organs become blue. In other words the tissues have removed the oxygen from methylene blue to form a colourless reduction product; on exposure to the air this once more unites with oxrgen to form methylene blue.

Carbonic Acid in the Blood. - What has been said for oxygen holds good in the reverse direction for carbonic acid. Compounds are formed in the tissues where the tension of the gas is high : these pass into the lymph, then into the blood, and in the lungs the compounds undergo dissociation, carbonic acid passing into the alveolar air where the tension of the gas is comparatively low, though it is greater here than in the expired air.

The relations of this gas and the compounds it forms are more complex than in the case of oxygen. If blood is divided into plasma and corpuscles, it will be found that both yield carbonic acid, but the yield from the plasma is the greater. If we place blood in a racuum it bubbles, and gives out all its gases; addition of a weak acid causes no further liberation of carbonic acid. If plasma or serum is similarly treated the gas comes off, but from 10 to 18 per cent. of the carbonic acid is fixed-that is, the addition of some stronger acid, like phosphoric acid, is necessary to displace it. Fresh red corpuscles will, however, take the place of the phosphoric acid, and thus 
it has been surmised that oxyhæmoglobin has the properties of an acid.

One hundred volumes of venous blood contain forty-six volumes of carbonic acid. Whether this is in solution or in chemical combination is determined by ascertaining the tension of the gas in the blood. One hundred volumes of blood plasma would dissolve more than an equal volume of the gas at atmospheric pressure, if its solubility in plasma were equal to that in water. ${ }^{1}$ If, then, the carbonic acid were in a state of solution, its tension would be very high, but it proves to be only equal to 5 per cent. of an atmosphere. This means that when venous blood is brought into an atmosphere containing 5 per cent. of carbonic acid, the blood neither gives off any carbonic acid nor takes up any from that atmosphere. Hence the remainder of the gas, 95 per cent., is in a condition of chemical combination. The chief compound appears to be sodium bicarbonate.

The carbonic acid and phosphoric acid of the blood are in a state of constant struggle for the possession of the sodium. The salts formed by these two acids depend on their relative masses. If carbonic acid is in excess, we get sodium carbonate $\left(\mathrm{Na}_{2} \mathrm{CO}_{3}\right)$, and mono-sodium phosphate $\left(\mathrm{NaH}_{2} \mathrm{PO}_{4}\right)$; but if the carbonic acid is diminished, the phosphoric acid obtains the greater share of sodium to form disodium phosphate $\left(\mathrm{Na}_{2} \mathrm{HPO}_{4}\right)$. In this way, as soon as the amount of free carbonic acid diminishes, as in the lungs, the amount of carbonic acid in combination also decreases; whereas in the tissues, where the tension of the gas is highest, a large amount is taken up into the blood, where it forms sodium bicarbonate.

The tension of the carbonic acid in the tissues is high, but one cannot give exact figures; we can measure the tension of the gas in certain secretions; in the urine it is 9 , in the bile 7 per cent. The tension in the cells themselves must be higher still.

The following figures (from Fredericq) give the tension of carbonic dioxide in percentages of an atmosphere:-

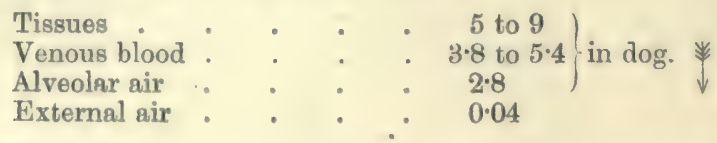

The arrow indicates the direction in which the gas passes, namely, in the direction of pressure from the tissues to the atmosphere.

' To be exact, the solubility of carbon dioxide in plasma is a little less than in pure water. 
In some other experiments, also on dogs, the following are the figures given :-

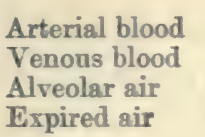

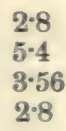

It will be seen from these figures that the tension of carbonic aciä in the venous blood (5.4) is higher than in the alveolar air (3.56); its passage into the alveolar air is therefore intelligible by the laws of diffusion. Diffusion, however, should cease when the tension of the gas in the blood and alveolar air are equal. But the transference goes beyond the establishment of such an equilibrium, for the tension of the gas in the blood continues to sink until it is, when the blood is arterial, ultimately less $(2 \cdot 8)$ than in the alveolar air.

The whole question is beset with great difficulties and contradictions. Analyses by different observers have given very different results, but if such figures as those just quoted are ultimately found to be correct, we can only explain this apparent reversal of a law of nature by supposing with Bohr that the alveolar epithelium possesses the power of excreting carbonic acid, just as the cells of secreting glands are able to select certain materials from the blood and reject others. Recent work by Bohr and Haldane has also shown that in all probability the same explanation-epithelial activity-must be called in to account for the absorption of oxygen. Haldane, in fact, states that the tension of oxygen in the blood is greater than in the atmosphere. In the swim-bladder of fishes (which is analogous to the lungs of mammals) the oxygen is certainly far in excess of anything that can be explained by mere diffusion. The storage of oxygen, moreover, ceases when the vagus nerves which supply the swim-bladder are divided.

Some continental observers have stated that certain noxious substances are ordinarily contained in expired air which are much more poisonous than carbonic acid, but researches in this country have entirely failed to substantiate this. If precautions be taken by absolute cleanliness to prevent admixture of the air with exhalations from skin, teeth, and clothes, the expired air only contains one noxious substance, and that is carbonic acid.

Tissue-Respiration.-Before the processes of respiration were fully understood the lungs were looked upon as the seat of combustion; they were regarded as the stove for the rest of the body where effete material was brought by the venous blood to be burnt up. When it was shown that the venous blood going to the lungs already contained 
carbonic acid, and that the temperature of the lungs is not greater than that of the rest of the body, this explanation had of necessity to be dropped.

Physiologists next transferred the seat of the combustion to the blood; but since then innumerable facts and experiments have shown that it is in the tissues themselves, and not in the blood, that combustion occurs. The methylene-blue experiments already described (p. 101) show this; and the following experiment is also quite conclusive. A frog can be kept alive for some time after salt solution is substituted for its blood. The metabolism goes on actively if the animal is kept in pure oxygen. The taking up of oxygen and giving out of carbonic acid must therefore occur in the tissues, as the animal has no blood. 


\section{LESSON $\mathrm{X}$}

\section{ORINE}

1. Test the reaction of urine to litmus paper.

2. Determine its specifie gravity by the urinometer.

3. Test for the following inorganic salts:

(a) Chlorides.-Acidulate with nitric acid and add silver nitrate; a white precipitate of silver chloride, soluble in ammonia. is produced. The object of acidulating with nitric acid is to prevent phosphates being precipitated by the nitrate of silver.

(b) Sulphates. - Acidulate with hydrochloric acid and add barium chloride. A white precipitate of barium sulphate is produced. Hydrochloric acid is again added first, to prevent precipitation of phosphates.

(c) Phosphates.-i. Add ammonia; a white crystalline precipitate of earthy (that is, calcium and magnesium) phosphates is produced. This becomes more apparent on standing. The alkaline (that is, sodium and potassium) phosphates remain in solution.

ii. Mix another portion of urine with half its volume of nitric acid; add amponium molrbdate, and boil. A yellow crystalline precipitate falls. This test is given by both kinds of phosphates.

4. Orea.-Take some urea crystals. Observe that they are readily soluble in water, and that effervescence occurs when fuming nitric acid (i.e. nitric acid containing nitrous acid in solution) is added to the solution. The efferrescence is due to the breaking up of the urea. Carbonic acid and nitrogen come off. A similar bubbling, due to evolution of nitrogen, occurs when an alkaline solution of sodium hypobromite is added to another portion of the solntion.

5. Heat some urea crystals in a dry test-tube. Biuret is formed, and ammonia comes off. Add a drop of copper-sulphate solution and a few drops of 20 -per-cent. potash. A rose-red colour is produced.

6. Quantitative estimation of urea.

For this purpose Dupré's apparatus (fig. 38) is the most convenient. "It consists of a bottle united to a measuring tube by indiarubber tubing. The measuring tube (an inverted burette will do very well) is placed within a cylinder of water, and can be raised and lowered at will. Measure 25 c.c. of alkaline solution of sodium hypobromite (made by mixing 2 c.c. of bromine with 23 c.c. of a 40 -per-cent. solution of caustic soda) into the bottle. Measure 5 c.c. of urine into a small tube, and lower it carefully, so that no urine spills, into the bottle. Close the bottle securely with a stopper perforated by a glass tube; this glass tube ${ }^{1}$ is connected to the measuring tube by indiarnbber tubing and a T-piece. The third limb of the $T$-piece is closed by a piece of indiambber tubing and a pinch-cock, seen at the top of the

' The efficiency of the apparatus is increased by having a glass bulb blown on this tube to prerent froth passing into the rest of the apparatus. This is not shown in the figure. 
figure. Open the pinch-cock and lower the measuring tube until the surface of the water with which the outer cylinder is filled is at the zero point of the graduation. Close the pinch-cock, and raise the measuring tube to ascertain

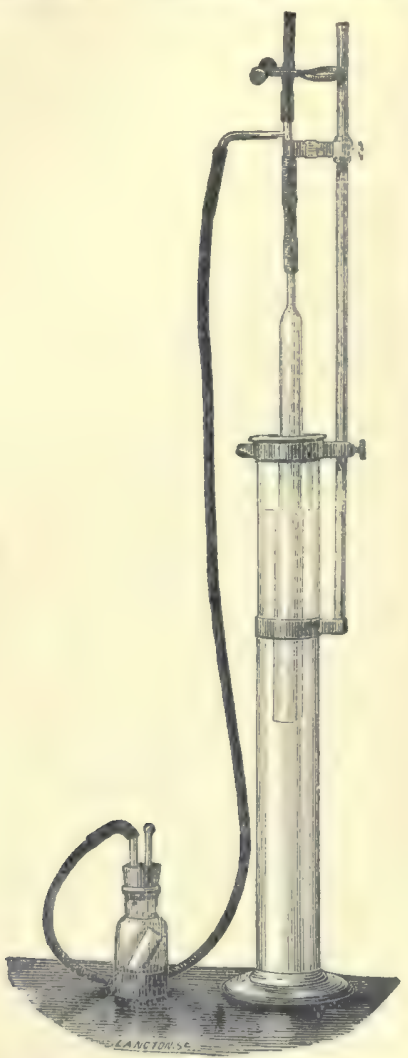

FIG. 38.-Dupré's urea apparatus. if the apparatus is air-tight. Then lower it again. Tilt the bottle so as to upset the urine, and shake well for a minute or so. During this time there is an evolution of gas. Then immerse the bottle in a large beaker containing water of the same temperature as that in the cylinder. After two or three minutes raise the measuring tube until the surfaces of the water inside and outside it are at the same level. Read off the amount of gas evolved. This is nitrogen. The earbonic acid resulting from the decomposition of urea has been absorbed by the excess of soda in the bottle. 35.4 c.c. of nitrogen are yielded by 0.1 gramme of urea. From this the quantity of urea in the 5 c.c. of urine and the percentage of urea can be calculated. If the total urea passed in the twenty-four hours is to be ascertained, the twenty-four hours' urine must be earefully measured and thoroughly mixed. A sample is then taken from the total for analysis; and then, by a simple sum in proportion, the total amount of urea is ascertained. Sometimes the measuring tubes supplied with this apparatus are graduated in divisions corresponding to percentages of urea.

7. Creatinine,-This substance may be deteeted by adding a little sodium nitro-prusside and caustic soda to the urine. A red colour develops which fades on boiling.

The kidney is a compound tubular gland, the tubules of which it is composed differing much in the character of the epithelium that lines them in various parts of their course. The true secreting part of the kidney is the glandular epithelium that lines the convoluted portions of the tubules; there is in addition to this what is usually termed the filtering apparatus: tufts of capillary blood vessels called the Malpighian glomeruli are supplied with afferent vessels from the renal artery; the efferent vessels that leave these have a smaller calibre, and thus there is high pressure in the Malpighian capillaries. Certain constituents of the blood, especially water and salts, pass 
through the thin walls of these ressels into the surrounding Bowman's capsule which forms the commencement of each renal tubule. Bowman's capsule is lined by a flattened epithelium, which is reflected over the capillary tuft. Though the process which occurs here is generally spoken of as a filtration, yet it is no purely mechanical process, but the cells exercise a selective influence, and prevent the albuminous constituents of the blood from escaping. During the passage of the water which leaves the blood at the glomerulus through the rest of the renal tubule, it gains the constituents urea, urates, \&c., which are poured into it by the secreting cells of the convoluted tubules.

The term excretion is better than secretion as applied to the kidney, for the constituents of the urine are not actually formed in the kidney itself (as, for instance, the bile is formed in the liver), but they are formed elsewhere; the kidney is simply the place where they are picked out from the blood and eliminated from the body.

\section{GENERAL CHARACTERS OF URINE}

Quantity.-A man of average weight and height passes from 1,400 to 1,600 c.c., or about $50 \mathrm{oz}$. daily. This contains about 50 grammes ( $1 \frac{1}{2} \mathrm{oz}$.) of solids. The urine should be collected in a tall glass ressel capable of holding 3,000 c.c., which should have a smooth-edged neck accurately covered by a ground-glass plate to exclude dust and aroid evaporation. The vessel, moreover, should be graduated so that the amount may be easily read off. From the total quantity thus collected in the twenty-four hours, samples should be drawn off for examination.

Colour.-This is some shade of yellow which raries considerably in health with the concentration of the urine. It appears to be due to a mixture of pigments: of these urobilin is the one of which we have the most accurate knowledge. Urobilin has a reddish tint and is ultimately derived from the blood pigment, and like bile pigment is an iron-free derivative of hæmoglobin. The bile pigment (and possibly also the hæmatin of the food) is in the intestines converted into stercobilin; most of the stercobilin leaves the body with the frees; but some is reabsorbed and is excreted with the urine as urobilin. Urobilin is very like the artificial reduction product of bilirubin called hydrobilirubin (see p. 73). Normal urine, however, contains very little urobilin. The actual body present is a chromogen or mother substance called urobilinogen, which by oxidation (such as occurs when the urine stands exposed to the air) is converted into 
the pigment proper. In certain diseased conditions the amount of urobilin is considerably increased.

The most abundant urinary pigment is a yellow one called urochrome. It shows no absorption bands. It is probably an oxidation product of urobilin (Riva, A. E. Garrod). (See Lesson XXVI.)

Reaction.-The reaction of normal urine is acid. This is not due to free acid, as the uric and hippuric acids in the urine are combined as urates and hippurates respectively. The acidity is due to acid salts, especially acid sodium phosphate. Under certain circumstances the urine becomes less acid and even alkaline; the most important of these are as follows:-

1. During digestion. Here there is a formation of free acid in the stomach, and a corresponding liberation of bases in the blood

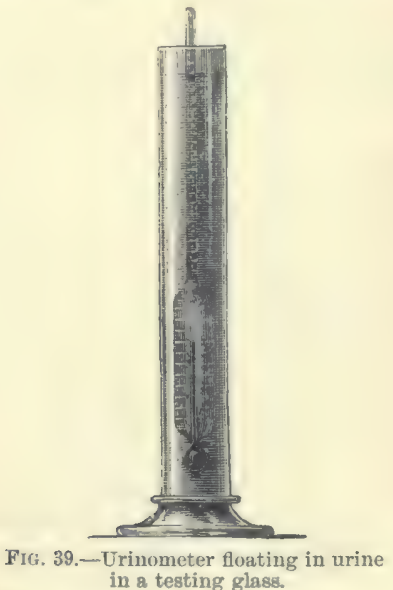

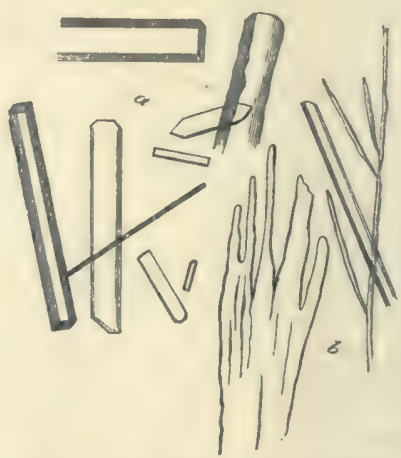

FIG. 40.-Crystals of ures : $a$, four-sided prisms : $b$, indefinite crystals, such as are usually formed from alcohol solutions.

which passing into the urine diminish its acidity, or even render it alkaline. This is called the alkaline tide; the opposite condition, the acid tide, occurs after a fast, for instance, before breakfast.

2. In herbivorous animals and vegetarians. The food here contains excess of alkaline salts of acids like tartaric, citric, malic, \&c. These acids are oxidised into carbonates, which passing into the urine give it an alkaline reaction.

Specific Gravity.-This should be taken in a sanpple of the twentyfour hours' urine with a good urinometer (see fig. 39).

The specific gravity varies inversely as the quantity of urine passed under normal conditions from 1015 to 1025 . A specific gravity below 1010 should excite suspicion of hydruria; one over 1030 of a febrile condition, or diabetes, a disease in which it may rise 
to 1050 . The specific grarity has, however, been known to sink as low as 1002 (after large potations, urina potus), or to rise as high as 1035 (after great sweating) in perfectly healthy persons.

Composition.--The following table gires the arerage amounts of the urinary constituents passed by a man in the twenty-four hours :-

Water
Total solids :
Urea :
Uric acid :
Hippurie acid
Creatinine
Pigment and other
Sulphuric acid
Phosphoric acid
Chlorine :
Ammonia :
Potassium :
Sodium :
Calcium :
Magnesium :

:

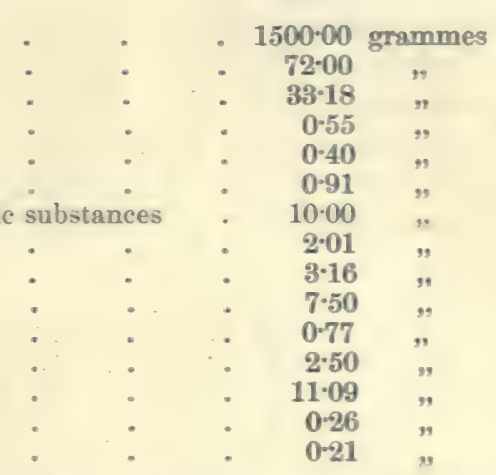

The most abundant constituents of the urine are water, urea, and sodium chloride. In the foregoing table the student must not be misled by seeing the names of the acids and metals separated. The acids and the bases are combined to form salts :- urates, chlorides, sulphates, phosphates, \&c.

\section{UREA}

Urea, or Carbamide, $\mathrm{CO}\left(\mathrm{NH}_{2}\right)_{2}$, is isomeric (that is, has the same empirical, but not the same structural formula) with ammonium cyanate $\left(\mathrm{NH}_{4}\right) \mathrm{CNO}$, from which it was first prepared synthetically by Wöhler in 1828. Since then it has been prepared synthetically in other ways. Wöhler's observation derives interest from the fact that this was the first organic substance which was prepared synthetically by chemists.

It may be crystallised out from the urine, and it is then found to be readily soluble both in water and in alcohol: it has a saltish taste, and is neutral to litmus paper. The form of its crystals is shown in fig. 40 .

When treated with nitric acid, nitrate of urea $\left(\mathrm{CON}_{2} \mathrm{H}_{4} \cdot \mathrm{HNO}_{3}\right)$ is formed; this crystallises in octahedra, lozenge-shaped tablets, or hexagons (fig. 41, a). When treated with oxalic acid, flat or prismatic crystals of urea oxalate $\left(\mathrm{CON}_{2} \mathrm{H}_{4} \cdot \mathrm{H}_{2} \mathrm{C}_{2} \mathrm{O}_{4}+\mathrm{H}_{2} \mathrm{O}\right)$ are formed (fig. 41, b). 
These crystals may be readily obtained in an impure form by adding excess of the respective acids to urine which has been concentrated to a third or a quarter of its bulk. ${ }^{1}$

Under the influence of an organised ferment, the torula or micrococcus ureæ, which grows readily in stale urine, urea takes up water, and is converted into ammonium carbonate $\left[\mathrm{CON}_{2} \mathrm{H}_{4}+2 \mathrm{H}_{2} \mathrm{O}=\right.$ $\left(\mathrm{NH}_{4}\right)_{2} \mathrm{CO}_{3}$. Hence the ammoniacal odour of putrid urine.

By means of nitrous acid, urea is broken up into carbonic acid, water, and nitrogen, $\mathrm{CON}_{2} \mathrm{H}_{4}+2 \mathrm{HNO}_{2}=\mathrm{CO}_{2}+3 \mathrm{H}_{2} \mathrm{O}+2 \mathrm{~N}_{2}$. This may be used as a test for urea. Add fuming nitric acid (i.e. nitric acid containing nitrous acid in solution) to a solution of urea, or to urine; an abundant evolution of gas bubbles takes place.

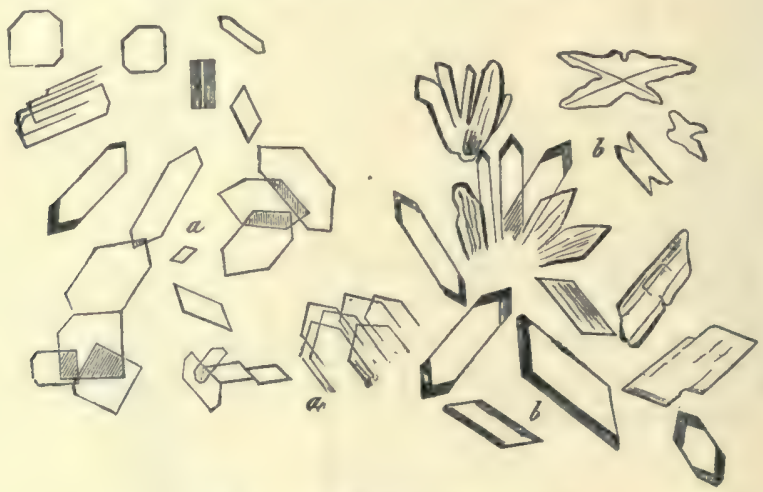

FIG. 41. $-a$, nitrate ; $b$, oxaiate of urea.

Hypobromite of soda decomposes urea in the following way :-

$$
\begin{aligned}
& \mathrm{CON}_{2} \mathrm{H}_{4}+3 \mathrm{NaBrO}=\mathrm{CO}_{2}+\mathrm{N}_{2}+2 \mathrm{H}_{2} \mathrm{O}+3 \mathrm{NaBr} \\
& \text { [urea] } \begin{array}{c}
\text { [sodium] } \\
\text { hypobromite] }
\end{array} \begin{array}{c}
\text { [carbonic [nitrogen] [water] } \\
\text { aoid] }
\end{array} \text { bromide] }
\end{aligned}
$$

This reaction is important, for on it one of the readiest methods for estimating urea depends. There have been various pieces of apparatus invented for rendering the analysis easy ; but the one described in the practical exercise at the head of this lesson appears to be the best. If the experiment is performed as directed, nitrogen is the only gas that comes off, the carbonic acid being absorbed by excess of soda. The amount of nitrogen is a measure of the amount of urea.

The quantity of urea excreted is somewhat variable, the chief cause of variation being the amount of proteid food ingested. In a man in a

1 The preparation of urea nitrate and uren oxalate is postponed to the next lesson, when other microscopic crystals will also be under examination. 
state of equilibrium the quantity of urea excreted daily averages 33 grammes (500 grains). The normal percentage in human urine is 2 per cent.; but this also varies, because the concentration of the urine varies considerably in health. In dogs it may be 10 per cent. The excretion of urea is usually at a maximum three hours after a meal, especially after a meal rich in proteids. The urea does not come, however, direct from the food; the food must be first assimilated, and become part of the body before it can break down to form urea. An exception to this rule is to be found in the case of the amidoacids, especially leucine and arginine, which are formed in the intestinal canal from proteids during digestion. These substances are carried to the liver and converted into urea ; but only a very small fraction of the urea in the urine is formed in this way. Food increases the elimination of urea because it stimulates the tissues to increased activity ; their waste nitrogenous products are converted into urea, which, passing into the blood, is directly excreted by the kidneys. The greater the amount of proteid food given, the more waste products do the tissues discharge from their protoplasm, in order to make room for the new proteid which is built into its substance.

Muscular exercise has little immediate effect on the amount of urea discharged. During intense muscular work there is a slight immediate increase of urea, but this is quite insignificant when compared with the increase of work. This is strikingly different from what occurs in the case of carbonic acid; the more the muscles work, the more carbonic acid do they send into the renous blood, which is rapidly discharged by the expired air. Careful research has, howerer, shown that an increase of nitrogenous waste does occur on muscular exertion, but appears as urea in the urine to only a slight extent on the day of the work; the greater part is excreted during the next day.

Where is Urea formed?-The older authors considered that it was formed in the kidneys, just as they also erroneously thought that carbonic acid was formed in the lungs. Prévost and Dumas were the first to show that after complete extirpation of the kidneys the formation of urea goes on, and that it accumulates in the blood and tissues. Similarly, in those cases of disease in which the kidneys cease work, urea is still formed and accumulates. This condition is called urcemia (or urea in the blood), and unless the urea be discharged from the body the patient dies. There is no doubt, however, that it is not urea but some antecedent of urea that acts most poisonously, and is the cause of death, for considerable quantities of urea can be injected into the circulation without untoward results.

Where, then, is the seat of urea formation? Nitrogenous waste 
occurs in all the living tissues, and the principal final result of this proteid metabolism is urea. It may not be that the formation of urea is perfected in each tissue, for if we look to the most abundant tissue, the muscular tissue, very little urea is to be found. Yet there can be no doubt that the chief place from which urea uitimately comes is the muscular tissue. Some intermediate step occurs in the muscles; the final steps occur elsewhere.

In muscles we find a substance called creatine in fairly large quantities. If creatine is injected into the blood it is discharged as creatinine. But there is very little creatinine in normal urine; what little there is can be nearly all accounted for by the creatine in the food; if the muscular creatine and creatinine are discharged as urea, they must undergo some further change before they leave the muscle.

Similarly, other cellular organs, spleen, lymphatic glands, secreting glands, participate in the formation of urea; but the most important appears to be the liver: at any rate this is the organ where the final changes take place. The urea is then carried by the blood to the kidney, and is there excreted.

The facts of experiment and of pathology point very strongly in support of the theory that urea is formed in the liver. The principal are the following:-

1. After removal of the liver in such animals as frogs, urea formation almost ceases, and ammonia is found in the urine instead.

2. In mammals, the extirpation of the liver is such a serious operation that the animals die. But the liver of mammals can be very largely thrown out of gear by the operation known as Eck's fistula, which consists in connecting the portal vein directly to the inferior vena cava. Under these circumstances the liver receives blood only by the hepatic artery. The amount of urea is lessened, and its place is taken by ammonia.

3. When degenerative changes occur in the liver, as in cirrhosis of that organ, the urea formed is much lessened, and its place is taken by ammonia. In acute yellow atrophy urea is almost absent in the urine, and, again, there is considerable increase in the ammonia. In this disease leucine and tyrosine are also found in the urine; undue stress should not be laid upon this latter fact, for the small amounts of leucine and tyrosine found doubtless originate in the intestine, and, escaping further decomposition in the degenerated liver, pass as such into the urine.

We have to consider next the intermediate stages between proteid and urea. A few years ago Drechsel succeeded in artificially pro- 
ducing urea from casein. More recent work has shown that this is true for other proteids also. If a proteid is decomposed by hydrochloric acid, a little stannous chloride being added to prevent oxidation, a number of products are obtained, such as ammonium salts, leucine, tyrosine, aspartic and glutaminic acids. This was known before, so the chief interest centres round two new substances, precipitable by phosphotungstic acid. One of these is called lysine $\left(\mathrm{C}_{6} \mathrm{H}_{14} \mathrm{~N}_{2} \mathrm{O}_{2}\right.$, probably di-amido-caproic acid); the other was first called lysatinine. Hedin then showed that lysatinine is a mixture of lysine with another base called arginine $\left(\mathrm{C}_{6} \mathrm{H}_{14} \mathrm{~N}_{4} \mathrm{O}_{2}\right)$; it is from the arginine that the urea comes in the experiment to be next described. Arguing from some resemblances between this substance and creatine, Drechsel expected to be able to obtain urea from it, and his expectation was confirmed by experiment. He took a silver compound of the base, boiled it with barium carbonate, and after twenty-five minutes' boiling obtained urea. Drechsel's comparison of arginine to creatine has turned out to be correct; on decomposition it breaks up into di-amido-valerianic acid and cyanamide $\left(\mathrm{CN} . \mathrm{NH}_{2}\right)$ from which the urea originates. (Schulze and Winterstein.) Lysine and arginine are two of the hexone bases (see p. 32).

It is, however, extremely doubtful whether the chemical decompositions produced in laboratory experiments on proteids are comparable with those occurring in the body. Many physiologists consider that the amido-acids are intermediate stages in the metabolic processes that lead to the formation of urea from proteids. We have already alluded to this question in relation to the creatine of muscle, and we are confronted with the difficulty that injection of creatine into the blood leads to an increase not of urea, but of creatinine in the urine. If creatine is an intermediate step, it must undergo some further change before it leaves the muscle. Other amido-acids, such as glycocine (amido-acetic acid) and leucine (amido-caproic acid) and arginine, are to be included in the same category. The facts upon which such a theory depends are (1) that the introduction of glycocine or leucine into the bowel, or into the circulation, leads to an increase of urea in the urine; there is, however, no evidence that tyrosine acts in this way; and (2) that amido-acids appear in the urine of patients suffering from acute yellow atrophy of the liver. Then again it is perfectly true that, in the laboratory, urea can be obtained from creatine, and also from uric acid, but such experiments do not prove that creatine or uric acid is a normally intermediate product of urea formation in the body. Still, if we admit for the sake of argument 
that amido-acids are normally intermediate stages in proteid metabolism, and glance at their formulæ-

$$
\begin{array}{ll}
\text { Glycocine, } \mathrm{C}_{2} \mathrm{H}_{5} \mathrm{NO}_{2} & \text { Creatine, } \mathrm{C}_{4} \mathrm{H}_{9} \mathrm{~N}_{3} \mathrm{O}_{2} \\
\text { Leucine, } \mathrm{C}_{6} \mathrm{H}_{13} \mathrm{NO}_{2} & \text { Arginine, } \mathrm{C}_{6} \mathrm{H}_{14} \mathrm{~N}_{4} \mathrm{O}_{2}
\end{array}
$$

-we see that the carbon atoms are more numerous than the nitrogen atoms. In urea, $\mathrm{CON}_{2} \mathrm{H}_{4}$, the reverse is the case. The amidoacids must therefore be split into simpler compounds, which unite with one another to form urea. Urea formation is thus in part synthetic. There have been various theories advanced as to what these simpler compounds are. Some have considered that cyanate, others that carbamate, and others still that carbonate of ammonium is formed. Schröder's work proves that ammonium carbonate is one of the urea precursors, if not the principal one. The equation which represents the reaction is as follows:-

$$
\begin{aligned}
& \left(\mathrm{NH}_{4}\right)_{2} \mathrm{CO}_{3}-2 \mathrm{H}_{2} \mathrm{O}=\mathrm{CON}_{2} \mathrm{H}_{4} \\
& \text { [ammonium [water] [urea] }
\end{aligned}
$$

Schröder's principal experiment was this : a mixture of defibrinated blood and ammonium carbonate was injected into the liver by the portal vein; the blood leaving the liver by the hepatic vein was found to contain urea in great abundance. This does not occur when the same experiment is performed with any other organ of the body, so that Schröder's experiments also prove the great importance of the liver in urea formation. Similar results were obtained by Nencki with ammonium carbamate.

There is, however, no necessity to suppose that the formation of amido-acids is a necessary preliminary to urea formation. The conversion of the leucine and arginine formed in the intestine into ammonium salts and then into urea does certainly occur, but this only accounts for quite an insignificant fraction of the urea in the urine. If this also occurs in tissue metabolism, we ought to find considerable quantities of leucine, glycocine, creatine, arginine, and such substances in the blood leaving the various tissues and entering the liver; but we do not. We do, however, constantly find ammonia, which, after passing into the blood or lymph, has united with carbonic acid to form either carbonate or carbamate of ammonium. It is quite probable that the nitrogenous waste that leaves the muscles and other tissues is split off from them as ammonia, and not in the shape of large molecules of amido-acid which are subsequently converted into ammonia. The experiments outside the body which most closely imitate those occurring within the body are those of Drechsel, 
in which he passed strong alternating currents through solutions of proteid-like materials. Such alternating currents are certainly absent in the body, but their effect, which is a rapidly changing series of small oxidations and reductions, is analogous to metabolic processes; under such circumstances the carbon atoms are burnt off as carbon dioxide, the nitrogen being split off in the form of ammonia, and by the union of these two substances ammonium carbonate is formed.

The following structural formulæ show the relationship between ammonium carbonate, ammonium carbamate, and urea.

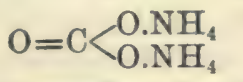

[ammonium carbonate]

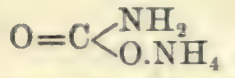

[ammonium carbamate]

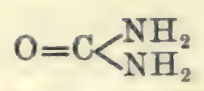

[urea or carbamide]

The loss of one molecule of water from ammonium carbonate produces ammonium carbamate; the loss of a second molecule of water produces urea.

\section{THE INORGANIC CONSTITUENTS OF URINE}

The inorganic or mineral constituents of urine are chiefly chlorides, phosphates, sulphates, and carbonates; the metals with which these are in combination are sodium, potassium, ammonium, calcium, and magnesium. The total amount of these salts varies from 19 to 25 grammes daily. The most abundant is sodium chloride, which averages in amount 10 to 13 grammes per diem. These substances are derived from two sources-first from the food, and secondly as the result of metabolic processes. The chlorides and most of the phosphates come from the food ; the sulphates and some of the phosphates are a result of metabolism. The salts of the blood and of the urine are much the same, with the important exception that, whereas the blood contains only traces of sulphates, the urine contains abundance of these salts. The sulphates are derived from the changes that occur in the proteids of the body ; the nitrogen of proteids leaves the body as urea and uric acid; the sulphur of the proteids is oxidised to form sulphuric acid, which passes into the urine in the form of sulphates. The execretion of sulphates, moreover, runs parallel to that of urea. The chief tests for the various salts have been given in the practical exercises at the head of this lesson.

Chlorides. - The chief chloride is that of sodium. The ingestion of sodium chloride is followed by its appearance in the urine, some on the same day, some on the next day. Some is decomposed to form the hydrochloric acid of the gastric juice. The salt, in passing through 
the body, fulfils the useful office of stimulating metabolism and excretion.

Sulphates.-The sulphates in the urine are principally those of potassium and sodium. They are derived from the metabolism of proteids in the body. Only the smallest trace enters the body with the food. Sulphates have an unpleasant bitter taste (for instance, Epsom salts); hence we do not take food that contains them. The sulphates vary in amount from 1.5 to 3 grammes daily.

In addition to these sulphates there is a small quantity of sulphuric acid comprising about one-tenth of the total which is combined with organic radicles; the compounds are known as ethereal sulphates, and they originate from putrefactive processes occurring in the intestine. The most important of these ethereal sulphates are phenyl sulphate of potassium and indoxyl sulphate of potassium. The latter originates from the indole formed in the intestine, and as it yields indigo when treated with certain reagents it is sometimes called indican. It is very important to remember that the indican of urine is not the same thing as the indican of plants. Both yield indigo, but there the resemblance ceases.

The equation representing the formation of potassium phenylsulphate is as follows:--

$$
\underset{\text { [pheno!] }}{\mathrm{C}_{6} \mathrm{H}_{5} \mathrm{OH}}+\underset{\text { hydrogeu sulphate] }}{\mathrm{SO}_{2}<} \underset{\mathrm{OK}}{\mathrm{OH}}=\underset{\substack{\text { [potassium } \\ \text { phenyl-sulphate] }}}{\mathrm{OO}_{2}<\mathrm{OC}_{6} \mathrm{H}_{5}}+\underset{\mathrm{O}_{2} \mathrm{O}}{\mathrm{O}_{\text {[water }}}
$$

The formation of potassium indoxyl-sulphate may be represented as follows :- Indole, $\mathrm{C}_{6} \mathrm{H}_{4}<\mathrm{NH}$.CH , on absorption is converted into indoxyl : $\mathrm{C}_{6} \mathrm{H}_{4}<\mathrm{NH}$. OH.CH

Indoxyl then interacts with potassium hydrogen sulphate as follows :-

$$
\underset{\text { [indoxgl] }}{\mathrm{C}_{8} \mathrm{H}_{7} \mathrm{NO}}+\underset{\substack{\text { [potassium } \\ \text { hydrogen sulphate] }}}{\mathrm{SO}_{2}<\underset{\mathrm{OK}}{\mathrm{OH}}=\underset{\substack{\text { [potassium } \\ \text { indoxyl-sulphate] }}}{\mathrm{OOK}_{2}}<\mathrm{OC}_{8} \mathrm{H}_{6} \mathrm{~N}}+\underset{\mathrm{H}_{2} \mathrm{O}}{\text { [water] }}
$$

The formation of such sulphates is important; the aromatic substances liberated by putrefactive processes in the intestine are poisonous, but their conversion into ethereal sulphates renders them innocuous.

Carbonates.-Carbonates and bicarbonates of sodium, calcium, magnesium, and ammonium are only present in alkaline urine. They arise from the curbonates of the food, or from vegetable acids (malic, 
tartaric, \&c.) in the food. They are, therefore, found in the urine of herbivora and vegetarians, whose urine is thus rendered alkaline. Urine containing carbonates becomes, like saliva, cloudy on standing, the precipitate consisting of calcium carbonate, and also phosphates.

Phosphates.-Two classes of phosphates occur in normal urine :-

(1) Alkaline phosphates - that is, phosphates of sodium (abundant) and potassium (scanty).

(2) Earthy phosphates-that is, phosphates of calcium (abundant) and magnesium (scanty).

The composition of the phosphates in urine is liable to variation. In acid urine the acidity is due to the acid salts. These are chiefly sodium dihydrogen phosphate, $\mathrm{Na}_{2} \mathrm{PO}_{4}$, and calcium dihydrogen phosphate, $\mathrm{Ca}\left(\mathrm{H}_{2} \mathrm{PO}_{4}\right)_{2}$.

In neutral urine, in addition, disodium hydrogen phosphate $\left(\mathrm{Na}_{2} \mathrm{HPO}_{4}\right)$, calcium hydrogen phosphate, $\mathrm{Ca}_{2} \mathrm{HPO}_{4}$, and magnesium hydrogen phosphate, $\mathrm{MgHPO}_{4}$, are found. In alkaline urine there may be instead of, or in addition to the above, the normal phosphates of sodium, calcium, and magnesium $\left[\mathrm{Na}_{3} \mathrm{PO}_{4}, \mathrm{Ca}_{3}\left(\mathrm{PO}_{4}\right)_{2}, \mathrm{Mg}_{3}\left(\mathrm{PO}_{4}\right)_{2}\right]$.

The earthy phosphates are precipitated by rendering the urine alkaline by ammonia. In decomposing urine ammonia is formed from the urea: this also precipitates the earthy phosphates. The phosphates most frequently found in the white creamy precipitate which occurs in decomposing urine are-

(1) Triple phosphate or ammonio-magnesium phosphate $\left(\mathrm{NH}_{4} \mathrm{MgPO}_{4}+6 \mathrm{H}_{2} \mathrm{O}\right)$. This crystallises in ' coffin-lid' crystals (see fig. 42) or feathery stars.

(2) Stellar phosphate, or calcium phosphate, which crystallises in star-like clusters of prisms.

As a rule normal urine gives no precipitate when it is boiled; but sometimes neutral, alkaline, and occasionally faintly acid urines give a precipitate of calcium phosphate when boiled; this precipitate is amorphous, and is liable to be mistaken for albumin. It may be distinguished readily from albumin, as it is soluble in a few drops of acetic acid, whereas coagulated proteid does not dissolve.

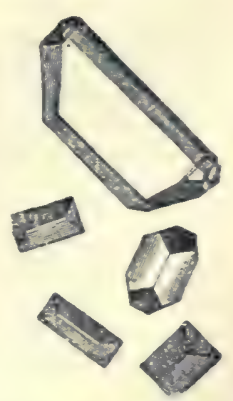

FIG. 42-Ammoniomagnesium or triple phosphate.

The phosphoric acid in the urine chiefly originates from the phosphates of the food, but is partly a decomposition product of the phosphorised organic materials in the body, such as lecithin and nuclein. The amount of $\mathrm{P}_{2} \mathrm{O}_{5}$ in the twenty-four hours' urine varies from 2.5 to 3.5 grammes, of which the earthy phosphates contain about half (1 to $1.5 \mathrm{gr}$.). 


\section{LESSON XI}

\section{URINE (continued)}

1. Urea Nitrate.-Evaporate some urine in a capsule to a quarter of its bulk. Pour the concentrated urine into a watch-glass; let it cool, and add a few drops of strong, but not fuming, nitric acid. Crystals of urea nitrate separate out. Examine these microscopically.

2. Urea 0xalate-Concentrate the urine as in the last exercise, and add oxalic acid; crystals of urea oxalate separate out. Examine these microseopically.

3. Uric Acid.-Examine microscopically the crystals of uric acid in some urine, to which 5 per cent. of hydrochloric acid has been added twenty-four hours previously. Note that they are deeply tinged with pigment, and to the naked eye look like granules of cayenne pepper.

When microscopically examined, the crystals are seen to be large bundles, principally in the shape of barrels, with spicules projecting from the ends, and whetstones. If oxalic acid is used instead of hydrochloric acid in this experiment, the crystals are smaller, and more closely resemble those observed in pathological urine in cases of uric acid gravel (see fig. 43).

Dissolve the crystals in caustic potash and then carefully add excess of hydrochloric acid. Small erystals of uric acid again form.

Murexide Test.-Place a little uric acid, or a urate (for instance, serpent's urine), in a capsule; add a little dilute nitric acid and evaporate to dryness. A yellowish-red residue is left. Add a little ammonia carefully. The residue turns to violet. This is due to the formation of murexide or purpurate of anmonia. On the addition of potash the colour becomes bluer.

Schiff's Test.-Dissolve some uric acid in sodium carbonate solution. Put a drop of this on blotting paper, add a drop of silver nitrate, and warm gently; the black colour of reduced silver is seen on the paper.

4. Deposit of Urates or Lithates (Lateritious Deposit).-The specimen of urine from the hospital contains excess of urates, which have become deposited on the urine becoming cool. They are tinged with pigment (uroerythrin), and have a pinkish colour, like brickdust; hence the term 'lateritious.' Examine microscopically. The deposit is usually amorphous-that is, noncrystalline. Sometimes crystals of calcium oxalate (envelope crystalsoctahedra) are seen also ; these are colourless.

The deposit of urates dissolves on heating the urine.

5. Deposit of Phosphates.-Another specimen of pathological urine contains excess of phosphates, which have formed a white deposit on the urine becoming alkaline. This precipitate does not dissolve on heating; it may be increased. It is, however, soluble in acetic acid. Examine microscopically for coffin-lid erystals of triple phosphate (ammonio-magnesium phosphate), for crystals of stellar (calcium) phosphate, and for mucus. Mucus is floceulent to the naked eye, amorphous to the microscope.

N.B.-On boiling neutral, alkaline, or even faintly acid urine it may become turbid from deposition of phosphates. The solubility of this deposit in 
a few drops of acetic acid distinguishes it from albumin, for which it is liable to be mistaken.

Some of the facts described in the foregoing exercises bave been already dwelt upon in the preceding lesson. They are, however, conveniently grouped together here, as all involve the use of the microscope.

IVe have now studied urea, the principal nitrogenous constituent of urine, at some length. There are still left for our consideration a number of other nicrogenous constituents, the most important of which are uric acid, hippuric acid, and creatinine.

\section{URIC ACID}

Uric acid $\left(\mathrm{C}_{5} \mathrm{~N}_{4} \mathrm{H}_{4} \mathrm{O}_{3}\right)$ is in mammals the medium by which only a small quantity of nitrogen is excreted from the body. It is, however, in birds and reptiles the principal nitrogenous constituent of their urine. It is not present in the free state, but is combined with bases to form urates.

It may be obtained from human urine by adding 5 c.c. of hydrochloric acid to 100 c.c. of the urine, and allowing the mixture to stand for twelve to twenty-four hours. The crystals which form are deeply tinged with urinary pigment, and though by repeated solution in caustic soda or potash, and reprecipitation by hydrochloric acid, they may be obtained fairly free from pigment, pure uric acid is more readily obtained from the solid urine of a serpent or bird, which consists principally of the acid ammonium urate. This is dissolved in soda, and then the addition of hydrochloric acid produces as before the crystallisation of uric acid from the solution.

The pure acid crystallises in colourless rectangular plates or prisms. In striking contrast to urea it is a most insoluble substance, requiring for its solution 1,900 parts of hot and 15,000 parts of cold water. The

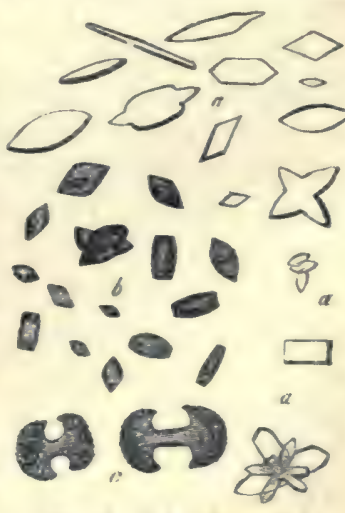

PIG. 43.- - Tric aciul crystals. forms which uric acid assumes when precipitated from human urine, either by the addition of hydrochloric acid or in certain pathological processes, are very various, the most frequent being the whetstone shape ; there are also bundles of crystals resembling sheaves, barrels, and dumb-bells (see fig. 43).

The murexide test which bas just been described among the 
practical exercises is the principal test for uric acid. The test has received the name on account of the resemblance of the colour to the purple of the ancients, which was obtained from certain snails of the genus Murex.

Another reaction that uric acid undergoes (though it is not applicable as a test) is that on treatment with certain oxidising reagents urea and oxalic acid can be obtained from it. It is, however, doubtful whether a similar oxidation occurs in the normal metabolic processes of the body (see p. 113).

Uric acid is dibasic, and thus there are two classes of urates-the normal urates and the acid urates. A normal urate is one in which two atoms of the hydrogen are replaced by two of a monad metal like sodium; an acid urate is one in which only one atom of hydrogen is thus replaced. The formulæ would be-

$$
\begin{aligned}
\mathrm{C}_{5} \mathrm{H}_{4} \mathrm{~N}_{4} \mathrm{O}_{3} & =\text { uric acid } \\
\mathrm{C}_{5} \mathrm{H}_{3} \mathrm{NaN}_{4} \mathrm{O}_{3} & =\text { acid sodium urate } \\
\mathrm{C}_{5} \mathrm{H}_{2} \mathrm{Na}_{2} \mathrm{~N}_{4} \mathrm{O}_{3} & =\text { normal sodium urate }
\end{aligned}
$$

The acid sodium urate is the chief constituent of the pinkish deposit of urates, which, as we have already stated, is called the lateritious deposit.

The quantity of uric acid excreted by an adult varies from 7 to 10 grains $(0.5$ to 0.75 gramme) daily.

The best method for determining the quantity of uric acid in the urine is that of Hopkins. Ammonium chloride in crystals is added to the urine until no more will dissolve. This saturation completely precipitates all the uric acid in the form of ammonium urate. After standing for two hours the precipitate is collected on a filter, washed with saturated solution of ammonium chloride, and then dissolved in weak alkali. From this solution the uric acid is precipitated by neutralising with hydrochloric acid. The precipitate of uric acid is collected on a weighed filter, dried and weighed, or titration may be performed with potassium permanganate (see Advanced Course).

Origin of Uric Acid.-Uric acid is not made by the kidneys. When the kidneys are removed uric acid continues to be formed and accumulates in the organs, especially in the liver and spleen. The liver has been removed from birds, and uric acid is then hardly formed at all, its place being taken by ammonia and lactic acid. It is therefore probable that ammonia and lactic acid are normally synthesised in the liver to form uric acid.

The prinoipal conditions which lead to an increase of uric acid in the urine are- 
1. Increase of meat diet and diminution of oxidation processes, such as occur in people with sedentary habits.

2. Increase of white corpuscles in the blood, especially in the disease known as leucocythæmia. This latter fact is of great interest, as leucocytes contain large quantities of nuclein. Nuclein yields nitrogenous bases which are closely related to uric acid.

Purine Substances.-The bases just alluded to are sometimes called the xanthine bases, because xanthine is a prominent member of the group. Sometimes they are termed the nuclein bases, because of their origin from nuclein. Another name they have received is the alloxuric bases, because they contain in combination two radicles, one of alloxan, and the other of urea. Emil Fischer's recent work, however, has shown that they are to be rather regarded as derivatives of a substance he has named purine; hence the name by which they are generally called now, the purine bases. The empirical formulæ for purine, the purine bases, and uric acid are as follows :-

\begin{tabular}{|c|c|c|c|}
\hline Purine . & $\mathrm{C}_{5} \mathrm{H}_{4} \mathrm{~N}_{4}$ & & \\
\hline Hypoxanthine & . $\mathrm{C}_{5} \mathrm{H}_{4} \mathrm{~N}_{4} \mathrm{O}$ & Monoxypurine & \\
\hline Xanthine. & - $\mathrm{C}_{5} \mathrm{H}_{4} \mathrm{~N}_{4} \mathrm{O}_{2}$ & Dioxypurine & Purine \\
\hline Adenine. & . $\mathrm{C}_{5} \mathrm{H}_{4} \mathrm{~N}_{4} \cdot \mathrm{NH}$ & Amino-purine & bases \\
\hline Guanine & . $\mathrm{C}_{5} \mathrm{H}_{4} \mathrm{~N}_{4} \mathrm{O} . \mathrm{NH}$ & Amino-oxypurine & \\
\hline Uric acid. & . $\mathrm{C}_{5} \mathrm{H}_{4} \mathrm{~N}_{4} \mathrm{O}_{3}$ & Trioxy-purine & \\
\hline
\end{tabular}

There are a vast number of purine derivatives, but only a few of them have at present any physiological importance. Others in addition to those already enumerated are theophylline (dimethyl-xanthine), theobromine (also a dimethyl-xanthine), caffeine (trimethyl-xanthine); these are of interest, as they occur in tea, cocos, and coffee. A few words more may be added in respect to those in our list.

Purine itself has never been discovered in the body. It has the following structural formula :

$$
\begin{gathered}
\mathrm{N}=\mathrm{C}-\mathrm{H} \\
\mathrm{H}-\underset{\mathrm{C}}{\mathrm{C}} \stackrel{\mathrm{C}}{\mathrm{N}}-\stackrel{\mathrm{NH}}{\mathrm{C}}-\mathrm{N} \\
\mathrm{N}-\mathrm{H}
\end{gathered}
$$

The purine nucleus is depicted in the next formula, and its atoms have been empirically numbered as shown for convenience of description :-

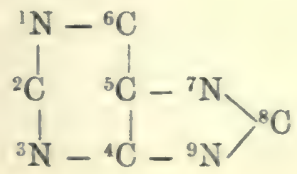


Hypoxanthine or Sarcine is found in the body tissues and fluids, and in the urine. It is derived from some nucleins, especially those from fishes' spermatozow. It may be termed 6-oxypurine, as the oxygen is attached to the atom numbered 6 in the purine nucleus.

Xanthine is found with hypoxanthine in the body, and has been obtained from a number of nucleins (from spermatozoa, thymus, pancreas, \&c.). It is 2, 6-dioxypurine, its oxygen atoms being attached to the atoms numbered 2 and 6 in the purine nucleus.

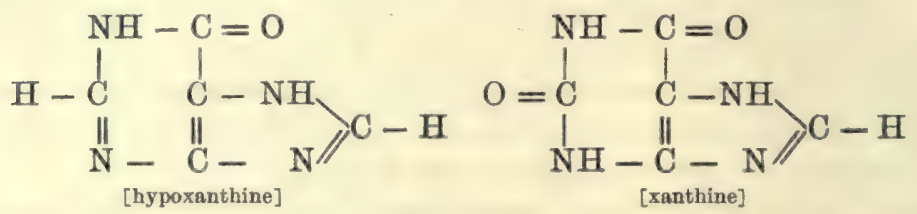

Adenine is found in the tissues, blood, and urine. It is obtained from several nucleins, but especially from the nuclein derived from the thymus. It is 6-rmino-purine.

Guanine is also a decomposition product of nucleins, especially of that obtained from the pancreas. Combined with calcium it gives the brilliancy to the scales of fishes, and is also found in the bright tapetum of the eyes in these animals. It is a constituent of guano, and here is probably derived from the fish eaten by marine birds. It is 2-amino-6-oxypurine.<smiles></smiles><smiles>CC(N)=C(NC#N)C(N)=O</smiles>

Uric Acid is 2, 6, 8-trioxypurine.<smiles>O=C1NC(=O)C2NC(=O)NC2N1</smiles>

We thus see the close relationship between uric acid and the nuclein bases. Leaving aside other possible ways in which uric acid is undoubtedly formed in the organism, we have here a way in which uric acid may arise by oxidation from the nuclein bases and thus ultimately from the nuclei of cells. Certain forms of diet increase uric acid formation by leading to an increase of leucocytes 
and consequently increase in the metabolism of their nuclei; some investigators think, however, that the increase is chiefly due to nuclein in the food. The question is not yet settled.

\section{HIPPURIC ACID}

Hippuric acid $\left(\mathrm{C}_{9} \mathrm{H}_{9} \mathrm{NO}_{3}\right)$, combined with bases to form hippurates, is present in small quantities in human urine, but in large quantities in the urine of herbivora. This is dùe to the food of herbivora containing substances belonging to the aromatic group-the benzoic acid series. If benzoic acid is given to

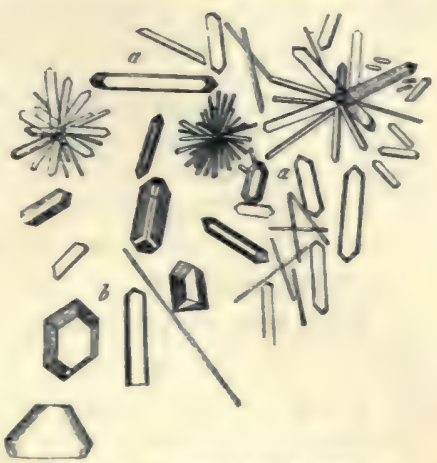

Fig. 44.-Hippuric acid ergstals. a man, it unites with glycocine with the elimination of a molecule of water, and is excreted as hippuric acid-

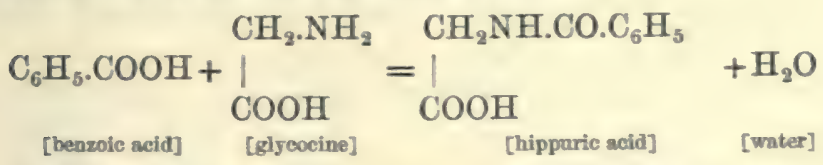

This is a well-marked instance of synthesis carried out in the animal body, and experimental investigation shows that it is accomplished by the living cells of the kidney itself ; for if a mixture of glycocine, benzoic acid, and blood is injected through the kidney (or mixed with a minced kidney just removed from the body of an animal), their place is found to have been taken by hippuric acid.

\section{CREATININE}

The creatinine in the urine is nearly all derived from the creatine contained in the meat of the food. There is, however, a small amount in the urine even during starvation: this represents a small percentage of creatine from the muscles.

Sarcosine $\left(\mathrm{C}_{3} \mathrm{H}_{7} \mathrm{NO}_{2}\right)$ united to cyanamide $\left(\mathrm{CN} . \mathrm{NH}_{2}\right)$ yields creatine $\left(\mathrm{C}_{4} \mathrm{H}_{9} \mathrm{~N}_{3} \mathrm{O}_{2}\right)$. Cyanamide plus water yields urea $\left(\mathrm{CON}_{2} \mathrm{H}_{4}\right)$.

The formation of creatinine from creatine is represented in the following equation :-

$$
\mathrm{C}_{4} \mathrm{H}_{9} \mathrm{~N}_{3} \mathrm{O}_{2}-\mathrm{H}_{2} \mathrm{O}=\mathrm{C}_{4} \mathrm{H}_{7} \mathrm{~N}_{3} \mathrm{O}
$$

Creatine and creatinine are of considerable chemical interest, because urea can be obtained from them as one of their decomposition products 
in the laboratory; the equation which represents the formation of urea from creatine is as follows:-

$$
\underset{\text { [creatine] }}{\mathrm{C}_{4} \mathrm{H}_{9} \mathrm{~N}_{3} \mathrm{O}_{2}}+\underset{\text { [water] }}{\mathrm{H}_{2} \mathrm{O}}=\underset{\text { [sarcosine] }}{\mathrm{C}_{3} \mathrm{H}_{7} \mathrm{NO}_{2}}+\underset{\text { [urea] }}{\mathrm{CON}_{2} \mathrm{H}_{4}}
$$

The second substance formed is sarcosine. Sarcosine is methyl-glycocine-that is, amido-acetic acid in which one $\mathrm{H}$ is replaced by methyl $\left(\mathrm{CH}_{3}\right)$

$$
\mathrm{CH}_{2}<\mathrm{COOH}_{\mathrm{NH}}
$$

It is, however, doubtful whether decompositions of this kind occur in the body (see p. 113).

With sodium nitro-prusside creatinine gives a colour reaction described on p. 106.

Creatinine with zine chloride gives a characteristic crystalline precipitate (groups of fine needles) with composition $\mathrm{C}_{4} \mathrm{H}_{7} \mathrm{~N}_{3} \mathrm{O} . \mathrm{ZnCl}_{2}$.

According to the recent researches of G. S. Johnson, urinary creatinine, though isomeric with the creatinine obtained artificially

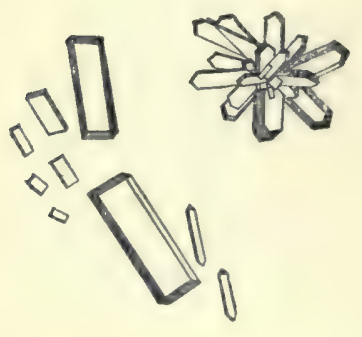

FIG. 45.-Creatine crystals.

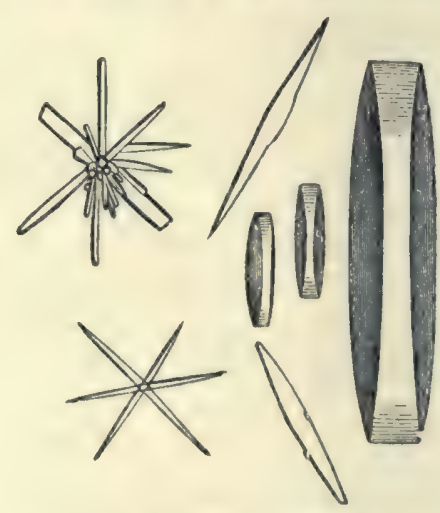

FIG. 46.-Creatinine crystals.

from the creatine of flesh, differs from it in some of its properties, such as reducing power, solubility, and character of its gold salts. The reducing action of urinary creatinine has led to some confusion, for some physiologists have supposed that the reducing action on Fehling's solution and picric acid of normal urine is due to sugar, whereas it is really chiefly due to creatinine. The readiest way of separating creatinine from urine is the following:-To the urine a twentieth of its volume of a saturated solution of sodium acetate is added, and then one-fourth of its volume of a saturated solution of mercuric chloride: this produces an immediate abundant precipitate 
of urates, sulphates, and phosphates, which is removed by filtration; the filtrate is then allowed to stand for twenty-four hours, when the precipitation of a mercury salt of creatinine $\left(\mathrm{C}_{4} \mathrm{H}_{5} \mathrm{HgN}_{3} \mathrm{OHCl}\right)$ $3 \mathrm{HgCl}_{2}+2 \mathrm{H}_{2} \mathrm{O}$ occurs in the form of minute spheres, quite typical on microscopic examination. This compound lends itself very well to quantitative analysis. It may be collected, dried, and weighed, and one-fifth of the weight found is creatinine. ${ }^{1}$ Creatinine may be obtained from it by suspending it in water, decomposing it with sulphuretted hydrogen, and filtering. The filtrate deposits creatinine hydrochloride, from which lead hydrate, $\mathrm{Pb}(\mathrm{OH})_{2}$, liberates creatinine. An important point in Johnson's process is that all the operations are carried out in the cold; if heat is applied one obtains the creatinine of former writers, which has no reducing power.

\section{URINARY DEPOSITS}

The different substances that may occur in urinary deposits are formed elements and chemical substances.

The formed or anatomical elements may consist of blood corpuscles, pus, mucus, epithelium cells, spermatozoa, casts of the urinary tubules, fungi, and entozoa. All of these, with the exception of a small quantity of mucus, which forms a flocculent cloud in the urine, are pathological, and the microscope is chiefly employed in their detection.

The chemical substances are uric acid, urates, calcium oxalate, calcium carbonate, and phosphates. Rarer forms are leucine, tyrosine, xanthine, and cystin. We shall, however, here only consider the commoner deposits, and for their identification the microscope and chemical tests must both be employed.

Deposit of Uric Acid.-This is a sandy reddish deposit resembling cayenne pepper. It may be recognised by its crystalline form (fig. $43, p .119)$ and by the murexide reaction. The presence of these crystals generally indicates an increased formation of uric acid, and, if excessive, may lead to the formation of stones or calculi in the bladder. The way in which uric acid is split off from the urates is of great interest to pathologists, and will be found fully discussed in Sir W. Roberts's Croonian Lectures. ${ }^{2}$

Deposit of Urates.-This is much commoner, and may, if the urine is concentrated, occur in normal urine when it cools. It is

If only a quantitative analysis is required, the process may be considerably accelerated by boiling the first filtrate for ten minutes instead of letting it stand for twenty-four hours.

? Published by Smith, Elder, \& Co., London, 1892. 
generally found in the concentrated urine of fevers; and there appears to be a kind of fermentation, called the acid fermentation, which occurs in the urine after it has been passed, and which leads to the same result. The chief constituent of the deposit is the acid

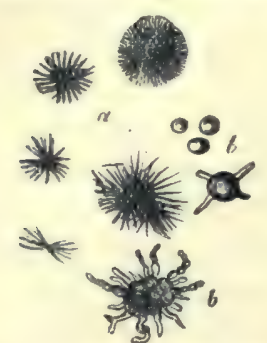

FtG. 47.-Acia sodium urate.

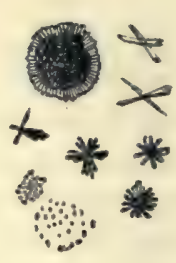

FIu. 48,-Aeid ammonium urate.

sodium urate, the formation of which from the normal sodium urate of the urine may be represented by the equation-

$$
\underset{\substack{\text { [normal sodium } \\ \text { urate] }}}{2 \mathrm{C}_{5} \mathrm{H}_{2} \mathrm{Na}_{2} \mathrm{~N}_{4} \mathrm{O}_{3}}+\underset{\text { [water] }}{\mathrm{H}_{2} \mathrm{O}}+\underset{\substack{\text { [oarbonic } \\ \text { acid] }}}{\mathrm{CO}_{2}}=\underset{\substack{\text { [aidd soodium } \\ \text { urate] }}}{2 \mathrm{C}_{5} \mathrm{H}_{3} \mathrm{NaN}_{4} \mathrm{O}_{3}}+\underset{\substack{\mathrm{Na}_{2} \mathrm{CO}_{3} \\ \text { [sodium } \\ \text { carbonate] }}}{\mathrm{CO}_{3}}
$$

This deposit may be recognised as follows :-

1. It has a pinkish colour; the pigment called uro-erythrin is one

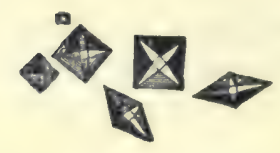

Frt. 49,-Rnvelope erystals of calcium oxslate.

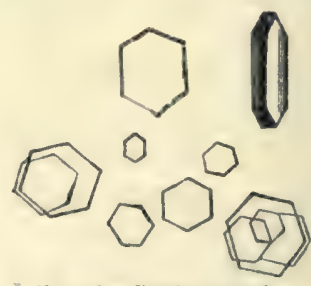

Fid, 50, - Cystin crystals.

of the pigments of the urine, but its relationship to the other urinary pigments is not known (see further Lesson XXVI.).

2. It dissolves upon warming the urine.

3. Microscopically it is usually amorphous, but crystalline forms similar to those depicted in figs. 47 and 48 may occur.

Crystals of calcium oxalate may be mixed with this deposit (see fig. 49).

Deposit of Calcium 0xalate.-This occurs in envelope crystals (octahedra) or dumb-bells.

It is insoluble in ammonia, and in acetic acid. It is soluble with difficulty in hydrochloric aoid. 
Deposit of Cystin.-Cystin $\left(\mathrm{C}_{6} \mathrm{H}_{12} \mathrm{~N}_{2} \mathrm{~S}_{2} \mathrm{O}_{4}\right)$ is recognised by its colourless six-sided crystals (fig. 50). These are rare: they occur only in acid urine, and they may form concretions or calculi. Cystinuria (cystin in the urine) is hereditary.

Deposit of Phosphates.-These occur in alkaline urine. The urine may be alkaline when passed, due to fermentative changes occurring in the bladder. All urine, however, if exposed to the air (unless the air is perfectly pure, as on the top of a snow mountain), will in time become alkaline owing to the growth of the micrococcus urea. This forms ammoniun carbonate from the urea.

$$
\underset{\text { [urea] }}{\mathrm{CON}_{2} \mathrm{H}_{4}}+\underset{\text { [water] }}{2 \mathrm{H}_{2} \mathrm{O}}=\underset{\text { [mumonium }}{\left(\mathrm{NH}_{4}\right)_{2} \mathrm{CO}_{3}}
$$

The ammonia renders the urine alkaline and precipitates the earthy phosphates. The chief forms of phosphates that occur in urinary deposits are-

1. Calcium phosphate, $\mathrm{Ca}_{3}\left(\mathrm{PO}_{4}\right)_{2}$; amorphous.

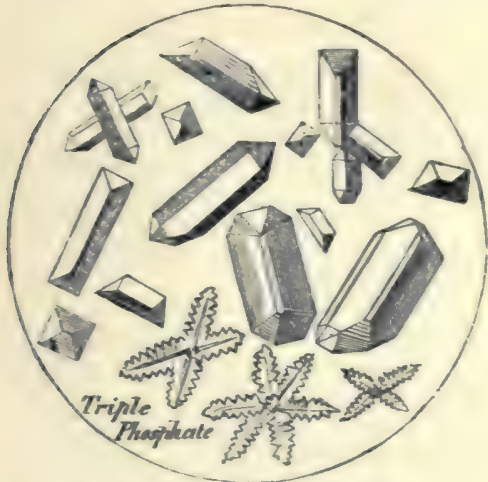

Fig. 51.-Triple phosphate crystals

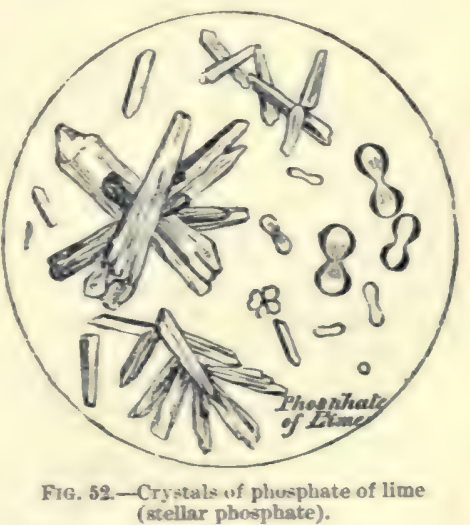
(stellar pbosphate).

2. Triple or ammonio-magnesium phosphate, $\mathrm{MgNH}_{4} \mathrm{PO}_{4}$; coffinlids and feathery stars (fig. 51).

3. Crystalline phosphate of calcium, $\mathrm{CaHPO}_{4}$, in rosettes of prisms, in spherules, or in dumb-bells (fig. 52).

4. Magnesium phosphate, $\mathrm{Mg}_{3}\left(\mathrm{PO}_{4}\right)_{2}+22 \mathrm{H}_{2} \mathrm{O}$, occurs occasionally, and crystallises in long plates.

All these phosphates are dissolved by acids. such as acetic acid, without effervescence.

They do not dissolve on heating the urine; in fact, the amount of precipitate may be increased by heating. Very often neutral or 
alkaline urine will become cloudy when boiled: this may be due to albumin or to phosphates. It is very important to distinguish between these two, as albuminuria is a serious condition. They may be distinguished by the use of acetic acid, which dissolves phosphates but not albumin.

A solution of ammonium carbonate (1-in-5) eats magnesium phosphate away from the edges; it has no effect on the triple phosphate. A phosphate of calcium $\left(\mathrm{CaHPO}_{4}+2 \mathrm{H}_{2} \mathrm{O}\right)$ may occasionally be deposited in acid urine. Pus in urine is apt to be mistaken for phosphates, but can be distinguished by the microscope.

Deposit of calcium carbonate, $\mathrm{CaCO}_{3}$, appears but rarely as whitish balls or biscuit-shaped bodies. It is commoner in the urine of herbivora (see p. 116). It dissolves in acetic or hydrochloric acid, with effervescence.

The following is a summary of the chemical sediments that may occur in urine :-

\section{CHEMICAL SEDIMENTS IN URINE}

\section{IN ACID URINE}

Uric Acid.-Whetstone, dumbbell, or sheaf-like aggregations of crystals deeply tinged by pigment (fig. 43).

Urates.-Generally amorphous. The acid urate of sodium (fig. 47) and of ammonium (fig. 48) may sometimes occur in star-shaped clusters of needles or spheroidal clumps with projecting spines. Tinged brick-red. Soluble on warming.

Calcium Oxalate. - Octahedra, so-called envelope crystals (fig. 49). Insoluble in acetic acid.

Cystin.-Hexagonal plates (fig. 53). Rare.

Leucine and Tyrosine,-Rare.

Calcium Phosphate. $\mathrm{CaHPO}_{4}+2 \mathrm{H}_{2} \mathrm{O}$ - - Rare.

\section{In ALKaLing Uring}

Phosphates.-Calcium phosphate, $\mathrm{Ca}_{3}\left(\mathrm{PO}_{4}\right)_{2}$. Amorphous. Triple phosphate,

$\mathrm{MgNH}_{4} \mathrm{PO}_{4}+6 \mathrm{H}_{2} \mathrm{O}$. Coffin-lids or feathery stars (figs. 42 and 51).

Calcium hydrogen phosphate, $\mathrm{CaHPO}_{4}$. Rosettes, spherules, or dumb-bells (fig. 52).

Magnesium phosphate, $\mathrm{Mg}_{3}\left(\mathrm{PO}_{4}\right)_{2}+22 \mathrm{H}_{2} \mathrm{O}$. Long plates.

All soluble in acetic acid without effervescence.

Calcium Carbonate, $\mathrm{CaCO}_{3} \cdot-$ Biscuit-shaped crystals. Soluble in acetic acid with effervescence.

Ammonium Urate, $\mathrm{C}_{3} \mathrm{H}_{2}\left(\mathrm{NH}_{4}\right)_{2} \cdot \mathrm{N}_{4} \mathrm{O}_{3}$. - 'Thorn-apple' spherules.

Leucine and Tyrosine.--Very rare. 


\section{LESSON XII}

\section{PATHOLOGICAL URINE}

1. Urime $\mathbf{A}$ is pathological urine containing albumin. It gires the usual proteid tests. The two following are most frequently used in practice.

(a) Boil the top of a long column of urine in a test-tube. If the urine is acid, the albumin is coagulated. If the quantity of albumin is small, the cloudiness produced is readily seen, as the unboiled urine below it is clear. This is insoluble in a few drops of acetic acid, and so may be distinguished from phosphates. If the urine is alkaline, it should be first rendered acid with a little dilute acetic acid.

(b) Heller's Nitric-Acid Test.-Pour some of the urine gently on to the surface of some nitric acid in a test-tube. A ring of white precipitate occurs at the junction of the two liquids. This test is used for small quantities of albumin.

If the urine is cloudy, it should be filtered before applying these tests.

2. Estimation of Albumin by Esbach's Albuminometer.-Esbach's reagent for precipitating the albumin is made by dissolving 10 grammes of picric acid. and 20 grammes of eitric acid in 800 or 900 c.c. of boiling water, and then adding sufficient water to make up to a litre (1,000 c.c.).

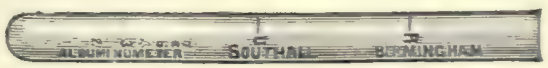

Fig. 53.-Albuminometer of Esbach.

Pour the urine into the tube up to the mark $\mathrm{U}$; then the reagent up to the mark $\mathrm{R}$. Close the tube with a cork, and to ensure complete mixture tilt it to and fro a dozen times without shaking. Allow the corked tube to stand upright twenty-four hours; then read off on the scale the height of the coagulum. The figures indicate grammes of dried albumin in a litre of urine. The percentage is obtained by dividing by 10 . Thus, if the coagulum stands at 3 , the amount of albumin is 3 grammes per litre, or $0.3 \mathrm{gr}$. in $100 \mathrm{c.c}$. If the sediment falls between any two figures, the distance $\frac{1}{4}$, $\frac{1}{2}$, or $\frac{3}{4}$ from the npper or lower figure can be read off with sufficient accuracy. Thas the surface of the sediment being midway between 3 and 4 would be read as 3.5 . When the albumin is so abundant that the sediment is abore 4 , a more accurate result is obtained by first diluting the urine with one or two volumes of water, and then multiplying the resulting figure by 2 or 3 , as the case may be. If the amount of albumin is less than 0.05 per cent., it cannot be accurately estimated by this method.

3. Urine B is diabetic urine. It has a high specific gravity. The presence of sugar is shown by the reduction (yellow precipitate of cuprous oxide) that occurs on boiling with Fehling's solution. Fehling's solution is an alkaline solution of copper sulphate to which Rochelle salt has been added. The Rochelle salt (double tartrate of potash and soda) holds the cupric hydrate in 
solution. Fehling's solution should always be freshly prepared, as, on standing, racemic acid is formed from the tartaric acid, and this substance itself reduces the cupric to cuprous oxide. Fehling's solution should, therefore, always be tested by boiling before it is used. If it remains unaltered by boiling, it is in good condition.

4. Quantitative Determination of Sugar in Urine.-Fehling's solution is prepared as follows:-34.639 grammes of copper sulphate are dissolved in about

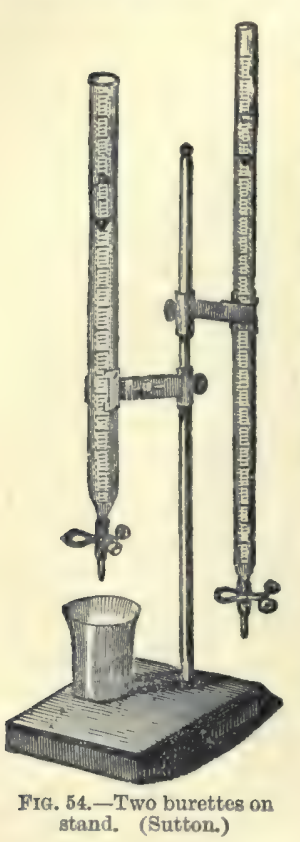
200 c.c. of distilled water; 173 grammes of Rochelle salt are dissolved in 600 c.c. of a 14-per-cent. solution of caustic soda. The two solutions are mixed and diluted to a litre. Ten c.c. of this solution are equivalent to 0.05 gramme of dextrose. Dilute 10 c.c. of this solution with about 40 c.c. of water, and boil it in a white porcelain dish. Run into this from the burette (see fig. 54) the urine (which should be previously diluted with nine times its volume of distilled water) until the blue colour of the copper solution disappears-that is, till all the cupric hydrate is reduced. The mixture in the basin should be boiled after every addition. ${ }^{1}$ The quantity of diluted urine used from the burette contains 0.05 gramme of sugar. Calculate the percentage from this, remembering that urine has been diluted to ten times its original volume.

The following formula will be found useful in converting grammes into grains :-

$x=$ number of grains of sugar in the 24 hours.

$a=$ number of ounces of urine in the 24 hours.

1 ounce $=28 \cdot 396$ c.c.

$b=$ number of c.c. of urine used from the burette to decompose 10 c.c. of Fehling's solution (equivalent to 0.05 gramme $=0.77$ grain of sugar).

Then

$$
x=\frac{a}{b} \times 28.396 \times 0.77=\frac{a}{b} \times 21.865 .
$$

Pavy's modification of Fehling's solution is some. times used. Here ammonia holds the copper in solution, and no precipitate forms on boiling with sugar, as ammonia holds the cuprous oxide in solution. The reduction is complete when the blue colour disappears; 10 c.c. of Pavy's solution $=1$ c.c. of Fehling's solution $=0.005$ gramme of dextrose. In some cases of diabetic urine where there is excess of ammonio-magnesic phosphate, the full reduction is not obtained with Fehling's solution, and when the quantity of sugar is small it may be missed. In such a case excess of soda or potash should be first added; the precipitated phosphates filtered off, and the filtrate after it has been well boiled may then be titrated with Fehling's or Pavy's solution.

5. Picric Acid Test.-The work of Sir George Johnson and G. S. Johnson has shown the value of this reagent in detecting both albumin and sugar in the urine. The same reagent may be employed for the detection of both substances. The method of testing for albumin has been already studied with Esbach's tubes. To test for sugar do the following experiment. Take a drachm (about 4 c.c.) of diabetic urine; add to it an equal volume of saturated aqueous solution of picric acid, and half the volume (i.e. 2 c.c.) of the liquor potassæ of the British Pharmacopcia. Boil the mixture for about

${ }^{1}$ On cooling the blue colour reappears, owing to re-oxidation. 
a minute, and it becomes so intensely dark red as to be opaque. Now do the same experiment with normal urine. An orange-red colour appears even in the cold, and is deepened by boiling, but it never becomes opaque, and so the urine for clinical purposes may be considered free from sugar. This reduction of picric acid by normal urine is due to creatinine (see p. 123).

The full significance and causes of pathological urine cannot be appreciated until a theoretical and practical acquaintance with disease is obtained, and we shall briefly consider only those abnormal constituents which are most frequently met with.

\section{PROTEIDS IN THE URINE}

There is no proteid matter in normal urine, and the most common cause of the appearance of albumin in the urine is disease of the kidney (Bright's disease). The best methods of testing for and estimating the albumin are given in the practical heading to this lesson. The term 'albumin' is the one used by clinical observers. Properly speaking, it is a mixture of serum albumin and serum globulin.

A condition called 'peptonuria,' or peptone in the urine, is observed in certain pathological states, especially in diseases where there is a formation of pus, and particularly if the pus is decomposing owing to the action of a bacterial growth called staphylococcus; one of the products of disintegration of pus cells appears to be peptone; and this leaves the body by the urine. The term 'peptone,' however, is in the strict sense incorrect; the proteid present is deuteroproteose. In the disease called 'osteomalacia' a proteose is usually found in the urine, which more nearly resembles hetero-proteose in its characters.

\section{SUGAR IN THE URINE}

Normal urine contains no sugar, or so little that for clinical purposes it may be considered absent. It occurs in the disease called diabetes mellitus, which can be artificially produced by puncture of the medulla oblongata, by extirpation of the pancreas, and by the administration of the drug called phloridzin. The disease as it occurs in man may be due to disordered metabolism of the liver, to disease of the pancreas, or to other not fully understood causes. Transitory glucosuria is found in many diseases.

The methods usually adopted for detecting and estimating the sugar are given at the head of this lesson. The sugar present is dextrose. Lactose may occur in the urine of nursing mothers. Diabetic urine also contains hydroxybutyric acid, and may contain or yield on distillation acetone and ethyl-diacetic acid. 
Fehling's test is not absolutely trustworthy. Often a normal urine will decolorise Fehling's solution, though seldom a red precipitate is formed. This is due to excess of urates and creatinine. Another substance called glycuronic acid $\left(\mathrm{C}_{6} \mathrm{H}_{10} \mathrm{O}_{7}\right)$ is, however, very likely to be confused with sugar by Fehling's test; the cause of its appearance is sometimes the administration of drugs (chloral, camphor, \&c.); but sometimes it appears independently of drug treatment. The cause of this is not known, but the condition has not the serious meaning one attaches to diabetes; hence, for life assurance purposes, it is most necessary to confirm the presence of sugar by other tests.

Then, too, in the rare condition called alcaptonuria, confusion may similarly arise. Alcapton is a substance which probably originates from tyrosine by an unusual form of metabolism. It gives the urine a brown tint, which darkens on exposure to the air. It is an aromatic substance, and the researches of Baumann and Wolkow ${ }^{1}$ have identified it with homogentisinie acid $\left(\mathrm{C}_{6} \mathrm{H}_{3} \cdot(\mathrm{OH})_{2} \mathrm{CH}_{2} \cdot \mathrm{COOH}\right)$.

The best confirmatory tests for sugar are the phenyl-hydrazine test (see Lesson XIII.), and the fermentation test, which is performed as follows :-

Half fill a test-tube with the urine and add a little German yeast. Fill up the tube with mercury; invert it in a basin of mercury, and leave it in a warm place for twenty-four hours. The sugar will undergo fermentation: carbonic acid gas accumulates in the tube, and the liquid no longer gives the tests for sugar, or only faintly, but gives those for alcohol instead. A control experiment should be made with yeast and water in another test-tube, as a small yield of carbonic acid is sometimes obtained from impurities in the yeast.

Sir W. Roberts introduced a method for estimating sugar in urine, by the diminution in specific gravity which it undergoes on fermentation. Every degree lost in the specific gravity corresponds to one grain of sugar per fluid ounce. Four ounces of urine are placed in a bottle, and a piece of German yeast about the size of a small walnut is added. The bottle is closed with a cork, through which a small hole is bored to allow the carbonic acid to escape. This is put in a warm chamber $\left(40^{\circ} \mathrm{C}\right.$.), and beside it is placed another similar bottle containing 4 ounces of the urine without any yeast. After 18 to 24 hours, fermentation is complete, and the specific gravity of both is taken: suppose that the specific gravity of the unfermented urine is 1040 , and that of the urine which has undergone fermentation is 1030 : the number of degrees lost is ten; i.e. the urine contained 10 grains of sugar per ounce. The percentage of sugar may be ascertained by multiplying the degrees of specific gravity lost by 0.22 ; thus the percentage in the example just given will be $0.22 \times 10=2 \cdot 2$. The method, however, is too rough for trustworthy observations to be made, and has dropped out of use.

\section{BILE IN THE URINE}

This occurs in jaundice. The urine is dark-brown, greenish, or in extreme cases almost black in colour. The most readily applied test is Gmelin's test for the bile pigments. Pettenkofer's test for the

I Zeit. physiol. Chem. xv. 228. 
bile acids seldom succeeds in urine if the test is done in the ordinary way. The best method is to warm a thin film of urine and canesugar solution in a flat porcelain dish. Then dip a glass rod in strong sulphuric acid, and draw it across the film. Its track is marked by a purplish line. Excess of urobilin should not be mistaken for bile pigment.

\section{BLOOD AND BLOOD PIGMENT IN THE URINE}

When hæmorrhage occurs in any part of the urinary tract, blood appears in the urine. It is found in the acute stage of Bright's disease. If a large quantity is present, the urine is deep red. Microscopic examination then reveals the presence of blood corpuscles, and on spectroscopic examination the bands of oxyhæmoglobin are seen.

If only a small quantity of blood is present, the secretionespecially if acid-has a characteristic reddish-brown colour, which physicians term 'smoky.'

The blood pigment may, under certain circumstances, appear in the urine without the presence of any blood corpuscles at all. This is produced by a disintegration of the corpuscles occurring in the circulation, and the most frequent cause of this is a disease allied to ague, which is called paroxysmal hamoglobinuria. The pigment is in the condition of methæmoglobin mixed with more or less oxyhæmoglobin, and the spectroscope is the means used for identifying these substances (see pp. 96-152).

\section{PUS IN THE URINE}

Pus occurs in the urine as the result of suppuration in any part of the urinary tract. It forms a white sediment resembling that of phosphates, and, indeed, is always mixed with phosphates. The pus corpuscles may, however, be seen with the microscope; their nuclei are rendered evident by treatment with 1 per cent. acetic acid, and the pus corpuscles are seen to resemble white blood corpuscles, which, in fact, they are in origin.

Some of the proteid constituents of the pus cells-and the same is true for blood-pass into solution in the urine, so that the urine pipetted off from the surface of the deposit gives the tests for albumin.

On the addition of liquor potassæe to the deposit of pus cells a ropy gelatinous mass is obtained. This is distinctive. Mucus treated in the same way is dissolved. 


\section{DETECTION OF PHYSIOLOGICAL PROXIMATE PRINCIPLES}

Subsequent lessons may be very usefully employed by the class in testing for the various substances the properties of which they have studied. The following scheme will form a rough guide to the tests to be employed for the most important of the proximate principles :-

1. Note reaction, colour, clearness or opalescence, taste, smell. Coloured liquids suggest blood, bile, urine, \&c. Opalescent liquids suggest starch, gly. cogen, or certain proteids.

2. Add iodine. A colour is produced:

If blue : starch. Confirm by converting into a reducing sugar by saliva at $40^{\circ} \mathrm{C}$., or boiling with dilute sulphuric acid.

If reddish brown: Glycogen or dextrin. Glycogen forms an opalescent solution in water, and is readily precipitated by alcohol. It is precipitated by basic lead acetate. Dextrin forms a clear solution: it is not precipitated by basic lead acetate unless ammonia is added also. It is not precipitated by alcohol unless a large excess is added. Both dextrin and glycogen are, like starch, convertible into a reducing sugar.

3. Add copper sulphate and caustic potash.

(a) Blue solution: boil ; yellow or red precipitate. Dextrose, maltose, or lactose (for distinguishing tests see Lesson XIII.).

(b) Blue solution; no reduction on boiling; boil some of the original solution with 25 per cent. sulphuric acid, and then boil with copper sulphate and caustic potash; abundant yellow or red precipitate : Cane augar. Confirm by $\mathrm{HCl}$ test (see p. 9).

(c) Violet solution : Proteids (albumins, globulins, albuminates). In presence of magnesium sulphate the potash causes also a white precipitate of magnesia.

(d) Pink solution; biuret reaction. Peptones or albumoses (proteoses). In presence of ammonium sulphate very large excess of potash is necessary for this test. Only a trace of copper sulphate must be used.

4. When proteids are present proceed as follows: Boil the original solution. (after adding a trace of 2-per-cent. acetic acid).

(a) Precipitate produced: Albumins or globulins.

(b) No precipitate: Albuminates, proteoses, or peptones.

5. If albumin, or globulin, or both, are present, saturate a fresh portion with magnesium sulphate or half saturate with ammonium sulphate; filter; the precipitate contains the globulin, the filtrate the albumin. Test temperature of heat coagulation. 
6. If albumin or globulin is absent :-

(a) Neutralisation causes a precipitate soluble in excess of weak acid or alkali. Acid albumin or alkali albumin, according as the reaction of the original liquid is acid or alkaline respectively. If the original liquid is nentral, acid albumin and alkali albumin must be both absent.

(b) Neutralisation produces no such precipitate : Proteose or peptone.

7. If proteose, or peptone, or both, are present, saturate a fresh portion with ammonium sulphate:

(a) Precipitate: Proteose. (b) No precipitate: Feptone.

If both are present, the precipitate contains the proteose, and the filtrate the peptone.

8. To a fresh portion add nitric acid (proteids haring been proved to be present).

(a) No precipitate, even though excess of sodium chloride be also added: Peptone.

(b) No precipitate, until excess of sodium chloride is added: Deuteroproteose.

(c) Precipitate which disappears on heating and reappears on cooling : Proteoses. This is the distinctive test of all the proteoses or albumoses, and is given by all of them. For one of them, however (deutero-proteose), excess of sodium chloride must be added also.

(d) Precipitate little altered by heating: Albumin or globulin.

In all four cases nitric acid plus heat causes a yellow colour, turned orange by ammonia.

9. Confirmatory tests for proteids:-

(a) Millon's test.

(b) Ferrocyanide of potassium and acetic acid causes a precipitate (except in the case of peptones and some proteoses).

(c) To test for fibrinogen:-

i. It coagulates by heat at $56^{\circ} \mathrm{C}$.

ii. It is changed into fibrin by fibrin ferment and calcium chloride.

(d) To test for caseinogen :-

i. It is not coagulated by heat.

ii. It is changed into easein by rennet and calcium chloride.

10. If blood is suspected-

(a) Examine spectroscopically, diluting if necessary.

i. Oxyhrmoglobin shows two bands between $\mathrm{D}$ and $\mathrm{E}$.

ii. Add ammonium sulphide; one band only appears.

iii. Carbonic oxide hæmoglobin shows two bands also, but will not reduce with ammonium sulphide.

iv. Methæmoglobin gives a typical band in the red between $\mathrm{C}$ and $\mathrm{D}$.

v. Hæmatin \&c. show special spectra (see Adranced Course).

(b) Dry : boil with glacial acetic acid and a crystal of sodium chloride on a glass slide under a cover glass. Hæmin crystals are obtained. 
(c) If the blood is old and dry, and its hæmoglobin converted into hæmatin.

i. Try hæmin test.

ii. Dissolve it in potash; add ammonium sulphide, and examine for spectrum of hæmochromogen.

11. If bile is suspected.

(a) Try Gmelin's test for bile pigments. This is the test for bile in urine.

(b) Try Pettenkofer's test for bile salts.

12. Miscellaneous substances:

(a) Mucin. Precipitated by acetic acid or by alcohol. The precipitate is soluble in lime water. By collecting the precipitate and boiling it with 25 . per-cent. sulphuric acid, a reducing sugar is obtained. Mucin gives the proteid colour tests.

(b) Nucleo-proteid.-Precipitated by acetic acid or by alcohol. The precipitate is often viscous. It is soluble in dilute alkalis like 1 per cent. sodium carbonate. This solution causes intra-vascular clotting. If the precipitate is collected and subjected to gastric digestion, an insoluble deposit of nuclein is left, which is rich in phosphorus. Nucleo-proteid gives the proteid colour tests.

(c) Gelatin. This also gives the proteid colour tests. It is not coagulated, but dissolved in hot water. The solution gelatinises when cold.

(d) Urea. Very soluble in water. The solution effervesces when sodium hypobromite or fuming nitric acid is added. Concentrate a fresh portion, add nitric acid, and examine for crystals of urea nitrate. Solid urea heated in a dry test-tube gives off ammonia, and the residue is called biuret. This gives a rose-red colour with copper sulphate and caustic potash.

(e) Uric acid. Very insoluble in water; soluble in potash, and precipitated from this solution in crystals by hydrochloric acid. Uric acid crystals from human urine are deeply pigmented red. Try murexide test.

$(f)$ Cholesterin. Characteristic flat crystalline plates. Play of colours with iodine and concentrated sulphuric acid.

13. Urine. Normal constituents :

(a) Chlorides. Acidulate with nitric acid; add silver nitrate; white precipitate.

(b) Sulphates. Acidulate with nitric or hydrochloric acid: add barium chloride; white precipitate.

(c) Phosphates. Acidulate with nitric acid; add ammonium molybdate; boil; and a yellow crystalline precipitate forms. To another portion add ammonia ; earthy (i.e. calcium and magnesium) phosphates are precipitated.

(d) Urea (see above).

(e) Uric acid. To 100 c.c. of urine add 5 c.c. of hydrochloric acid; leave for twenty-four hours, and pigmented crystals of uric acid are formed. For tests see above.

( $f$ ) Hippuric acid. Evaporate the urine with nitric acid, and heat the residue in a dry test-tube. A smell of oil of bitter almonds is given off.

(g) Creatinine. Take 100 c.c. of urine: add 5 c.c. of a saturated solution 
of sodium acetate and 20 c.c. of a saturated solution of mereuric chloride. Filter. Set the filtrate aside for twenty-four hours, and the spherical mercury compound of creatinine crystallises out. Examine this with the microscope.

For colour test with sodium nitro-prusside see p. 106.

14. Urine. Abnormal constituents.

(a) Blood. Microseope (blood corpuscles). Spectroscope (for oxyhæmoglobin or methæmoglobin). Hæmin test.

(b) Blood pigment may be present without blood corpuseles. Spectroscope.

(c) Bile. Gmelin's test.

(d) Pus. White deposit. Microseope (pus cells). Add potash; it becomes stringy.

(e) Albumin. (i.) Precipitated, if acid, by boiling; precipitate insoluble in acetic acid, so distinguishing it from phosphates. (ii.) Preeipitated by nitric acid in the cold. (iii.) Precipitated by picric acid.

(f) Sugar. (i.) Brown colour with potash and heat (Moore's test).

Ferments with yeast. (iii.) Reduces Fehling's solution. (iv.) Urine has a high specific gravity. (v.) Add picric acid, potash, and boil ; the urine becomes a dark opaque red; the similar slight colouration in normal urine due to creatinine.

(g) Mucus. Flocculent cloud; may be increased by acetic acid; soluble in alkalis. A little mucus in urine is not abnormal.

(h) Deposits.

i. Examine microscopically for blood corpuseles, pus cells, crystals, dc.

ii. Phosphates. White deposit often mixed with mucus or pus. In. soluble on heating; soluble in acetic acid. Urine generally alkaline Examine microscopically for coffin-lids of triple phosphate and star-like clusters of stellar (calcium) phosphate.

iii. Urie acid. Like cayenne pepper. Whetstone \&c. crystals. Very insoluble in water. Soluble in potash. Murexide test. Urine acid.

iv. Urates. Pink deposit, usually amorphous; may be mixed with envelope crystals of calcium oxalate. Deposit soluble on heating urine. Murexide test. 



\section{ADVANCED COURSE}

\section{INTRODUCTION}

Ir will be presupposed that students who take the following lessons have already been through the elementary course. The order in which the subjects are treated is the same as that already adopted. The instructions given will be mainly practical; theoretical matter on which they depend, or to which they lead, is, as a rule, too lengthy to be discussed in a short manual like the present volume. The Appendix contains a description of various instruments which are not generally contained in sufficient numbers in a physiological laboratory to admit of each student being able to use them in a class. It also contains a deseription of certain methods of research which should always be shown in demonstrations, though there may be practical difficulties in allowing each member of the class to perform the experiments. The description of the phenomena of polarised light and their application has been considerably extended, and a section added on osmosis, a subject which is becoming of more and more importance to the student of physiology.

The fow experiments in which living animals are employed will also necessarily be of the nature of demonstrations. 


\section{LESSON XIII}

\section{CARBOHYDRATES}

1. Glycogen.-A rabbit which has been fed five or six hours previously on carrots is killed by bleeding. The chest and abdomen are opened quickly and a cannula inserted into the portal vein, and another into the vena cava inferior. A stream of salt solution is then allowed to pass through the liver until it is uniformly pale. The washings are collected in three beakers labelled $a, b$, and $c$.

The liver is cut out quickly, chopped into small pieces, and thrown into boiling water acidulated with acetic acid. The acidulated water extracts a

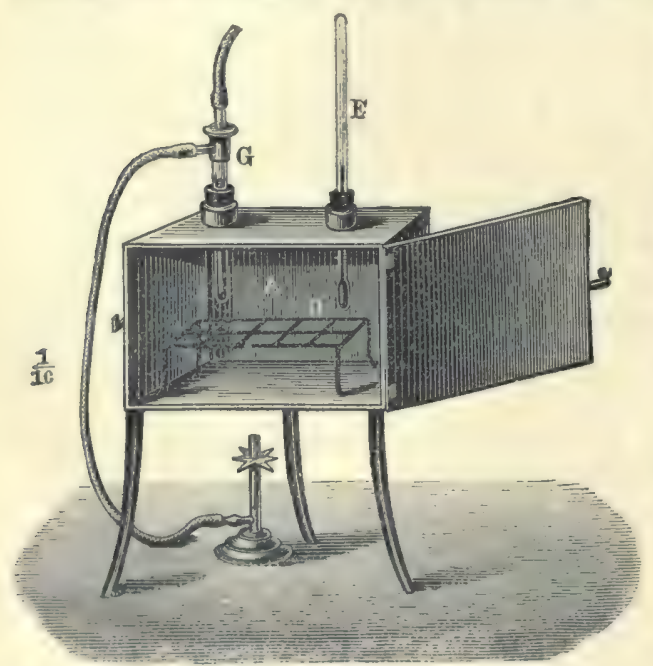

F1G. 85.-Hot-air oven with gas regulator $(a)$, (Gscheidlen.) small quantity of glyeo. gen. The pieces of scalded liver are then ground up in a mortar with hot water, and thoroughly extracted with boiling water. Filter. A strong solution of glyeogen is thus obtained.

Test the solution when cold with iodine.

To separate the glycogen ${ }^{1}$ evaporate the solution to a small bulk on the water-bath and addexcess of alcohol; the glyeogen is precipitated as a floceu. lent powder, which is collected on a filter and dried in an oven at the temperature of $100^{\circ}$ (see fig. 55).

If the experiment is to be a quantitative one, the piece of liver taken and the glycogen obtained must be weighed.

1 This method of preparation of glycogen has the advantage that only traces of proteid are mixed with it. In Kiilz's method (extraction with dilute potash) there is more proteid. This is precipitated by the alternate addition of hydrochlorio acid and potassio-mercuric iodide. 


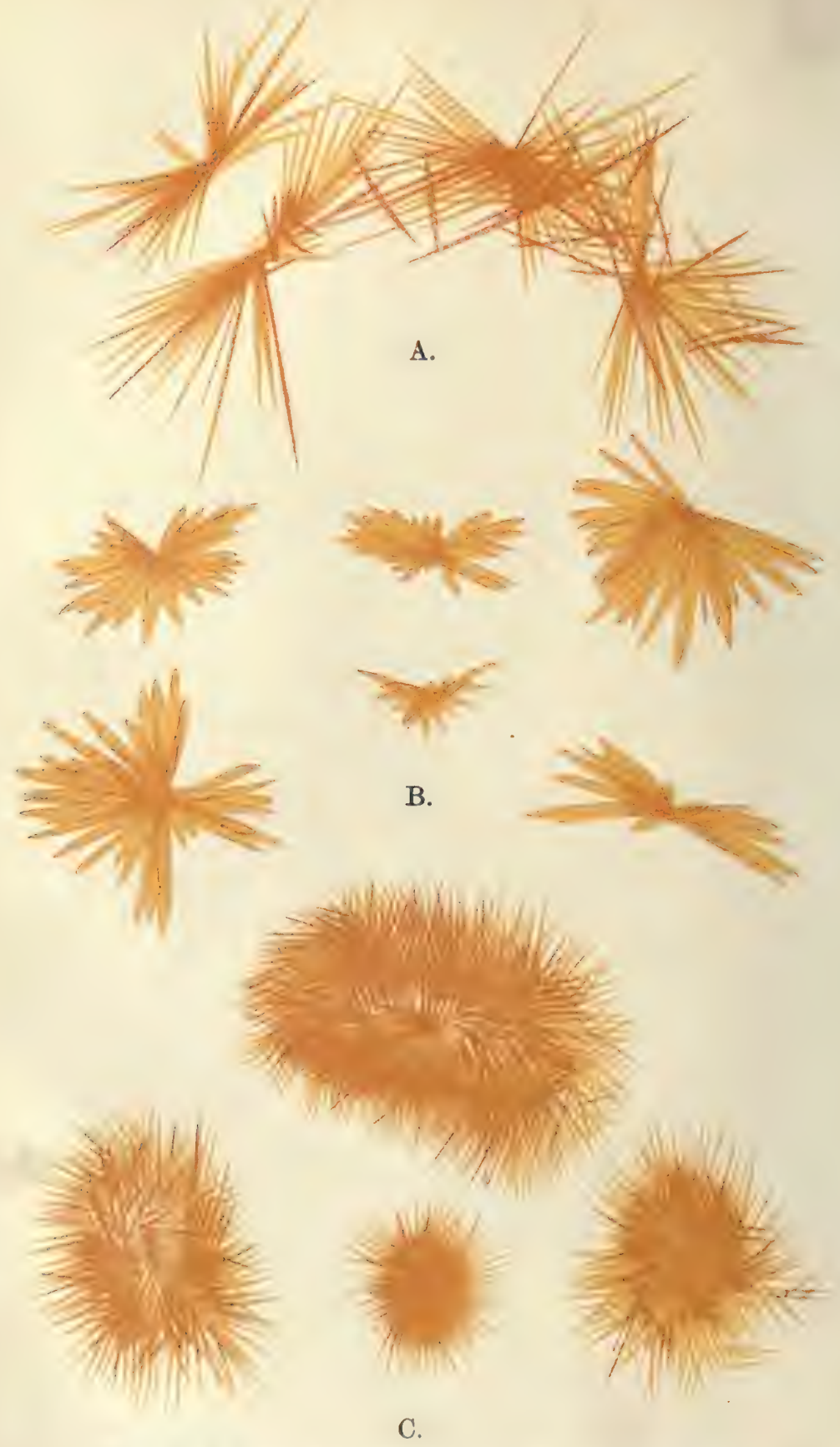

Fig. 56.-Plate of osazone crystals highly magnified.

$A$, phenyl-glucosazone. B, phenyl-maltosazone. $C$, phenyl-lactosazone. 
2. Examine the washings of the liver in the beakers $a, b$, and $c$ for sugar. This may be done in a rough quantitative manner as follows:-Take equal quantities of $a, b$, and $c$ in three test-tubes; to each add an equal amount of Fehling's solution, and boil : $a$ will give a heavy precipitate, $b$ one not so heavy, and $e$ least of all, or none at all.

3. Micro-chemical detection of Glycogen, -A thin piece of the same liver is hardened in 90 per cent. alcohol. Sections are cut by the free hand, or after embedding in paraffin. If paraffin is used, this is got rid of by means of turpentine; and the sections prepared by either method are treated with chloroform in which iodine is dissolved, and mounted in chloroform balsam containing some iodine. The glycogen is stained brown, and is most abundant in the cells around the radicles of the hepatic vein.

4. Phenyl-Hydrazine Test for Sugars.-To 5 c.c. of the suspected fluid (e.g. diabetic urine) add 1 decigramme of phenyl-hydrazine hydrochloride, 2 decigrammes of sodium acetate, and heat on the water-bath for half an hour. On cooling, if not before, a crystalline or amorphous precipitate separates out. If amorphous, dissolve it in hot alcohol; dilute the solution with water, and boil to expel the alcohol, whereupon the osazone separates out in yellow crystals. Examine the crystals with the microseope (see accompanying plate).

Dextrose gives a precipitate of phenyl-glucosazone $\left(\mathrm{C}_{18} \mathrm{H}_{22} \mathrm{~N}_{4} \mathrm{O}_{4}\right)$, which crystallises in yellow needles (melting-point $205^{\circ} \mathrm{C}$.).

Levulose yields an osazone identical with this.

Galactose yields a very similar osazone (phenyl-galactosazone). It differs from phenyl-glucosazone by melting at $190-193^{\circ}$, and in being optically inactive when dissolved in glacial acetic acid.

Cane sugar does not form a compound with phenyl-hydrazine.

Lactose yields phenyl-lactosazone $\left(\mathrm{C}_{23} \mathrm{H}_{23} \mathrm{~N}_{4} \mathrm{O}_{9}\right)$. It crystallises readily in needles, usually in clusters (melting-point $200^{\circ} \mathrm{C}$.). It is soluble in 80-90 parts of boiling water. Lactose in urine does not give this test readily.

Maltose yields phenyl-maltosazone $\left(\mathrm{C}_{24} \mathrm{H}_{33} \mathrm{~N}_{4} \mathrm{O}_{9}\right)$. It crystallises in yellow needles much wider than those yielded by glucose or lactose (melting-point $206^{\circ} \mathrm{C}$.). Unlike phenyl-glucosazone it dissolves in 75 parts of boiling water, and is still more soluble in hot alcohol.

Isomaltose is a sugar formed at the same time as maltose by the action of diastase, ptyalin, and amylopsin on starch. It is also an intermediate product in the formation of dextrose by mineral acids from starch. An amylolytic ferment in blood serum, capable of forming dextrose from starch, aets similarly. It is readily soluble in water, is very sweet, and ferments very slowly with yeast. Its formula and general characters are like those of maltose, but its osazone forms fine yellow needles, which melt at $150^{\circ} \mathrm{C}$.

The chemistry of the phenyl-hydrazine reaction is represented in the following equations, dextrose being taken as an example of the sugar used :- 
I. $\mathrm{CH}_{2} \mathrm{OH}[\mathrm{CH}(\mathrm{OH})]_{3} \mathrm{CH}(\mathrm{OH}) \mathrm{COH}+\mathrm{H}_{2} \mathrm{~N} \cdot \mathrm{NH}\left(\mathrm{C}_{6} \mathrm{H}_{5}\right)$ [dextrose] [phenyl-hydrazine] $\mathrm{CH}_{2} \mathrm{OH}[\mathrm{CH}(\mathrm{OH})]_{3} \mathrm{CH}(\mathrm{OH}) \mathrm{CH}^{-}$

$$
=\begin{array}{lll}
\| & & \\
\text { [hydrazone] } & \mathrm{N}-\mathrm{NH}\left(\mathrm{C}_{6} \mathrm{H}_{5}\right) & +\mathrm{H}_{2} \mathrm{O} \\
\text { [water] }
\end{array}
$$

II. $\mathrm{CH}_{2} \mathrm{OH}[\mathrm{CH}(\mathrm{OH})]_{3} \mathrm{CH}(\mathrm{OH}) \mathrm{CH}$

$$
\begin{aligned}
& \text { II } \quad+\mathrm{C}_{6} \mathrm{H}_{5} \cdot \mathrm{NH}-\mathrm{NH}_{2} \\
& \text { [hydrazone] [phenyl-hydrazine] } \\
& =\mathrm{C}_{6} \mathrm{H}_{5} \cdot \mathrm{NH}-\stackrel{\mathrm{N}}{\mathrm{N}}-\mathrm{NH}_{0} \mathrm{C}_{6} \mathrm{H}_{5}+\mathrm{H}_{2}+\mathrm{H}_{2} \mathrm{O} \\
& \text { [osarone] [hydrogen] [water] }
\end{aligned}
$$

5. Barfoed's Reagent.-Dissolve 1 part of cupric acetate in 15 parts of water; to 200 c.e. of this solution add 5 c.c. of acetic acid containing 38 per cent. of glacial acetic acid. Dextrose reduces this reagent on boiling; maltose and lactose do not. This test is not very delicate.

6. The Polarimeter.-Estimate the strength of a solution of dextrose by means of the polarimeter (see Appendix). 


\section{LESSON XIV}

\section{CARBOHYDRATES: ACTION OF MALT UPON STARCH}

1. Prepare a 0.5-per-cent. solution of starch.

2. Prepare some malt extract by digesting 10 grammes of powdered malt with 50 c.e. of water at $50^{\circ} \mathrm{C}$. for three hours, and subsequently straining. This extract contains the diastatic or malting ferment.

Solutions 1 and 2 may be conveniently prepared beforehand by the demonstrator.

3. To the starch solution add one-tenth of its volume of malt extract, and place the mixture in a water-bath at $40^{\circ} \mathrm{C}$. From time to time test portions of the liquid by mixing a drop with a drop of iodine solution on a testing slab. The blue colour at first seen is soon replaced by a violet (mixture of blue and red), and then by a red reaction (due to erythrodextrin) which gradually vanishes. Alcohol added to the liquid when all starch and erythrodextrin have gone still causes a precipitate of a dextrin, which, as it gives no colour with iodine, is called achroö-dextrin. The liquid also contains a reducing sugar, maltose.

4. Treat the solution of starch as before with one-tenth of its volume of malt extract, and keep it in the warm chamber $\left(50^{\circ} \mathrm{C}\right.$.) for three hours. This may be conveniently done beforehand by the demonstrator.

5. Take 50 c.c. of the product (which is a solution of maltose and isomaltose, the reducing action of which is the same as that of maltose), and determine how much of it is necessary to reduce 10 c.c. of Fehling's solution. The manner of earrying out Fehling's quantitative method is given in Lesson XII.

6. Take another 50 c.c. and boil it with 1 c.e. of strong sulphuric acid for half an hour in a flask. This converts it into dextrose. After cooling bring the liquid to its original volnme (50 c.c.) by adding water, and again determine its inereased reducing power with Fehling's solution. If $x=$ c.e. of maltose solution necessary to reduce 10 c.c. of Fehling's solution, then $\frac{2 x}{3}=$ c.c. of dextrose solution necessary for the same purpose. The strength of the maltose solution ean be calculated from the fact that 10 c.c. of Fehling's solution corresponds to 0.05 gramme of dextrose. 


\section{LESSON XV}

\section{CRYSTALLISATION OF EGG ALBUMIN}

Fresh egg-white is mixed with an equal bulk of fully saturated, filtered, neutral ammonium sulphate solution. 100 c.c. of the former are measured into a porcelain basin or strong beaker, and 100 e.e. of ammonium sulphate solution are added in successive quantities of 10 or 15 c.c., the mixture being thoroughly churned with an egg whisk after each addition. The whole should be finally so thoroughly beaten up as to form a large proportion of light froth. After the greater part of the froth has broken down the mixture is thrown on a folded filter-paper, moderately rapid filtration being obtained without the use of a filter-pump. The filtrate is strongly alkaline to litmus, and smells of ammonia. To the filtrate in a flask, or to as much of it as can be obtained in a convenient time of filtration, further ammonium sulphate solution is very cautiously added (best, drop by drop from a burette) until a slight permanent precipitate remains, and this precipitate is afterwards just redissolved by the equally cautions addition of water. Dilute acetic acid (10 per cent.) from a burette is now added drop by drop until such a stage of reaction is reached that a precipitate forms and only just redissolves. Finally one or two drops (not more) of acid are added in excess of this, whereupon a bulky white precipitate falls. The flask is now corked and allowed to stand. In 24 hours or less the precipitate, which will have increased in quantity, will be found to consist entirely of acicular crystals. Small portions should be examined under a $\frac{1}{6}$ th objective, avoiding pressure on the cover slip (F. G. Hopkins). 


\section{LESSON XVI}

\section{COAGULATION OF MILK}

1. Prepare a solution of rennet by extracting the fourth stomach of the sucking calf with glycerin. Clark's rennet, which is sold for making junkets, will do equally well.

2. Prepare a solution of pure caseinogen in the following way :-Saturate milk with magnesium sulphate by shaking it with excess of the powdered salt; or the caseinogen may be more readily precipitated by half saturation with ammonium sulphate-that is, by adding to the milk an equal volume of saturated solution of ammonium sulphate. Filter. The caseinogen and fat remain together on the filter. Sare the filtrate, and label it A. Wash the precipitate on the filter with saturated solution of magnesium sulphate or half-saturated ammonium sulphate solution, as the case may be, until the washings contain no albumin. Add water to the precipitate. The caseinogen dissolves, the fat being insoluble. In this way a solution of caseinogen in weak magnesium or ammonium sulphate is obtained. So far the operations should be performed beforehand by the demonstrator.

3. To this solution add acetic acid. The caseinogen is precipitated; collect it on a filter; wash the acid away with distilled water. Dissolve the precipitate in lime water by grinding it up in a mortar with the lime water; filter, and an opalescent solution of caseinogen is obtained.

4. To a portion of this solution add a few drops of rennet extract. Put it in the water-bath at $40^{\circ} \mathrm{C}$., and if the caseinogen has been thoroughly washed to free it from calcium salts no coagulation will occur. The calcium contained in the lime water subsequently added is not effective in promoting coagulation.

5. Treat another portion in the same way, adding, howerer, a few drops of 0.5 -per-cent. phosphoric acid as well as the rennet. Warm to $40^{\circ} \mathrm{C}$. Coagulation-that is, formation of casein from caseinogen-usually occurs in a few minutes. The addition of the phosphoric acid causes the formation of calcium phosphate, which is effective in promoting coagulation.

6. Examine the filtrate A (see above). Saturate a portion with sodium chloride. A small amount of precipitate of a proteid comes down. This is the so-called lacto-globulin. This contains only a trace of true globulin: it is mostly caseinogen previously left in solution, together with calcium sulphate.

7. Heat another portion of $A$ to $77^{\circ}$. acidifying faintly with a few drops of 2-per-cent. acetic acid. Lactalbumin is coagulated at this temperature. 
8. Ringer's method of showing the conversion of caseinogen into casein :Milk is strongly acidified with acetic acid. This precipitates the caseinogen and entangled fat. The precipitate is collected on a filter, thoroughly washed with distilled water, and ground up in a mortar with calcium carbonate. The mixture is thrown into excess of distilled water. The fat rises to the top : the excess of calcium carbonate falls to the bottom. The intermediate fluid contains the caseinogen in solution; it is usually very opalescent. Take some of this solution and divide it into three parts, $\mathrm{A}, \mathrm{B}$, and $\mathrm{C}$.

To $A$ add rennet.

To B add a few drops of 2-per-cent. solution of calcium chloride.

To $\mathrm{C}$ add both rennet and ealcium chloride.

Put all three in the water-bath at $40^{\circ} \mathrm{C}$. A clot of casein forms in C, but not in $\mathrm{A}$ and $\mathrm{B}$.

2. The formation of casein from caseinogen is a double process; the first action is that of the ferment, which converts the caseinogen into what may be called soluble casein; the second action is that of the calcium salt, which precipitates the casein in an insoluble form, or curd. This is probably a caseate of lime. This may be shown by taking some of Ringer's caseinogen solution and adding rennet. Warm to $40^{\circ} \mathrm{C}$.; no visible change occurs, but nevertheless soluble casein and not caseinogen is now present. Then boil this mixture to destroy the rennet, cool, and add calcium chloride. A formation of insoluble curd now occurs. 


\section{LESSON XVII}

\section{THE ALBUMOSES}

1. Witte's peptone contains very little true peptone, but consists chiefly of albumoses, which are soluble like peptone, in neutral saline solutions.

2. Make a solution of this substance in 10-per-cent. sodium chloride solution, and filter. Very little residue is left on the filter. This consists of dysalbumose, an insoluble form of hetero-albumose, formed during the process of preparing the substance. If hot saline solution is used instead of cold as a solvent, this amount of insoluble residue is increased, hetero-albumose being to a slight extent precipitated by heat.

3. The solution gives the following tests:-

(a) Biuret reaction (due both to peptone and albumoses).

(b) A drop of nitric acid, best added by a glass rod, gives a precipitate which dissolves upon heating and reappears on cooling. (This is due to the albumoses present.)

(c) It does not coagulate on heating.

Otherwise it gives the ordinary proteid reactions.

4. For the separation of the albumoses and peptone proceed as follows:-

(a) Saturate the solution with ammonium sulphate, and filter. The filtrate contains the peptone and the precipitate the albumoses. The peptone is not precipitated by nitric acid, nor by most of the reagents that precipitate other proteids. It is precipitated completely by alcohol, tannin, and potassiomercuric iodide; imperfectly by phospho-tungstic and phospho-molybdic acid.

It gives the biuret reaction, but in the presence of ammonium sulphate a large excess of caustic potash is necessary.

(b) Dialyse another portion of the solution; hetero-albumose is precipitated.

(c) Saturate another portion of the solution with sodium chloride (or half saturate with ammonium sulphate) after faintly acidnlating with acetic acid. Proto-albumose and hetero-albumose are precipitated. Filter. The filtrate contains the dentero-albumose and peptone.

The proto- and hetero-albumose may be redissolved by adding distilled water, and may be separated from each other by dialysis (see $b$ ).

Deutero-albumose may be separated from the peptone by saturation with ammonium sulphate, or by the addition of a crystal of phosphoric acid. These reagents precipitate the deutero-albumose, but not the peptone.

Deutero-albumose gives the nitric acid reaction (see $3, b$ ) characteristic of the albumoses only in the presence of excess of salt. If the salt is removed by dialysis, nitric acid then causes no precipitate. 
5. Among the important reactions of proteids is Piotrowski's reactionthat is, the coloration produced by copper sulphate and a caustic alkali; the term ' biuret reaction' is applied to the rose-red colour which proteoses and peptones give with these reagents, because biuret (a derivative of urea) gives: a similar colour. It does not, however, prove that biuret is contained in the proteid molecule. Biuret and proteid both contain some radicle to which the colour is due. Gnezda ${ }^{1}$ thought it was cyanogen, and that the cyanogen was differently combined in the peptones and native proteids (albumins and globulins) respectively; hence the rose-red given by one group and the violet by the other. More recent work by Pickering, ${ }^{2}$ however, points to a CONH group rather than cyanogen. Gnezda found that if a dilute solution of nickel sulphate is used instead of copper sulphate, the native proteids give different colours from the peptones and proteoses, and Pickering has found the same with cobalt. Their results may be given in the following table :-

\begin{tabular}{|c|c|c|c|c|c|c|c|}
\hline Proteid & $\begin{array}{c}\text { Copper aul- } \\
\text { phate and } \\
\text { ammonia }\end{array}$ & $\begin{array}{c}\text { Copper sul- } \\
\text { phate and } \\
\text { potash }\end{array}$ & $\begin{array}{c}\text { Nickel sul- } \\
\text { phate and } \\
\text { ammonia }\end{array}$ & $\begin{array}{c}\text { Nickel sul- } \\
\text { phate and } \\
\text { potash }\end{array}$ & $\begin{array}{c}\text { Cobalt sul- } \\
\text { phate and } \\
\text { ammonis }\end{array}$ & $\begin{array}{c}\text { Cobalt sul- } \\
\text { phate and } \\
\text { potash }\end{array}$ \\
\hline $\begin{array}{c}\text { Albumins and } \\
\text { globulins }\end{array}$ & Blue & Vlolet & Nil & Yellow & Nil & $\begin{array}{c}\text { Heliotrope- } \\
\text { purple }\end{array}$ \\
\hline $\begin{array}{c}\text { Proteoses and } \\
\text { peptones }\end{array}$ & Plose-red & Rose-red & Yellow & Orange & Nil & Red-brown \\
\hline
\end{tabular}

6. Another delicate test introduced by McWilliam may here be mentioned: Salicyl-sulphonic acid precipitates albumins and globulins: on heating the precipitate is coagulated. The same reagent precipitates proteoses. On heating the precipitate dissolves and reappears on cooling. It does not precipitate peptones.

7. The use of trichloracetic acid for the separation of various proteids may be illustrated by the following experiment. Take some blood and add to it some solution of Witte's peptone (i.e. proteoses and peptone). Add to this mixture an equal volume of a 10-per-cent. solution of trichloracetic acid. There is an abundant precipitate. Boil rapidly and filter hot. The filtrate contains the proteoses and peptone, all the other proteids being contained in the precipitate. On cooling, the filtrate deposits some of the proteose. The proteose and peptone may be detected in the usual way.

'Proc. Roy. Society, vol. xlvii. p. 202.

2 Journal of Physiology, vol. xiv. Most of the other colour reactions of proteids depend on the aromatic radicle they contain. 


\section{LESSON XVIII}

\section{DIGESTION}

1. Activity of pepsin solutions. Examine the comparative digestive power of the glycerin extracts of two stomachs. Take in two test-tubes an equal small weighed quantity of fibrin stained with carmine. Add to each 10 c.c. of 0-2-per-cent. hydrochloric acid. Add to one a measured quantity of one glycerin extract, and to the other an equal quantity of the other glycerin extract. As the fibrin is digested the carmine is set free, and colours the liquid; that which is more deeply stained is that which contains the more active preparation of pepsin.

This exercise illustrates the principle of Grützner's method of comparing the digestive powers of solutions. In the original method the amount of earmine set free is estimated by an artificial seale consisting of ten solutions of carmine of different known strengths.

The carmine solution for staining the fibrin is prepared by dissolving 1 gramme of carmine in about 1 c.c. of ammonia ; to this 400 c.c. of water are added, and the mixture is kept in a loosely stoppered bottle till the smell of ammonia has become faint.

The fibrin is stained by taking it perfectly fresh and clean. It is chopped finely and placed in the carmine solution for twenty-four hours. The fluid is strained off and the fibrin washed in water till the washings are colourless. It is kept in a stoppered bottle with just enough ether to cover it.

2. Tests for Free Hydrochloric Acid. (a) Gunsberg's reagent consists of 2 parts of phloroglucinol, 1 part of vanillin, and 30 parts of rectified spirit. A drop of filtered gastric juice is evaporated with an equal quantity of the reagent. Red crystals form, or if much peptone is present, there will be a red paste. The reaction takes place with 1 part of hydrochloric acid in 10,000. The organic acids do not give the reaction.

(b) Tropæolin test. Drops of a saturated solution of tropæolin-00 in 94 per cent. methylated spirit are allowed to dry on a porcelain slab at $40^{\circ} \mathrm{C}$. A drop of the fluid to be tested is placed on the tropreolin drop, still at $40^{\circ} \mathrm{C}$. ; and if hydrochloric acid is present, a violet spot is left when the fluid has evaporated. A drop of 0.006 per cent. hydrochloric acid leaves a distinct mark.

(For a very complete account of these and other colour reactions see ‘Diseases of the Stomach,' chap. v. By Sidney Martin, F.R.S. 1895.)

3. Panereatic Digestion. A finely divided ox-pancreas has been allowed to digest at $40^{\circ} \mathrm{C}$. for twenty-four to thirty-six hours in a litre of 1 per cent. 
solution of sodium carbonate to which the white of an egg has been added every ten hours. Note the odour due to putrefaction. Another preparation has been similarly made, except that thymol has been added to prevent de. composition. These should be got ready by the demonstrator.

Filter some of the extract and examine for leucine and tyrosine as follows :

(a) To some of the liquid add Millon's reagent and filter off the precipitated proteid. Boil the filtrate. The presence of tyrosine is indicated by a red colour. If tyrosine is abundant the red colour appears without boiling.

(b) Faintly acidify another portion of the filtered extract with 2-per-cent. acetic acid and boil ; filter off the proteid thus coagulated; reduce the filtrate to a small bulk by evaporation on the water-bath at the boiling temperature. Examine a drop microscopically for crystals of leucine and tyrosine. Treat the remainder with excess of alcohol, to precipitate the albumoses and peptones, and again filter. Concentrate the filtrate on the water-bath till it becomes sticky from the presence of leucine. Examine some of the concentrated fluid with the microscope; leucine will be found in crystalline spheroidal clumps.

Examine microscopic specimens of leucine and tyrosine which have been prepared by the demonstrator. ${ }^{1}$.

4. Zymogen granules.-Examine microscopically, mounting in aqueous humour or serum (or in glycerin after treatment with osmic acid vapour), small pieces of the pancreas, parotid and submaxillary glands in a normal guinea-pig ${ }^{2}$ and also in one in which profuse secretion had been produced by the administration of pilocarpine.

Note that zymogen granules are abundant in the former, and scarce in the latter, being situated chiefly at the free border of the cells.

Extremely good, though not permanent, microscopic specimens may be obtained by teasing in a 33-per-cent. solution of caustic potash.

1 The deposit often found in rather old specimens of Benger's liquor pancreaticus will be found to consist of leucine and tyrosine crystals.

2 The guinea-pigs should be killed by bleeding, and the blood collected and defibrinated, and utilised for the preparation of oxyhæmoglobin crystals. This will give students an opportunity of seeing the exceptional form (tetrahedra) in which the blood-pigment of this animal crystallises.

The three methods of obtaining crystals described on p. 89 all give good results. If amyl nitrite is used instead of ether in the third method, crystals of methrmoglobin are obtained. 


\section{LESSON XIX}

\section{HAEOGLOBIN AND ITS DERIVATIVES}

Defibrinated ox-blood suitably diluted may be used in the following experiments as in those described in Lesson IX.

1. Place some in a hæmatoscope (see fig. 33, p. 93) in front of the large spectroseope. Note the position of the two characteristic bands of oxyhæmoglobin; these are replaced by the single band of hæmoglobin after reduction by the addition of Stokes's reagent (see footnote, p. 92) or ammonium sulphide. By means of a small reetangular prism a comparison speetrum showing the bright sodium line (in the position of the dark line named D in the solar spectrum) may be obtained, and focussed with the absorption spectrum.

2. Obtain similar comparison spectra by the use of the mierospectroseope. For this purpose a cell containing a small quantity of oxyhæmoglobin solution may be placed on the microscope stage, and a test-tube containing carbonic oxide hæmoglobin in front of the slit in the side of the instrument. Notice that the two bands of earbonic oxide hæmoglobin are very like those of oxyhæmoglobin, but are a little nearer to the violet end of the spectrum.

Carbonic oxide hæmoglobin may be readily prepared by passing a stream of coal gas through the diluted blood. It has a cherry-red colour, and is not reduced by the addition of ammonium sulphide (fig. 57 , spectrum 4).

3. Methæmoglobin.-Add a few drops of ferricyanide of potassium to dilute blood and warm gently. The colour changes to mahogany-brown. Place the test-tube in front of the small direct vision spectroseope. Note the characteristic band in the red (fig. 57, spectrum 5). On dilution other bands appear (fig. 57, spectrum 6). Treat with ammonium sulphide, and the band of hemoglobin appears.

4. Acid Hæmatin,-Add a few drops of glacial acetic acid to dilute blood; the colour changes to brown. Examine with the spectroseope. Compare the position of the absorption band in the red with that of methrmoglobin; that of acid hæmatin is further from the $\mathrm{D}$ line (fig. 57, spectrum 7).

Take some undiluted blood and add glacial acetic acid as before. Extract this with ether by gently agitating it with that fluid. The ethereal extract should then be poured off and examined. The band in the red is seen, and on further diluting with ether three additional bands appear.

5. Alkaline Hæmatin.-Add to diluted blood a small quantity of strong eanstic potash and warm. The colour changes to brown, and with the spectroscope a faint shading on the left side of the $\mathrm{D}$ line is seen (fig. 57 , spectrum 8).

6. Hæmochromogen.-Add ammonium sulphide to a solution of slkaline 


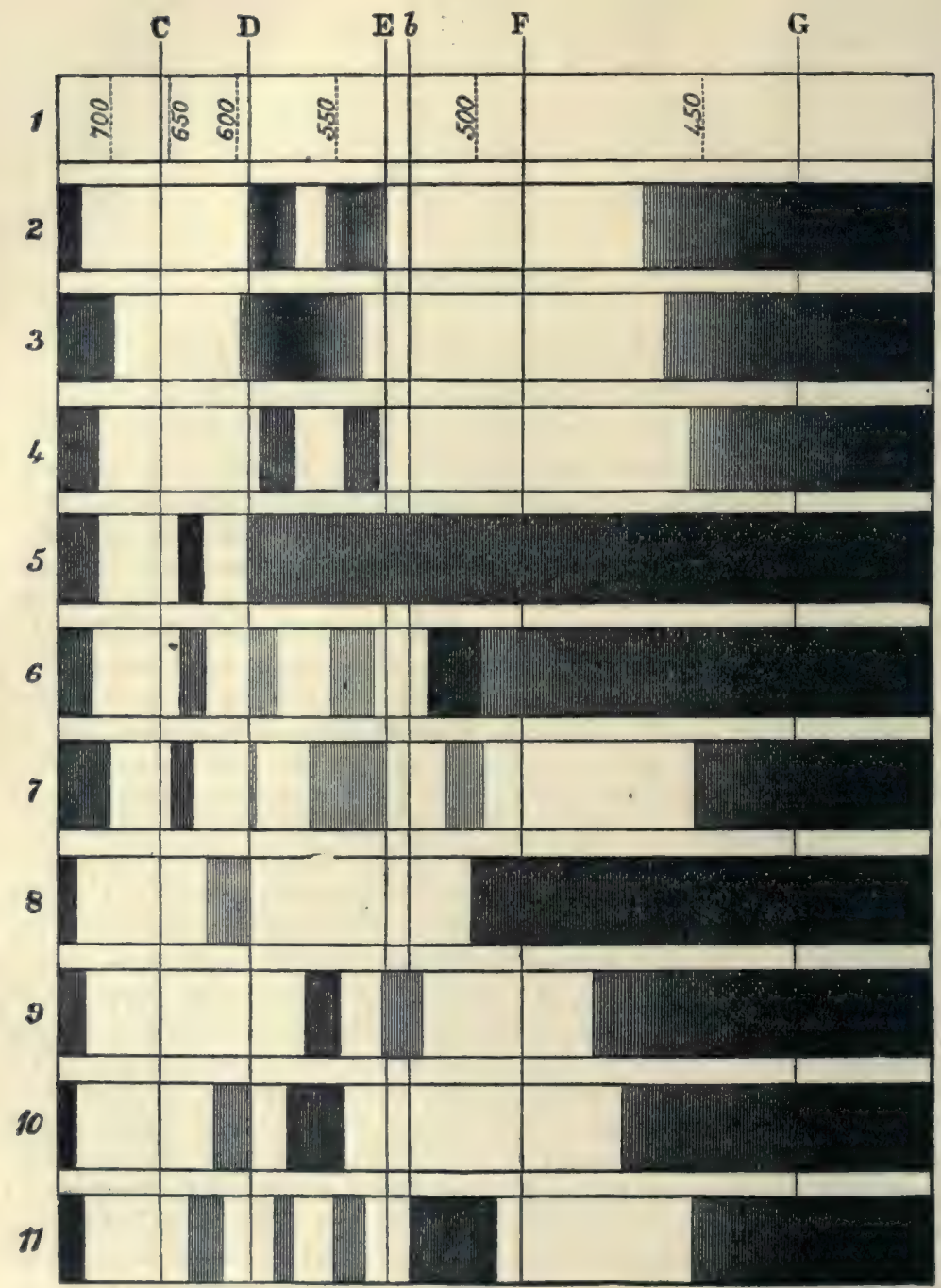

F16. 57. - 1, Solar spectrum. 2, Spectrum of oxyhæmoglobin $(0.37$ p.o. solution). First band, $\lambda$ 588564 ; seoond band, $\lambda$ 555-517. 3, Spectrum of hæmoglobin. Band, $\lambda$ 597-535. 4, Spectrum of CO. hromoglobin. First hand, $\lambda$ 583-564; second band, $\lambda$ 547-521. 5, Spectrum of methæmoglobin (concentrated solution). 6, speetrum of methremoglobin (dilute solution). First band, $\lambda$ 647622 ; second bund, $\lambda$ 587-571; thiril band, $\lambda$ 552-532; fourth band, $\lambda$ 514-480. 7, Spectrum of acli hematin (ethereal solution). First band, $\lambda$ 656-615; second band, $\lambda$ 697-577; third band, $\lambda$ 567-529 ; fourth band, $\lambda$ 517-488. 8. Spectrum of alkaline hæmatin. Band from $\lambda$ 630-581. 9. Spectrum of hemochromogen (redueed lizenatin). First band, $\lambda$ 569-542 : secoud band, $\lambda$ 836-504. 10, Spectrum of acid hæmatoporphyrin. First band, $\lambda$ 607-593: second band, $\lambda$ 686586. 11, spectrum of alkaline hsematoporphyrin. First band, $\lambda$ $833-612$; secout baul, $\lambda$ 589- 584 ; third band, $\lambda$ 549-529; fourth banil, $\lambda$ 518-488. The sabove measurements (after MacMunn) are in millionths of a millimetre. The liquid was examined in a layer 1 centimetre thiek. The edges of ill-defined bands vary a good deal with the conoentration of the solutions. 
hrematin; the other changes to red, and two bands are seen, one between D and $\mathrm{E}$, and the other nearly coinciding with $\mathrm{E}$ and $b$ (fig. 57, spectrum 9). The spectrum of alkaline hæmatin reappears for a short time after vigorons shaking with air.

7. Hæmatoporphyrin.-To some strong sulphuric acid in a test-tube add a few drops of undiluted blood. and observe the spectrum of acid hremato-

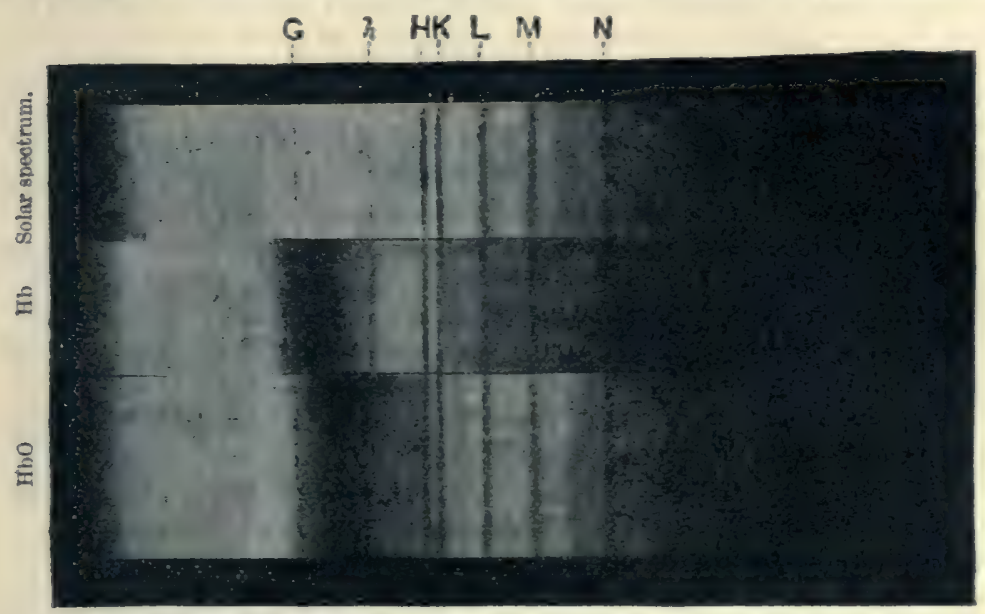

Fit. 58.-The photographic spectrum of hremoglobin and oxyhremoglobin (Gamgee)

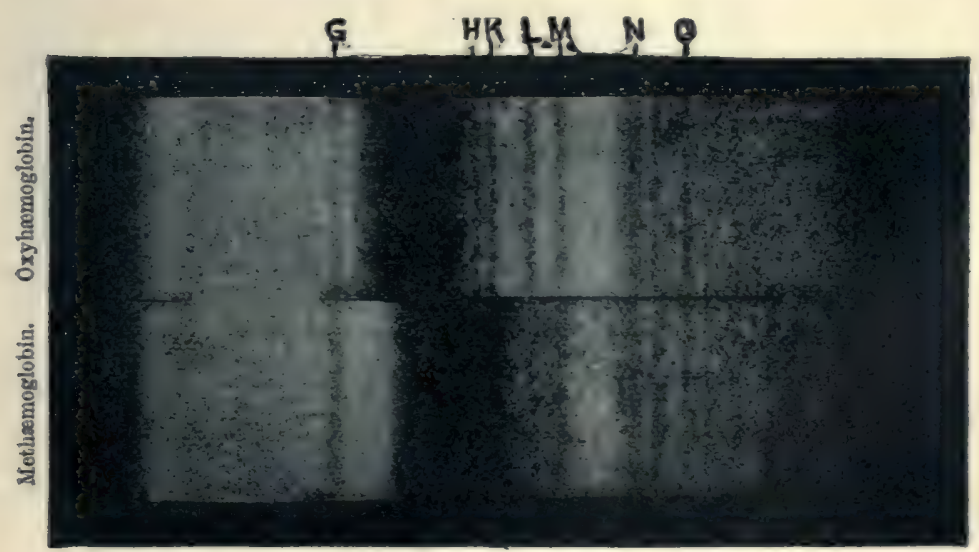

F16. 58.-The photographic spectrum of oxyharmoglobin and methremoglobin. (Gamgee)

porphyrin (iron-free hæmatin) (fig. 57, spectrum 10). Map out all the spectra you see on a chart.

8. The Photographic speetrum.-Hrmoglobin and its compounds also show absorption bends in the ultra-violet portion of the spectrum. This portion of the spectrum is not visible to the eye, but can be rendered visible 
by allowing the spectrum to fall on a fluoreseent screen, or on a sensitive photographic plate. In order to show absorption bands in this part of the spectrum very dilute solutions of the pigment must be used.

In order to demonstrate these bands, the telescope of a large spectroseope is removed, and a beam of sunlight or of light from the positive pole of an are lamp is allowed to fall on the slit of the collimator. The spectrum is focussed on a fluorescent screen. ${ }^{1}$ The slit is then opened very widely, and the coloured solution is interposed on the path of the beam falling on the slit.

Oxyhæmoglobin shows a band (Soret's band) between the lines $\mathrm{G}$ and $\mathrm{H}$. In hæmoglobin, carbonic oxide hæmoglobin, and nitric oxide hæmoglobin, this band is rather nearer G. Methæmoglobin and hæmatoporphyrin show similar bands.

The two preceding figures show the 'photographic spectra' of hæmoglobin, oxyhæmoglobin, and methæmoglobin, and will serve as examples of the results obtained. I am greatly indebted to Prof. Gamgee, to whom we owe most of our knowledge on this subject, for permission to reproduce these two specimens of his numerous photographs.

9. Preparation of Pure 0xyhæmoglobin.-The following method is described in Stirling's 'Practical Physiology' (3rd edit. p. 65). Centrifugalise dog's defibrinated blood and pour off the serum. Centrifugalise again with physiological saline solution repeatedly until the supernatant fluid contains only traces of proteid. Mix the magma of corpuseles with two or three volumes of water saturated with acid-free ether; the solution becomes clear. Then add a few drops of 1-per-cent. solution of acid sodium sulphate till the mixture looks tinted like fresh blood, owing to the precipitation of the stromatr. These can be separated by centrifugalising. (I have found that they aggregate together and can be easily removed by filtration.) Pour off the clear red fluid: cool it to $0^{\circ} \mathrm{C}$., add one-fourth of its volume of absolute alcohol previously cooled to $0^{\circ} \mathrm{C}$. Shake well, and then let the mixture stand at $5^{\circ}-15^{\circ} \mathrm{C}$. for 24 hours. As a rule the whole passes into a glittering crystalline mass. Filter at $0^{\circ} \mathrm{C}$. and wash with ice-cold 25-per-cent. alcohol. Redissolve the crystals in a small quantity of water, and recrystallise as before. The crystals may then be spread on plates of porous porcelain, and dried in a vacuum over sulphuric acid.

1 Fluorescent screens, similar to those in common use in observations made with Röntgen rays, may be made by coating white cardboard with barium platinocyanide. 


\section{LESSON XX}

\section{$S E R U M$}

1. The following methods of precipitating serum globulin (paraglobulin should be performed :-

(a) Panum's Method.-Dilute serum with fifteen times its bulk of water. It becomes cloudy owing to partial precipitation of the serum globulin. Add a few drops of 2-per-cent. acetic acid; the precipitate becomes more abundant, and it dissolves in excess of the acid. It was formerly called 'serum casein.'

(b) Alexander Schmidt's Method.-Dilute serum with twenty times its bulk of water and pass a stream of earbonic acid through it. A fairly abundant precipitate of serum globulin falls. Let it settle, and an additional precipitate can be obtained from the decanted liquid by treating it with a trace of acetic acid (the 'serum casein' mentioned above). Repeat the carbonic acid method without dilution; no precipitate forms.

(c) By Dialysis.-Put some serum in a dialyser with distilled water in the outer vessel. The water must be frequently changed. In order to prevent decomposition a few crystals of thymol are added. In a day or two the salts have passed out; the proteids remain behind: of these the serum albumin is still in solution; the serum globulin is in part precipitated, as it requires a small quantity of salt to hold it in solution.

(d) By Addition of Sslts:-

(i.) Schmidt's method. Saturate some serum with sodium chloride. A precipitate of serum globulin is produced.

(ii.) Hammarsten's method. Use magnesium sulphate instead of sodium chloride. A more abundant precipitate is produced, because this salt is a more perfect precipitant of serum globulin than sodium chloride. In order to obtain complete saturation with these salts it is necessary to shake the mixture of salt and serum for some hours. ${ }^{1}$

(iii.) Kauder's method. Half saturate serum with ammonium sulphate. This is done by adding to the serum an equal volume of saturated solution of ammonium sulphate. This precipitates the globulin. Complete saturation with the salt precipitates the albumin also.

2. Heat Coagulation.-Saturate serum with magnesium sulphate and filter off the precipitate ; preserve the filtrate and label it ' $B$.' Wash the precipitate on the filter with saturated solution of magnesium sulphate until the washings do not give the tests for albumin, ${ }^{2}$ then dissolve the precipitate

1 This may be conveniently done by a shaking machine before the class meets.

2 On account of the prolonged nature of these operations they must necessarily be performed by the demonstrator beforehand. 
by adding distilled water. It readily dissolves, owing to the salt adherent to it. The solution is opalescent. Label it 'A.'

Render A faintly acid with a drop of 2-per-cent. acetic acid, and heat in a test-tube. The temperature of the test-tube may be raised by placing it in a flask of water gradually heated over a flame. A thermometer is placed in the test-tube, and should be kept moving so as to ensure that all parts of the liquid are at the same temperature. The quantity of liquid in the test-tube should be just sufficient to cover the bulb of the thermometer. A flocculent precipitate of coagulated serum globulin separates out at about $75^{\circ}$.

Now take the filtrate B. This contains the serum albumin. Dilute it with an equal volume of water; render it faintly acid as before, testing the reaction with litmus paper. Heat. A floceulent precipitate $(a)$ falls at about $73^{\circ} \mathrm{C}$; filter this off; note that the filtrate is less acid than that from which the precipitate has separated, or it may even be alkaline. If so, make it faintly acid again, and heat; a precipitate falls at $77-79^{\circ} \mathrm{C} .(\beta)$. A third precipitate is similarly obtained at $84-86^{\circ} \mathrm{C} .(\gamma)$. In the serum of the ox, sheep, and horse the $a$ precipitate is absent: in cold-blooded animals, the $\beta$ and $y$ varieties are absent.

3. Take a fresh portion of $\mathrm{B}$, and saturate it with sodium sulphate. The serum albumin is precipitated (completely after a long shaking). This is due to the formation of sodio-magnesium sulphate. B was already saturated with magnesium sulphate $\left(\mathrm{MgSO}_{4}+7 \mathrm{H}_{2} \mathrm{O}\right)$; on adding sodium sulphate a double salt $\left(\mathrm{MgSO}_{4} \cdot \mathrm{Na}_{2} \mathrm{SO}_{4}+6 \mathrm{H}_{2} \mathrm{O}\right)$ is formed. Shake some serum with sodium sulphate alone. A small precipitate of globulin is produced. Saturate another portion of the serum with sodio-magnesium sulphate; both globulin and albumin are precipitated.

Of the methods used for precipitating serum globulin practically only two are used now. These are Hammarsten's and Kauder's. The other methods only precipitate the globulin incompletely. Kauder's method is rapid and efficacious : if the globulin is filtered off, the albumin may be precipitated in the filtrate by complete saturation with the same salt, ammonium sulphate. This method avoids the trouble of using two salts as described under 3. This last method is instructive, but not nearly so quick as Kauder's.

With regard to the separation of serum albumin into $a, \gamma$, and $\beta$ varieties by the use of the method of fractional heat coagulation, it must be men. tioned that at present no further difference has been shown to exist between them, and the opinion has been very freely expressed that the results obtained are not trustworthy. I am convinced that the method is a good one, especially as in other cases (see MuscLE) the proteids so separated can be shown to possess other differences. In the ease of serum, however-and the same is true for egg albumin-the matter must still be considered sub judice.

Recent research has shown that serum globulin is not a single proteid. We have already seen that the precipitation that oecurs by means of dialysis is incomplete. It has now been shown that serum globulin as - salted out ' by means of the sulphate of magnesium or ammonium really consists of two proteids; one of these (eu-globulin) is precipitable by dialysis: the other (pseudo-globulin) is not. 


\section{LESSON XXI COAGULATION OF BLOOD}

1. Salted plasma and oxalate plasma are the two kinds of blood-plasma. which are most easily prepared (Lesson IX.). The separation of the plasmas and corpuseles may most readily be carried out by the centrifugal machine (one form of this is represented in the next figure); the corpuscles settle and the supernatant plasma is pipetted off.

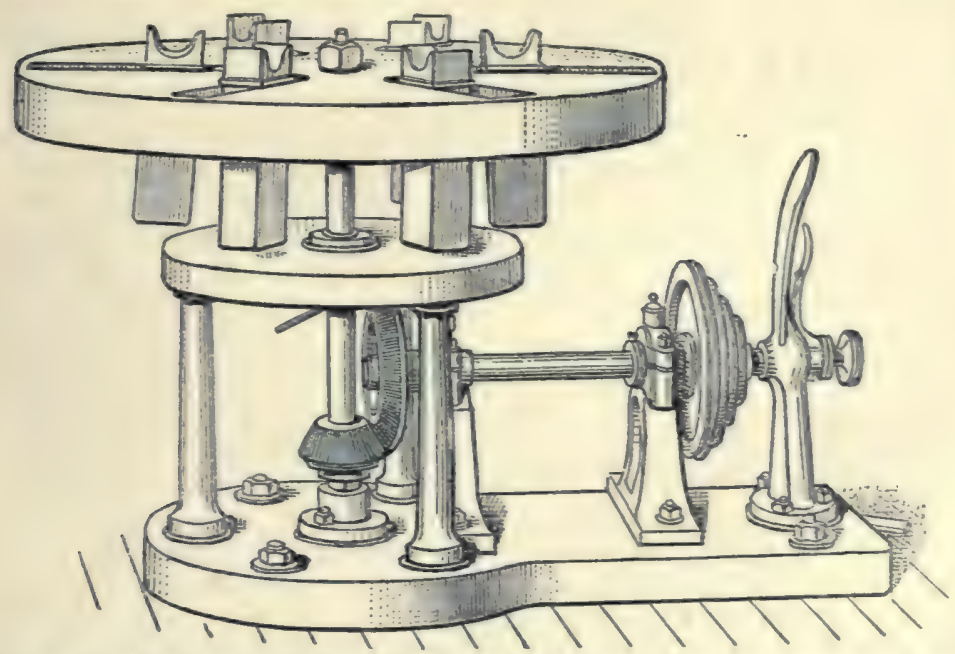

Fig. 60.-Centrifugal machine as marle br Runne of Heidelberg. Glass ressels containing the substances to be centrifugalised are placed within the six metallie tubes which hang rertically while the disc is at rest ; when the machinery is set going ther fly out into the horizontal position. A water motor or gas engine may be used to work the instrument. A small but effective handcentrifuge is made by Watson, Laidlaw, \& $\mathrm{Co}_{n}$ Glasgow.

The principal properties of these two forms of plasma have already been described in Lesson IX.; the following additional experiments may now be performed.

2. Heat a portion of the salted plasma to $60^{\circ} \mathrm{C}$. The fibrinogen is precipitated (coagulated by heat) at $56^{\circ} \mathrm{C}$. Filter. Dilute the filtrate as in Lesson IX. 3, and add fibrin ferment. No coagnlation occurs.

3. Oxalate plasma or decalcified plasma coagulates when a little calcium 
chloride is added, but not if the oxalate plasma has been previously heated to $60^{\circ} \mathrm{C}$. and filtered, because the fibrinogen has been thus removed.

4. Hydrocele Fluid.-This does not clot spontaneously, or only very slowly. Divide it into four parts-A, B, C, and D.

To $A$ add an equal volume of serum.

To $B$ add a few drops of fibrin-ferment solution.

To $C$ add a piece of buffy coat.

Put them into the warm bath, and coagulation takes place in each. The serum or the buffy coat supplies the missing fibrin ferment. The serum does not produce its effect in virtue of the serum globulin it contains; hydrocele fluid contains both fibrinogen and serum globulin, as the following experiment shows :-

Take the portion $\mathrm{D}$ and half saturate it with sodium chloride by adding to it an equal bulk of saturated solution of sodium chloride. Fibrinogen is precipitated. The precipitate is a small one, and on standing aggregates together, and so becomes more apparent. Filter, and saturate the filtrate with sodium chloride, or, better, magnesium sulphate; serum globulin is precipitated.

5. Intravascular coagulation.-A solution of nucleo-proteid from the thymus, testis, lymphatic glands, or kidney has been prepared beforehand by the demonstrator. It may be prepared in one of two ways.

(a) Wooldridge's Method.-The gland is cut up small and extracted with water for twenty-four hours. Weak acetic acid $(0.5$ c.c. of the acetic acid of the 'Pharmacopœia' diluted with twice its volume of water for every 100 c.c. of extract) is then added to the decanted liquid. After some hours the precipitated nucleo-proteid (called tissue-fibrinogen by Wooldridge) falls to the bottom of the vessel. This is collected and dissolved in 1-per-cent. sodium earbonate solution.

(b) The Sodium Chloride Method.-The finely divided gland is ground up in a mortar with about an equal volume of sodium chloride. The resulting viscous mass is poured into excess of distilled water. The nucleoproteid rises to the surface of the water, where it may be collected and dissolved as before.

A rabbit is anæsthetised, and a cannula inserted into the external jugular vein. The solution is injected into the circulation through this. The animal soon dies from cessation of respiration; the eyeballs protrude and the pupils are widely dilated. On opening the animal the heart will be found still beating, and its cavities (especially on the right side) distended with clotted blood. The vessels, especially the veins, also are full of clot. 


\section{LESSON XXII}

\section{MUSCLE AND NERVOUS TISSUES}

1. A rabbit has been killed and its muscles washed free from blood by a stream of salt solution injected through the aorta. The muscles have been quickly removed, chopped up small, and extracted with 5-per-cent. solution of magnesium sulphate. This extract is given out.

2. The extract will probably be faintly acid. The acid is lactic acid. It may be identified by the following reaction :-

A solution of dilute ferric chloride and carbolic acid is made as follows:- -

10 c.e. of a 4-per-cent. solution of carbolic acid.

20 c.c. of distilled water.

1 drop of the liquor ferri perchloridi of the British Pharmacopoia.

On mixing a solution containing a mere trace (up to 1 part in 10,000) of lactic acid with this violet solution, it is instantly turned yellow. Larger percentages of other acids (for instance, more than 0.2 per cent. of hydrochlorie acid) are necessary to decolorise the test solution.

3. The coagulation of muscle is very like that of blood. This may be shown with the salted muscle plasma (the extract given out) as follows: Dilute some of it with four times its rolume of water; divide it into two parts; keep one at $40^{\circ} \mathrm{C}$. and the other at the ordinary temperature. Coagulation, that is, formation of a clot of myosin, occurs in both, but earliest in that at $40^{\circ} \mathrm{C}$.

4. Add a few drops of 2-per-cent. acetic acid to some of the extract; a stringy precipitate of myosinogen is produced.

5. Remove the clot of myosin from 3 ; observe it is readily soluble in 10-per-cent. sodium chloride, and also in 0.2-per-cent. hydrochloric acid, forming syntonin.

6. Perform fractional heat coagulation$73^{\circ} \mathrm{C}$.

(a) With the original extract. Coagula are obtained at $47^{\circ}, 56^{\circ}, 63^{\circ}$,

(b) With the liquid (salted muscle serum) in 3, after separation of the clot. Coaguls are obtained at $63^{\circ}$ and $73^{\circ} \mathrm{C}$.

(c) With muscle extract which has been saturated with magnesium sulphate and filtered. The globulins are thus separated. Coagulation now occurs at $73^{\circ} \mathrm{C}$., but the amount of coagulum is small. 
The following table represents these facts concisely :

\begin{tabular}{|c|c|c|c|c|}
\hline Name of proteli & $\begin{array}{l}\text { Coagula- } \\
\text { tion tema- } \\
\text { perature }\end{array}$ & Action of $\mathrm{MgSO}_{*}$ & $\begin{array}{l}\text { Is it glo- } \\
\text { bulin or } \\
\text { albumin? }\end{array}$ & Fate \\
\hline 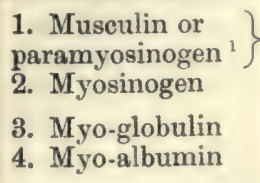 & $\begin{array}{l}47^{\circ} \mathrm{C} . \\
56^{\circ} \mathrm{C} . \\
63^{\circ} \mathrm{C} . \\
73^{\circ} \mathrm{C} .\end{array}$ & $\begin{array}{c}\text { precipitated } \\
\text { " } \\
\text { not precipitated }\end{array}$ & $\begin{array}{l}\text { globulin } \\
\text { ", } \\
\text { albumin }\end{array}$ & $\begin{array}{l}\left\{\begin{array}{c}\text { These go to form } \\
\text { the muscle } \\
\text { clot (myosin) } \\
\text { These are left in } \\
\text { the muscle } \\
\text { serum }\end{array}\right.\end{array}$ \\
\hline
\end{tabular}

7. Pigments of Muscle :-

(a) Notice the difference between the red and pale muscles of the rabbit.

(b) Examine a piece of red muscle (e.g. the diaphragm) spectroseopically for oxyhæmoglobin (or it may be more convenient to make an aqueous extract of the muscle and examine that).

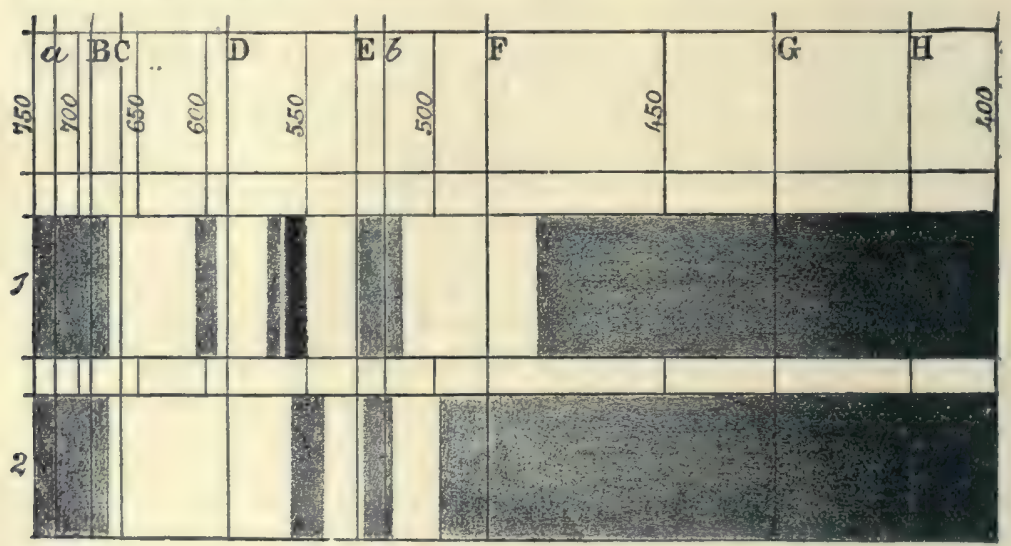

F1. 61.-1, Absorption spectrum of myohæmatin, as seen in muscle rendered transparent by glycerin. 2, Absorption spectrum of modified myoh:matin.

(c) A piece of the pectoral muscle of a pigeon has been soaked in glycerin. Press a small piece between two glass sides and place it in front of the spectroscope. Observe and map out the bands of myohæmatin.

(d) Pieces of the same muscles have been placed in ether for twenty-four hours. The ether dissolves out a yellow lipochrome from the adherent fat. A watery fluid below contains modified myohæmatin. Filter it; compare its spectrum with that of hæmochromogen. The myohæmatin bands are rather nearer the violet end of the spectrum (fig. 61, spectrum 2) than those. of hremochromogen (fig. 57, spectrum 9).

8. Creatine :-

(a) Take some of the red fluid described in $7, d$, and let it evaporate to. dryness in a desiccator over sulphuric acid (fig. 62).

? This proteid appear's to be absent in many forms of involuntary muscle. 
In a day or two crvstals of creatine tinged with myohæmatin separate out.

(b) Take an aqueous extract of muscle, like Liebig's extract or beef-tea ; add baryta water to precipitate the phosphates, and filter. Remove excess of baryta by a stream of carbonic acid; filter off the barium earbonate and evaporate the filtrate on the water-bath to a thick syrup. Set it aside to cool, and in a few days crystalline deposits of creatine will be found at the bottom of the vessel. These are washed with alcohol and dissolved in hot water. On concentrating the aqueous solution crystals once more separate out, which may be still further purified by recrystalli sation.

Creatinine can be obtained from meat extracts by Johnson's method (see pp. 124, 125) : indeed, Johnson states it is usually more abundant than creatine, and that the same is true for fresh meat.

Norb. - The exercises on muscle plasma described in this lesson have been in the main derived from my own investigations on the subject

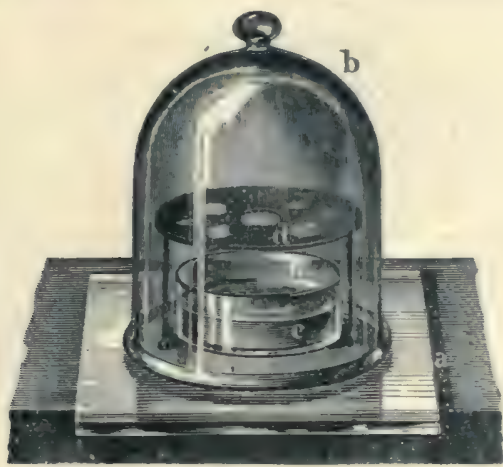

F10. 62. -A desiccator. (Gscheidlen.)

('Journ. of Physiol.,' viii. p. 133, ' Chemical Physiology and Pathol.,' Chap. XX.). The same subject has been recently taken up by v. Fürth ('Arch. Exp. Path. u. Pharm. 1895,' vol. xxxvi. p. 231). His nomenelature of the proteids is somewhat different from mine, but on main questions we are in substantial agreement-viz. that in the muscle plasma there are two principal proteids; these become changed, and so lead to the formation of the muscle clot, or myosin-fibrin as he terms it. He uses physiological saline solution to extract the muscle plasma, and this coagulates spontaneously on standing ; paramyosinogen ( $\mathrm{r}$. Fürth's myosin) passes directly into the condition of myosin-fibrin; but myosinogen ( $v$. Fürth's myogen) first passes into a soluble condition (coagulable by heat at the remarkably low temperature of $40^{\circ} \mathrm{C}$.) before the myogen-fibrin separates out. The myo-albumin which occurs in minute amount is probably serum albumin from adherent blood or lymph. The main points of difference between us are (1) he looks upon myosinogen as not being a true globulin, though like aglobulin in some of its characters; (2) myo-globulin is not a separate proteid, but only some myosinogen which has escaped coagulation. (3) The phenomenon I have termed recoagulation of muscle plasma he looks upon as being merely a reprecipitation 
of the globulins, and not a true coagulation process. He does not appear to have investigated the question of a specific myosin ferment.

When a muscle is gradually heated, at a certain temperature it contracts permanently and loses its irritability. This phenomenon is known as heatrigor, and is due to the coagulation of the proteids in the muscle. If a tracing is taken of the shortening, it is found that the first shortening occurs at the coagulation temperature of paramyosinogen $\left(47^{\circ}-50^{\circ} \mathrm{C}\right.$.), and if the heating is continued a second shortening occurs at $56^{\circ} \mathrm{C}$., the coagulation temperature of myosinogen. If frog's muscles are used there are three shortenings-namely, at $40^{\circ}, 47^{\circ}$, and $56^{\circ} \mathrm{C}$. ; frog's muscle thus contains an additional proteid which coagulates at $40^{\circ}$ C. (T. G. Brodie). Von Fürth regards this additional proteid as the soluble myosin alluded to above, some of which in frog's muscle is present before rigor mortis occurs.

In addition to all the proteids previously enumerated, there is a small quantity of nucleo-proteid.

\section{NERVOUS TISSUES}

The chemical investigation of nervous tissues does not lend itself very well to class exercises; still it may not be uninteresting to state briefly the principal known facts in relation to this subject. The most important points which any table of analyses will show are:(1) the large percentage of water, especially in the grey matter; (2) the large percentage of proteid. In grey matter, where the cells are prominent structures, this is most marked, and of the solids, proteid material here comprises more than half of the total. The following are some analyses which give the mean of a number of observations on the nervous tissues of human beings, monkeys, dogs, and cats :

\begin{tabular}{|c|c|c|c|c|c|c|}
\hline 一 & - & ; & & Water & Solids & $\begin{array}{l}\text { Percentage of } \\
\text { Proteids in } \\
\text { Solids }\end{array}$ \\
\hline Cerebral grey ma & atter. & : & . & $83 \cdot 5$ & 16.5 & 51 \\
\hline " white & , . & . & - & $69 \cdot 9$ & $30 \cdot 1$ & 33 \\
\hline Cerebellum . & .. & . & , & $79 \cdot 8$ & $20 \cdot 2$ & 42 \\
\hline Spinal cord as a & whole & . & . & $71 \cdot 6$ & $28 \cdot 4$ & 31 \\
\hline Cervical cord. & . $\quad$. & . & . & $72 \cdot 5$ & $27 \cdot 5$ & 31 \\
\hline Dorsal cord. & . & . & . & $69 \cdot 8$ & $30 \cdot 2$ & 28 \\
\hline Lumbar cord & . & . & . & $72 \cdot 6$ & $27 \cdot 4$ & 33 \\
\hline Sciatic nerves & . & - & . & $65 \cdot 1$ & $34 \cdot 9$ & 29 \\
\hline
\end{tabular}

The most abundant proteid is nucleo-proteid; there is also a certain amount of globulin, which, like the paramyosinogen of muscle, is coagulated by heat at the low temperature of $47^{\circ} \mathrm{C}$. A certain small amount of neurokeratin (especially abundant in white matter) is included in the above table with the proteids. The granules in nerve cells (Nissl's bodies), which stain readily with methylene blue, are nucleo-proteid in nature. The next most abundant substances are of a fatty nature; the most prominent of these is the phosphorised fat called lecithin (see p. 18). In the nervous tissues lecithin is combined with cerebrin to form a complex substance called protagon, which crystallises out on cooling a hot alcoholic extract of brain or 
other nervous structures. Cerebrin is a term which probably includes several substances, which are nitrogenous glucosides; they yield on hydrolysis the sugar called galactose (see p. 12). They are sometimes called cerebrosides. The crystalline monatomic aleohol cholesterin (see ps 73 ) is also a fairly abundant constituent of nervous structures, especially of the white substance of Schwann. Finally there are smaller quantities of other extractives, and a small proportion of mineral salts (about 1 per cent. of the solids).

Fresh nervous tissues are alkaline, but, like most other living structures, they turn acid after death. The change is particularly rapid in grey matter. The acidity is due to lactic acid.

Little or nothing is known of the chemical changes nervous tissues undergo during actirity. We know that oxygen is very essential, especially for the activity of grey matter; cerebral anæmia is rapidly followed by loss of conseiousness and death. Waller has suggested that small quantities of carbonic acid are produced during activity, because the increase in the action current (detected by the galvanometer) which oceurs after a nerve has been repeatedly excited is very like the increase also noted on the application of small quantities of this gas. Waller's statement that the action current is increased by small amounts of carbonic acid has, however, received other explanations. Certainly large quantities of carbonic acid act like an anæsthetic, abolishing nerrous actirity. Of all parts of the nervous system, the cells in the grey matter are those which most readily manifest fatigue; the next most sensitive region is the termination of nerves in such endings as the end plates. Fatigue in a medullated nerve trunk has never yet been experimentally demonstrated ; Waller's view that this is due to inter-nutritional changes between the axis cylinder and the investing medullary sheath can hardly be considered proved, for it is just as difficult to demonstrate fatigue in non-medullated nerres.

Chemistry of nerve-degeneration.-Mott and I have shown that in the disease General Paralysis of the Insane, the marked degeneration that occurs in the brain is accompanied by the passing of the products of degeneration into the cerebro-spinal fluid. Of these, nueleo-proteid and choline-a decomposition product of the lecithin (see p. 18) -are those which can be most readily detected. Choline can also be found in the blood. But this is not peculiar to the disease just mentioned, for in various other degenerative nervous diseases (combined sclerosis, disseminated"sclerosis, meningitis, alcoholic neuritis, beri-beri) choline can also be detected in these situations. The tests employed to detect choline are mainly two: (1) a chemical test. namely the obtaining of the characteristic octahedral errstals of the platinum double salt from the alcoholic extract of the cerebro-spinal fluid or blood; ${ }^{1}(2)$ a

1 This test is performed as follows: the fluid is diluted with about fire times its volume of alcohol and the precipitated proteids are filtered off. The filtrate is evaporated to dryness at $40^{\circ} \mathrm{C}$. and the residue dissolved in absolute alcohol and filtered; the filtrate from this is again eraporated to dryness, and again dissolved in absolute alcohol, and this should be again repeated. "To the final alcoho'ic solution, an alcoholic solution of platinum chloride is added, and the precipitate so formed is allowed to settle and washed with absolute alcohol by decantation; the precipitate is then dissolved in 15-per-cent. alcohol, filtered, and the filtrate is allowed to slowly evaporate in a watch-glass at $40^{\circ} \mathrm{C}$. The crystals ean then be seen with the microscope. They are recognised not only by their sellow colour 
physiological test, namely the lowering of arterial blood-pressure (partly cardiac in origin, and partly due to dilatation of peripheral vessels) which a saline solution of the residue of the alcoholic extract produces: this fall is abolished, or even replaced by a rise of arterial pressure, if the animal has been atropinised. It is possible that such tests may be of diagnostic value in the distinetion between organic and so-called functional diseases of the nervous system. The chemical test can frequently be obtained with 10 c.c. of blood.

A similar condition can be produced artificially in animals by a division of large nerve trunks; and is most marked in those animals in which the degenerative process is at its height as tested histologically by the Marchi reaction. ${ }^{2}$ A chemical analysis of the nerves themselves was also made. A series of cats was taken, both sciatic nerves divided, and the animals subsequently killed at intervals varying from 1 to 106 days. The nerves remain practically normal as long as they remain irritable, that is up to 3 days after the operation. They then show a progressive increase in the percentage of water, and a progressive decrease in the percentage of phosphorus until degeneration is complete. When regeneration occurs, the nerves return approximately to their previous chemical condition. The chemical explanation of the Marchi reaction appears to be the replacement of phosphorised by non-phosphorised fat. When the Marchi reaction disappears in the later stages of degeneration, the non-phosphorised fat has been absorbed. This absorption oceurs earlier in the peripheral nerves than in the central nervous system.

Further, it has been found that in human spinal cords in which a unilateral degeneration of the pyramidal tract has been produced by a lesion in the opposite hemisphere, and which gives the Marchi reaction. there is a similar increase of water and diminution of phosphorus in the degenerated side.

The table on next page shows these main results in the experiments on cats just deseribed.

Cerebro-spinal ffuid.-This functions as the lymph of the central nervous system, but differs considerably from all other forms of lymph. It is a very watery fluid, containing, besides some inorganic salts similar to those of the blood, a trace of proteid matter (globulin) and a small amount of a reducing substance, the nature of which is uncertain. It is, however, not sugar, but is possibly an aromatic substance allied to pyrocatechin. It contains the merest trace of choline; but this is not devoid of significance, for this fact taken in conjunction with another--namely, that physiological saline solution will extract from perfectly fresh nervous matter a small quantity of cholineshows us that protagon is not a stable substance, but is constantly breaking down and building itself up afresh; in fact, undergoing the process called metabolism. This is most marked in the most active region of the brainviz., the grey matter.

and octahedral form, and by their solubility in water and 15-per-cent. alcohol, but also by the fact that on incineration they yield 31 per cent. of platinum and give off the odour of trimethylamine.

1 The Marchi reaction is the black staining that the medullary sheath of degenernted nerve fibres shows when, after being hardened in Müller's fluid, they are treated with Marchi's reagent, a mixture of Müller's fluid and osmic acid. Healthy nerve fibres are not affected by the reagent, but degenerated myelin is blackened like the fat of normel adipose tissue. 


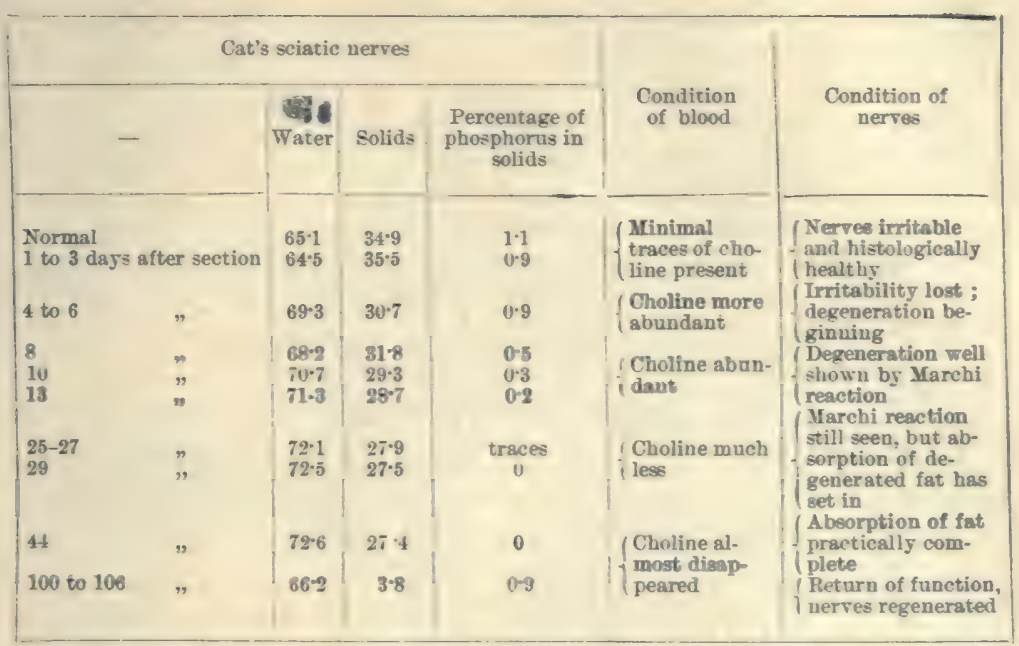

The foregoing figures relate to the peripheral portions of the nerves. Noll has also shown that the phosphorised material protagon diminishes somewhat in the central ends of cut nerves due to ' disuse atrophy.' 


\section{LESSON XXIII}

\section{UREA AND CHLORIDES IN URINE}

\section{ESTIMATION OF UREA}

If albumin is present it must be first separated by boiling after acidulation with acetic acid if necessary, and filtering off the flakes of coagulated proteid.

The three chief methods of estimating urea are-

(a) The mercuric nitrate or Liebig's method.

(b) The hypobromite, or Hüfner's method.

(c) The method of Mörner and Sjöqvist.

a. Liebig's Method.-The combination between urea and mercury has the formula $\left(\mathrm{CON}_{2} \mathrm{H}_{4}\right)_{2} \mathrm{Hg}\left(\mathrm{NO}_{3}\right)_{2}(\mathrm{HgO})_{3}$. It forms a white precipitate, insoluble in water and weak alkaline solutions. It is therefore necessary to prepare a standard solution of mercuric nitrate, and to have an indicator by which to detect the point when all the urea has entered into combination with the mercury, and the latter slightly predominates. This indicator is sodium carbonate, which gives a yellow colour with the excess of mercury, owing to the formation of hydrated mercuric oxide.

Theoretically, 100 parts of urea should require 720 parts of mercuric oxide, but practically $\mathbf{7 7 2}$ of the latter are necessary to remove all the urea, and at the same time show the yellow colour with alkali; consequently the solution of mercuric nitrate must be of empirical strength in order to give accurate results.

The following solutions must be prepared-

i. Standard mercuric nitrate solution. Dissolve $77 \cdot 2$ grammes of red oxide of mercury (weighed after it has been dried over a water-bath), or $71.5 \mathrm{gr}$. of the metal itself, in dilute nitric acid. Expel excess of acid by evaporating the liquid to a syrupy consistence. Make up to 1,000 c.c. with distilled water, adding the water gradually. This solution is of such a strength that 19 c.c. will precipitate 10 c.c. of a 2-per-cent urea solution. Add 52.6 c.c. of water to the litre of the mercuric nitrate solution and shake well ; then 20 c.c. (instead of 19$)=10$ c.c. 2 -per-cent. urea solution, i.e. 1 c.c. $=\cdot 01$ gr. urea.

ii. Baryta mixture. This is a mixture of two volumes of solution of barium hydrate with one of solution of barium nitrate, both saturated in the cold.

Analysis.-Take 40 c.c. of urine. Add to this 20 c.c. baryta mixture and filter off the precipitate of barium salts (phosphates and sulphates). Take15 c.c. of the filtrate (this corresponds to 10 c.c. of urine) in a beaker. Run into it the mercuric nitrate solution from a burette, until it is found that, on mixing a drop of the mixture with a drop of a saturated solution of sodium 
carbonate on a white tile, a pale lemon colour is produced. Then read the amount used from the burette, and calculate thence the percentage of urea.

Corrections. - This method only approaches accuracy when the quantity of urea present is about 2 per cent., which is about the normal percentage of urea in urine. The chlorine in the urine must also be estimated, and the quantity of urea indicated reduced by the subtraction of 1 gramme of urea for every 1.3 gramme of sodium chloride found. If the urine contains less than 2 per cent. of urea, $0 \cdot 1$ c.c. of mercuric nitrate solution must be deducted for every 4 c.c. used; if more than 2 per cent. of urea, a second titration must be performed with the urine diluted with half as much water as has been needed of the mercurial solution above 20 c.c. Suppose that 28 c.c. have been used in the first titration, the excess is 8 c.c.; therefore 4 c.c. of water must be added to the urine before the second titration is made. When ammonium carbonate is present, first estimate the urea in one portion of urine, and the ammonia by titration with normal sulphuric acid in another; 0.017 gramme of ammonia $=0.030$ of urea. The equivalent of ammonia must be added to the urea found in the first portion of urine.

b. The Hypobromite Method.-This is a far easier method. It consists in decomposing urea into water, earbonic acid, and nitrogen by means of an alkaline solution of hypobromite of soda; the carbonic acid combines with the soda, and the nitrogen which is evolved is measured, and the quantity of urea calculated from this. There are many kinds of apparatus for performing this operation, but the best is that of Dupré (see Lesson X.).

Reactions and Corrections.-The reaction by which urea is decomposed in this proceeding may be denoted by the following formula :-

$$
\mathrm{CON}_{2} \mathrm{H}_{4}+3 \mathrm{NaBrO}=\mathrm{CO}_{2}+\mathrm{N}_{2}+2 \mathrm{H}_{2} \mathrm{O}+3 \mathrm{NaBr} \text {. }
$$

From 1 gramme of urea 0.46 gramme of nitrogen $=372 \cdot 7$ c.c. is obtained.

In practice, however, it is found that only $354 \cdot 3$ c.c. are obtained, ${ }^{1}$ except in diabetic urine, in which the urea yields nearly the normal amount of nitrogen. Moreover, urine contains small quantities of creatinine and urates, which yield some of their nitrogen when acted on by sodium hypobromite. When great exactitude is required these must be removedcreatinine by an alcoholic solution of zinc chloride, and the urates by acetate of lead followed by sodium phosphate (Yvon).

5 c.c. of a 2 -per-cent. solution of urea in urine yield 35.4 c.c. of nitrogen. This quantity is taken as representing 2 per cent. of urea, and serves as a basis for the graduations of the tubes, which are marked in percentages.

When exactitude is required, the quantity of nitrogen must be measured in cubic centimetres, and the volume obtained corrected for temperature, pressure, and tension of aqueous vapour by the formula below. ${ }^{2}$

1 The cause of this loss of nitrogen has been investigated by Luther, Zeit. physiol. Chem. xiii. p. 500. He finds part is combined as a nitrate, and part in an unknown organic compound which gives off ammonia when distilled with alkali.

$2 \mathrm{~V}^{\prime}=$ correct volume $; \mathbf{V}=\mathrm{vol}$ observed $; \mathbf{B}=$ barometric pressure corrected for temperature ; $t=$ temp. in degrees Centigrade; $T=$ tension of aqueous vapour in millimetres of mercury at $t^{\circ}$ (see table, p. 8). Then

$$
V^{\prime}=\frac{V \times(B-T)}{760 \times(1+0.003665 t)}
$$


Of the two methods just described, Liebig's is so cumbrous and inexact that it has almost passed out of use. The hypobromite method holds its own, as it is easy and sufficiently exact for clinical purposes. When absolute accuracy is necessary, one of the numerous recently introduced methods must be employed, and of these the method of Mörner and Sjöqvist appears to be best.

(c) Method of Mörner and sjöqvist.-The following reagents are necessary:

i. A saturated solution of barium chloride containing 5 per cent. of barium hydrate.

ii. A mixture of ether and alcohol in proportion $1: 2$.

iii. The apparatus, \&c., necessary for carrying out Kjeldahl's method of estimating nitrogen (see p. 199).

Analysis.-Five c.c. of urine are mixed with 5 c.c. of the barium mixture and 100 e.c. of the mixture of ether and alcohol. By this means all nitrogenous substances except urea are precipitated. Twenty-four hours later this is filtered off, and the precipitate is washed with 50 c.c. of the ether-alcohol mixture, the filter-pump being used to accelerate the process. The washings are added to the filtrate; a little magnesia is added to this to drive off ammonia. The alcohol and ether is then driven off at a temperature of $55^{\circ} \mathrm{C}$. and evaporation is continned at this temperature until the volume of the residue is 10-15 c.e. The nitrogen in this is estimated by Kjeldahl's method. The nitrogen found is multiplied by $2 \cdot 143$, and the result is the amount of urea.

\section{PREPARATION OF UREA FROM URINE}

(1) Evaporate the urine to a small bulk. Add strong pure nitric acid in excess, keeping the mixture cool during the addition of the acid. Pour off the excess of fluid from the crystals of ureq nitrate which are formed; strain through muslin and press between filter paper. Add to the dry product barium carbonate in large excess. This forms barium nitrate and sets the urea free. Mix thoroughly with sufficient methylated spirit to form a paste. Dry on a water-bath and extract with alcohol; filter; evaporate the filtrate on a water-bath and set aside. The urea crystallises out, and may be decolorised by animal charcoal and purified by recrystallisation.

(2) The following method is well adapted for the preparation of microscopic specimens of urea and urea nitrate: Take 20 c.c. of urine; add

aryta mixture' (two volumes of barium hydrate solution and one volume of barium nitrate solution, both saturated in the cold) until no further precipitate is produced; filter, evaporate the filtrate to a thick syrup on the water-bath, and extract with alcohol; pour off and filter the alcoholic extract; evaporate it to dryness on the water-bath and take up the residue with water. Place a drop of the aqueous solution on a slide and allow it to crystallise; crystals of urea separate out. Place another drop on another slide and add a drop of nitric acid ; crystals of urea nitrate separate out.

\section{ESTIMATION OF CHLORIDES}

The chlorides in the urine consist of those of sodium and potassium, the latter only in small quantities. The method adopted for the determination 
of the total chlorides consists in their precipitation by a standard solution of silver nitrate or mercuric nitrate.

Mohr's'Method.-Precipitation by silver nitrate.

The following solutions must be prepared :

Standard silver nitrate solution. Dissolve 29.075 grammes of fused nitrate of silver in a litre $(1,000$ c.c. $)$ of distilled water; 1 c.c. $=001$ gramme of sodium chloride.

(a) Saturated solution of neutral potassium chromate.

Analysis.-Take 10 c.c. of urine; dilute with 100 c.c. of distilled water.

Add to this a few drops of the potassium chromate solution.

Drop into this mixture from a burette the standard silver nitrate solution; the chlorine combines with the silver to form silver chloride, a white precipitate. When all the chlorides are so precipitated, silver chromate (red in colour) goes down. but not while any chloride remains in solution. The silver nitrate must therefore be added until the precipitate has a pink tinge.

From the amount of standard solution used, the quantity of sodium chloride in 10 c.c. of urine, and thence the percentage, may be calculated.

Sources of Error and Corrections. - A high-coloured urine may give rise to difficults in seeing the pink tinge of the silver chromate: this is overcome by diluting the urine more than stated in the preceding paragraph.

1 c.c. should always be subtracted from the total number of c.c. of the silver nitrate solution used, as the urine contains small quantities of certain compounds more easily precipitable than the chromate.

(b) To obviate such sources of error the following modification of the test, as described by Sutton, ${ }^{1}$ may be used : 10 c.c. of urine are measured into a thin porcelain capsule and 1 gramme of pure ammonium nitrate added; the whole is then evaporated to dryness, and gradually heated over a small spirit lamp to low redness till all vapours are dissipated and the residue becomes white. It is then dissolved in a small quantity of water, and the carbonates produced by the combustion of the organic matter neutralised by dilute acetic acid; a few grains of pure calcium carbonate to remove all free acid are then added, and one or two drops of potassium chromate. The mixture is then titrated with decinormal silver solution (16.966 gr. of silver nitrate per litre) nutil the end reaction, a pink colour. appears. Each c.c. of silver solution represents $0.005837 \mathrm{gr}$. of salt : consequently, if 12.5 c.c. have been used, the weight of salt in the 10 c.c. of urine is $0.07296 \mathrm{gr}$., or 0.7296 per cent. If 5.9 c.e. of urine are taken for titration, the number of c.c. of silver solution used will represent the number of parts of salt per 1,000 parts of urine.

(c) Liebig's Method.-Precipitation by mercuric nitrate.

The following solutions must be first prepared :

i. Standard mercuric nitrate solntion: Dissolve 20 grammes of pure mercury in boiling nitric acid; then dilute to nearly a litre. To dilute this to the right strength, preliminary experiments must be performed with a standard solution of pure sodium chloride, 20 grammes to the litre. Take 10 c.c. of the standard sodium chloride solution, add to this 2 c.c. of a 4 -percent. solution of urea and 5 c.c. of a saturated solution of sodium sulphate.

1 Tolumetric Analysis, p. 309. 
Into this mixture allow the mercuric nitrate solution to flow from a burette, stirring the mixture the while. A precipitate forms, which redissolves on stirring; add the mercuric nitrate solution till a permanent precipitate (not an opaleseence) forms ; the reaction is then complete. The strength of the mercurial solution is thus determined, and it is then diluted so that 20 c.c. $=0.2$ gramme of sodium chloride $=10$ c.c. of the standard sodium chloride solution; 1 c.c., therefore, corresponds to 0.01 gramme of sodium chloride, or 0.006059 gramme of chlorine.

ii. Baryta mixture, made by adding two volumes of barium hydrate solution to one of barium nitrate solution, both saturated in the cold.

iii. Dilute nitric acid (1 in 20).

Analysis.-Take 40 c.e. of urine.

Add 20 c.e. of baryta mixture. Filter off the precipitate which forms, which consists of sulphate and phosphate of barium.

Take 15 c.e. of the filtrate: this corresponds to 10 e.c. of the original urine.

Render this slightly acid with dilute nitric acid.

Run in the standard mercuric nitrate solution from a burette, stirring the mixture well until a permanent precipitate appears.

Read off the number of c.c. used; multiply by 0.01 . This gives the amount of chloride as sodium chloride contained in 10 c.c. urine.

Explanation and Corrections.-This test depends on the fact that when mercuric nitrate and sodium chloride in solution are mixed, sodium nitrate and mercuric chloride, which are both soluble in water, are formed. It is not till all the chloride in the urine is so decomposed that mercuric nitrate begins to combine with the urea present to form a permanent white precipitate. Hence the necessity of estimating the chlorides when using Liebig's method for the determination of urea.

In order to obtain the exact point at which the precipitate becomes a permanent one, the process must be repeated in another specimen. The advantage of this process is its simplicity : its disadvantage is that the end point is rather obscure.

If the urine used is albuminous, the albumin must be first removed by boiling, after the addition of a few drops of acetic acid, and filtering off the precipitated proteid. 


\section{LESSON XXIV}

\section{ESTIMATION OF PHOSPHATES AND SULPHATES IN URINE}

\section{ESTIMATION OF PHOSPHATES}

The phosphoric acid in the urine is combined with soda, potash, lime, and magnesia.

(a) Estimation of the total phosphates.

For this purpose the following reagents are necessary:

i. A standard solution of uranium nitrate. The uranium nitrate solution contains 35.5 grammes in a litre of water ; 1 c.c. corresponds to 0.005 gramme of phosphoric acid $\left(\mathrm{P}_{2} \mathrm{O}_{5}\right)$.

ii. Acid solution of sodium acetate. Dissolve 100 grammes of sodium acetate in 900 c.c. of water; add to this 100 c.c. of glacial acetic acid.

iii. Solution of potassium ferrocyanide.

Method.-Take 50 c.c. of urine. Add 5 c.c. of the acid solution of sodium acetate. ${ }^{1}$ Heat the mixture to $80^{\circ} \mathrm{C}$.

Run into it while hot the standard uranium nitrate solution from a burette until a drop of the mixture gives a distinct brown colour with a drop of potassium ferrocyanide placed on a porcelain slab. Read off the quantity of solution used and calculate therefrom the percentage amount of phosphoric acid in the urine.

(b) Estimation of the phosphoric acid combined with lime and magnesia (alkaline earths).

Take 200 c.c. urine. Render it alkaline with ammonia. Lay the mixture aside for twelve hours. Collect the precipitated earthy phosphates on a filter ; wash with dilute ammonia ( 1 in 3$)$. Wash the precipitate off the filter with water acidified by a few drops of acetic acid. Dissolve with the aid of heat, adding a little more acetic acid if necessary. Add 5 c.c. of the acid solution of sodium acetate. Bring the volume up to 50 c.c., and estimate the phosphates in this volumetrically by the standard uranium nitrate as before. Subtract the phosphoric acid combined with the alkaline earths thus obtained from the total quantity of phosphoric acid, and the difference is the amount of acid combined with the alkalis soda and potash.

(c) Instead of uranium nitrate a standard solution of uranium acetate may be used. The directions for the making of these standard solutions will be found in Sutton's 'Volumetric Analysis.' As a rule, it is less troublesome, and not much more expensive, to purchase standard solutions ready-made.

${ }^{1}$ In using uranium nitrate it is imperative that sodium acetate should accompany the titration in order to avoid the possible occurrence of free nitric acid in the solution. If uranium acetate is used, it may be omitted. 


\section{ESTIMATION OF SULPHATES}

The sulphates in the urine are of two kinds: the pre-formed sulphatesviz. those of soda and potash, and the combined or ethereal sulphates.

(a) For the determination of the total amount of sulphuric acid $\left(\mathrm{SO}_{3}\right)$ (i.e. pre-formed and combined sulphuric acid together) in the urine, one of two methods is adopted:

1. Volumetric method.

2. Gravimetric method.

Both methods will be given here; the former is, however, better suited for class experiments.

1. Volumetric Determination.-This process consists in adding to a given volume of the urine a standard solution of chloride of barium so long as a precipitate of barium sulphate is formed.

The following solutions are necessary :-

i. Standard barium chloride solution: 30.5 gramnes of crystallised chloride of barium in a litre of distilled water; 1 c.c. of this solution corresponds to 0.01 gramme of sulphuric acid $\left(\mathrm{SO}_{3}\right)$.

ii. Solution of sulphate of potash : 20 per cent.

iii. Pure hydrochloric acid.

Method.-100 c.c. of urine are taken in a flask. This is rendered acid by 5 c.c. of hydrochloric acid, and boiled. The combined sulphates are thus converted into ordinary sulphates, and give a precipitate like them with barium chloride. The chloride of barium solution is allowed to drop into this mixture as long as any precipitate occurs, the mixture being heated before every addition of barium chloride to it. After adding 5 to 8 c.c. of the standard solution, allow the precipitate to settle; pipette off a few drops of the clear supernatant fluid into a watch-glass; add to it a few drops of the standard barium chloride solution. If any precipitate occurs, return the whole to the flask and add more barium chloride; again allow the precipitate to settle, and test as before; go on in this way until no more barium sulphate is formed on the addition of barium chloride.

Excess of barium chloride must also be avoided; when only a trace of excess is present a drop of the clear fluid removed from the precipitate gives a cloudiness with a drop of the potassium sulphate solution placed on a glass plate over a black ground. If more than a cloudiness appears, too large a quantity of barium chloride has been added, and the operation must be repeated. From the quantity of barium chloride solution used, the percentage of sulphuric acid in the urine is calculated.

2. Gravimetric Determination (i.e. by weight).- This method consists in weighing the precipitate of barium sulphate obtained by adding barium chloride to a known volume of urine; 100 parts of sulphate of barium correspond to 34.33 parts of sulphuric acid $\left(\mathrm{SO}_{3}\right)$.

Method (Salkowski).-100 c.c. of urine are taken in a beaker. This is boiled with 5 c.c. of hydrochloric acid as before.

Chloride of barium is added till no more precipitate occurs.

The precipitate is collected on a small filter of known ash, and washed with hot distilled water till no more barium chloride occurs in the filtrate- 
i.e. until the filtrate remains clear after the addition of a few drops of hydric sulphate. Then wash with hot alcohol, and afterwards with ether. Remove the filter, and place it with its contents in a platinum crucible. Heat to redness. Cool over sulphuric acid in a desiccator; weigh, and deduct the weight of the crucible and filter ash; the remainder is the weight of barium sulphate formed.

Error.-When the experiment is carried out as above there is a slight error from the formation of a small quantity of sulphicle of barium. This may be corrected as follows: After the platinum crucible has become cool add a few drops of pure sulphuric acid $\left(\mathrm{H}_{2} \mathrm{SO}_{1}\right)$. The sulphide is converted into sulphate. Heat again to redness to drive off excess of sulphuric acid.

(b) The following is Salkowski's ${ }^{1}$ method of estimating the combined sulphuric acid-that is, the amount of $\mathrm{SO}_{3}$ in ethereal sulphates:-100 c.c. of urine are mixed with 100 c.c. of alkaline barium chloride solution, which is a mixture of two volumes of solution of barium hydrate with one of barium chloride, both saturated in the cold. The mixture is stirred, and after a : $\mathbf{v}$ minutes filtered : 100 c.c. of the filtrate ( $=50$ c.c. of urine) are aciditied with 10 c.c. of hydrochloric acid, boiled, kept at $100^{\circ} \mathrm{C}$. on the water-bath for an hour, and then allowed to stand till the precipitate has completely settled; if possible, it should be left in this way for twenty-four hours. The further treatment of this precipitate ( = combined sulphates) is then carried out as in the last ease.

Calculation.-233 parts of barium sulphate correspond to 98 parts of $\mathrm{H}_{2} \mathrm{SO}_{4}$, or 80 parts of $\mathrm{SO}_{3}$ or 32 parts of $\mathrm{S}$. To calculate the $\mathrm{H}_{2} \mathrm{SO}_{4}$, multiply the weight of barium sulphate by $\frac{98}{233}=0.4206$; to calculate the $\mathrm{SO}_{3}$ multiply by $\frac{80}{233}=0 \cdot 34335$; to calculate the S multiply by $\frac{32}{233}=0 \cdot 13734$. This method of calculation applies to the gravimetric estimation both of total sulphates and of combined sulphates.

(c) To obtain the amount of pre-formed sulphuric acid subtract the amount of combined $\mathrm{SO}_{3}$ from the total amount of $\mathrm{SO}_{3}$. The difference is the pre-formed $\mathrm{SO}_{3}$.

Example: 100 c.c. of urine gave 0.5 gramme of total barium sulphate. This multiplied by $\frac{80}{233}=0.171 \mathrm{gr}$. = total SO $\mathrm{SO}_{3}$. Another 100 c.c. of the same urine gave $0.05 \mathrm{gx}$. of barium sulphate from ethereal sulphates; this multiplied by ${ }_{233}^{80}=0.017 \mathrm{gr}$. of combined $\mathrm{SO}_{3}$. Total $\mathrm{SO}_{3}$-combined $\mathrm{SO}_{3}$ $=0.171-0.017=0.154 \mathrm{gr}$. of pre-formed $\mathrm{SO}_{3}$.

'Zeit.physiol. Chem. x. p. 346. This method is a modification of Baumann's original method, $i b i d$. i. p. 71 . 


\section{LESSON XXV \\ URIC ACID AND CREATININE}

1. Prepartion of Pure Uric Acid.-If one wishes to prepare pure uric acid the solid urine of a reptile or bird, which consists principally of the acid ammonium salt, should be selected; one has not then to separate any pigment. It is boiled with 10 per cent. caustic soda or ammonia, diluted, and then allowed to stand. The clear fluid is decanted and poured into a large excess of water to which 10 per cent. of hydrochloric acid has been added; after twenty-four hours, crystals of uric acid are deposited. These may be purified by washing, re-solution in soda, and re-precipitation by acid.

2. Estimation of Uric Acid (Hopkins's method).-The following reagents are required :

Pure chloride of ammonium, finely powdered.

A wash bottle containing a filtered saturated solution of the same salt.

A twentieth normal solution of potassium permanganate made by dissolving 1.581 grammes of permanganate in a litre of water.

Separation of uric acid from the urine.-Measure 100 c.c. of urine into a beaker of about 150 c.c. capacity.

Add to this 25 grammes (approximately weighed) of ammonium chloride, stirring briskly till all the salt is dissolved. Now add 2 c.c. of strong ammonium hydrate, and allow the mixture to stand until the precipitate of ammonium urate, which rapidly forms, has wholly settled to the bottom of the beaker; its subsidence is promoted by occasional brisk stirring.

Adjust a small filter paper $(7 \mathrm{~cm}$. diam.) in a funnel of such size that only a small margin of glass projects above the edge of the folded paper, and transfer to this the ammonium urate precipitate.

Filtration should not be commenced until the precipitate has settled satisfactorily, and the supernatant liquid is clear. The latter should be first poured on to the filter, the precipitate being so far as possible retained in the beaker until the greater part of the clear liquid has filtered through ; finally transfer the whole to the filter with the help of a wash bottle containing saturated ammonium chloride solution. After the filter has thoroughly drained, wash the precipitate twice again with the same solution.

While the last washings are running through the paper, distilled water should be heated to boiling in a wash bottle provided with a fine jet. The funnel containing the filter is now held horizontally over a small porcelain basin (of about 50 c.c. capacity) and the precipitate washed into the latter with a jet of hot water, the filter itself being afterwards opened out over the basin in order that any urate adhering to its folds can be washed off. Not 
more than 20-30 c.c. of water need be employed in this transference: if much more has been used the liquid should be concentrated over the water bath at this stage. A little strong $\mathrm{HCl}$ (1 c.c.) is next added to the contents of the basin, and the whole is then heated over a burner until it just reaches the boiling point. It is then set aside for the uric acid to crystallise out.

Titration of the uric acid.-If the mixture is artificially cooled all the uric acid will separate out in two hours, otherwise it is best allowed to stand over night or longer.

The crystals are filtered off through a very small filter paper $(4 \mathrm{~cm}$. diam.); the filtrate is received into a graduated cylinder so that the amount of mother liquor may be noted (see below). The uric acid is next washed with cold distilled water until free from chlorides. It is unnecessary to transfer the whole to the filter ; the greater part may be washed by decantation. Such of the crystals as are upon the filter are now washed back into the basin (best by the aid of hot water) and the whole-quantity is dissolved by heating to boiling with 1 c.c. of 10 -per-cent. sodium carbonate solution and as much distilled water as the basin will safely hold.

The solution is transferred to a $\frac{1}{4}$-litre Erlenmeyer flask, which should be marked roughly at 100 c.c. The solution is made up to this mark with distilled water, and cooled to the temperature of the room.

The standard permanganate solution being ready in a burette, 20 c.c. of strong sulphuric acid are added to the contents of the flask, and the mixture shaken and titrated.

During the addition of the standard solution the liquid in the flask should be kept in vigorous movement. It will be found that at first the disappearance of the pink colour is so rapid that each drop as it is added is decolorised before it has time to diffuse through the whole liquid. The first instantaneous appearance of a diffused flush throughout the solution indicates the end point of the reaction. This colour rapidly disappears, but it will be found that the effect of adding further quantities of permanganate after the end point has been passed is quite different from the effect before the end point was reached; each drop is now able to diffuse throughout the fluid.

For each c.c. of the solution necessary to produce the end point just described 0.00375 gramme of uric acid is present. To the value so obtained $1 \mathrm{mgm}$. must be added for each 15 c.c. of the mother liquor from which the crystals separated.

Thus the uric acid from 100 c.c. of a sample of urine used up 18.5 c.c. of the standard permanganate solution. The mother liquor filtered from the crystals measured 25 c.c.

$$
\begin{aligned}
18.5 \times .00375 & =\cdot 0694 \text { gr. nearly } \\
.001 \times \frac{25}{15} & =\cdot 0017 \\
\text { Total } & =\cdot \overline{0711}
\end{aligned}
$$

The urine contained 71 mgms. uric acid per 100 c.c.

3. Estimation of Creatinine.-The crystalline compound which creatinine forms with zine chloride is employed in estimating the quantity of creatinine in urine; 100 parts of the compound correspond to $62 \cdot 42$ of creatinine.

Method.-Take 250 c.c. of urine. Add milk of lime and calcium chloride 
in excess to precipitate the phosphates. Filter, and evaporate the filtrate to a small bulk; to this add 50 c.e. absolute alcohol, and let the mixture stand for six hours. Then add 10 or $\mathbf{1 5}$ drops of an aleoholic solution of zine chloride; the crystals form, and after two or three days' standing in a dark place may be collected on a weighed filter.

Wash with 90 per cent. alcohol, dry and weigh, and thence calculate the percentage of creatinine.

4. Estimation of Creatinine. Johnson's Method.-Take 100 c.c. of urine; add to it 5 c.c. of a saturated solution of sodium acetate, and then 20 c.c. of a saturated solution of mercuric chloride. This produces an abundant precipitate of urates, sulphates, and phosphates. Filter. Set the filtrate aside for twenty-four hours, and the mercury compound of creatinine crystallises out. Examine this deposit with the microseope : note it is composed of spherules. For quantitative purposes, this is collected, washed, dried, and weighed in the usual way. One-fifth of the weight obtained is creatinine. Throughout the processes no heat is used, otherwise the characteristic properties of urinary creatinine are altered; but if only a quantitative analysis is wanted the method may be hastened by boiling the first filtrate for ten minutes, instead of letting it stand twenty-four hours.

In order to separate the base itself (see p. 125), much larger volumes of urine must be employed, for there is considerable loss in the later stages of the process. Tohnson himself used some hundreds of litres. 


\section{LESSON XXVI}

\section{THE PIGMENTS OF THE URINE}

The urinary pigments are numerous, and have from time to time been deseribed under different names by various observers.

1. Urochrome.-This is the essential yellow pigment of the urine. The word was originally introduced by Thudichum, and the substance he obtained is now recognised to have been a mixture of several pigments, of which, however, the essential yellow pigment formed a large proportion. Garrod's method of separating it from the urine is as follows:-

The urine is saturated with ammoninm sulphate and filtered. The filtrate contains the pigment; this is shaken with alcohol. The alcohol separates readily from the saline mixture, and as it does so dissolves out much of the urochrome. By repeated extraction all the pigment passes into solution in the alcohol. The alcoholic solution is diluted with water, and the mixture again saturated with ammonium sulphate. The alcohol containing the pigment in solution again separates out. The second alcoholic solution is made faintly alkaline with ammonia and evaporated to dryness. The residue is extracted once or twice with acetic ether, and then again dissolved in strong alcohol. Finally the alcohol is concentrated till it is deep orange in tint, and poured into an equal volume of ether. The pure pigment is by this means precipitated as an amorphous brown powder.

Urochrome shows no absorption bands. As already stated (p. 108), it is probably an oxidation product of urobilin.

2. Urobilin.-Urobilin is a derivative of the blood-pigment, and is identieal with stercobilin (see pp. 73,107 ). Probably both reduction and hydration occur in its formation. It is very like the substance named hydrobilirubin by Maly, which he obtained by the action of sodium amalgam on bilirubin. The following formulæ ${ }^{1}$ show the relationship between these allied pigments :-

$$
\begin{aligned}
& \text { Hrematin - . . . . . } \mathrm{C}_{32} \mathrm{H}_{32} \mathrm{~N}_{4} \mathrm{O}_{4} \mathrm{Fe} \\
& \text { Bilirubin . . . . . }{ }^{-} \mathrm{C}_{32} \mathrm{H}_{36} \mathrm{~N}_{4} \mathrm{O}_{6} \\
& \text { Hydrobilirubin . . . . . } \mathrm{C}_{52} \mathrm{H}_{40} \mathrm{~N}_{4} \mathrm{O}_{7}
\end{aligned}
$$

Urobilin is probably a further stage in reduction.

Normal urine contains but little urobilin; what is present is chiefly in the form of a colourless chromogen, which by oxidation is converted into urobilin. In numerous pathological conditions urobilin is abundant. The

1 The formulæ given are those of Nencki and Sieber. They differ from hose previously given (p. 90) by Hoppe-Seyler. 
so-called 'pathological urobilin' described by previous writers is ordinary urobilin incompletely separated from various impurities.

The following are the methods introduced by Garrod and Hopkins for its separation from the urine:-

(a) The urine is first saturated with ammonium chloride, and the urate so precipitated is filtered off. The filtrate is then acidified with sulphuric acid and saturated with ammonium sulphate. This causes a precipitate of urobilin, which may be collected and dissolved in water. The aqueous solution is again saturated with ammonium sulphate, and the pigment is thus precipitated in a state of purity.

(b) The urates are first removed, then the urine is acidified and saturated with ammonium sulphate as before. The urobilin is then extracted from the mixture by shaking it with a mixture of chloroform and ether $(1: 2)$ in a large separating funnel. The ether-chloroform extract is then rendered faintly alkaline and shaken with distilled water, and the urobilin passes into solution in the water. The aqueous solution is now once more saturated with ammonium sulphate and slightly acidified; it then once more yields its pigment to ether chloroform.

By means of either of these methods urobilin is obtained in a pure condition; even normal urine will give some, for the chromogen is partly converted into the pigment by the acid employed.

Urobilin dissolved in alcohol exhibits a green fluorescence, which is greatly increased by the addition of zine chloride and ammonia. It shows a well-marked absorption band between $b$ and $\mathrm{F}$, slightly overlapping the latter (fig. 63, spectrum 4).

Urobilin, like most animal pigments, shows acidic tendencies and forms compounds with bases; it is liberated from such combinations by the addition of an acid.

If urobilin is dissolved in caustic potash or soda, and sufficient sulphuric or hydrochloric acid is added to render the liquid faintly acid, a turbidity is produced. This turbid liquid shows an additional band in the region of the E line (fig. 63, spectrum 6), which is probably due to the special light absorption exercised by fine particles of urobilin in suspension. It wholly disappears when the precipitate is filtered off, and when it is re-dissolved the ordinary band alone is visible.

3. Uroerythrin.-This is the colouring matter of pink urate sediments. It may be separated from the sediment as follows:-The deposit is washed with ice-cold water, dried, and placed in absolute alcohol. The alcohol, though a solvent for uroerythrin, does not extract it from the urates. The alcohol is poured off, and the deposit dissolved in warm water. From this solution the pigment is easily extracted by amylic alcohol.

Uroerythrin has a great affinity for urates, with which it appears to form a loosecompound. Its solutions are rapidly decolorised by light. Spectroscopically it shows two rather ill-defined bands (fig. 63, spectrum 7). It gives a green colour with caustic potash, and red or pink with mineral acids. Uroerythrin appears to be a small but constant constituent of urine. Its origin and relationship to other pigments are unknown.

4. Hæmatoporphyrin.--This also occurs in small quantities in normal 
urine. In some pathological conditions, especially after the administration of certain drugs (e.g. sulphonal), its amount is increased. Its amount is stated to increase when the urine stands; this points to the existence of a colourless chromogen. It may be separated from the urine as follows:Caustic alkali is added to the urine; this causes a precipitate of phos-
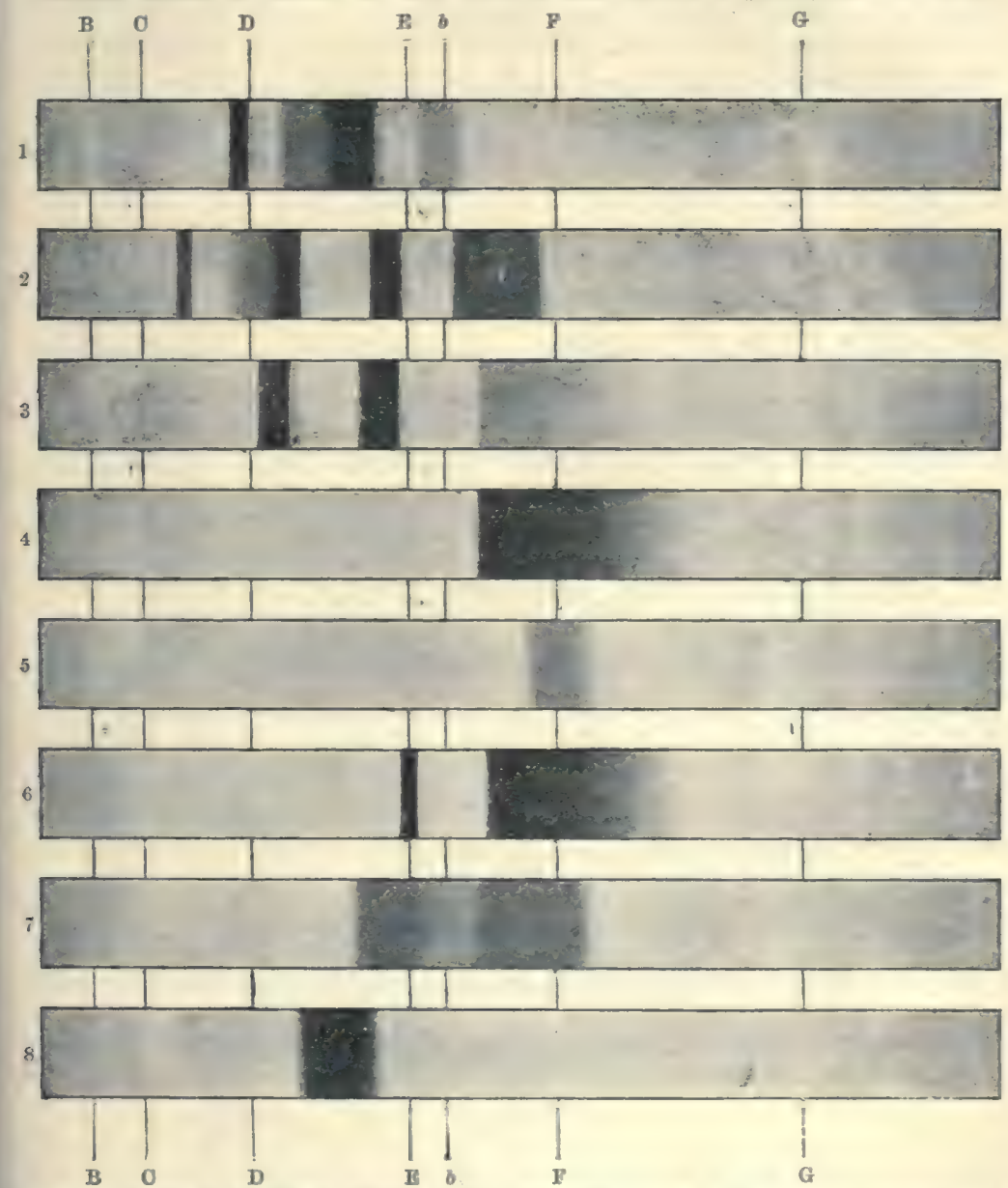

FlG. 63.-Chart of absorption speetra: 1, acil Læmatoporphyrin; 2, alkaline hæuatoporphyrin; 3, hæmatoporphyrin as found sometimes in urate sediments: 4, acil urobilin, concentrated ; 5 , acid urobilin, dilute; 6 , the $\mathrm{E}$ band spectrum of urvbilin; 7 , uroervthriu; 8 , urorosein concentrated-on dilution the band shrinks rapidly from redward end. (After F. G. Hopkius.)

phates, which earries down the pigment with it: the pigment may be dissolved out with chloroform. The chloroform is evaporated, the residue washed with alcohol, and finally dissolved in acidified alcohol. Urines rich in the pigment yield it easily to acetic ether or to amylic alcohol.

When the urine is sufficiently rich in the pigment, the bands shown are 
those of alkaline hæmatoporphyrin (fig. 63, spectrum 2). On adding sulphuric acid the spectrum of acid hæmatoporphyrin is seen (fig. 63, spectrum 1). Occasionally urate sediments are pigmented with a form of the pigment which shows a two-banded spectrum, very like that of oxyhæmoglobin (fig. 63 . spectrum 3); by treatment with dilute mineral acids this changes immediately to the spectrum of acid hæmatoporphyrin.

5. Chromogens in urine.-In addition to the chromogens of urobilin and hæmatoporphyrin alluded to in the foregoing paragraphs there are others of which the following may be mentioned:-(a) Indoxyl.- The origin of this substance from indole is mentioned on p. 116. It is easily oxidised to indigo-blue or indigo-red.

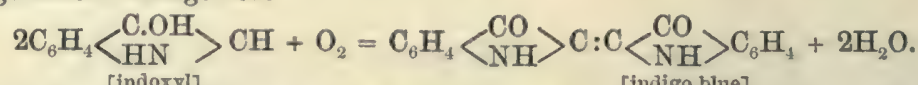

Indigo red is isomeric with indigo-blue, its structural formula being $\mathrm{C}_{6} \mathrm{H}_{4}<\mathrm{NH}>\mathrm{C}\left\langle\left\langle\mathrm{C}_{6} \mathrm{H}_{4}>\mathrm{N}\right.\right.$. It is very rare for the urine to be actually pigmented with indigo, for the urinary indoxyl is excreted as a conjugated sulphate which resists oxidation. When the urine is mixed with an equal volume of hydrochloric acid, indoxyl is liberated from the sulphate. A solution of a hypochlorite is then added drop by drop, when indigo-blue is formed, and on shaking the mixture with chloroform the indigo-blue passes into the chloroform. (Jaffé.) (b) Skatoxyl.-When skatoxyl is given by the mouth it passes into the urine, and yields skatoxyl-red on oxidation. (c) Urorosein is distinct from indigo-red. It is produced from its chromogen by the action of mineral acids. It frequently appears when urine is treated with strong hydrochloric acid and allowed to stand, but it appears more readily when an oxidising agent is added as well. It is readily soluble in amylic alcohol, but not in ether. The chromogen is precipitated by saturation with ammonium sulphate. The colour is destroyed by alkalis. It shows an absorption band between the $\mathrm{D}$ and $\mathrm{E}$ lines (fig. 63, spectrum 8).

6. Pathological pigments.-The most frequently appearing of abnormal pigments are those of blood and bile. The urine may contain accidental pigments due to the use of drugs (rhubarb, senna, logwood, santonin); in carbolic acid poisoning pyrocatechin and hydrochinon are chiefly responsible for the brown colour of the urine, which increases on exposure to the air. The black or dark brown pigment called melanin may pass into the urine in cases of melanotic sarcoma. For alcaptonuria see p. 132. 


\section{APPENDIX}

\section{HEMACYTOMETERS}

Gowers's Hæmacytometer.-The enumeration of the blood corpuseles is readily effected by the hæmacytometer of Gowers. This instrument consists of a glass slide (fig. 64, C), the centre of which is ruled into $\frac{1}{10}$ millimetre squares and surrounded by a glass rim $\frac{1}{5}$ millimetre thick. It is provided with messuring pipettes (A and B), a vessel (D) for mixing the blood with a saline solution (sulphate of soda of specific gravity 1015), a glass stirrer (E), and \& guarded needle (F).

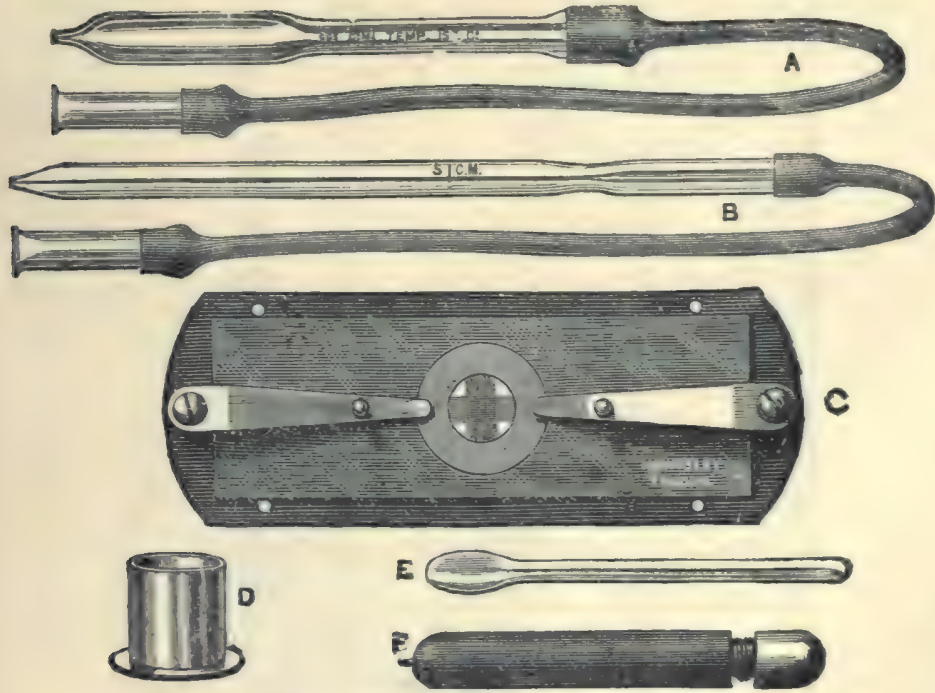

Fi6. 64-Hremacytometer of Sir W. Gower.

Nine hundred and ninety-five cubic millimetres of the saline solution are measured out by means of $\mathrm{A}$, and then placed in the mixing jar; 5 cubic millimetres of blood are then drawn from a puncture in the finger by means of the pipette $\mathrm{B}$, and blown into the solution. The two fluids are well mixed by the stirrer, and a small drop of this diluted mixture placed in the 
centre of the slide $\mathrm{C}$, a cover glass is gently laid on (so as to touch the drop which thus forms a layer $\frac{1}{5}$ millimetre thick between the slide and cover glass), and pressed down by two brass springs. In a few minutes the corpuscles have sunk to the bottom of the layer of fluid, and rest on the squares. The number on ten squares is then counted, and this multiplied by 10,000 gives the number in a cubic millimetre of blood. The average number of red corpuscles in each square ought therefore in normal human blood to be $45-50$.

Oliver's Hæmacytometer.-The following method devised by Dr. George Oliver is a ready way of determining the total number of corpuscles. It is, however, not possible to determine the relative proportion of red and white corpuseles by this means.
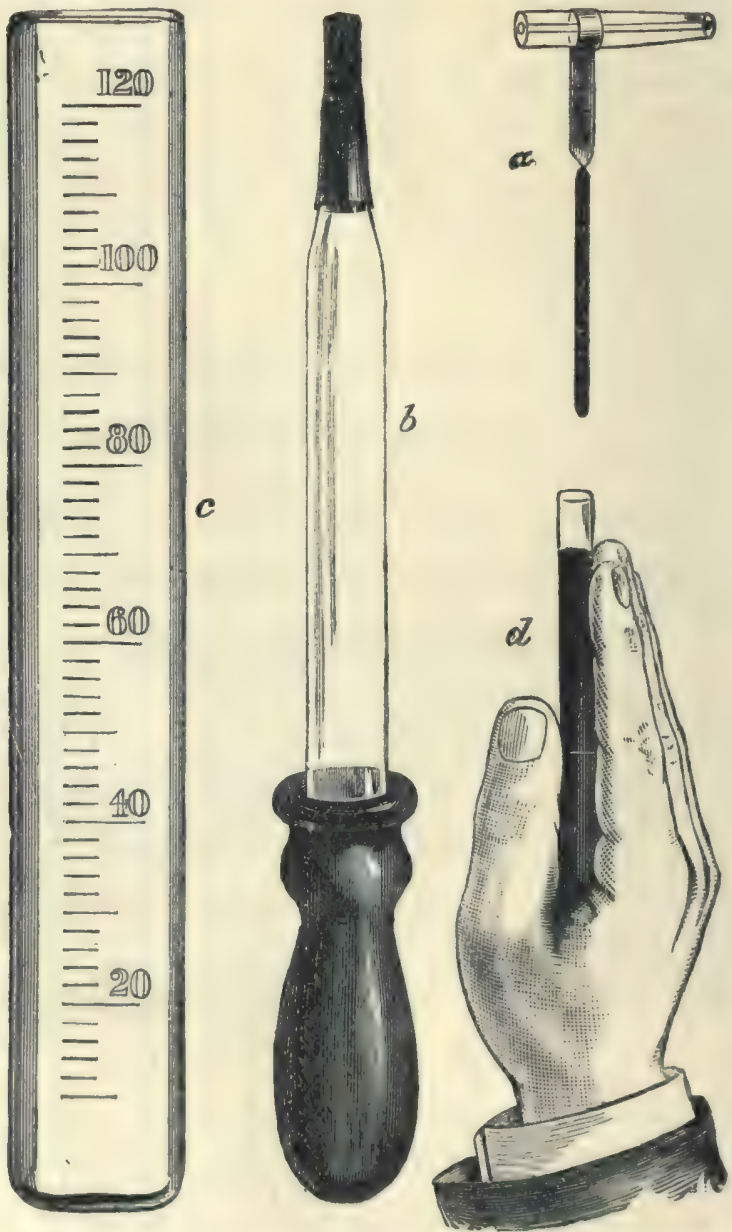

Frg, 65.-Oliver's hremaoytometer. 
The finger is pricked, and the blood allowed to flow into the small capillary pipette (fig. $65, a$ ) until it is full. This is washed out by the dropping tube $b$ into a graduated flattened test-tube, $c$, with Hayem's fluid. ${ }^{1}$ The graduations of the tube are so adjusted that with normal blood containing 5,000,000 coloured corpuseles per cubic millimetre, the light of a small wax candle placed at a distance of 9 feet from the eye in a dark room is just transmitted as a fine bright line when looked at through the tube held edgeways between the fingers $(d)$ and filled up to the 100 mark of the graduation. If the number of corpuscles is less than normal, less of the diluting solution is required for the light to be transmitted ; if above the normal, more of the Hayem's fluid must be added. The tube is graduated, so as to indicate in percentages the decrease or increase of corpuseles per cubic millimetre as compared with the normal standard of 100 per cent.

\section{HEMOGLOBINOMETERS}

Gowers's Hæmoglobinometer.-The apparatus consists of two glass tubes, $\mathrm{C}$ and $\mathrm{D}$ of the same size. D contains glycerin jelly tinted with carmine to a standard colour-viz., that of normal blood diluted 100 times with distilled water. The finger is pricked and 20 cubic millimetres of blood are measured out by the capillary pipette, B. This is blown out into the tube C, and diluted

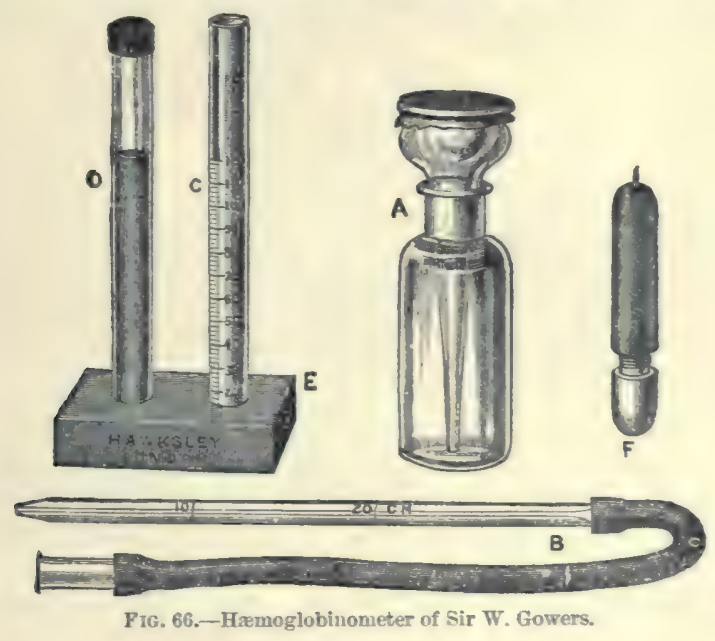

with distilled water, added drop by drop from the pipette stopper of the bottle, $\mathrm{A}$, until the tint of the diluted blood reaches the standard colour. The tube $\mathrm{C}$ is graduated into $\mathbf{1 0 0}$ parts. If the tint of the diluted blood is the same as the standard when the tube is filled up to the graduation 100 , the quantity of oxyhæmoglobin in the blood is normal. If it has to be diluted

1 Sodium sulphate 5 grammes, sodium chloride $1 \mathrm{grm}$., mercuric chloride 05 grm., distilled water 200 c.c. 
more largely, the oxyhæmoglobin is in excess; if to a smaller extent, it is less than normal. If the blood has, for instance, to be diluted up to the graduation 50, the amount of hæmoglobin is only half what it ought to be50 per cent. of the normal-and so for other percentages.

The instrument only yields approximate results, but is extremely useful in clinical observations.

Von Fleischl's Hæmometer.-The apparatus (fig. 67) consists of a stand bearing a white reflecting surface (S) and a platform. Under the platform is a slot carrying a glass wedge stained red $(\mathrm{K})$ and moved by a wheel $(\mathrm{R})$. On the platform is a small cylindrical vessel divided vertically into two compartments, $a$ and $a^{\prime}$.

Fill with a pipette the compartment $a^{\prime}$ over the wedge with distilled water. Fill about a quarter of the other compartment $(a)$ with distilled water.

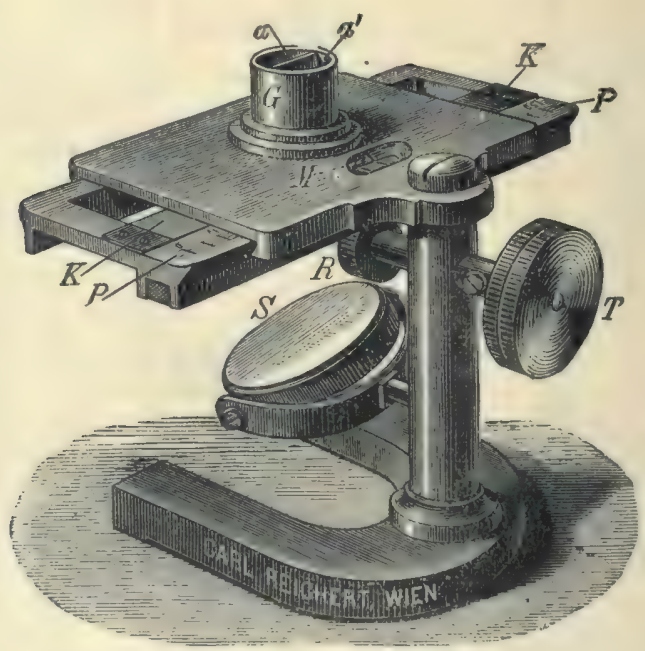

FIG. 67.-Fleischl's hæmometer.

Prick the finger and fill the short capillary pipette provided with the instrument with blood. Dissolve this in the water in compartment $a$, and fill it up with distilled water.

Having arranged the reflector (S) to throw artificial light vertically through both compartments, look down through them, and move the wedge of glass by the milled head (T) until the colour in the two is identical.

Read off the scale which is so constructed as to give the percentage of hæmoglobin.

Dr. Oliver's Hæmoglobinometer.-This method consists in comparing a specimen of blood suitably diluted with water in a shallow white palette, with a number of standard tests very carefully prepared by the use of Lovibond's coloured glasses. The capillary pipette $c$ (fig. 68) is first filled with blood obtained by pricking the finger. This is washed with water 
by the mixing pipette $d$ into the blood cell $e$; the cell is then just fllled with water, and the blood and water thoroughly mixed by the handle of $c$ being

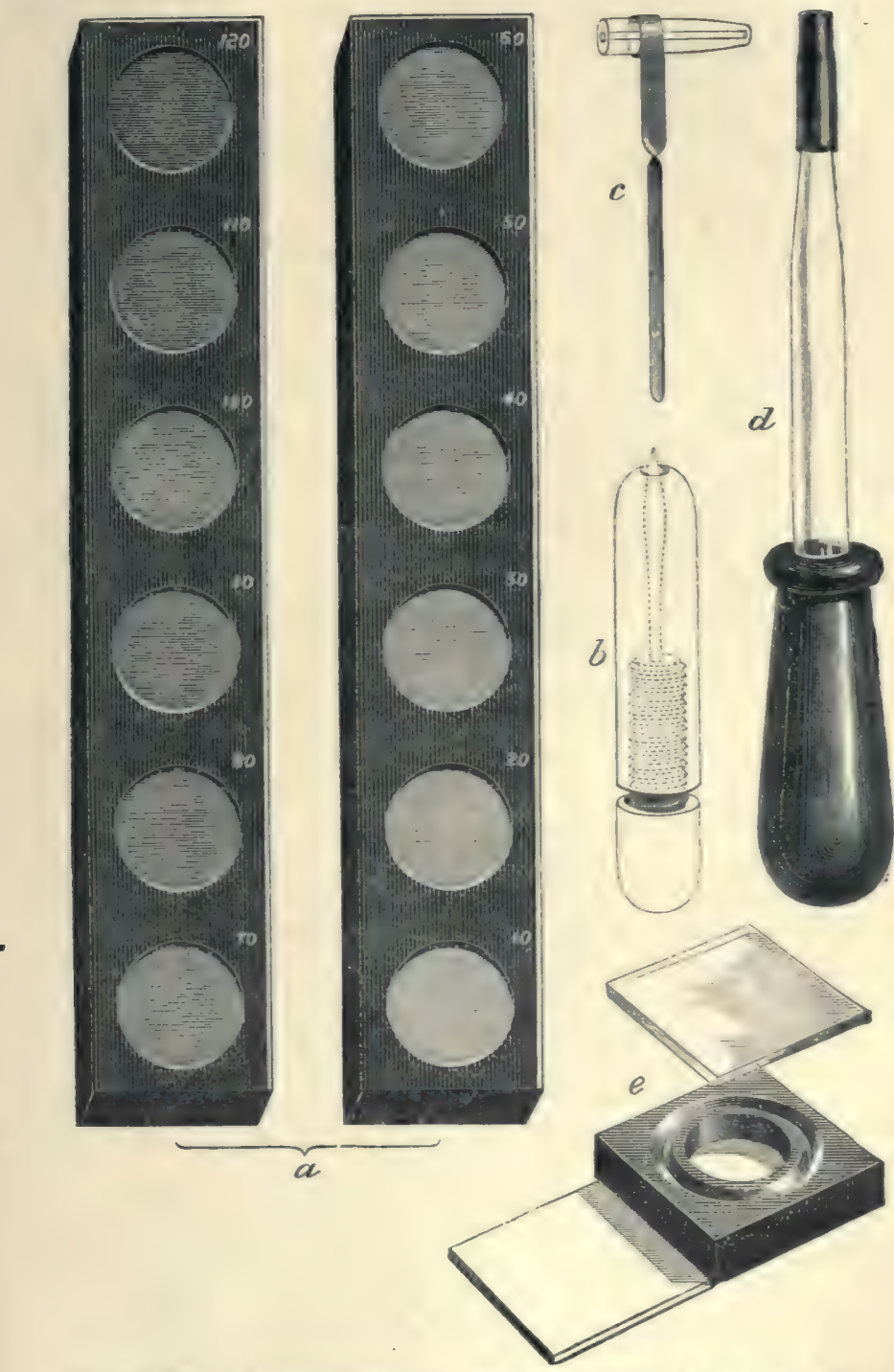

FIG. 68.-Olirer's hemoglobinometer : $a$, stmulard graulations ; $b$, lancez; $c$, capillary measuring pipette; $d$, mixing pipette ; e. blood cell and cover glass.

used as a stirrer. The cover glass is then adjusted, when a small bubble should form a clear sign that the cell has not been overfilled. The cell is 
then placed by the side of the standard gradations, and the eye quickly recognises its approximate position on the scale. The camera tube provided with the instrument will more accurately define it. Artificial light should be used.

If it is proved that the blood solution is matched in depth of colour by one of the standard grades, the observation is at-an end; but if the tint is higher than one grade, but lower than another, the blood cell is placed opposite to the former, and riders (not shown in the illustration) are added to complete the observation. The standard gradations are marked in percentages, 100 per cent. being taken as normal.

'Worth' of the Corpuscles.-If the percentage of hæmoglobin is 100 , and the percentage number of corpuseles is 100 also, then the quotient $\frac{100}{100}=1$ is taken as the normal. This varies in health from 0.95 to 1.05 in men, and from 0.9 to 1 in women. This quotient has been termed the worth of the corpuscle.

Specific Gravity of Blood.--Of the numerous methods introduced for taking the specific gravity of fresh blood, that of Hammerschlag is the simplest. A drop of blood from the finger is placed in a mixture of chloroform and benzene. If the drop falls, add chloroform till it just begins to rise ; if the drop rises, add benzene till it just begins to fall. The fluid will then be of the same specific gravity as the blood. Take the specific gravity of the mixture in the usual way with an accurate hydrometer.

Schmalz's capillary picnometer is more accurate.

\section{POLARISATION OF LIGHT}

If an object, such as a black dot on a piece of white paper, be looked at through a crystal of Iceland spar, two black dots will be seen; and if the crystal be rotated, one black dot will move round the other, which remains stationary. That is, rays of light entering such a crystal are split into two rays, which travel through the crystal with different velocities, and consequently one is more refracted than the other. One ray travels just as it would through glass; this is the ordinary ray, the ray which gives the stationary image; the other ray gives the moveable image when the crystal is rotated; the ordinary laws of refraction do not apply to it, and it is called the extraordinary ray. Both rays are of equal brilliancy. In one direction, however, that of the optic axis of the crystal, a ray of light is transmitted without double refraction.

Ordinary light, according to the wave theory, is due to vibrations occurring in all planes transversely to the direction of the propagation of the wave. Light is said to be plane polarised when the vibrations take place all in one plane. The two rays produced by double refraction are both polarised, one in one plane, the other in a plane at right angles to this one. Doubly refracting bodies are called anisotropous; singly refracting bodies, isotropous. The effect of polarisation may be very roughly illustrated by a model.

If a string be stretched as in the figure, and then touched with the finger, it can be made to vibrate, and the vibrations will be free to occur from above down, or from side to side, or in any intermediate position. If, however, a 
dise with a rertical slit be placed on the course of the string, the vibrations will be all obliged to take place in a vertical plane, any side to side movement being stopped by the edges of the slit ${ }^{1}$ (fig. 69).

Light ean be polarised not only by the action of crrstals, but by reflection from a surface at an angle which varies for different substances (glass

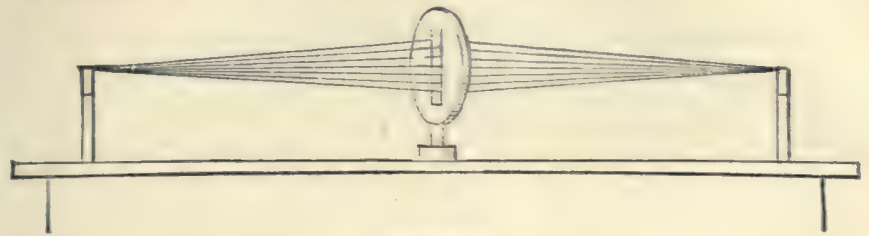

FIG. 69.

$54^{\circ} 35^{\prime}$, water $52^{\circ} 45^{\prime}$, diamond $68^{\circ}$, quartz $57^{\circ} 32^{\prime}$, \&c.). It is also found that certain non-crystalline substances, like muscle, eilia, ke., are doubly refracting.

The Nicol's Prism is the polariser usually employed in polariscopes; it consists of a rhombohedron of Iceland spar divided into two by a section through its obtuse angles. The cut surfaces are polished and cemented together in their former position with canada balsam. By this means the ordinary ray is totally reflected through the canada balsam; the extraordinary ray passes on and emerges in a direction parallel to the entering ray. In this polarised ray there is nothing to render its peculiar condition visible to the naked eye; but if the eye is aided by a second nicol's prism, which is called the analyser, it is possible to detect the fact that it is polarised.

This may be again illustrated by reference to our model (fig. 70 ).

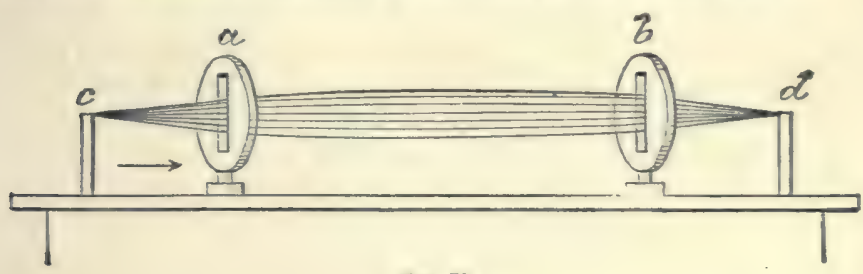

Fig. 70.

Suppose that the string is made to vibrate, and that the wares trarel in the direction of the arrow. From the fixed point $c$ to the dise $a$, the string is theoretically free to vibrate in any plane $;^{2}$ but after passing throu gh the vertical slit in $a$, the vibrations must all be vertical also; if a second similar dise $b$ be placed further on, the ribrations will also pass on freely to the other extremity of the string $d$, if as in the figure (fig. 70 ) the slit in $b$ be also placed

' Such a model is, of course, imperfect ; it does not, for instance, represent the splitting of the ray into two, and moreorer the polarisation takes place on each side of the slit; whereas, in regard to light, it is only the rays on one side of a polariser, viz. those that have passed through it, which are polarised.

3 The imperfection of the model has been explained in preceding footnote. 
vertically. If, however, $b$ be so placed that its slit is horizontal (fig. 71), the vibrations will be extinguished on reaching $b$, and the string between $b$ and $d$ will be motionless.

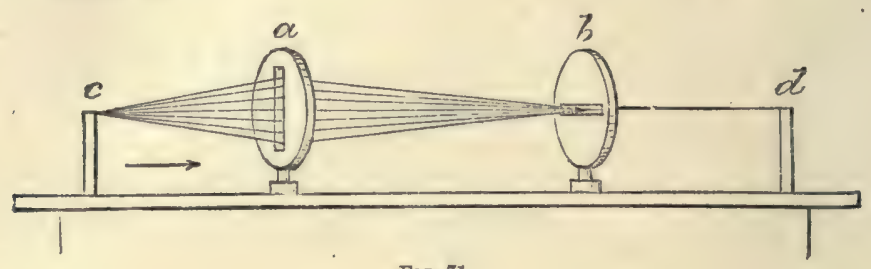

Fig. 71.

$c$ here represents a source of light, and the vibrations of the string the undulations which by the nicol's prism $a$ are polarised so as to occur in one plane only; if the second nicol or the analyser $b$ is parallel to the first, the vibrations will pass on to the eye, which is represented by $d$; but if the planes of the two nicols are at right angles, the vibrations allowed to pass through the first are extinguished by the second, and so no light reaches the eye. In intermediate positions, $b$ will allow only some of the light to pass through it. It must be clearly understood that a nicol's prism contains no actual slits, but the arrangement of its molecules is such that their action on the particles of rther may be compared to the action of slits in a diaphragm to vibrations of more tangible materials than æother.

The Polarising Microscope consists of an ordinary microscope with certain additions; below the stage is the polarising nicol; in the eye-piece is the analysing nicol; the eye-piece is so arranged that it can be rotated; thus the directions of the two nicols can be made parallel, and then the field is bright; or crossed, and then the field is dark. The stage of the microscope is arranged so that it also can be rotated.

The polarising microseope is used to detect doubly refracting substances. Let the two nicols be crossed, so that the field is dark; interpose between the two, that is, place upon the stage of the microscope, a doubly refracting plate of which the principal plane is parallel to the first prism or polariser the ray from the first prism is unaffected by the plate, but will be extinguished by the second ; the field therefore still remains dark. If the plate is parallel to the second nicol the field is also dark; but in any intermediate position, the light will be transmitted by the second nicol. In other words, if between two crossed nicols, which consequently appear dark, a substance be interposed which in certain positions causes the darkness to give place to illumination, that substance is doubly refractive. How this takes place may be explained as follows:-

Let $\mathrm{N}_{1} \mathrm{~N}_{1}$ (fig. 72) represent the direction of the principal plane of the first nicol, and $\mathrm{N}_{2} \mathrm{~N}_{2}$ that of the second. They are at right angles, and so the ray transmitted by the first will be extinguished by the second. Let PP represent the principal plane of the interposed doubly refractive plate. The extraordinary ray transmitted by $N_{1} N_{1}$ vibrates in the plane $N_{1} N_{1}$, and falls obliquely on the plate PP; it is by this plate itself split into two rays, an ordinary and an extraordinary one, at right angles to one another, one 
vibrating in the plane $P P$, the other in the plane $P^{1} P^{1}$. These two rays meet the second nicol, which can only transmit vibrations in the plane $\mathrm{N}_{2} \mathrm{~N}_{2}$. The vibrations in $\mathrm{PP}$ can be resolved into a vibration in $\mathrm{N}_{1} \mathrm{~N}_{1}$ and a vibration in $\mathrm{N}_{2} \mathrm{~N}_{2}$; the former is extinguished, the latter transmitted. Similarly the vibration in $\mathrm{P}^{1} \mathrm{P}^{1}$ can be resolved into two sub-rays in $\mathrm{N}_{1} \mathrm{~N}_{1}$ and $\mathrm{N}_{2} \mathrm{~N}_{2}$ respectively, the latter only being transmitted. The illumination is thus due to two sub-rays, one of the vibrations in $\mathrm{PP}$, the other of those in $\mathrm{P}^{\mathbf{1}} \mathrm{P}^{\mathbf{1}}$ which have been made to vibrate in $\mathrm{N}_{2} \mathrm{~N}_{2}$.

Now, although these two subrays vibrate in the same plane, they are of different velocities; hence the phases of the vibrations

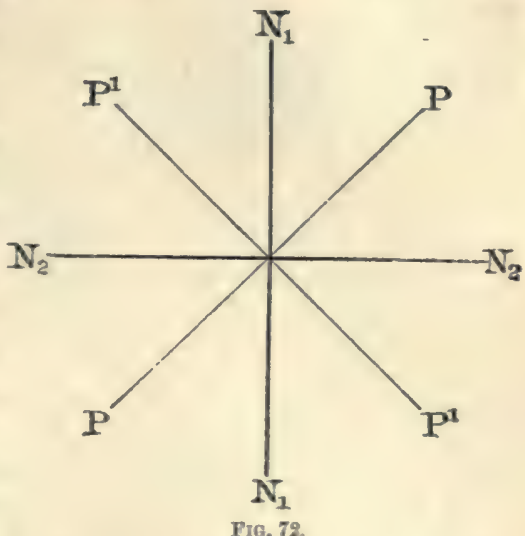
do not coincide, and thus the phenomena of interference are obtained. If we have two sets of vibrations fused, the crest of one wave may coincide with the crest of the other, in this case the wave will be higher; or the crest of one may coincide with the hollow of the other, that is, the undulation would be extinguished; in other intermediate cases, the movement would be interfered with, either helped or hindered more or less. Interference in the case of many kinds of doubly refracting substances (Iceland spar is in this an exception) shows itself in the extinction of certain rays of the white light, and the light seen through the second nicol is white light minus the extinguished rays; those extinguished and those transmitted will together form white light,and are thus eomplementary. Moreover, the rays extinguished in one position of the plate will be transmitted in one at right angles and vice versa; thus a crystal showing these phenomena of pleochromatism, as it is termed, will transmit one colour in one position, and the complementary colour in a position at right angles to the first; blue and yellow, and red and green, are the pairs of colours most frequently seen in this way.

Rotation of the plane of Polarisation.-Certain crystals such as those of quartz, and certain fluids such as the essence of turpentine, aniseed, \&c., and solutions of certain substances like sugar, and albumin, have the power of rotating the plane of polarised light to the right or left. The polarisation of light that is produced by a quartz crystal is different from that produced by a rhombohedron of Iceland spar. The light that passes through the latter is plane polarised; the light that passes through the former (quartz) is circularly polarised, i.e. the two sub-rays are made np of vibrations which occur not in a plane, but are curved. The two rays are circularly polarised in opposite directions, one describing circles to the left, the other to the right; these unite on issuing from the quartz plate; and the net result is a plane polarised ray with the plane rotated to right or left according as the right circularly polarised ray or the left proceeded through 
the quartz with the greater velocity. There are two kinds of quartz, one which rotates the plane to the right (dextrorotatory), the other to the left (lævorotatory).

Gordon explains this by the following mechanical illustration. Ordinary light may be represented by a wheel travelling in the direction of its axle, and the vibrations composing it executed along any or all of its spokes $(a)$. If the vibrations all take place in the same direction, i.e. along one spoke,

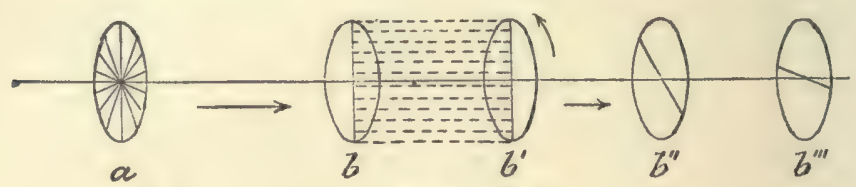

FIg. 73.

and the spoke opposite to it $(b)$, the light is said to be plane polarised. The two spokes as they travel along in the direction of the arrow will trace out a plane (see fig. 73) between $b$ and $b^{\prime}$. If this polarised beam be made to travel now through a solution of sugar, the net result is that the plane so traced out is twisted or rotated ; the two spokes, as in $b b^{\prime}$, do not trace out a plane, but we must consider that they rotate as they travel along, as though guided by a spiral or screw thread eut on the axis, so that after a certain distance the vibrations take place as in $b^{\prime \prime}$; later in $b^{\prime \prime \prime}$, and so on. This effect on polarised light is due to the molecules in solution, and the amount of rotation will depend on the strength of the solution, and on the length of the column of the solution through which the light passes or in the case of a quartz plate on its thickness.

If a plate of quartz be interposed between two nicols, the light will not be extinguished in any position of the prisms, but will pass through various colours as rotation is continued. The rotation produced for different kinds of light being different, white light is split into its various constituent colours; and the angle of rotation that causes each colour to disappear is constant for a given thickness of quartz plate, being least for the red and greatest for the violet. These facts are made use of in the construction of polarimeters. Polarimeters are instruments for determining the strength of solutions of sugar, albumin, \&c., by the direction and amount of rotation they produce on the plane of polarised light. They are often called saccharimeters, as they are specially useful in the estimation of sugar.

\section{POLARIMETERS}

Soleil's Saccharimeter. - This instrument (see fig. 74) consists of a nicol's prism, $d$, called the polariser: this polarises the light entering it, and the polarised beam then passes through a quartz plate ( $b$ in fig. 74 ), $3 \cdot 75 \mathrm{~mm}$. thick, one half of which ( $d$ in fig. 75 ) is made out of dextrorotatory, the other half ( $g$ in fig. 75) of lævorotatory quartz.

The light then passes through the tube containing the solution in the position of the dotted line in fig. 74 , then through a quartz plate cut per- 
pendicularly to its axis ( $q$ in fig. 75 ), then through an arrangement called a compensator ( $r$ in fig. 75), then through a second nicol called the analyser, and lastly through a telescope ( $\mathrm{L}$ in fig. 75).

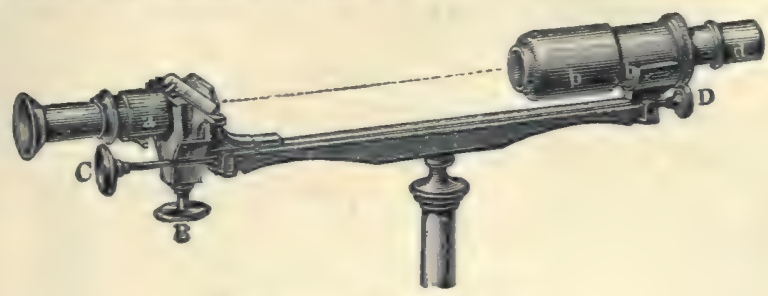

FrG. 74. Soleil's saccharimeter.

The compensator consists of two quartz prisms (RR, fig. 75) cut perpendicularly to the axis, but of contrary rotation to the plate just in front of them. These are wedge-shaped, and slide over each other, the sharp end of one being over the blunt end of the other. By a screw the wedges may be moved from each other, and this diminishes the thickness of quartz interposed; if moved towards each other the amount of quartz interposed is increased.

The effeet of the quartz plate $(d, g)$ next to the polariser ( $i$ in fig. 75) is to give the polarised light $\mathrm{a}$ riolet tint when the two nicols are parallel to each other. But if the nicols are not parallel, or if the plane of the polarised light has been rotated by a solution in the tube, one half the field will change in colour to the red end, the other to the violet end of the spectrum, because the two halves of the quartz act in the opposite way.

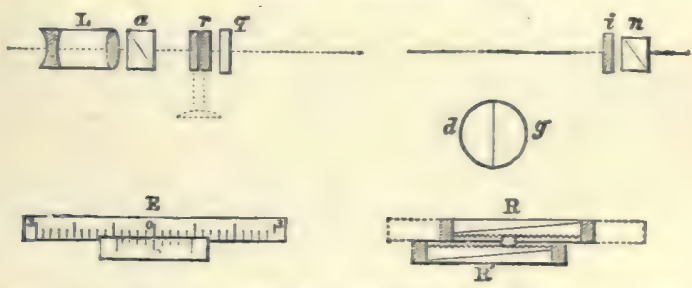

FIG. 75.-Diugram of optical arraugements in Soleil's saccharimeter.

The instrument is first adjusted with the compensator at zero, and the nicols parallel, so that the whole field is of one colour. The tube containing the solution is then interposed; and if the solution is optically inactive the field is still uniformly violet. But if the solution is dextrorotatory the two halves will have different tints; a certain thickness of the compensating quartz plate which is lævorotatory must be interposed to make the tint of the two halves of the field equal again; the thickness so interposed can be read off in amounts corresponding to degrees of a circle by means of a vernier and seale ( $\mathrm{E}$ in fig. 75 ) worked by the serew which moves the compensator. If the solution is lærorotatory, the screw must be turned in the opposite direction. 
Zeiss's polarimeter is in principle much the same as Soleil's; the chief difference is that the rotation produced by the solution is corrected not by $a$ quartz compensator but by actually rotating the analyser in the same direction, the amount of rotation being directly read off in degrees of a circle.

Laurent's polarimeter is a more valuable instrument. Instead of using daylight, or the light of a lamp, monochromatic light (a sodium flame pro.

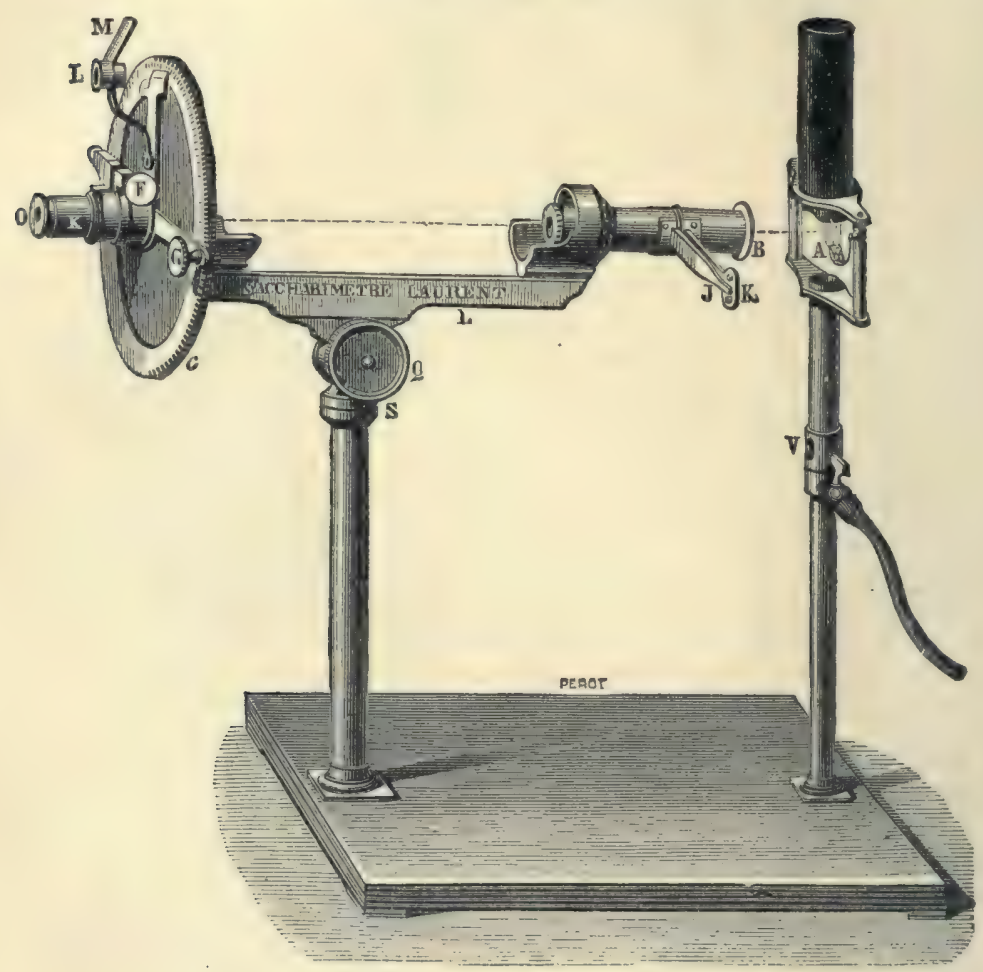

F1G, 76.-Laurent's polarimeter.

duced by volatilising common salt in a colourless gas flame) is employed; the amount of rotation varies for different colours; and observations are recorded as having been taken with light corresponding to the $\mathrm{D}$ or sodium line of the spectrum. The essentials of the instrument are, as before, a polariser, a tube for the solution, and an analyser. The polarised light before passing into the solution traverses a quartz plate, which, however, covers only half the field, and retards the rays passing through it by half a wave-length. In the $0^{\circ}$ position the two halves of the field appear equally illuminated : in any other position, or if rotation has been produced by the solution when the nicols have been set at zero, the two halves appear un. 
equally illuminated. This is corrected by means of a rotation of the analyser that can be measured in degrees by a seale attached to it.

Specific rotatory power of any substance is the amount of rotation in degrees of a circle of the plane of polarised light produced by 1 gramme of the substance dissolved in 1 c.c. of liquid examined in a column 1 decimetre long.

$$
\begin{gathered}
\text { If } \begin{aligned}
& a=\text { rotation observed. } \\
& w=\text { weight in grammes of the substance per cubic centimetre. } \\
& l=\text { length of tube in decimetres. } \\
&(a)_{\mathrm{D}}=\text { specific rotation for light with wave-length corresponding to } \\
& \text { the D line (sodium flame). }
\end{aligned}
\end{gathered}
$$

\section{Then $(a) \mathrm{D}= \pm \frac{a}{w l}$.}

In this formula + indicates that the substance is dextrorotatory, - that it is lavorotatory.

If, on the other hand, $(a)_{D}$ is known, and we wish to find the value of $w$, then

$$
w=\frac{a}{(a)_{\mathrm{D}} \times l}
$$

\section{THE SPECTRO-POLARIMETER}

This instrument is one in which a spectroscope and polarising apparatus are combined for the purpose of determining the concentration of substances which rotate the plane of polarised light. It was invented by E. v. Fleischl

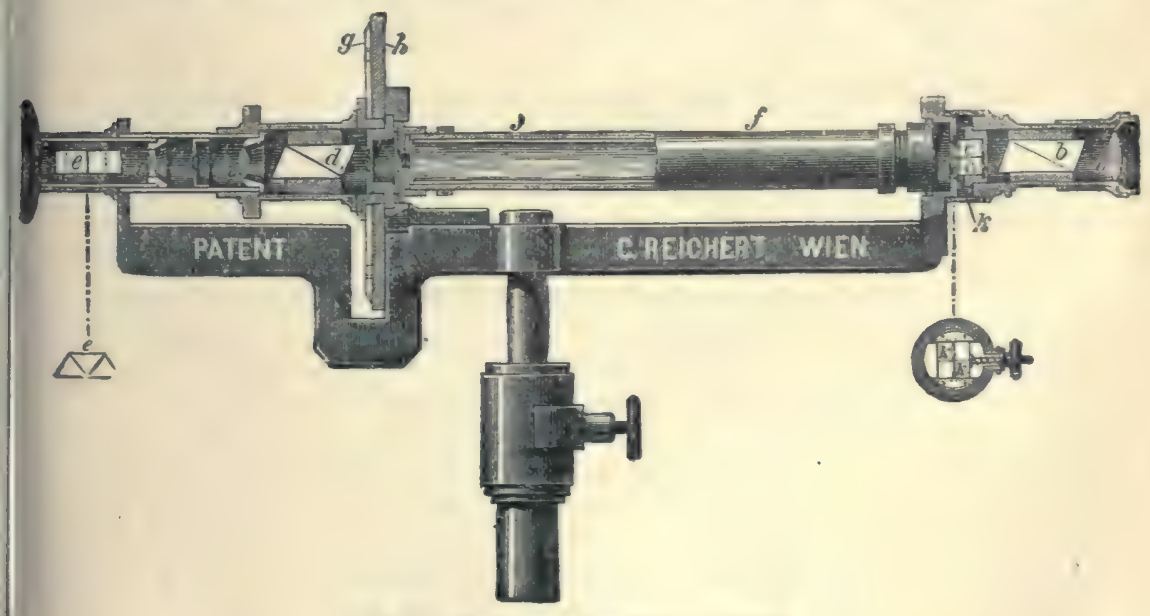

FIG. 77.-Spectro-polarimeter of $\nabla$. Fleischl.

for the estimation of sugar in diabetic urine. Its chief advantage is that no difficulty arises of forming a judgment as to the identitv of two coloured surfaces, as in Soleil's saccharimeter, or of two shades of the same colour, as in Laurent's instrument. The light enters at the right-hand end of the 
instrument, is polarised by the nicol's prism $b$, and then passes through two quartz plates, $c c$, placed horizontally over each other. One of these plates is dextro-, the other lævorotatory, and they are of such a thickness $(7.75 \mathrm{~mm}$.) that the green rays between the $\mathrm{E}$ and $b$ lines of the spectrum are circularly polarised through an angle of $90^{\circ}$, the one set passing off through the upper quartz to the left, the other through the lower to the right. The light then eontinues through a long tube, $f f$, which contains 15 c.c. of the solution under examination. It then passes through an analysing nicol $d$, and finally through a direct-vision spectroscope, $e$. On looking through the instrument, the tube $f f$ being empty or filled with water or some other optically inert substance, two spectra are seen, one over the other, but each shows a dark band between $\mathrm{E}$ and $b$ owing to the extinetion of these rays by the circular polarisation, produced by the quartz. The analyser can be rotated: a vernier, $g$, is attached to, and moves with it, round a circular dise (seen in section at $h$ ) graduated in degrees. The two bands in the spectra coincide when the zeros of vernier and scale correspond. If now the tube $f$ is filled with an optically active substance like sugar, the bands are shifted, one to the right, the other to the left, according to the direction of rotation of the substance in $f$. The rotation is corrected by rotating the analyser into such a position that the two bands exactly coincide once more as to vertical position. The number of degrees through which it is thus necessary to move the analyser measures the amount of rotation produced by the substance in $f$, and is a measure of the concentration of the solution. The degrees marked on the circular scale are not degrees of a circle, but an arbitrary degree of such a length that each corresponds to 1 per cent. of sugar in the given length of the column of fluid in ff $(\mathbf{1 7 7 \cdot 2} \mathrm{mm}$.).

\section{RELATION BETWEEN CIRCULAR POLARISATION AND CHEMICAL CONSTITUTION}

The first work in this direction was performed by Pasteur, and it was his publications on this subject that brought him into prominence. He found that racemic acid, which is optically inactive, can be decomposed into two isomerides, one of which is common tartaric acid which is dextrorotatory, and the other tartaric acid differing from the common variety in being lævorotatory. The salts of tartaric acid usually exhibit hemihedral faces, while those of racemic acid are holohedral. Pasteur found that, although all the tartrate crystals were hemihedral, the hemihedral faces were situated on some crystals to the right, and on others to the left hand of the observer, so that one formed, as it were, the reflected image of the other. These crystals were separated, purified by recrystallisation, and those which exhibited dextro-hemihedry possessed dextrorotatory power, whilst the others were lavorotatory. Pasteur further showed that if the mould Penicillium glaucum is grown in a solution of racemic acid, dextro-tartaric acid first disappears, and the læro-acid alone remains. The subject remained in this condition for many years; it was, however, conjectured that probably there is some molecular condition corresponding to the naked-eye crystalline appearances which produces the opposite optical effects of various substances. What this mole- 
cular structure was, was pointed out independently by two observers-Le Bel in Paris, and Van't Hoff in Holland-who published their researches within a few days of each other. They pointed out that all optically active bodies contain one or more asymmetric carbon atoms, i.e. one or more atoms of earbon connected with four dissimilar groups of atoms, as in the following examples:-<smiles>CCc1ccc(C(O)O)c(C)c1</smiles><smiles>O=C(O)CCc1ccccc1C(=O)O</smiles>

The question, however, remained-do all substances containing such atoms rotate the plane of polarised light? It was found that they do not; this is explained by Le Bel by supposing that these, like racemic acid, are compounds of two molecules - one dextro-, the other lævo-rotatory; that this
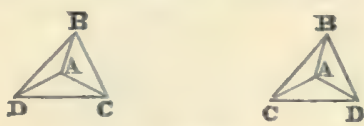

FiG. 78 .

was the case was demonstrated by growing moulds, the fermenting action of which is to separate the two molecules in question. Then the other question -how is it that two isomerides, which in chemical characteristies, in graphic as well as empirical formulæ, are precisely alike, differ in optical properties ? -is explained ingeniously by Van't Hoff. He compares the carbon atom to a tetrahedron with its four dissimilar groups, A, B, C, D, at the four corners. The two tetrahedra represented in fig. 78 appear at first sight precisely alike ; but if one be superimposed on the other, $\mathrm{C}$ in one and $\mathrm{D}$ in the other could never be made to coincide. This difference cannot be represented in any other graphic manner, and probably represents the difference in the way the atoms are grouped in the molecule of right- and left-handed substances respectively.

\section{MERCURIAL AIR PUMPS}

Pflüger's Pump. $-l$ is a large glass bulb filled with mercury; from its lower end a straight glass tube, $m$, about 3 feet long, extends, which is connected by an indiarubber tube, $n$, with a reservoir of mercury, $o$, which can be raised or lowered as required, by a simple mechanical arrangement. From the upper end of the bulb, $l$, a rertical tube passes; above the stopcock, $k$, this has a horizontal branch, which ean be closed by the stopcock, $f$. The vertical part is continued into the bent tube, which dips under mercury in the trough, $h$. A stopcock, $j$, is placed on the course of this trbe. Beyond $f$ the horizontal tube leads into a large double glass bulb, $a b$; a mercurial gauge, $e$, and a drying-tube, $d$, filled with pieces of pumice-stone moistened with sulphuric acid, are interposed. $a$ is called the blood-bulb, and the blood is brought into it by the tube $c$; the gases, as they come off, cause the 
blood to froth, and the bulb, $b$, is called the froth-chamber, as it intercepts the froth, preventing it from passing into the rest of the apparatus.

The pump is used in the following way: $l$ is filled with mercury, the level in $l$ and $o$ being the same; $k$ is closed; $o$ is then lowered, and when it is 30 inches lower than the stopeock, $k$, the mercury in $l$ falls also, leaving

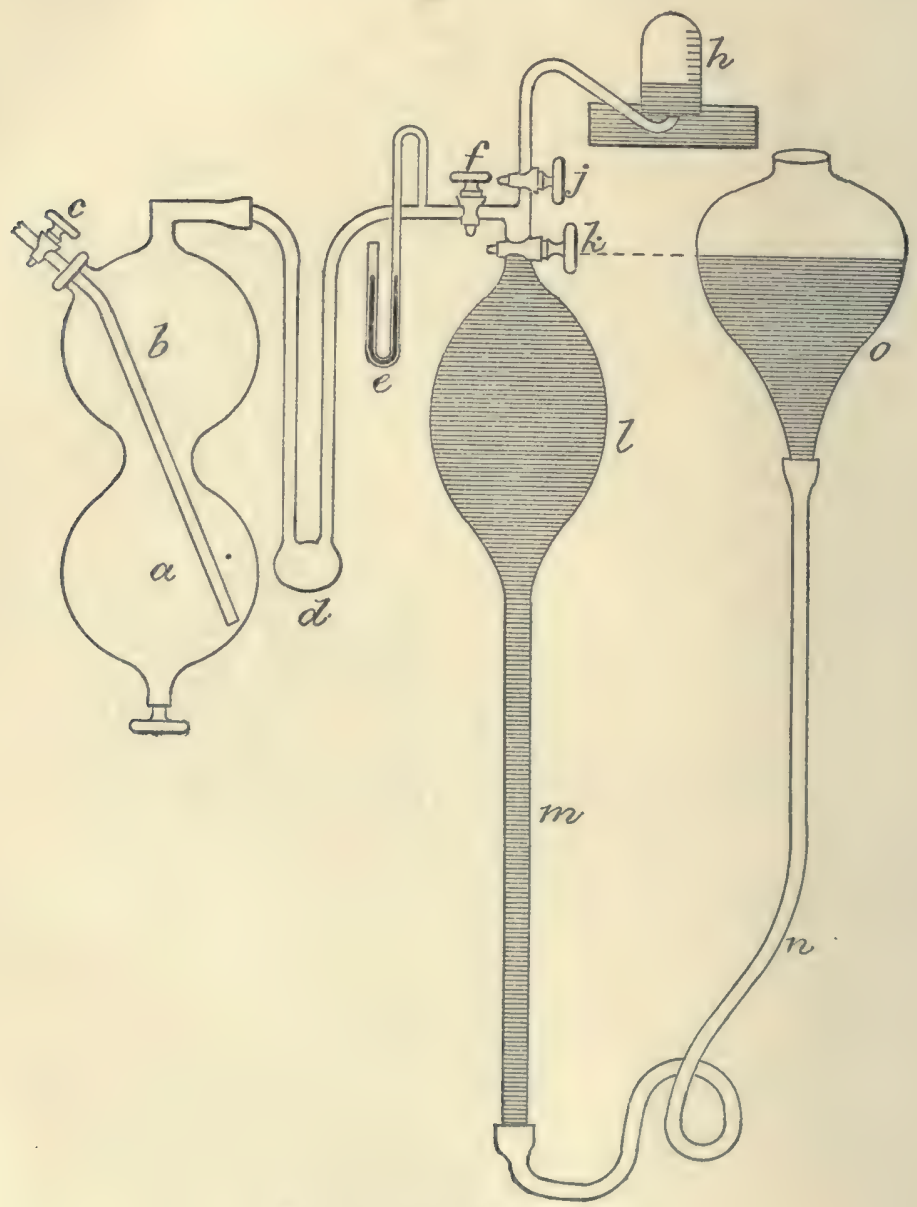

F10. 79.-Diagram of Pfliger's pump.

that bulb empty; $j$ being closed and $f$ open, $k$ is then opened, and the air in $a, b, d$, \&ce. rushes into the Torricellian vacuum in $l ; f$ is closed and $j$ opened; the reservoir, $o$, is raised; the mercury in 7 rises also, pushing the air before it, and it bubbles out into the atmosphere through the mercury (the tube, $h$, is not-at this stage in position). When $l$ is full of mereury, $k$ and $j$ are once more closed and $o$ is again lowered; when $l$ is thus rendered once more a 
vacuum, $k$ and $f$ are opened and more of the air remaining in $a, b, d$, de. rushes into the vacuum ; $f$ is closed, $j$ is opened, and this air is expelled as before. The process is repeated as often as is necessary to make $a, b, d$, dc. as complete a vacuum, as indicated by the mercury in the gange, $\bar{e}$, as is obtainable.

$a$ being now empty and the stopcock, $f$, closed, blood is introduced by the tube $c$; it froths and gives off all its gases, especially if heated to $40-45^{\circ} \mathrm{C}$. In the case of serum, acid has to be added to disengage the more firmly combined carbonic acid. ${ }^{2}$ The bulb, $l$, is once more rendered a vacuum, and $k$ and $f$ are opened, $j$ being closed. The gas from $a$ and $b$ rushes into the bulb $l$, being dried as it passes through $d ; f$ is then closed and $j$ opened; the reservoir $o$ is raised, and as the mereury in $l$ rises simultaneously, it pushes the gases into the cylinder, $h$, which is filled with mercury and inverted over the end of the bent tube. This gas can be subsequently analysed. By alternately raising and lowering $o$, and regulating the stopcocks in the manner already described, all the gas from the quantity of blood used can be ultimately expelled into $h$.

A good grease for the stopeocks is a mixture of two parts of raseline to one of white wax.

Alvergniat's pump has the advantage over Pfluger's of fewer connections, and all of these are surrounded by mercury, which effectually prevents leakage; it has the disadvantage of a rather small bulb in place of $l$, and thus it is more labour to obtain a vacunm.

Leonard Hill's Pump. -This is a simpler instrument, and is sufticient for most purposes. It consists of three glass bulbs (B.B. in fig. 80), which we will call the blood bulb; this is closed above by a piece of tubing and a clip, $a$; this is connected by good indiarubber tubing to another bulb, $d$. Above $d$, however,

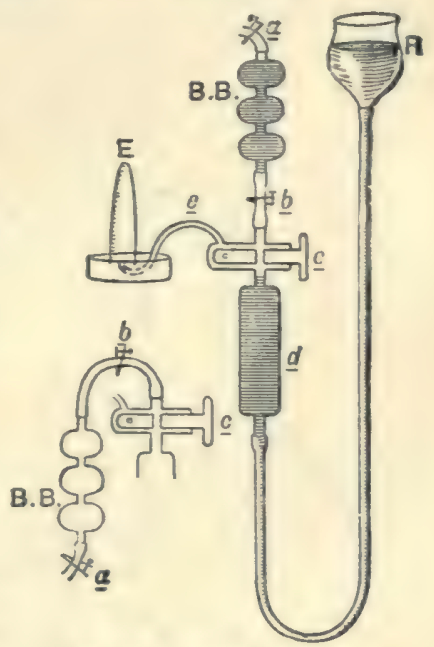

Fig, 80,-L, Hill's air-pump. there is a stopeock with two ways cut through it: one by means of which B.B. and $d$ may be connected, as in the figure; and another seen in section, which unites $d$ to the tube $e$, when the stopeock is turned through a right angle. In intermediate positions the stopcock cuts off all communication from $d$ to all parts of the apparatus above it ; $d$ is connected by tubing to a receiver, $\mathbf{R}$, which can be raised or lowered at will. At first the whole apparatus is filled with mereury, $\mathbf{R}$ being raised. Then $a$ being closed, $\mathbf{R}$ is lowered, and when it is more than the height of the barometer ( 30 inches) below the top of B.B. the mercury falls and leaves the blood bulb empty; by lowering $\mathrm{R}$ still further, $d$ can also be rendered a vacuum. A few drops of mereury should be left behind in B.B. B.B. is then detached from the rest

' Phosphoric acid is usually employed. 
of the apparatus and weighed, the clips, $a$ and $b$, being tightly closed. Blood is then introduced into it by connecting the tube with the clip $a$ on it to a cannula filled with blood inserted in an artery or vein of a living animal. Enough blood is withdrawn to fill about half of one of the bulbs. This is defibrinated by shaking it with the few drops of mercury left in the bulb. It is then weighed again; the increase of weight gives the amount of blood which is being investigated. B.B. is then once more attached to the rest of the apparatus, hanging downwards, as in the side drawing in fig. 80 , and

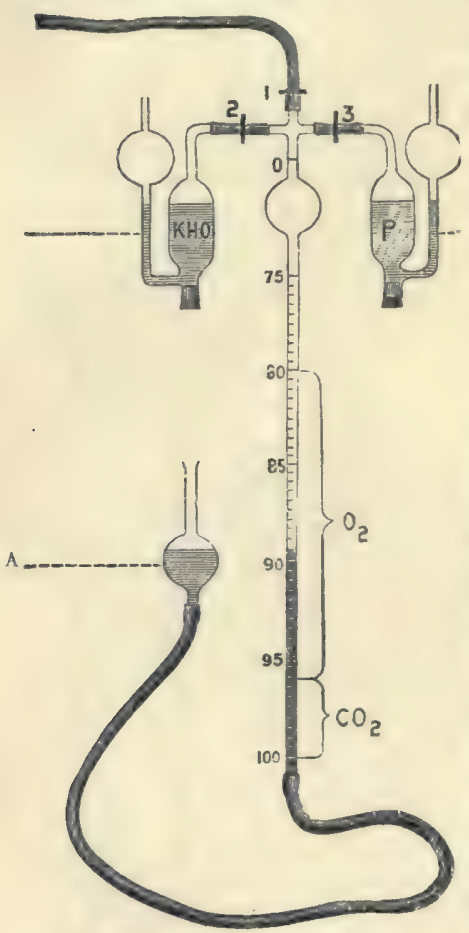

FiG. 81.-Waller's apparatus for gas analysis. the blood gases boiled off ; these pass into $d$, which has been made a vacuum; and then, by raising $\mathbf{R}$ again, the mercury rises in $d$, pushing the gases in front of it through the tube $e$ (the stopcock being turned in the proper direction) into the eudiometer, E, which has been filled with, and placed over, mereury. The gas can then be measured and analysed.

\section{ANALYSIS OF GASES}

Waller's modification of Zuntz's more complete apparatus will be found very useful in performing gas analysis, say of the expired air or blood gases: a 100 c.c. measuring-tube graduated in tenths of $a$ cubic centimetre between 75 and 100 ; a filling bulb and two gas pipettes are connected up as in the diagram.

It is first charged with acidulated water up to the zero mark by raising the filling bulb $\mathrm{A}$, tap 1 being open. It is then filled with 100 e.c. of expired air, the filling bulb being lowered till the fiuid in the tube has fallen to the 100 mark. Tap 1 is now closed. The amount of carbonic acid in the expired air is next ascertained; tap 2 is opened, and the air is expelled into the gas pipette

B containing strong caustic potash solution by raising the filling bulb until the fluid has risen to the zero mark of the measuring tube. Tap 2 is closed, and the air left in the gas pipette for a few minutes, during which the carbonic acid is absorbed by the potash. Tap 2 is then opened and the air drawn back into the measuring tube by lowering the filling bulb. The volume of air (minus the carbonic acid) is read, the filling bulb being adjusted so that its contents are at the same level as the fluid in the measuring tube. The amount of oxygen is next ascertained in a precisely similar manner by sending the air into the other gas pipette, which contains sticks of phosphorus in water, and measuring the loss of volume (due to absorption of od the air when drawn back into the tube. The remaining gas is nitrogen. 


\section{KJELDAHL'S METHOD OF ESTIMATING NITROGEN}

This simple and accurate method has very largely replaced the older complicated processes.

I take the following account of the method with the modifications proposed by Warington from Sutton's 'Volumetric Analysis.'

From 0.1 to 1 gramme of the dry powdered substance is put into a boiling flask holding about 100-120 c.c. The acid used for the destruction of the organic material is made by mixing 200 c.e. pure oil of vitriol with 50 c.c. Nordhausen oil of vitriol, and 2 grammes of phosphoric acid in sticks; all these must, of course, be free from ammonia: 10-20 c.c. of this mixture are poured over the substance in the tlask and heated on wire gauze over a small Bunsen flame. The temperature must be kept below boiling; with prolonged heating the organic matter is gradually destroyed, and the liquid becomes clear and

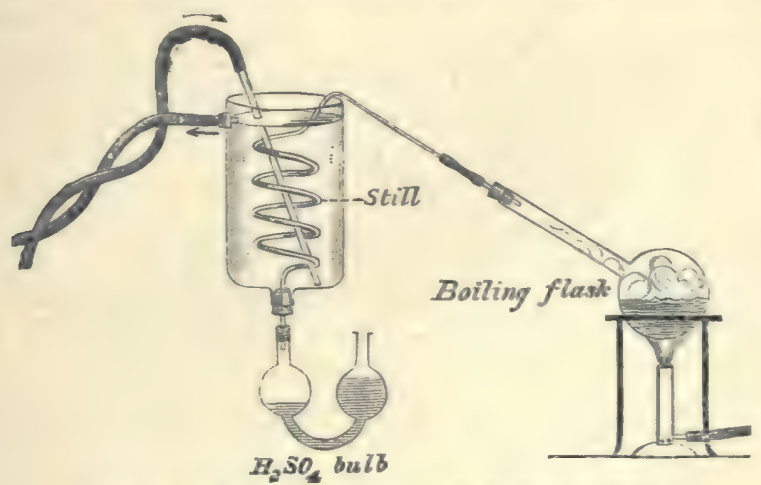

Fic. 82.-Kjeldahl's method. (Waller, after Argatinsky.)

quiet. The nitrogen originally present is thus converted into ammonia, and this may be hastened by adding to the liquid very minute pinches of pure potassium-permanganate. A violent commotion takes place with every addition, but there is no fear of any ammonia being lost. The operation is ended when the mixture becomes permanently greenish (from one to two hours), and moderate heat is continued for a few minutes more. The flask is cooled, some water added, and the contents washed out into a large flask of 700 c.c. capacity with as little water as possible. It is then made alkaline with excess of either pure caustic soda or potash solution (sp. gr. 1.3). A little metallic zine is added to prevent bumping during the subsequent distillation. The fiask is then rapidly closed with a perforated caoutchoue stopper, through which passes an upright tube with two bulbs about an inch in diameter blown upon it : these arrest and carry back any sprsy of soda from the liquid. The tube above the bulbs is bent over and connected to a condenser, and the delivery end of the condenser leads into a flask, containing a measured excess of standard acid. The mixture in the flask is then distilled, and the ammonia passes over into the acid. Distillation is continued from forty-five to sixty minutes. The amount of acidity is then determined in the distillate by titration with standard potash or soda, methyl orangs boing msed the 
indicator of the end of the reaction. (This gives a pink colour with acid, yellow with alkali.)

Example.-Suppose $0 \cdot 15$ gramme of a nitrogenous substance is taken, treated with acid, neutralised, and the ammonia distilled over and received by 100 c.c. of a decinormal solution of hydrochloric acid ( $=10$ c.c. normal acid). The distillate is then titrated with decinormal soda, and it is found that the neutral point is reached when 60 c.c. of the decinormal soda have been added. The other 40 c.c. must therefore have been neutralised by the ammonia derived from the nitrogenous substance under investigation. This 40 c.c. of decinormal acid $=4$ c.c. of normal acid $=4$ e.c. of normal ammonia $=4$ $\times 0.017=0.068$ gramme of ammonia; 0.15 gramme of the substance therefore yields 0.068 gramme of ammonia, and this amount contains 0.056 gramme of nitrogen: 100 grammes of the substance will therefore contain $\frac{100 \times 0.056}{0.15}=37.3$ grammes of nitrogen.

Fig. 82 represents the apparatus as modified by Willfarth. In this, oxidation is assisted by adding a small quantity of metallic mercury (about $\frac{x}{10}$ c.c.). To avoid bumping during distillation talc is added instead of zinc. 12 c.c. of strong potassium sulphate solution are also added. Decinormal sulphuric acid is used as the standard acid, and this is contained in the bulbs shown in the figure.

When this method is used for determining the total nitrogen in urine, 5 c.c. of urine and 20 c.c. of the nixed acids are boiled for half an hour in a flask of 300 c.c. capacity. After cooling, this is distilled with soda, and the process. completed as already described.

\section{SOLUTIONS. DIFFUSION. DIALYSIS, OSMOSIS}

The investigations of physical chemists during recent years have given us. new conceptions of the meaning of the words that stand at the head of this article. I propose to state what these new conceptions are, and briefly to. indicate the bearing they have on the elucidation of physiological problems.

Solutions.-Water is the fluid in which soluble materials are usually dissolved, and our new ideas have'been principally worked out in connection with this fluid. Water at ordinary temperatures is a fluid the molecules of which are in constant movement; the hotter the water the more active are the movements of its molecules, until, when at last it is converted into steam, the molecular movements become much more energetic. Perfectly pure water consists of molecules with the formula $\mathrm{H}_{2} \mathrm{O}$, and these molecules undergo practically no dissociation into their constituent atoms, and it is for this reason that pure water is not a conductor of electricity.

If a substance like sugar is dissolved in the water, the solution still remains incapable of conducting an electrical current. The sugar molecules in solution are still sugar molecules; they do not undergo dissociation.

But if a substance like salt is dissolved in the water, the solution is then capable of conducting electrical currents, and the same is true for most acids, bases, and salts. These substances do undergo dissociation, and the simpler materials into which they are broken up in the water are called ions. Thus if sodium chloride is dissolved in water a certain number of its molecules: 
become dissociated into sodium ions, which are charged positively with electricity, and chlorine ions, which are charged negatively with electricity. Similarly a solution of hydrochloric acid in water contains free hydrogen ions and free chlorine ions. Sulphuric acid is decomposed into hydrogen ions and ions of $\mathrm{SO}_{4}$. The term ion is thus not equivalent to atom, for an 10n may be a group of atoms, like $\mathrm{SO}_{4}$, in the example just given.

Further, in the case of hydrochloric acid, the negative charge of the chlorine ion is equal to the positive charge of the hydrogen ion; but in the case of the sulphuric acid, the negative charge of the $\mathrm{SO}_{4}$ ion is equal to the positive charge of two hydrogen ions. We can thus speak of monovalent, diralent, trivalent \&ce. ions.

Ions positively charged are called kat-ions because they move towards the kathode or negative pole; those which are negatively charged are called an-ions because they move towards the anode or positive pole. The following are some examples of each class.

Kat-ions. Monovalent:- $\mathrm{H}, \mathrm{Na}, \mathrm{K}, \mathrm{NH}_{4}$, dec.

Divalent:- $\mathrm{Ca}, \mathrm{Ba}, \mathrm{Fe}$ (in ferrous salts), dre.

Trivalent:- $\mathrm{Al}, \mathrm{Bi}, \mathrm{Sb}, \mathrm{Fe}$ (in ferric salts), \&e.

An-ions. Monovalent: $-\mathrm{Cl}, \mathrm{Br}, \mathrm{I}, \mathrm{OH}, \mathrm{NO}_{3}$, \&c.

Divalent:- $\mathrm{S}, \mathrm{Se}, \mathrm{SO}_{4}$, \&c.

Roughly speaking, the greater the dilution the more nearly complete is the dissociation, and in a very dilute solution of such a substance as sodium chloride we may consider that the number of ions is double the number of molecules of the salt present.

The ions liberated by the act of dissociation are, as we have seen, charged with electricity, and when an electrical current is led into such a solution, it is conducted throngh the solution by the movement of the ions. Sub. stances which exhibit the property of dissociation are known as electrolytes.

The liquids of the body contain electrolytes in solution, and it is owing to this fact that they are able to conduct electrical currents.

The conception of electrolytes which we owe to Arrhenius is extremely important in view of the question of osmotic pressure which we shall be considering immediately; because the act of dissociation increases the number of particles moving in the solution and so increases the osmotic pressure, for in:this relation an ion plays the same part as a molecule.

Another physiological aspect of the subject is seen in a study of the actions of mineral salts in solution on living organisms and parts of organisms. Many years ago Dr. Ringer showed that contractile tissues (heart, cilia, ikc.) continue to manifest their activity in certain saline solutions. Indeed, as Howell puts it, the eause of such rhythmical action is the presence of these inorganic substances in the blood or lymph which usually bathes them. In the case of the heart, the sinus, or venous end of the heart is peculiarly susceptible to the stimulus of the inorganic salts, and the rhythmical peristaltic waves so started travel thence orer the rest of the heart muscle.

Loeb and his fellow workers have confirmed these statements but interpret them now as ionic action. Contractile tissues will not contract in pure solutions of non-electrolytes (like sugar, urea, albumin). But different contractile tissues differ in the nature of the ions which are most farourable 
stimuli. Thus cardiac muscle, cilia, amœboid movement, karyokinesis, cell division are all alike in requiring a proper adjustment of ions in their surroundings if they are to continue to act, but the proportions must be different in individual cases. Ions affecting the rhythmical contractions may be divided into three classes: (1) Those which produce such contractions; of these the most efficacious is Na. (2) Those which retard or inhibit rhythmical contractions ; for instance, $\mathrm{Ca}$ and $\mathrm{K}$. (3) Those which act catalytically, that is, they accelerate the action of $\mathrm{Na}$, though they do not themselves produce rhythmical contractions directly: for instance, $\mathrm{H}$ and $\mathrm{OH}$. In spite of the antagonistic effect of $\mathrm{Ca}$, a certain minimal amount of it must be present if contractions are to continue for any length of time. Ions produce rhythmical contraction only because they affect either the physical condition of the colloidal substances (proteid \&c.) in protoplasm, or the rapidity of chemical processes.

Loeb has even gone so far as to consider that the process of fertilisation is mainly ionic action. He denies that the nuclein in the head of the spermatozoon is essential, but asserts that all the spermatozoon does is to act as the stimulus in the due adjustment of the proportions of the surrounding ions. He supports this view by numerous experiments on ova, in which, without the presence of spermatozoa, he has produced larvæ (generally imperfect ones, it is true) by merely altering the saline constituents of the fluid that bathes them. Whether such a sweeping and almost revolutionary notion will stand the test of further verification must be left to the future.

Gramme-molecular Solutions. - From the point of view of osmotic pressure a convenient unit is the gramme-molecule. A gramme-molecule of any substance is the quantity in grammes of that substance equal to its molecular weight. A gramme-molecular solution is one which contains a grammemolecule of the substance per litre. Thus a gramme-molecular solution of sodium chloride is one which contains 58.5 grammes of sodium chloride $(\mathrm{Na}=23.05 ; \mathrm{Cl}=35.45)$ in a litre. A gramme-molecular solution of grape sugar $\left(\mathrm{C}_{6} \mathrm{H}_{12} \mathrm{O}_{6}\right)$ is one which contains 180 grammes of grape sugar in a litre. A gramme-molecule of hydrogen $\left(\mathrm{H}_{2}\right)$ is 2 grammes by weight of hydrogen, and if this was compressed to the volume of a litre, it would be comparable to a gramme-molecular solution. It therefore follows that a litre containing 2 grammes of hydrogen contains the same number of molecules of hydrogen in it as a litre of a solution containing 58.5 grammes of sodium chloride, or one containing 180 grammes of grape sugar, has in it of salt or sugar molecules respectively. To put it another way, the heavier the weight of a molecule of any substance the more of that substance must be dissolved in the litre to obtain its gramme-molecular solution. Or still another way: if solutions of various substances are made all of the same strength per cent., the solutions of the materials of small molecular weight will contain more molecules of those materials than the solutions of the materials which have heavy molecules. We shall see that the calculation of osmotic pressure depends upon these facts.

Diffusion, Dialysis, 0smosis.-If two gases are brought together within a closed space, a homogeneous mixture of the two is soon obtained. This is due to the movements of the gaseous molecules within the confining space, 
and the process is called diffusion. In a similar way diffusion will effect in time a homogeneous mixture of two liquids or solutions. If water is carefully poured on to the surface of a solution of sait, the salt or its ions will soon be equally distributed throughout the whole. If a solution of albumin or any other colloidal substance is used instead of salt in the experiment, diffusion will be found to occur much more slowly. If, instead of pouring the water on to the surface of a solution of salt or sugar, the two are separated by a membrane made of such a material as parchment paper, a similar diffusion will occur, though more slowly than in cases where the membrane is absent. In time, the water on each side of the membrane will contain the same quantity of sugar or salt. Substances which pass through such membranes are called crystalloids. Substances which have such heary molecules (starch, proteid sc.) that they will not pass through such nembranes are called colloids. Diffusion of substances in solution in which we hare to deal with an interrening membrane is usually called dialysis. The process of filtration (i.e. the passage of materials through the pores of a membrane under the influence of mechanical pressure) may be excluded in such experi. ments by placing the membrane (M) vertically as shown in the diagram (fig. 83), and the two fluids $A$ and $B$ on each side of it. Ditfusion through a membrane is not limited to the molecules of water, but it may occur also in the molecules of certain substances dissolved in the water. But very few or no membranes are equally permeable to water and to molecules of the substances dissolved in the water. If in the accompanying diagram the compartment $\mathrm{A}$ is filled with pure water, and $B$ with a sodium chloride solution, the liquids in the two compartments will ultimately be found to be equal in bulk as they were at the start, and each will be a solution of salt of half the onginal strength of that in the compartment $B$. But at first the volume of the liquid in compartment B increases, because more water molecules pass into it from $A$ than salt molecules pass from B into $A$. The term osmosis is generally limited to the stream of water molecules passing through a membrane, while the term dialysis is applied

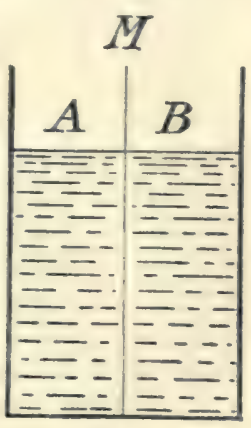

PIG. 83. to the passage of the molecules in solution in the water. The osmotic stream of water is especially important, and in connection with this it is next necessary to define the term osmotic pressure. At first, then, osmosis (the diffusion of water) is more rapid than the dialysis (the diffusion of the salt molecules or ions). The older explanation of this was that salt attracted the water, but we now express the fact differently by saying that the salt in solution exerts a certain osmotic pressure : the result of the osmotic pressure is that more water flows from the water side to the side of the solution than in the contrary direction. The osmotic pressure raries with the amount of substance in solution, and is also altered by variations of temperature occurring more rapidly at high than at low temperatures.

If we imagine two masses of water separated by a permeable membrane, as many water molecules will pass through from one side as from the other, 
and so the volumes of the two masses of water will remain unchanged. If now we imagine the membrane $\mathrm{M}$ is not permeable except to water, and the compartment A contains water, and the compartment B contains a solution of salt or sugar; under these circumstances water will pass through into B, and the volume of $\mathrm{B}$ will increase in proportion to the osmotic pressure of the sugar or salt in solution in B, but no molecules of sugar or salt can get through into $\mathbf{A}$ from $\mathbf{B}$, so the volume of fluid in A will continue to decrease, until at last a limit is reached. The determination of this limit, as measured by the height of a column of fluid or mereury which it will support, will give us a measurement of the osmotic pressure. Membranes of this nature are called semi-permeable. One of the best kinds of semi-permeable membrane is ferrocyanide of copper. This may be made by taking a cell of porous earthenware and washing it out first with copper sulphate and then with potassium ferrocyanide. An insoluble precipitate of copper ferrocyanide is thus deposited in the pores of the earthenware. If such a cell is filled with a 1-per-cent. solution of sodium chloride, water diffuses in till the pressure registered by a manometer connected to it registers the enormous height of 5,000 millimetres of mercury. Theoretically it is possible to measure osmotic pressure by a manometer in this way, but practically it is never done, and some of the indirect methods of measurement described later are used instead. The reason for this is that it has been found impossible to construct a membrane which is absolutely semi-permeable; they are all permeable in some degree to the molecules of the dissolved crystalloid. In course of time therefore the dissolved crystalloid will be equally distributed on both sides of the membrane, and osmosis of water will cease to be apparent, since it will be equal in both directions.

Many explanations of the nature of osmotic pressure have been brought forward, but none is perfectly satisfactory. The following simple explanation is perhaps the best, and may be rendered most intelligible by an illustration. Suppose we have a solution of sugar separated by a semi-permeable membrane from water, that is, the membrane is permeable to water molecules, but not to sugar molecules. The streams of water from the two sides will then be unequal; on one side we have water molecules striking against the membrane in what we may call normal numbers, while on the other side both water molecules and sugar molecules are striking against it. On this side, therefore, the sugar molecules take up a certain amount of room, and do not allow the water molecules to get to the membrane; the membrane is, as it were, screened against the water by the sugar, therefore fewer water molecules will get through from the screened to the unscreened side than vice versa. This comes to the same thing as saying that the osmotic stream of water is greater from the unsereened water side to the screened sugar side than it is in the reverse direction. The more sugar molecules that are present, the greater will be their screening action, and thus we see that the osmotic pressure is proportional to the number of sugar molecules in the solution, that is, to the concentration of the solution.

Osmotic pressure is, in fact, equal to that which the dissolved substance would exert it it occupied the same space in the form of a gas (Van't Hoff's hypothesis). The nature of the substance makes no difference; it is only the 
number of molecules which canses osmotic pressure to vary. The osmotic pressure, however, of substances like sodium chloride, which are electrolytes, is greater than what one would expect from the number of molecules present. This is because the molecules in solution are split into their constituent ions, and an ion plays the same part as a molecule, in questions of osmotic pressure. In dilute solutions of sodium chloride ionisation is more complete, and as the total number of ions is then nearly double the number of original molecales, the osmotic pressure is nearly double what would hare been calculated from the number of molecules.

The analogy between osmotic pressure and the partial pressure of gases is very complete, as may be seen from the following statements.

1. At a constant temperature osmotic pressure is proportional to the concentration of the solution (Boyle-Mariotte's law for gases).

2. With constant concentration, the osmotic pressure rises with and is proportional to the temperature (Gay-Lussac's law for gases).

3. The osmotic pressure of a solution of different substances is equal to the sum of the pressures which the individual substances would exert if they were alone in the solution (Henry-Dalton law for partial pressure of gases).

4. The osmotic pressure is independent of the nature of the substance in solution and depends only on the number of molecules or ions in solution (Arogadro's law for gases).

Calculation of 0smotic Pressure.- We may best illustrate this by an example, and to simplify matters we will take an example in the case of a non-electrolyte like sugar. We shall then not have to take into account any electrolytic dissociation of the molecules into ions. We will suppose we want to calculate the osmotic pressure of a 1-per-cent. solution of cane sugar.

One gramme of hydrogen at atmospheric pressure and $0^{\circ} \mathrm{C}$. occupies a volume of $11 \cdot 19$ litres; two grammes of hydrogen will therefore occupy"a volume of 22.38 litres. A gramme-molecule of hydrogen-that is, 2 grammes of hydrogen-when brought to the volume of 1 litre will exert a gas pressure equal to that of $22 \cdot 38$ litres compressed to 1 litre-that is, a pressure of $22 \cdot 38$ atmospheres. A gramme-molecular solution of cane sugar, since it contains the same number of molecules in a litre, must therefore exert an osmotic pressure of 22.38 atmospheres also. A gramme-molecular solution of cane sugar $\left(\mathrm{C}_{1.2} \mathrm{H}_{2,2} \mathrm{O}_{11}\right)$ contains 342 grammes of cane sugar in a litre. A 1 -per-cent. solution of cane sugar contains only 10 grammes of cane sugar in a litre ; hence the osmotic pressure of a 1-per-cent. solntion of cane sugar is $\frac{10}{342} \times 22 \cdot 38$ atmospheres or 0.65 of an atmosphere, which in terms of a column of mereury $=760 \times 0.65=494 \mathrm{~mm}$.

It would not be possible to make such a calculation in the case of an electrolyte, because we should not know how many molecules had been ionised. In the liquids of the body, both electrolytes and non-electrolytes are present, and so a calculation is here also impossible.

We have seen that for such liquids the osmotic pressure cannot be directly measured by a manometer, because there are no perfect semipermeable membranes; we now see that mere arithmetic often fails us; and so we come to the question to which we have been so long leading up, viz. how osmotic pressure is actually determined. 
Determination of Osmotic Pressure by means of the Freezing-point.-This is the method which is almost universally employed. A very simple apparatus (Beckmann's differential thermometer) is all that is necessary. The principle on which the method depends is the following:-The freezing-point of any substance in solution in water is lower than that of water; the lowering of the freezing-point is proportional to the molecular concentration of the dissolved substance, and that, as we have seen, is proportional to the osmotic pressure.

When a gramme-molecule of any substance is dissolved in a litre of water, the freezing-point is lowered by $1.87^{\circ} \mathrm{C}$., and the osmotic pressure is, as we have seen, equal to $22 \cdot 38$ atmospheres, that is, $22 \cdot 38 \times 760=17,008 \mathrm{~mm}$. of mercury.

We can, therefore, calculate the osmotic pressure of any solution if we know the lowering of its freezing-point in degrees Centigrade; the lowering of the freezing-point is usually expressed by the Greek letter $\Delta$.

$$
\text { Osmotic pressure }=\frac{\Delta}{1 \cdot 87} \times 17,008
$$

For example, a 1-per-cent. solution of sugar would freeze at $-0.052^{\circ} \mathrm{C}$.; its osmotic pressure is therefore $\frac{\cdot 052 \times 17,008}{1 \cdot 87}=473 \mathrm{~mm}$., a number approximately equal to that we obtained by calculation.

Mammalian blood serum gives $\Delta=0.56^{\circ} \mathrm{C}$. A 0.9 -per-cent. solution of sodium chloride has the same $\Delta$; hence serum and a 0.9 -per-cent. solution of common salt have the same osmotic pressure, or are isotonic. The osmotic pressure of blood serum is $\frac{56 \times 17,008}{1.87}=4,987 \mathrm{~mm}$. of mercury, or a pressure of nearly 7 atmospheres.

The osmotic pressure of solutions may also be compared by observing their effect on red corpuscles, or on vegetable cells such as those in Tradescantia. If the solution is hypertonic, i.e. has a greater osmotic pressure than the cell contents, the protoplasm shrinks and loses water, or if red corpuscles are used, they become crenated. If the solution is hypotonic, e.g. has a smaller osmotic pressure than the material within the cell-wall, no shrinking of the protoplasm in the vegetable cell occurs, and if red corpuscles are used they swell and liberate their pigment. Isotonic solutions produce neither of these effects, because they have the same molecular concentration and osmotic pressure as the material within the cell-wall.

Physiological Applications. - It will at once be seen how important all these considerations are from the physiological standpoint. In the body we have aqueous solutions of various substances separated from one another by membranes. Thus we have the endothelial walls of the capillaries separating the blood from the lymph; we have the epithelial walls of the kidney tubules scparating the blood and lymph from the urine; we have similar epithelium in all secreting glands; and we have the wall of the alimentary canal separating the digested food from the blood-vessels and lacteals. In such important problems, then, as lymph-formation, the formation of urine and other excretions and secretions, and absorption of food, we have to take into account the laws which regulate the movements both of water and of sub. stances which are held in solution by the water. In the body osmosis is not 
the only force at work, but we have also to consider filtration, that is, the forcible passage of materials through membranes. due to differences of mechanical pressure. Further complicating these two processes we have to take into account another force, namely, the secretory or selective actirity of the living cells of which the membranes in question are composed. This is sometimes called by the name vital action, which is an unsatisfactory and unscientific expression. The term is merely a confession of ignorance; what we cannot understand we may call vital, but it is no explanation of any matter to say we cannot understand it. The laws which regulate filtration, imbibition, and osmosis are fairly well known and can be experimentally verified. But we have undoubtedly some other force, or some other manifestation of force, in the case of living membranes. It probably is some physical or chemical property of living matter which has not yet been brought into line with the known chemical and physical forces which operate in the inorganic world. We cannot deny its existence, for it sometimes operates so as to neutralise the known forces of osmosis and filtration. It is, however, contrary to scientific usage and a bar to all progress in knowledge to sit quietly down and merely label it as vital; we must look forward to the time when workers will succeed in unravelling its so-called mysteries, and show what it really consists in.

The more one studies the question of lymph-formation, the more convinced one becomes that mere osmosis and filtration will not explain it entirely. The basis of the action is no doubt physical, but the living cells do not behave like the dead membranes of a dialyser; they bave a selective action, picking out some substances and passing them through to the lymph, while they reject others.

The question of gaseous interchanges in the lungs has been another battlefield of a similar kind. Some maintain that all can be explained by the laws of diffusion of gases; others assert that the action is wholly vital. Probably those are most correct who admit a certain amount of truth in both views; the main facts are explicable on a physical basis, but there are also some puzzling data that show that the pulmonary epithelium is able to exercise some other force as well which interferes to some extent with the known physical process. Take again the case of absorption. The object of digestion is to render the food soluble and diffusible; it can hardly be supposed that this is useless; the readily diffusible substances will pass more easily through into the blood and lymph : but still, as Waymouth Reid has shown, if the living epithelium of the intestine is removed, absorption comes very nearly to a standstill, although from the purely physical standpoint removal of the thick columnar epithelium would increase the facilities for osmosis and filtration.

The osmotic pressure exerted by crystalloids is very considerable, but their ready diffusibility limits their influence on the flow of water in the body. Thus if a strong solution of salt is injected into the blood, the first effect will be the setting up of an osmotic stream from the tissues to the blood. The salt, however, would soon diffuse out into the tissues, and would now exert osmotic pressure in the opposite direction. Moreover both effects will be but temporary, because excess of salt is soon got rid of by the excreting 
Osmotic Pressure of Proteids. - It has been generally assumed that proteids, the most abundant and important constituents of the blood, exert little or no osmotic pressure. Starling, however, has claimed that they have a small osmotic pressure; if this is so, it is of importance, for proteids, unlike salt, do not diffuse readily, and their effect therefore remains as an almost permanent factor in the blood. Starling gives the osmotic pressure of the proteids of the blood-plasma as equal to $30 \mathrm{~mm}$. of mercury. By others this is attributed to the inorganic salts with which proteids are always closely associated. Moore, for instance, finds that the purer a proteid is, the less is its osmotic pressure; the same is true for other colloidal substances. It really does not matter much, if the osmotic force exists, whether it is due to the proteid itself, or to the saline constituents which are almost an integral part of a proteid. It is merely interesting from the theoretical point of view. We should from the theoretical standpoint find it difficult to imagine that a pure proteid can exert more than a minimal osmotic pressure. It is made up of such huge molecules that, even when the proteids are present to the extent of 7 or 8 per cent., as they are in blood-plasma, there are comparatively few proteid molecules in solution. Still, by means of this weak but constant pressure it is possible to explain the fact that an isotonic or even a hypertonic sblution of a diffusible crystalloid may be completely absorbed from the peritoneal cavity into the blood.

The functional activity of the tissue elements is accompanied by the breaking down of their proteid constituents into such simple materials as urea (and its precursors), sulphates, and phosphates. These materials pass into the lymph, and increase its molecular concentration and its osmotic pressure; thus water is attracted (to use the older way of putting it) from the blood to the lymph, and so the volume of the lymph rises and its flow increases. On the other hand, as these substances accumulate in the lymph they will in time attain there a greater concentration than in the blood, and so they will diffuse towards the blood, by which they are carried to the organs of excretion.

But, again, we have a difficulty with the proteids; they are most important for the nutrition of the tissues, but they are practically indiffusible. WVe must provisionally assume that their presence in the lymph is due to filtration from the blood. The plasma in the capillaries is under a somewhat higher pressure than the lymph in the tissues, and this tends to squeeze he constituents of the blood, including the proteids, through the capillary walls. I have, however, already indicated that the question of lymph-formation is one of the many physiological problems which await solution by the physiologists of the future.

The whole subject of osmosis and its applications to physiology is attracting considerable attention at the present time. I have not attempted to discuss the question at all fully, but merely to indicate the lines research has followed and will have to follow in the future. In the preparation of this short sketch I have had of necessity to consult much of the current literature, particularly the writings of Waymouth Reid and Starling. I am also indebted for much help to the very excellent article on the subject in Howcll's 'Text-Book of Physiology,' and Dr. Koppe's 'Physikalische Chemie.' 


\section{INDEX}

In cases where there are several figures after any subject, the one in heary type indicates where the principal matter iu relation to the subject is to be fouml.

A

ABsonpros, 76 ; of earbohydrates, 77 ; of proteids, 77 ; of fats, 78

Absorption bands, 96, 152, 179

Absorption spectra of hrmoglobin and its derivatives, 96, 152 ; of myohømatin, 160; of urinary pigments, 179

Accessories of food, 43

Acetic acid, 11, 17

Acetone, 131

Acetyl, 17

Achroö-dextrin, 15, 47, 143

Acid-albumin, 20, 21, 27, 52, 58, 135

Acid hæmatin, 151

Acid hæmatoporphyrin, absorption bands of, 179

Acid, lactic, 38, 56 ; test for, 159

Acid sodium phosphate, 108

Aoid tide, 108

Acids, vegetable, 108

Acute yellow atrophy of liver, 112, 113

Adenine, 30, 121, 122

Adipose tissue, 2, 4, 16

Aörobic micro-organisms, 51

Air, expired and inspired, 99

Air pumps, mercurial, 195

Alanine, 67

Albumin, acid, 21, 27, 52, 58, 135

Albumin, action of acids and alkalis on, 20

Albumin, alkali, 20, 27, 60, 62, 135

Albuminates, 27

Albumin in urine, estimation of, 129

Albumin in urine, tests for, 129

Albumins, 4, 22, 26, 27, 59

Albuminoids, 3, 4, 31, 62

Albuminometer of Esbach, 129

Albumose, 19, 20, 50, 58, 77, 134, 147

Albumoses and peptone, separation of, 147
Albumoses, tests for, 52,147

Alcapton, 132

Alcaptonuria, 132

Alcohol, setion of, on proteids, 25

Alcoholic fermentation, 13, 14, 51; of milk, 39

Alcohols, 3, 4, 17, 43

Aldehyde, 11, 17

Aleurone grains, 24

Alexander Schmidt's method of precipitating serum globulin, 155

Alexis St. Martin, case of, 54

Alkali-albumin, 20, 27, 62, 135

Alkaline hæmatin, 151

Alkaline hrematoporphyrin, absorption bands of, 179

Alkaline tide, 108

Alkaloids, 43

Alloxuric bases, 30, 121

Alvergniat's pump, 197

Amides, 4

Amido-scetic acid, 66, 113

Amido-acids, 22, 66, 113

Amido-caproic acid, 66, 113

Amido-ethyl-sulphonic acid, 72

Amido-iso-butyl-acetic acid, 67

Amido-propionic acid, 67

Amido-pyrotartaric acid, 62

Amido-succinic acid, 62

Amido-valerianic acid, 32

Amidulin, 15

Amines, 4, 22

Amino-oxy-purine, 121

Amino-purine, 121

Ammonis, 4, 22

Ammoniacal odour of putrid urine, 110

Ammonium carbonate and carbamate as urea precursors, 115

Ammonium cyanate, 109

Ammonium sulphate, action of, on proteids, 19, 25, 27, 134, 144, 145

Amoboid movement, 2 
Amylolytic ferments, 47, 49; in blood serum, 141

Amylopøin, 14, 49, 60, 61, 63

Amyloses, 10, 11, 50

Anaërobic micro-organisms, 51

Analysis of gases, 198

Animal gum, 28

Animal starch, 10

Anions, 201

Anisotropous bodies, 186

Anti-peptone, 62, 63

Antiseptics, 48

Apparatus necessary for practical work, 4 Aqueous vapour, tension of, 8

Arginine, 22, 32, 62, 63, 113

Aromatic compounds, 4, 12, 24

Arterial blood, gases of, 100

Artificial gastric juice, 54

Aspartic acid, 62, 112

Assimilation, 2

Atmosphere, 99

Atomic weights, 8

Attraction sphere, 2

Avogadro's law, 205

B

\section{BACILL, 49}

Bacteria, 49, 76

Bacterial action, 65

Barfoed's reagent, 142

Bath, warm, 20

Baumann and Wolkow on alcapton, 132

Beaumont, Dr., 54

Beef, 34, 39

Beef-ten, 42

Beetroot, 13

Benger's liquor pancreaticus, 60, 150 ; liquor pepticus, 52

Benzene, derivatives of, 4

Benzoic acid, 123

Bernard, Claude, on glycogen, 77

Bile, 64, 69-80 ; amount secreted, 70 ; circulation, 71, 72; characters of, 71 ; constituents of, 70, 71; muoin of, 71 ; pigments, 72 ; salts of, 72 ; uses of, 74 ; in urine, 132

Biliary fistula, 69, 177

Bilirubin, 70, 72, 107 ; of meconium, 76

Biliverdin, 70,72 ; of meconium, 76

- Biuret, 24, 105

Biuret reaction, 19, 24, 52, 58, 60, 148

Blood, 81-104; coagulation of, 82, 85, 157 ; corpuscles, 87 ; detection of, 135 ; gases of, 100 ; tablets, 83 ; pigment, $87-98,151-156$; plasma and serum of, $3,81,155$; in urine, 133

Bohr on absorption of oxygen, 103 ; on hromoglobin, 98 ; on tension of caxbonic dioxide, 102
Bone, composition of, 31; marrow, 16

Bowman's oapsule, 107

Bran, 40

Bread, 34, 41

Bright's disease, 131

Brodie on muscle proteid, 162

Brown and Morris on digestion of starch, 47

Buffy coat, 83

Bunge on hrmatogens, 29 ; on milk, 36

Bush tea, 43

Butter, 33, 38

Butyric acid, 14, 17, 65

Butyrin, 38

\section{C}

Caffente, 43, 121

Calcium, 3, 8; phosphate, 4

Calcium oxalate in urine, 118, 126

Calcium salts, importance of, in cosgulation of blood, 81, 85, 157; of milk, $33,37,145$

Cane sugar, $9,10,12,77,141$; in urine, 13 ; tests for, 9,13

Caproic acid, 17

Caproin, 38

Caprylin, 38

Carbamide, 109, 115. See also Urea

Carbohydrates, 3, 4, 9-16, 140 ; absorption of, 77 ; classification of, 10 ; definition of, 10 ; tests for, 10-16, 140-144

Carbolic acid poisoning and urine, 180

Carbon, 3, 8

Carbonates in blood, 102 ; in urine, 116

Carbonic acid in air, 99; in blood, 100, 101

Carbonic oxide hæmoglobin, 97, 151

Cardiac glands, $\mathbf{5 3}, \mathbf{5 4}$

Carmine-stained fibrin, 149

Carnic acid, 63

Cartilage, hyaline, 31

Casein, 27, 33, 37, 145, 146

Caseinogen, 33, 37, 145 ; preparation of, 145,146

Cell, definition of, 2 ; diagram of, 29

Cells, differentiation of, 1

Celiulose, 10, 14, 15, 50

Centigrade scale, 8

Central cells of cardiac glands, 54

Centrosome, 2

Cerebrin, 162, 163

Cerebrosides 163

Cerebrospinal fluid, 163 ; funotions of, 164

Centrifugal machine, 157

Cheese, 38

Chemical physiology, 1

Chemical sediments of urine, 128 
Chemical structure of protoplasm, 2

Chemistry of respiration, 98

Chitin, 31

Chlorides of urine, 115 ; estimation of, 168 ; tests for, 105

Chlorine, 3, 8

Chlorophyll, 75

Cholalic acid, 72,75

Cholesterin, 3, 4, 18, 69, 70, 73, 88, 163 ; tests for, 74,136

Choletelin, 73

Choline, 18, 163, 165 ; tests for, 163,164

Chondrin, 31

Chorda tympani, 45

Chromatin, 29

Chromogens, 107 ; of urine, 180

Chyle, 78

Chyme, 70

Ciliary movement, 2

Circular polarisation and chemical constitution, 194

Circulation of bile, 71

Cirrhosis of liver, 112

Citric acid, 108

Clark's essence of rennet, 43

Claude Bernard on glycogen, 77

Clotting of blood, 82

Coagulated proteids, 27

Coagulation, 25

Coagulation of blood, 82,157 ; of hydrocele fluid, 158 ; of milk, 37,145 ; of musele, 159 ; of proteids, 22

Coagulative ferments, 50

Cobalt sulphate, actions on proteids, 148

Cocaine, 43

Cocoa, 43, 121

Coffee, 43, 121

Coffin-lid erystals, 117

Cola nut, 43

Collagen, 21, 31, 62

Collimator, 93, 154

Colloids, 23, 203

Colostrum, 36

Colostrum eorpuscles, 36

Commercial peptone, 84, 147

Compound proteids, 28

Compounds found in the body, 3

Compounds of carbon, 3

Condiments, 42

Cooking of foods, 41

Copper, 3, 8

Cream, 33

Creatine, 4, 22, 42; crystals, 124 ; in muscle, 160 ; as a urea precursor, 112

Creatinine, 42, 112, 123, 131 ; crystals of, 121 ; detection of, 106 ; estimation of, 176 ; preparation of, 124

Crypts of Lieberkühn, 64

Crystallin, 26

Crystalline lens, 26
Crystallisable proteids, 22, 89, 144

Crystallisation of egg albumin, 144

Crystalloids, 23, 204

Crystals from blood, 82, 89, 150

Curd, 146

Curds and whey, 37

Cyclopterine, 32

Cyanamide, 123

Cystin, 127 ; erystals of, 126

Decalcrited blood, 81, 157

Decalcified milk, 33, 145, 146

Decomposition, products of, 18

Density of water, 8

Dentine, composition of, 31

Deposits in urine, 117-127

Desiccator, 161

Deutero-albumose, 57, 147

Deutero-proteose, 59, 62, 131

Dextrin, $9,10,15,34,134,143$; tests for, 10,47

Dextro-rotatory, 10 -15

Dextrose, 9, 10, 11, 23, 77, 141, 142; erystals, 11 ; in blood, 11 ; in urine, 130

Diabetes mellitus, 11, 67, 131

Diabetic urine, 129

Diacetin, 17

Dialyser, 23

Dialysis, 23, 200, 202 ; of albumoses, 147 ; of serum, 155

Diastase, 49

Diastatic ferments, 14, 47, 143

Diet, 34

Diet tables, 35

Dietary, 35

Diffusion, 23, 200, 202

Digestion, 149 ; gastric, 52-59; intestinal, 64 ; pancreatic, $60-64$; salivary 45

Dimethylranthine, 121

Dioxy-purine, 121

Direct vision spectroscope, 94,95

Disaccharides, $10,11,12$

'Disuse atrophy,' 165

Dough, 33, 40

Drechsel on urea formation, 112

Dripping, 42

Dropsical effusions, 29

Dulcite, 11

Dupre's urea apparatus, 105, 106

Dysalbumose, 147

E

Eck's fistula, 112

Egg-albumin, 19, 26, 39; crystallisation of, 24,144 ; in urine, 77 
Egg-globulin, 19, 26, 39

Eggs, 34, 39

Egg white, 19, 20, 22, 39

Egg yolk, 39

Ehrlich's experiments with methylene blue, 101

Elastic fibres, 31

Elastin, 31, 62

Elastoses, 58

Elements found in the body, 3 ; symbols and atomic weights of, 8

Emulsification, 18

Emulsion, 18, 63

Enamel, composition of, 31

English system of weights and measures, 6,7

Envelope crystals, 118, 126

Enzymes, 47, 49, 51

Epidermis, 2

Epithelium of intestine, 78

Epsom salt, 116

Erlenmeyer flask, 175

Erythro-dextrin, 15, 47, 143

Esbach's albuminometer, 129; reagent, 5 ; tube, 129

Estimation of chlorides, 168 ; of ereatinine, 175 ; of dextrose, 130 ; of lactose, 13 ; of maltose, 14, 143 ; of nitrogen, 199 ; of phosphates, 171 ; of sulphates, 172 ; of urea, 105, 166; of uric acid, 174

Ethereal sulphates in arine, 116 ; estimation of, 172

Ethyl alcohol, 17

Ethyl-diacetic acid, 131

Eu-globulin, 156

Expired air, 99

External respiration, 99

Extirpation of pancreas, 67

Extractives of blood, 87; of muscle, 42 , 159,161

Extraordinary ray, 186

\section{F}

\section{F}

Fahrenheit scale, 7

Fats, 4, 16-18, 38

Fats, absorption of, 78-80 ; constitution of, 16 ; decomposition products of, 18 ; melting-point of, 16 ; tests for, 10,16

Fatty acids, 17

Fehling's solution, 8, 11, 129

Fehling's test, 9, 13, 14, 129

Ferment coagulation, 25

Ferment, invert, 64

Fermentation, 47

Fermentation test, 11, 132
Ferments, 47 ; of gastric juice, 55 ; of pancreatic juice, 61 ; of saliva, 49 ; of succus entericus, 64 ; organised, 49 ; unorganised, 49

Ferments, classification of, 49

Fibre, elastic; 31

Fibrin, 27, 84, 85

Fibrin ferment, 50, 84, 85, 158 ; preparation of, 81,87

Fibrin filaments, 83

Fibrinogen, 26, 84, 85, 86

Filtration, 203

Fistula, gastric, 54

Fleisohl's hæmometer, 184; spectropolarimeter, 193

Flour, 33, 40

Fluorescent sereens, 154

Fluorine, 3

Food, 33, 34; cooking of, 41

Formic acid, 17

Fractional heat coagulation of muscle proteids, 159; of serum proteids, 156

Frauenhofer's lines, 92, 152, 153

Fredericq on oxygen tension, 101 ; on tension of carbon dioxide, 102

Free hydrochloric acid in gastric juice, tests for, 149

Fürth, จ., on muscle plasma, 161

G

Gatactose, 10, 11, 12, 13, 141

Gall stones, 73

Gamgee on secretion of hydrochloric acid, 55 ; on photographic spectra, 153

Garrod on urochrome, 108

Garrod and Hopkins on urobilin and stercobilin, 177

Garrod's methods of separating pigments from urine, 178

Gas analysis, 198

Gaseous interchange in lungs, 207

Gases of blood, 100

Gastric fistula, 54

Gastric juice, 52 ; action of, 50, 57; composition of, 56 ; glands, 53 ; properties of, 57 ; secretion of, 52

Gay-Lussao's law, 205

Gelatin, 4, 21, 31, 43 ; tests for, 136

Gelatinisation, 21

Gelatoses, 58

Germ theory of disease, 48

Globin, 90

Globulin, 22, 26, 58, 162

Globulose, 58

Glossopharyngeal nerve, 44

Gluco-proteid, 28

Glucose, 10, 11, 77, 141, 143 
Glucosuria, transitory, 131

Glutaminic acid, 62,113

Gluten, 33, 40

Gljceric ethers, 17

Glycerides, 17

Glycerine, 17, 63

Glycerol, 17

Glyceryl, 17

Glycine, see Glycocine

Glycocholate of soda, 70

Glycocholic acid, 72

Glycocine, 22, 66, 72, 75, 113, 123

Glycogen, $10,15,22,49,134$; microscopical detection of, 141 ; preparation of, 140 ; tests for, 15,134

Glscosuria, 131

Glycuronic acid, 132

Glyoxylic acid, 5, 19

Gmelin's tcst, 69, 73

Gnezds on biuret reaction, 148

Gowers's hæmacytometer, 181 ; hæmoglobinometer, 183

Graham, Thomas, on colloids and erystalloids, 22

Gram-molecular solntions, 202

Granulose, 14

Grape sugar, see Dextrose

Ground substance, 21, 28

Grütrner's method of comparing digestive power of solutions of pepsin, 149

Granine, 30, 121, 122

Guarana, 43

Gums, 10

Gunsberg's reagent, 149

Gürber on serum albumin crystals, 24

\section{H}

H.evactTonsterk of Sir William Gowers, 181 ; of Oliver, 182

Hrmatin, 75, 90, 177; scid, 151 ; alkaline, 151 ; iron free, 151 ; of food, 107

Hrematogen, 29

Hrematoidin, 70, 91 ; crystals, 70

Hromatoporphyrin, 91, 153, 178 ; absorption bands of, 153,179

Hromatoscope of Hermann, 94

Hæmin, 90,91; crystals, prejaration of. 82

Hremochromogen, 151

Hæmoglobin, 23, 28, 82, 151 ; composition of, 90 ; derivatives of, 151,152 , 153

Hæmoglobinometer of Sir William Gowers, 183 ; of Oliver, 184

Hæmoglobinuria, paroxysmal, 133

Hæmometer of von Fleischl, 184
Haldane on methremoglobin, 97 ; on absorption of oxygen, 103

Halogens, action on proteid, 28

Hammarsten on blood coagulation, 84 ; method of precipitating serum globulin, 155

Hammerschlag's method of estimating the specific gravity of blood, 186

Hayem's fluid, 183

Heat coagulation of proteids, 22 ; of serum globulin and serum albnmin, 155,156

Heat rigor, 162

Heidenhain on secretion of gastric juice, 55 ; on pressure in bile duct, 70

Heller's nitric acid test, 129

Hemi-peptone, 62

Henry-Dalton law, 205

Herrmann, hæmatoscope of, 94

Hetero-8l bumose, 58, 5๊ , 147 ; proteose, 62,131

Hexatomic alcohols, 11

Hexone bases, 32, 63, 113

Hill's air-pump, 187

Hill, Croft, on ferments, 50

Hippuric acid, 123, 136; crystals of, 123

Histidine, 32, 63

Histone of Kossel, 90

Hofmeister on crystallisation of eggalbumin, 24

Homogentisinic acid, 132

Hopkins's method of estimating uric acid, 120,174; on erystallisation of egg-albumin, 24, 144

Hoppe-Seyler on hrmatin, 90 ; on proteids, 21

Hot-air oven, 140

Hüfner's method of estimating area, 167

Hyaline cartilage, 31

Hydrazone, 142

Hydrobilirubin, 73, 107, 177

Hydrocarbon, 17

Hydrocele fluid, 85, 158

Hydrochinon, 180

Hydrochloric acid, 4; of gastric juice, 55; tests for, 149; test for cane sugar, 9

Hydrochloride of hematin, 90

Hydrogen, 3, 8

Hydrolysis, 13, 58

Hydrolytic ferments, 50

Hydrometer, 36, 186

Hydroxybutyric acid, 131

Hydroxyl, 17

Hypertonic solutions, 206

Hrpobromite of soda, action of, on urea, $105,110,167$

Hypotonic solutions, 206

Hypoxanthine, 30, 121 


\section{I}

INDICAN, 116

Indiffusibility of proteids, 23,208

Indigo, 116 ; blue, 180 ; red, 180

Indole, $65,75,180$

Indoxyl, 116, 180

Indoxyl sulphate of potassium, 116, 180

Infection, 48, 49

Inorganic compounds, 3 ; salts, 3

Inosite, 11,12 ; crystals of, 12

Inspired air, 99

Internal respiration, 98

Internal secretion, 67,68

Interstitial substance, 21,28

Intestinal juice, 13 ; digestion, 64

Intravascular coagulation, 158

Inversion, 12, 13

Inversion of cane sugar, 50

Inversive ferments, 50

Invert ferments, 12

Invertin, 50, 64

Iodine, 3,8

Iodine test, $10,15,33,134,143$

Ions, 201

Iron, 3,8 ; in milk, 36

Iron-free hæmatin, 90, 153

Iso-cholesterin, 74

Iso-maltose, 14, 141

Isotonic solutions, 206

Isotropous bodies, 186

\section{J}

JAFFE on test for indoxyl, 180

Jaundice, 132

Jelly, Lieberkühn's, 28

Jelly, Whartonian, 21

Johnson, G. S., on creatinine, 176 ; on sugar in urine, 130

Johnson, Sir G., on picric-acid test, 130

Juice, intestinal, 12, 13, 64

Junkets, 43

K

KAT-TON8, 201

Kauder's method of precipitating serum globulin, 155

Keratin, 2, 4, 31, 75

Ketone, 11

Kidney, 106

Kidneys, removal of part of, 67

Kjeldahl's method of estimating nitrogen, 199

Kossel on protamines, 26, 32 ; on histone, 90

Koumiss, 39
Kühne, on peptone, 62 ; on precipitation of pepsin, 57

Külz's method of extracting glyeogen, 140

Kutsoher on antipeptone, 63

\section{L}

LaCtALBUmen, $26,33,37,145$; properties of, 37

Lactic acid, $11,14,38,42,56$; tests for, 159

Lactic acid fermentation, 14,65 ; in milk, 38 ; in muscle, 42, 159; organisms, 13

Lactometer, 33

Lactose, $10,13,33,38,141$; in urine, 131 ; tests for, 141

Laky blood, 89

Lanoline, 74

Lard, 10

Lateritious deposit, 118

Laurent's polarimeter, 192

Lead, 3, 8

Lecithin, 3, 4, 18, 39, 65, 71, 88, 162, 163

Leech extract, 84

Leucine, $22,32,61,63,65,66$; as \& urea precursor, 113 ; in urine, 128 ; tests for, 150

Lencine crystals, 66 ; preparation of, 150

Levo-rotatory, 10, 12, 24

Levulose, 10, 11, 12, 141 ; in blood, 12 ; in muscle, 12 ; in urine, 12 ; reactions of, 12

Lieberkühn's crypts, 64 ; jelly, 28

Liebig's extract, 161 ; method of estimating chlorides, 169 ; urea, 166

Lime water, 21

Lipochrome, 38, 39; in muscle, 160

Lipolytic ferments, 50

Liquor pancreaticus, 60 ; pepticus, 52

Lithates, see Urates

Lithium, 3, 8

Litre, standard of capacity, 7

Liver, function of, in relation to urea, 111 ; uric acid, 120

Living test-tube experiment, 85

Loeb on ionic action, 201 ; on fertilisation, 202

Lungs, 98

Luther on nitrogen loss in hypobromite method of estimating urea, 167

Lysatinine, 113

Lysine, 32, 62, 113

M

McKENDRICK on cholesterin, 74

MacMunn on stercobilin, 76 
McWilliam's test for proteids, 148

Magnesium, 3, 8

Magnesium sulphate, action of, on proteids, 19, 26, 156

Malic acid, 108

Mallow, 13

Malpighian eapillaries, 106

Malting ferment, 143

Maltase, 50

Maltose, 10, 14, 47, 77, 141, 143

Malt upon starch, action of, 143 ; diastase, 143

Maly on the formation of hydrochloric acid, 55

Manganese, 3, 8

Mannite, 11

Marchi reaction, 164

Marsh gas, 64

Measures of capacity, 7 ; of length, 6

Meat, 34, 39 ; constituents of, 40

Meconium, 76

Medulla oblongata, diabetic puncture of, 131

Melanin, 180

Mercurial air-pumps, 195

Mercuric nitrate, method of estimating chlorides, 168 ; urea, 166

Mereury compound of creatinine, 125. 176

Metabolism, 2, 67

Methæmoglobin, 96, 151 ; crystals of, 150 ; in urine, 133

Methane, 65

Methylene blue experiments, 101

Metric system, 7

Microchemical detection of glycogen 141

Micrococcus urea, 110, 127

Microspectroscope, 94, 151

Milk, 38, 34, 36; alcoholic fermentation of, 39 ; cosgulation of, 37, 57, 145 ; composition of, 37 ; fats of, 38 ; proteids of, 37 ; salts of, 39 ; souring of, 38

Milk-curdling ferment of pancreas, 61, 64 ; of stomach, 37,57

Milk-sugar, $10,13,33,38,77$; erystals, 13

Millon's reagent, 5; test, 19, 24, 33. 44

Mineral compounds, 5

Mohr's method of estimating chlorides, 169

Moleschott's diet, 35

Monatomic alcohols, 17

Monoacetin, 17

Monochromatic light, 192

Monosaccharides, 10, 11

Monoxypurine, 121

Moore and Rockwood on fat absorption, 80
Moore on osmotic pressure of proteids, 208

Moore's test for sugar, 11

Mörner and Sjöqrist's method of estimating urea, 168

Mörner on hremin, 91

Morris and Brown on starch digestion, 47

Mucic acid, 12

Mucin, 2, 21, 28, 75 ; in bile, 29, 69; in saliva, 45 ; in urine, 125 ; tests for, 21 , 44, 137

Mucinogen, 45

Mucoids, 28

Mucous glands, structure of, 46

Mucous membrane of frog's intestine, 78

Mucons salivary glands, 28

Munk on fat absorption, 79

Murexide test, 118

Muscle, 39, 156; clot, 161 ; pigments of, 160 ; plasma of, 156 ; extractives of, 160,161

Muscle sugar, 12

Muscular movement, 2; exercise and urea, 111 ; exercise and carbonic acid, 100

Musculin, 160

Mutton, 34

Myo-albumin, 160, 161

Myogen, 161 ; myogen-fibrin, 161

Myo-globulin, 160, 161

Myo-hrmatin, absorption spectrum of, 160

Myosin, 4, 27, 39, 5̌s, 161 ; ferment, 50 ; fibrin, 161

Myosinogen, 26, 159, 160, 161, 162

Myxcedema, 67

$\mathrm{N}$

Newcri and Sieber, on pigments, 177

Neneki's experiments on urea, 114

Nerve degeneration, chemistry of, 163

Nervous tissues, 162

Neurokeratin, 31, 162

Neutral salts, action of, on proteids, 19 . $25,26,33,37,82,134,147,155$

Nickel sulphate, action of, on proteids, 148

Nissl's bodies, 162

Nicol's prism, 187

Nitrate of urea, 110, 118

Nitric oxide hromoglobin, 91, 98, 154

Nitrogen, 3; estimation of, 199

Nitrogenous food, 39 ; glueosides. 163

Nitrous acid, action of, on urea. 110

Sucleic acid, 30 ; decomposition of, 30

Nuclein, 3, 29, 38, 117, 121; bases from, 120 
Nucleo-proteid, 3, 29, $30,158,163$; in bile, 71 ; decomposition of, 30 ; in muscle, 162 ; tests for, 136

Nucleus, functions of, 2

\section{0}

OLeIC aoid, 17

Olein, 16, 17, 38

Olfactory nerve, 44

Oliver's hæmacytometer, 182 ; hæmoglobinometer, 184

Organic compounds, 3

Ordinary ray, 186

Organic ferments, 49

Osæzones, 141, 142

Osmosis, 23, 200, 202

Osmotic pressure, 203, 204, 207 ; calculation of, 205,206 ; of proteids, 208 ; physiological application of, 206

Ossein, 31

Osteomalacia, 131

Ovarian cyst fluid, 29

Ovo-mucoid, 28, 39

Oxalate of calcium in milk, 33 ; plasma, 157 ; in urine, 118, 126

Oxalate of urea, 110, 118

Oxidases, 50

Oxygen, 3, 8; in blood, 100

Oxyhrmoglobin, $62,91,151$; crystals, $82,89,150$; in muscle, 160

Oxyhæmoglobin, pure, preparation of, 154

Oxyntic cells of cardiac glands, 54

Oxyphenyl-amido-propionic acid, 167

\section{$\mathbf{P}$}

Pate muscle, 160

Palmitio acid, 17

Palmitin, 16, 17, 38

Pancreas, extirpation of, 67,131 ; grafting the, 67 ; structure of, 61

Pancreatic digestion, 60, 149

Pancreatic juice, 14; Rotion of, 62 ; composition of, 61 ; secretion of, 60

Panum's method of precipitating serum globulin, 155

Paraglobulin, see Serum Globulin

Para-muein, 29

Paramyosinogen, $160,161,162$

Parapeptone, 52, 58

Parietal cells of cardiac glands, 54, 55

Parotid gland, 44, 46

Paroxysmal hæmoglobinuria, 133

Partial pressure of gases, 100-103

Pasteur on circular polarisation, 194

Pathological urine, 129 ; pigments of, 178 ; pigments, 180
Pavy on composition of proteid, 28 ; on glycogenic function of liver, 77 ; on estimation of sugar, 130

Pawlow on secretory nerve-fibres to the gastric glands, 56 ; to the pancreas, 60

Pepsin, 50, 52, 55, 57 ; solutions, activity of, 149 ; hydrochloric aoid, 56

Pepsinogen, 55

Peptic digestion, 52

Peptone, 19, 22, 52, 58, 59, 77, 134; precipitation of, 58,147 ; in urine, 131 ; tests for, 59,147

Peptoniria, 131

Perfect foods, 34

Pericardial fluids, 85

Pettenkofer's test for bile salts, 69,72 , 132

Pflüger's mercurial air-pump, 195, 196

Phenol, 65, 75

Phenyl sulphate of potassium, 116

Phenyl-hydrazine test for sugars, 141

Phloridzin, 131

Phosphates of urine, 117, 127, 128;

estimation of, 171 ; tests for, 105

Phosphates, stellar, 127

Phosphates, triple, 127

Phosphorus, 3, 8

Photographic spectra, 153

Physiological chemistry, 1

Physiological proximate principles, detection of, 134

Pickering on colour reactions of proteids, 148

Picramic acid, 11

Picric acid, test for sugar, 11, 130

Pigment of red corpusoles, 89; of muscle, 160 ; of urine, 177

Pigments, 3 ; pathological, 180

Piotrowski's reaction, 19, 24, 148

Plasms, constituents of, 86 ; gases of, 86 ; proteids of, 86

Plasma of blood, $81,85,157$; of muscle, 159

Pleochromatism, 189

Poisonous alkaloids, 65

Polarimeters, 190 ; of Laurent, 192 ; of Soleil, 190; of Zeiss, 192

Polarisation of light, 186

Polariscopes, 187

Polarised light, 189; action of carbohydrates on, 10-14; of proteids, 24

Polarising microscope, 188

Polysaccharides, $10,11,14$

Pork, 39

Portal vein, 69

Potash, method of extracting glycogen, 140 ; of showing zymogen granules, 150

Potassium, 3,8 
Potassium ferricyanide in preparation of methremoglobin, 151

Potassium ferrocyanide in the estimation of phosphates, 171

Potassium permanganate in estimation of uric acid, 175

Potassium sulphocyanide in saliva, 44, 45

Precipitants of proteids, 24, 25

Precipitation, 24

Prevost and Dumas on formation of area, 111

Primary albumoses, 58 ; proteoses, 59

Principal cells of stomach, 54

Prisms in direct vision spectroscope, 94

Propeptone, 52, 58

Propionic acid, 17

Protagon, 162

Protamines, 26, 32

Proteids, 2, 3, 19-32, 37, 39-41 ; absorption of, 77 ; classification of, 25,59 ; coagulated, 27; corgulation of, 22 , 27 ; colour reactions of, 24 ; composition of, 21 ; compound, 26,28 ; conjugated, 26 ; crystallisation of, 23 , 24 ; definition of, 21 ; digestion of, by gastric juice, $57-60$; digestion of, by pancreatic juice, 62,63 ; molecule, 21 ; of blood plasma, 86 ; of milk, 37 ; of muscle, 160 ; of serum, 86 ; osmotic pressure of, 208 ; in urine, 131 ; precipitants of, 24 ; simple, 26 ; solubilities of, 22, 26 ; tests for, 19, 22, 59,12 ऽ, 134

Proteid metabolism, 3

Proteid sparing food, 31

Proteolytic ferments, 50, 52; enzymes, 62

Proteoses, 19, 26, 27, 58, 59, 62, 77, 147 ; in urine, 131

Prothrombin, 84, 85

Proto-albumose, 58, 59, 62, 147

Protones, 32

Protoplasm, chemical structure of, 3 ; properties of, 2

Proximate principles, classification of, 4 ; of food, 34 ; scheme for detecting, 134-137

Pseudo-globulin, 156

Pseudo-mucin, 29

?'seudo-nuclein, 30

Promaines, 48

Ptyalin, 14, 45, 47, 49

Pulses, 41

Pumps, mercurial air, 195-198

Purine bases, 30, 121

Purpurate of ammonia, 118

Pus in urine, 133; tests for, 133

Putrefaction, 48, 49

Pyloric glands, 53

Pyrocatechin, 164, 180
Q

Quavirtartve estimation of albumin, 129 ; of chlorides, 168-170 ; of ereatinine, 175; of dextrose, 130 ; of glycogen, 140 ; of lactose, 13, 130 ; of maltose, 14, 130, 143; of nitrogen, 199 ; of phosphates, 171 ; of sulphates, 172 ; of sugar, 130 ; of ures, 105,166 , 167 ; of uric acid, 120,174

\section{R}

RACEMrIC acid, 130

Ranke's diet, 35

Reagents necessary for practical work, 4 Réaumur's scale, 7

Red blood corpuscles, 87, 88 ; composition of, 88 ; pigment of, 89

Ried muscle, 160

Reflex action, 44

Rennet, 33, 50, 145

Rennin, 55

Reproduction, 2

Respiration, chemistry of, 98

Respiratory pigments, 89

Respiratory quotient, 99

Rigor mortis, 42

Ringer on caseinogen, 146 ; on contractile tissue, 201

Riva on urochrome, 108

Rockwood and Moore on fat absorption, 80

\section{S}

Saccharic acid, 12

Saccharimeters, 190

Saccharoses, 10, 12

Salicyl-sulphonic acid, action of, on proteids, 148

Saliva, 21, 44 ; action of, 45 ; composition of, 45 ; secretion of, 44

Salivary corpuscles, 44 ; glands, 44

Salkowski's reaction for cholesterin, 74 method of estimating sulphates, 173

Salmine, 32

Salted whey, 33

Salting-out of proteids, 25

Saponification, 63

Sarcine, 122

Sarcolemma, 31

Sarcosine, 123, 124

Schäfer on internal secretion, 68 ; on fat absorption, 79

Schiff on bile circulation, 71, 75 ; test for uric acid, 118 
Schizomycetes, forms of, 48

Schmalz's capillary picnometer, 186

Schmidt on precipitating serum globulin, 155 ; on salts of plasma, 87 ; on preparation of fibrin-ferment, 87

Schröder's work on urea, 114

Schwann, white substance of, 73

Scombrine, 32

Sebum, 74

Secretion, internal, 67 ; of bile, 69

Sediments in urine, 125-128

Semipermeable membranes, 204

Serous glands, 46

Serum, 83, 155; albumin, $26,81,86$; crystallisation of, 24 ; beat coagulation of, 155

Serum casein, 155

Serum globulin, 26, 81, 86 ; heat coagulation of, 155,156

Serum lutein, 81

Serum of blood, 23, 81,85 ; proteids of, 86 ; of muscle, 159

Serum proteids, 86 ; separation of, 82

Sheep's-wool fat, 74

Shell of eggs, 39

Siegfried on antipeptone, 63

Silicon, 3, 8

Silver nitrate method of estimating chlorides, 169

Sir William Gowers's hæmacytometer, 181; hæmoglobinometer, 182

Sir William Roberts on estimation of sugar in urine, 132

Skatole, 65, 75

Skatoxyl, 180 ; red, 180

Skimmed milk, 33, 36

Smoky urine, 133

Snake venom, 49

Soap, $18,63,80,87$

Sodio-magnesium sulphate, action of, on proteids, $156^{\circ}$

Sodium, 3, 8

Sodium bicarbonate in blood, 101, 102

Sodium chloride, 3 ; action on proteids, 26,155 ; on nucleo-proteids, 29,158

Sodium hypobromite method of estimating urea, 105, 167

Sodium phosphate, 21 ; acid, 21, 102, 108

Sodium sulphate plasma, 81,157

Solar spectrum, 96,152

Soleil's saccharimeter, 190, 191

Soluble starch, 15

Solutions, 200

Sorbite, 11

Soret's band, 154

Soup, 43

Specific gravity of blood, 186 ; of milk, 33,36 ; of urine, 105,108

Specific rotatory power, 193

Spectra, 96; of hæmoglobin and its derivatives, 152 ; photographic, of methæmoglobin, oxyhæmoglobin, and hæmoglobin, 153 ; of myohrmatin, 160 ; of urinary pigments, 108,179

Spectro-polarimeter, 193

Spectroscope, 92, 93, 94

Spectrum, 92

Spermatozoa, 30

Starch, 4, 9, 10, 14, 41, 47, 134 ; soluble, 15 ; action of malt on, 143 ; digestion of, $44,49,63$; test for, 9,14

Starling on osmotic pressure of proteids, 208

Steapsin, $18,50,61$; action of, 60

Stearic acid, 17

Stearin, 16, 17, 38

Steatolytic ferments, 50

Stellar phosphates, 127

Stercobilin, 73, 107, 177

Stewart, G. N., dietary, 35

Stirling on preparation of pure oxyhæmoglobin, 154

Stokes' fluid, 92

Stomach, glands of, 53,54

Sturine, 32

Sublingual gland, 44, 45

Submaxillary gland, 44, 45

Succus entericus, $13,64,77$

Sucroses, 10, 11

Sugar, 4, 50 ; cane, 13 ; in blood, 87 ; in urine, 130,131 ; muscle, 12 ; tests for, $9-14,141,142$

Sugar, maple, 13

Sulphates of urine, 116 ; estimation of, 172 ; tests for, 105

Sulphonal poisoning, 179

Sulphur, 3, 8

Suprarenal gland, removal of, 67

Sutton's modification of Mohr's method of estimating chlorides, 169

Swim-bladder of fishes, 103

Symbols and atomic weights, 8

Syntonin, 21, 27, 52, 58, 159

\section{$\mathbf{T}$}

TANNIN, 43

Tartaric acid, 108

Taurine, 72,75

Tauro-carbamic acid, 75

Taurocholate of soda, 70, 72

Taurocholic acid, 72

Ten, 121

Teichmann's crystals, 90,91

Tendon, 21

Tension of aqueous vapour, 8 ; of gases, 102,103

Testis, removal of, 67

Theine, $\mathbf{4 3}$ 
Theobromine, 43, 121

Theophylline, 121

Thermometric scales, 7

Thrombin, 84, 85

Thudichum on urochrome, 177

Thyroid gland, removal of, 67

Tissue-fibrinogens, 29, 84, 158

Tissue respiration, 98, 103

Tomes on enamel, 31

Tonsils, 44

Torricellian vacuum, 92, 196

Toruls ares, 110

Torulæe, 47, 48, 49

Transitory glucosuria, 131

Triacetin, 17

Triatomic alcohol, 17

Trichloracetic acid as a precipitant of proteids, 148

Trimethyl-xanthine, 121

Triolein, 17

Trioxy-purine, 121

Tripalmitin, 17

Triple phosphate, 117, 118, 127

Tristearin, 17

Trommer's test, 9, 11-15, 33, 44

Tropreolin test, 149

Trypsin, 50 ; action of, 60,62

Trypsinogen, 61

Tryptic enzyme, 63

Tryptophan, 62

Tunicates, 16

Tyrosine, 22, 32, 61, 62, 63, 65, 66, 113, 132 ; crystals, 66 ; in urine, 113 , 128 ; tests for, 150

\section{$\mathrm{U}$}

Umbrtical cord, 21

Uncrystallisable sugar, 12

Unorganised ferments, 46,49

Uræmia, 111

Uranium acetate in estimation of phosphates, 171

Uranium nitrate in estimation of phosphates 171

Urate, acid ammonium, deposit of, 126 ; acid sodium, deposit of, 126

Urates, 118, 120, 125, 126

Ures, 3, 4, 22, 47, 71, 87, 105, 109 composition and compounds, 109 ; crystals of, 108; decomposition of, 110 ; estimation of, 105,166 ; mode and site of formation, 111 ; preparation of, 168; quantity excreted, 111 ; tests for, 105, 136; where formed, 111,112

Urea nitrate, 109 ; preparation of, 109, 118

Urea oxalate, 109, 118
Uric acid, 22, 87, 119, 121, 122 ; crystals of, 119 ; estimation of, 120, 174 ; preparation of, 118,174 ; origin of, 120 ; tests for, 118,136

Urina potus, 109

Urinary deposits, 125

Urine, 105 ; composition of, 109 ; inorganic constituents of, 115 ; pigments of, 177 ; tests for abnormal constituents of, 129; tests for constituents of, 105,136

Urinometer, 108

Urobilin, 73, 107, 108, 177, 178; absorption bands of, 179

Urobilinogen, 107

Urochrome, 108, 177

ro-erythrin, 126, 178 ; absorption bands of, 179

Urorosein, 180 ; absorption bands of, 179

\section{$\nabla$}

VAxienic acid, 17, 65

Van't Hoff on polarisation of light, 195 ; hypothesis, 204

Vegetable acids, 4 ; foods, composition of, 41 ; parchment, 23

Vegetables, composition of, 41, 43; green, 43

Venous blood, gases of, 100

Villug, section of, 78

Vital action, 207

Vitellin, 24, 29, 30, 39

Vitellose, 58

Vitreous humour, 21

W

WALLER'B modification of Zuntz's gas apparatus, 198

Warm bath, 20

Water in protoplasm, 2, 4; density of, 7 .

Wave theory of light, 186

Weights and messures, 6

Whartonian jelly, 21

Whey, 33, 37 ; salted, 33, 36

Whey-proteid, 37

White blood corpuscles, 2, 87

White of egg, 2, 19, 20, 39, 52, 59

Whole flour, 40

Witte's peptone, 147,148

Wōhler, preparation of urea, 109

Wooldridge on tissue-fibrinogen, 29, 84, 158

'Worth' of corpuscles, 186 
$\mathrm{x}$

XANTHive, 30, 61, 87, 121, 122

Xanthine group, 30, 121

Xanthoproteic test, 19, 44

\section{Y}

YEAST, action of, 11, 12, 13; cells, 47; in bread-making, 41 ; in testing for sugar, 11, 132
Yron on removal of creatinine and urates, 167

$\mathrm{Z}$

ZRIss' polarimeter, 192

Zinc chloride ereatinine, 124,175

Zuntz's gas apparatus 198

Zymogen, 55, 87 granules, 150 


\section{A LIST OF WORKS ON}

\section{MEDICINE, SURGERY, \\ AND GENERAL SCIENCE, \\ PEBLISHED BY}

\section{LONGMANS, GREEN, \& CO.,}

39 PATERTOSTER ROW, LONION, E.C.

91 AxD 9:3 FIFTH AVENUE, NEW YORK, AND 32 HORNBY ROAD, BOMBAY.

\section{Messis. LONGMANS, GREEN, \& CO.}

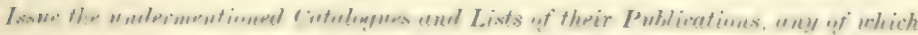
wroy he had post free on application.

1. Mosteli Lis "if New Burke asd New Enitions.

2. QUaRTERLY LIST OP Axyotychuents AND NeW BOOKs.

3. Nuten ox Books $\{$ QuARERLY) ; BeING Ax Aralysis OF THE WORKS PCRI.I*HED BY LrIXiMaNs, GREEN, \& C'n.

4. SELECT LINT UF BuUk's IN NATCRAL avd Physical Science, MathiMatICS ANI Trchrolngr.

5. SEIECT LIST UF BOOKS FOR SCIENCE AxD TeChNICAL SCHouls.

b. Vedical axd Serafeal Book:
7. Educational asd School Bouks.

8. Edocational Books Regently PubLISHBD.

9. Books For Elamentaky schools AND PUPI. TEACHERs.

10. Theoligical Books.

11. Theulohicai, BuUkis (Maisey Ru) May Catroutc)

12. BuOKS Is GENeRAL LITERitURE.

13. A Classified Catalogee (1 $14 \mathrm{pp}$.) (Grarkal, Literature, ScibNCE, Theologi, Euccatius).

ASHBY. - W"HK'S h! HEYIY ASHBY. M.I). Loud., F.R.C'P.

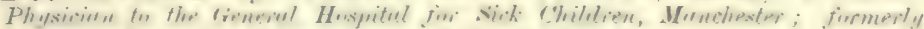
Inemonstrular of Physinligy, Lirerpoul School of Medicine.

NOTES ON PHYSIOLOGY FOR THE USE OF STUDENTS PREPARING FOR EXAMINATION. seventh Edition, thoroughly revised. With 149 Illustrations. $18 \mathrm{mo}, 5 \mathrm{~s}$.

HEALTH IN THE NURSERY. With 25 Illustrations. Crown swo, 3s. net.

ASHBY AND WRIGHT. THE DISEASES OF CHILDREN, MEDICAL AND SURGICAL. BY HENRY ASHBY, M.D. Lond., F.R.C.P., Physician to the General Hospital for Sick Children, Manchester: Lecturer and Examiner in Diseases of Children in the Victoria University: and G. A. WRIGHT, B.A. M.B. Oxon, F.R.O.S. Eng., Assistant Surgeon to the Manchester Royal Infirmary, and Surgeon to the Children's Hospital ; formerly Examiner in Surgery in the University of Oxford. Enlarged and Improved Edition. With 217 Illustrations. 8vo, $25 s$. 
BENNETT.-WORKS by Sir WILLIAM H. BENNETT, K.C.V.O., F.R.C.S., Surgeon to St. Gearge's Huspital; Member uf the Borend if Exceminers, Royal College of Surgeons of England.

CLINICAL LECTURES ON VARICOSE VEINS OF THE LOWER EXTREMITIES. With 3 Plates. 8vo, $6 s$.

ON VARICOCELE: A PRACTICAL TREATISE. With 4 Tables and a Diagram. 8vo, 5 s.

CLINICAL LECTURES ON ABDOMINAL HERNIA : chiefly in relation to Treatment, including the Radical Cure. With 12 Diagrams in the Text. 8vo, 8s. 6d.

ON VARIX, ITS CAUSES AND TREATMENT, WITH ESPECIAL REFERENCE TO THROMBOSIS : an Address delivered at the Inaugural Meeting of the Nottingham Medico-Chirurgical Society, Session 1898-9. 8vo, 3s. 6d.

ON THE USE OF MASSAGE AND EARLY PASSIVE MOVEMENTS IN RECENT FRACTURES AND OTHER COMMON SURGICAL INJURIES: THE TREATMENT OF INTERNAL DERANGEMENTS OF THE KNEEJOINT : THE MANAGEMENT OF SIIFF JOINTS : Three Clinical Lectures delivered at St. George's Hospital. With 17 Illustrations. $8 \mathrm{vo}, 6 s$.

THE PRESENT POSITION OF THE TREATMENT OF SIMPLE FRACIURES OF THE LIMBS : an Address delivered in opening a Discussion at the Meeting of the British Medical Assuciation held at Ipswich, August, 1900. To which is appended a iummary of the Opinions and Practice of about 300 Surgeons. 8 vo. $2 \mathrm{~s}, 6 d$.

BENTLEY. A TEXT-BOOK OF ORGANIC MATERIA MHDICA. Comprising \& Description of the Vegetable and Animal Drugs of the British Pharmacopoeia, with some others in common use. Arranged Systematically, and Especially Designed for Students. By ROBERT BENTLEY, M.R.C.S. Eng., F.L.S. With 62 Illus, on Wood. C'r. 8vo, $7 s .6 r$.

BRODIE. THE ESSENTIALS OF EXPERIMENTAL PHYSIOLOGY. For the use of Students. By T. G. BRODIE, M.D., Lecturer on Physiology, St. Thomas's Hospital Medical School. With 2 Plates and 177 Illustrations in the Text. Crown 8vo, 6s, $6 d$.

CABOT. A GUIDF TO THE CIINICAL EXAMINATION OF THE BLOOD FOR DIAGNOSTIC PURPOSES. By RICHARD C. CABOT, M.D., Physician to Out.Patients, Massachusetts General Hospital. With 3 Coloured Plates and 28 Illus. in Text. 8vo, 16s.

CARR, PICK, DORAN, DUNCAN. THE PRACTITIONER'S GUIDE. By J. WAI.TER CARR, M.I. I,ond., F R.C.P., Physician, Royal Free Hospital; Physician, Victoria Hospital for Children; Joint Lecturer on Medicine, London (Roynl Free Hospital) School of Merdicine for Women; 'T. PICKFRING PICK, F.R C.S., Consulting Surgeon, St. (ieorge's Hospital and Victoria Hospital for Children; ALLAN H. (A. DORAN, F.R.C.S.. Surgeon to the Samaritan Free Hospital ; ANDREW DUNCAN, M.D., B.S. Lond., F. R.C.S., M.R.C.P., Physician, Branch Hospital Seamen's Hospital Society; Joint Lecturer on Tropical Medicine at London School of T'ropical Medicine; P'hysician, Westminster Dispensary ; Fellow of King's College, London. 8vo, 21s. net. 
CELLI. MALARIA ACCORDING 'TO THE NEW RESEARr'HES.

$\mathrm{By}$ Professor ANGELU ('EILI. I)irector of the Institute of Hygiene, Liniversity of Rume. Translated from the Second Italian Edition by JOHN JOSEPH EYRE, M.R.C.P.. L.R.C.S. Irel., D.P.H. Cambridge. With an Introduction br Lr. PATRICK MANSON, Medical Adviner to the Colonial Office. With 3 Maps and 40 Illustrations. 8vo, 10s. $6 r l$.

\section{CHEYNE AND BURGHARD. A MANUAL OF SCRGICAL} TREATMENT. By W. WATSUN CHEYXE, C.B., M.B.. F.R.C.S., F.R.S.. Professor of Surgery in King : College, London; surgeon to King's College Hospital, and the Children's Hospital. Paddington (rreen. cte. ; and F. F. BUR(iHARD, M.D. and M.s. Lond., F.R.C.S., Teacher of Practical Surgerv in King's College. London: Surgeon to King's College Hospital, and the Children's Hospital, Paddington Green, ete. PROPOSED DIVISION OF WORK.

PART I. The treatment of (ieneral PART V. The treatment of the Surgica. Surgical Diseases, including inflammation, suppuration, ulceration, gangrene, wounds and their complications, infective diseases and tumours; the administration of anesthetics. With 66 Illustrations. Rova] 8 vo, 10s. $6 d$.

[Revidy.

Part II. The treatment of the Surgical Affections of the Tissues, including the skin and subcutaneous tissues, the nails, the lymphatic vessels and glands, the fascir, burse, muscles, tendonsand tendon-sheaths, nerves. arteries and veins; deformities. With 141 Hlustrations. Royal 8vo, $14 s$.

Ready.

Part IIT. The treatment of the Surgical Affections of the Bones. Amputations. With 100 Illustrations. Royal 8vo, 12 s.

Part IV. The treatment of the Surgical Affections of the Joints (including excisions) and the spine. With Affection - of the head. face, jawsl lips. larvux and trachea: and the Intrinsic Diseases of the nose, ear and larynx, by $H$. LAMBERT LACK, M.D. (Lond.), F.R.C.S., Surgeon to the Hospital for Diseases of the Throat, Grolden Square, and to the Throst and Ear Department, the Children's Hospital, Paddington Green. With 145 Illustrations. Royal 8vo, 18 s.

Part VI. - Section 1. The Surgical Affections of the tongue and floer of the mouth, the pharynx, neck, nesophagus, stomach and intestimes. With 124 Ilustrations. Royal 8vo, $18 s$.

Section 2. The Surgical Affections of the rectum, liver, spleen, pancreas, throat, breast and genitourinary organs. With Illustrations. Royal 8ro.

In preparation.

\section{CLARKE. POST-MORTEM EXAMINATIONS IN MEDICO-} LEGAL AND ORDINARY CASES. With Special C'hapters on the Legal Aspects of Post-Mortems, and on Certificates of Death. Br J. JACKSON CL.ARKE. M.B. Lond., F.K.C.S., Assistaut-Surgeon at the North-IVest London and City Orthopaedic Hospitals. Parhologist and Curator of the Museum at St. Mary's Hospital. Feap. Sro. 2s. 6u?.

COATS. A MANUAL OF PATHOLOGY. BY JOSEPH COATS, M.D., late Professor of Pathology in the Lniversisy of (1)lasgow. Fourth Edition. Revised throughout and Edited by LEWIS R. SLTHERLAND, M.D., Professor of Pathology, Lniversity of St. Anctrews. Witb 490 Illus. trations, $8 \mathrm{vo}, 31 s, 6 d$.

* A considerable portion of the work of revisal necessary in the preparation of a Fourth Edition of the above text-book had been already accomplished by the Author, Professor Joseph Coats, in the four months immediately preceding his death. It is in response to his expressed wish that the editorial duties have been assumed br Dr. Lewis $\mathbf{R}$. Sutherland. 


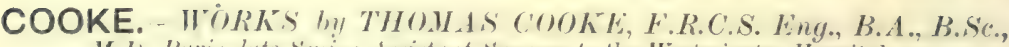

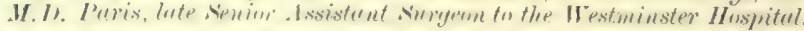

TABLETS OF ANATOMY. Being a Synopsis of demonstrations given in the Westminster Hospital Medical School. Eleventh Edition in three Parts, thoroughly brought up to date, and with over 700 Illustrations from all the best sources, British and Foreign. Post 4 to. Part I. The Bones, 7s. 6d. net; Part II. Limbs, Abdonen, Pelvis, 10s. 6d. net; Part III. Head and Neck, Thorax, Brain, 10s, 6d. net.

APHORISMS IN APPLIEI ANATOMY AND OPERATIVE SLRGERY. Including 100 Typical rira voce Questions on Surface Marking, etc. Crown 8vo, 3s. 6d.

DISSECTION GUIDES. Aiming at Extending and Facilitating such P'ractical Work in Anatomy as will be specially useful in connection with an ordinary Hospital Curriculum. 8vo, 10s. $6 \dot{d}$.

\section{CURTIS. THE ESSENTIALS OF PRACTICAL BACTERI-}

OLOGY : an Elementary Laboratory Book for Students and Practitioners. By H. J. CLRTIS, B.S. and M.D. Lond., F.R.C.S., Assistant Surgeon, Royal Hospital for Children and Women, Waterloo Road; late Surgical Registrar, University College Hospital ; formerly Assistant to the Professor of Pathology, Lniversity College, Londion. With 133 Illustrations. 8vo, 9s.

DAKIN. A HANDBOOK OF MIDWIFERY. BY WILLIAM RADFORD DAKIN, M.D., F.R.C.P., Obstetric Physician and Lecturer on Midwifery at St. ('eorge's Hospital, Examiner in Midwifery and Diseases of Women on the Conjoint Board of the Roral Colleges of Physicians and Surgeons in England, etc. With 394 Illustrations. Large crown 8vo, 18s.

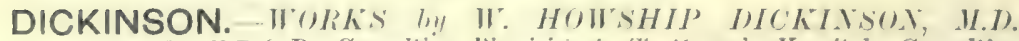
Cantab., F.R.C.P. Comsulting I'leysician to St. Cieirge's Hospital; Cemsultin Physician to the Hospital for sick Children, etc.

ON RENAL, AND URINARY AFFECTIONS. Complete in Three Parts, 8vo, with 12 Plates, and 122 Woodents. $\& 34 s .6 d$.

THE TONGUE AS AN INDICATION OF DISEASF; being the Lumleian Tectures delivered at the Royal College of Physicians in March, 1888, 8vo, $7 s, 6 d$.

OCCASIONAL PAPERS ON MEDICA L, SUBJECTS, 1855-1896. $8 \mathrm{vo}, 12 \mathrm{~s}$

MEDICINE OLD AND NEW : an Introductory Address delivered on the occasion of the Opening of the Winter Session, 1899-1900, at St. George's Hospital Medical School, on 2nd October, 1899. Crown 8vo, 2s. 6d.

ERICHSEN. THL SCIENCE AND ART OH SLRGERY : A TREATISE ON SURGICAL INJURILS, DISEASLS AND OPERATIONS. By Sir JOHN ERIC ERICHSEN, Bart., F.R.S., LI.D. Edin., Hon. M.Ch, and F.R.C.S. Ireland. Tenth Edition. Revised by the late MARCY'S BECK, M.S. and M.B. Lond., F.R.C.S., furgeon to Iniversity College Hospital, and Professor of Surgery in University College, I sondon; and by RAYMONI) JOHNSON, M.B. and B.S. Lond., F.R.C.S., Assistant Surgeon to I Tiversity College Hospital, etc. Illustrated by nearly 1,000 Engravings on Wood. 2 vols. Royal 8vo, 4 s.s. 
FOWLER AND GODLEE. THE DISEASES OF THE LUNGS. By JAMES KINGSTON FOWL.ER, M.A.. M.D.. F.R.C.P., Physician to the Middlesex Hospital and to the Hospital for Consumption and Diseases of the Chest, Brompton; late Examiner in Medicine at the Lniversity of Cambridge, and on the Conjoint Examining Board in England : and RICKMAN JOHN GOIDLEE. M.S., F.R.C.S., Honorary Surgeon-in-Ordinary to His Majestr, Fellow and Professor of Clinical Surgery, Iniversity College, London: Surgeon to Lniversity College Hospital and to the Hospital for Consumption and Diseases of the Chest, Brompton : Surgeonin-Ordinary to His Majesty's Household. With 160 Illustrations 8 vo, 25s.

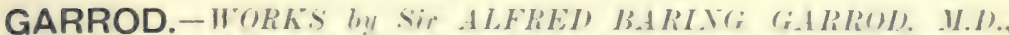

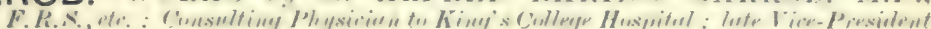
of the Romal College of Physicians.

A TRE.ATISE ON GOLT AND RHEUMATIC GOUT (RHEUMATOID ARTHRITIS). Third Edition. thoroughy Revised and Enlarged; with 6 Plates, comprising :-1 figures (14 Colnured), and 27 Illustrations engraved on Wood. 8vo, 21 s.

THE ESSENTIALS OF MATERIA MEDICA AND THERAPEUTICS. The Fourteenth Edition, Revised and Edited, under the Supervision of the Author. by XESTOR TIRARD, II.I. Lond., F.R.U.P., Professor of Materia Medica and Therapenties in Kings College. I.ondon, etc. Crown 8 vo, $12 s$. $6 d$.

GOADBY. THE MYCOLOGY OF THE MOLTH: A TENTBOOK OF ORAL BACTERIA. BY KFNNETH W. (FOADBI, L.D.S. Fng.. D.I'H. Camb., I.R.C.P.. II.R.C.S.. Hacteriologist and Lecturer on Bacteriologr. National Dental Huspital, etc. With \$2 Illustrations. 8vo, 8s. 6d. net.

GOODSALL. AND MILES. IISEASES OF THE ANLS AND REC'TUM. By D. H. (FOODSALL, F.R.C.S., senior surgeon Metropolitan Hospital. Senior Surgeon (late House Surgeon) St. Mark's Hospital : and WV. FRNE.ST MILES. F.R.C.S., Assistant Surgeon to the Cancer Hospital, surveon lont-patients) to the Gordon Hospital, etc. (In Two Parts).

PART I.-Anatomy of the Ano-rectal Region-General Diagnosis-AbscessAno-rectal Fistula - Recto-urethral, Recto-resical and Recto-vaginal Fistula-Sinus over the Sacro-cocevgeal Articulation-Fissure-Hiemorrhoids (External and Intermal). With 91 Illustrations. Sro, T.s. Erl. net.

PART II.-(Nearly ready).

GRAY. ANATOMY, DESC'RIPTIVE AND SURGICAL. By HENRY GRAY, F.R.S., late Lecturer on Anatomy at St. George's Hospital Medical School. The Fifteenth Edition Enlarged, edited by T. PICKERING PICK, F.R.C.S.. Consulting surgeon to St. George's Hospital. ete., and by R()BERT HOWDEN, M.A., M.P.. C.M., Professor of Anatomy in the University of Durham, etc. With 772 Illustrations, a large proportion of which are Coloured, the Arteries being coloured red. the Veins blue, aud the Nerves vellow. The attachment of the muscles to the bones, in the section on Osteology, are also shown in coloured outline. Royal svo, $32 s$. net. 
HALLIBURTON.-WORK's In W. I). HALIIBLRTON, M.D., F.R.S., F.R.C.P., Professor of Physinlingy in King's Cullege, London.

A TEXT-BOOK OF CHEMICAL PHYSIOLOGY AND PATHOLOGY. With 104 Illustrations. 8vo, $28 \mathrm{~s}$.

THE ESSENTIALS OF CHEMICAL PHYSIOLOGY. For the ['se of Students. Third Edition. With 77 Illustrations. 8vo, 5 s.

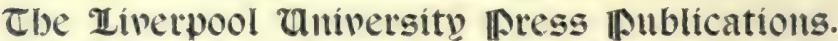

THE THOMPSON YATES LABORATORIES REPORTS. Plivsiology: Pathology; Bacteriology; Tropical Medicine; Hygiene. Edited by RUBERT BOYCE and C. S. SHERIRINGTON. With Plates and IHus. in Text. Demy 4to. Vol. 1. 1898-9, 10s. 6d.; Vol. II. 1898-9, 35.5. ; Vol. III., Part I., 1900, 7.s. 6id.; Vol. III.. Part II., 1901, 12s. 6d. ; Vol. IV., Part I., 1901, 20s.; Vol. IV., Part II., 1902, limp, 20s.; cloth, 21s.

\section{THE LIVERPOOL SCHOOL OF TROPICAL MEDICINE MEMOIRS.}

With Plates and Illustrations in the Text. Demy 4 to.

I. MALARIAL FETER: ITS CAUSE, PREVENTION AND TRFATMENT. Containing full Details for the Use of Travellers, Sportsmen, Soldiers and Residents in Malarions Places. By RONALD liosS, F.R.S., F.R.C.S. Ninth Fdition, revised and enlarged. With Frontispiece. 8vo, 2s. $6 d$.

II. REPORT OF THE MALARIA EAPEDITION TO WEST AFRICA, A C.G., 1899. By RONALD ROSS, D.P.H., M.R.C.S.; H. E. ANNETT, M.D., D.P.H., and E. E. ALSTEN. With Supplementary Reports by Major G. M. ('ILES, M.B., and R. FIELDI VG-OLI,D, M.B. 21 .

III. REPORT OF THE MALARIA ENPEDITION TO NIGERIA. By H. E. ANNETT, II.D. : J. EVERETT DITTON, M.B., and J. H. ELLIOTT, M.D. Part I. Malarial Fever, etc. 10s. $6 d$.

IV. REPORT OF THE MALARIA EXPEDITION TO NIGERIA. By H. E. ANNETT, M.D. ;. EVERETT DUTTON, M.B., and J. H. ELLIOTT DCTTON, M.D. Part II. Filariasis. $15 s$.

․ PART 1. FIRST PROGRESS REPORT OF THE CAMPAIGN AGAINST MOSQUITOES IN SIERRA LEONE (1901). By Major R. RosS, F.R.C.S., F.R.S. 8vo, 18.

I'AR'T 8. SECOND PROGRFSS REPORT OF THF CAMPAIGN AGAINST MOSQUITOFS IN SIERRA I.EONE. By M. LOGAN TAYLOR, M.B. 8vo, sewed, 18.

YII. REPORT OF THE YELLOW FLVER EXPEDITION TO PARÁ (1900). By H. E. DURHAM, M.B., F.R.C.s., and the late WALTER MYERS, M.B, 4to, 7s.6d.

VII. REPOR'T ON THE SANITARY CONIITIONS OF CAPE COAST TOWN, with Suggestions as to Improvement of same. By M. LOGAN TAYLOK, M.B. 8vo, sewed, $1 s$.

$$
\text { MISCELLANEOL'S'. }
$$

II. NOTLS ON SANITARY CONDITIONS OBTAINING IN PARS. By the MEMBERS OF THE YELLOW FEVER EXPEDITLON: H. F. IUCRHAM, M.B., F.R.(C.S., and the late WALTEK MYFiR M.B. June, 1900, to April, 1901. BNo, 1s. 
LANG. THE METHODICAL EXAMINATION OF THE EYE. Being Part I. of a Guide to the Practice of Ophthalmology for Students and Practitioners. By WILLIAM LANG. F.R.C.S. Eng., Surgeon to the Roysl London Ophthalmic Hospital, Moorfields, etr. With 15 Illustrations. Crown 8vo, 3s. 6d.

\section{LIVEING. HANDBOOK ON DISEASES OF THE SKIN.} With especial reference to Diagnosis and Treatment. By ROBERT LIVEING, M.A. and M.D. Cantab.. F.R.C.P. Loud., etc., Physician to the Department for Diseases of the Skin at the Middlesex Hospital, etc. Fifth Edition, revised and enlarged. Fcap. 8vo, 58.

\section{LUFF. TEAT - BOOK OF FORENSIC MEDICINE AND} TOXICOLOGY. By ARTHLR P. LLFF, M.D., B.Sc. Lond. Physician in Charge of ()ut-Patients and Lecturer on Medical Jurisprudence and Toxicology in St. Mary's Hospital; Examiner in Forensic Medicine in the University of London; External Examiner in Forensic Mediciue in the Victoria Cniversity; Official Analyst to the Home Office. With 13 fullpage Plates ( 1 in colours) and 33 Iilustrations in the Text. 2 rols., Crown 8 vo, $24 s$.

MOORE. ELEMENTARY PHYSIOLOGY. Br BENJAMN MO(IRE, M.A.. Lecturer on Physiology at the Charing Cross Hospital Medical School. With 125 Illustration:. Crown 8vo, 3s. 6d.

NOTTER AND FIRTH. HYGIENE. Bv J. L. NOTTER, M.A.. MI.D., Professor of Hygiene in the Army Medical School, Netley; Colonel Royal Army Medical Corps: and R. H. FIRTH, F.R.C.S., late Assistant Professor of Hygiene in the Army Medical School, Netley; Mrajor Royal Army Medical Corps. With 93 Illustrations. Crown 8vo, 3s. 6i.

PAGET. MEMOIRS AND LETTERS OF SIR JAMES PAGET, Bart.. F.K.S.. D.C.L., late Sergeant-Surgeon to Her late Majesty Queeu Victoria. Edited hy STEPHEX PAGET, F.R.C.S. With Portrait. Sro, 6s. net.

SELECTED ESSAYS AND ADDRESSES BY SIR JAMES PAGET. Edited by STEPHEN PAGET, F.R.C.S. 8ro, 12s. 6d. net. ConTEnts: Senile Serofula (1867)—Cases that Bonesetters Cure (1867)On Stammering with other Organs than those of Speech (1868) - What becomes of Medisal Students (1869) - Sexual Hypochondriasis (1870)—On Dissection-wounds (1871)-Nervous Mimiery (1873)-On Disease of the Nammary Areola preceding Cancer of the Mammary Gland (1874)-On a Form of ('hronic Inflammation of Bones (Osteitis Deformans) (1877) Hunterian Oration (1877) - On some of the Sequels of Typhoid Fever (1879) -Ancstheties: The History of a Discovery (1879)-Elementary Pathology (1880) - Theology and Science (1880) - Presidential Address at the Opening of the International Medical Congress (1881) - The Contrast of Temperance with Abstinence (18\$1)-Experiments on Animals (1881) - Some Rare and New Diseases (1892)-National Health and Yational Work (1884)-Periostitis following Strains (1891)-Spines Suspeeted of Deformity (1891)Ubseure Cases of Caries of the Spine (1891)-Errors in the Chronometry of Life (1891)-Use of the Will for Health (1891). 
PICK. SURGERY: A TREATISE FOR STLDENTS AND PRACTITIONERS. By T. PICKERING PICK, Consulting Surgeon to St. George's Hospital; Senior Surgeon to the Victoria Hospital for Children; H.M. Inspector of Anatomy in England and Wales. With 441 Tllustrations. Medium 8vo, 25s.

POOLE. COOKERY FOR THE DIABETIC. By W. H. and Mrs. POOLE. With Preface by Dr. PAVY. Fcap. 8vo, 2s. fir.

POORE, -WORKS by GEORGE VIVIAN POORE, M.J., F.R.C.P. THE EARTH IN RELATION TO THE PRESERVATION AND DESTRUCTION OF CONTAGIA : leing the Milroy Leetures delivered at the Royal College of Physicians in 1899, together with other Papers on Sanitation. 13 Illustrations. ('rown Sro, 5s.

ESSAYS ON RURAL HYGIENE. Crown 8vo, 6s. Gel.

THE DWELLING HOUSE. With 36 Illustrations. Crown 8 ro, $3 . s, 6 \pi$,

PROBYN-WILLIAMS. A PRACTICAL GUIDE TO THE ADMINISTRATION OF ANESTHETICS. By R. J. PROBYN-WILIIAMS, M.D., Anæsthetist and Instructor in Anresthetics at the London Hospital; Lecturer in Anæsthetics at the London Hospital Medical College, etc. With 34 Illustrations. Crown 8vo., 4s. 6rl. net.

QUAIN. QUAIN'S DICTIONARY OF MEDICINE. By Various Writers. Edited by H. MONTAGLE MURRAY, M.D., F.R.C.P.. Joint Lecturer on Medicine, Charing Cross Medical School, and Physician to Out-Patients, Charing Cross Hospital; Senior I'hysician to the Victoria Hospital for Children, Chelsea, and to the Foundling Hospital. Assisted by JOHN HAROLD, M.B., B.CH., B.A.(., Physician to St. John's and St. Elizabeth's Hospital, and Demonstrator of Mledieine at Cliaring Cross Medical School, and W. CECIL BOSANQIET, M.A., M.D.. M.R.C.P., Physician to Out-Patients, Victoria Hospital for Children, Chelsea, and P'athologist to Charing Cross Hospital ; late Fellow of New College, Oxford. Third and Cheaper Edition, largely Rewritten, and Revised throughout. With 21 Plates (14 in Colour) and numerous Illustrations in the Text. 8 vo, 21. net., buckram ; 30 s. net., half-motocco.

\section{QUAIN. QUAIN'S (JONES) ELEMENTS OF ANATOMY.}

The Tenth Edition. Hdited by EDWARD ALBERT SCHÄFER, F.R.S., Professor of Physiology in the Cniversity of Edinburgh : and CEORGE DANCER THANE, Professor of Anatomy in Iniversity College, London. In 3 vols.

* * The several parts of this work form complete 'Text-Books of thEIR RESPECTIVE sUBJECTS. 'They can be obtained separately as follows :-

Vol. I., PART I. EMBRYOLOGY. ByE. A. SCHÄFER, F.R.S. With 200 Illustrations. Royal 8vo, 9 s.

Vor. I., PAR' II. GENERAL ANATOMY OR HISTOL,OGY. By E. A. SCHÄFER, F.R.S. With 291 Illustrations. Royal svo, 12 s. $6 r$. 
QUAIN. QUAIN'S (JONES) ELEMENTS OF ANATOMY-cont.

Vol. II., Part I. OSTEOLOGY - ARTHROLOGY. By G. D. THANE. With 224 Illustrations. Roysal 8vo, 11s.

Tol. II., Part II. MYOLOGY - ANGEIOLOGY. By G. D. THANE. With 199 Illustrations. Royal 8vo, 16s.

Vol. III., PART I. THE SPIN.AL CORD AND BRAIN. By E. A. SCHÄFER, F.R.S. With 139 Illustrations. Royal 8vo, 12. Gut.

Vol. III., PARt II. THE NERTES. By G. D. THANE. With 102 Illustrations. Royal 8vo, 9 s.

Vol. 11I., Part III. THE ORGANS OF THE SENSES. By. A. SCHÄFER, F.R.S. With 178 Illustrations. Royal 8vo. 9s.

Vol. III., Part IV. SPLANCHNOLOGY. Br E. A. SCHÄFER, F.R.S., and JOHNSON SYMINGTON, M.D. With 337 Illustrutions. Royal, 8vo, $16 s$.

APPENDIX. SUPERFICLAL AND SLRGICAL ANATOMY. By Professor G. D. THANE and Professor R. J. (iOI)LEE, M.s. With 29 Illustrations. Royal 8vo, 6s.6d.

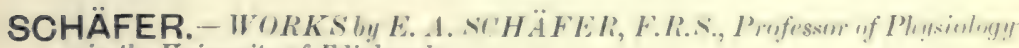
in the University of Edinburyh.

THE ESSENTIALS OF HISTOLOGY : Descriptive and Practical. For the Use of Students. With 463 Illustratims. Svo, 9.s. net.

DIRECTIONS FOR CLASS WORK IN L'RACTICAL PHYSIOLOGY : Elementary Physiology of Muscle and Nerve and of the Vascular and Nerrous Systems. With is Diagrams. Aro, 3*. net.

SCHENK. MANUAL OF BACTERIOLOGY. For Practitioners and Students. With especial reference to Practical Methods. Br Dr. S. L. Schenk, Professor (Extraordinary) in the (niversity of Vienna. Translated from the German, with an Appendix, by W. R. DAWSON. B.A., M.D. Lniv. Dub.; late Lniversity Travelling Prizeman in Medicine. With 100 Illustrations, some of which are coloured. 8ro, 10*, net.

\section{SMALE AND COLYER. DISEASES AND INJIRIES OF} THE TEETH, including Pathology and Treatment. By MORTON SMALE, M.R.C.S., L.S.A., L.D.S., Dental Surgeon to St. Mary's Hospital, Dean of the School. Dental Hospital of London, etc. : and J. F. COI.YER, L.R.C.P., M.R.C.S., L D.S., Dental Surgeon to Charing Cross Hospital and to the Dental Hospital of London. Second Edition Revised and Enlarged by J. F. COLYER. With 640 Illustrations. Large Crown svo, 21s. net.

SMITH (H. F.). THE HANDBOOK FOR MIDIVIVS. BY HENRY FLY SMITH, B.A., M.B. Oxon., MI.R.C.S. Second Edition. With 41 Woodeuts. Crown 8vo, 5 s.

STEVENSON. WOUNDS IN WAR: the Mechanism of their Production and their Treatment. By Surgeon-Colonel W. F. STEVENSON (Army Medical Staff), A.B., M.B., M.Ch. Dublin ('niversity; Profes-or of Military Surgery. Army Mledical School, Netley. With 86 Illustrations. $8 \mathrm{vo}, 18 s$. 
TAPPEINER. INTRODLCTION TO CHEMICAL METHODS OF CLINICAL DIAGNOSIS. By Dr. H. TAPPEINER, Professor of Pharmacology and Principal of the Pharmacological Institute of the University of Munich. Translated from the Sixth German Edition, with an Appendix on Micro-Biological Methods of Diagnosis, by EDMOND J. McWEENEY, M.A., M.D. Royal Lniv, of Ireland, L.R.C.P.I., etc. With 22 Illustrations. Crown 8vo, 3s.6el.

THORNTON. HUMAN PHYSIOLOGY. By JOHN THORNTON, M.A., Author of " Elementary Physiography," "Advanced Physiography," etc. With 267 Illustrations, some of which are Coloured. Crown 8vo, 6s.

WALLER. - W'(RKS by AUGLSTLS' 1). WALLER, M.I), Lecturer

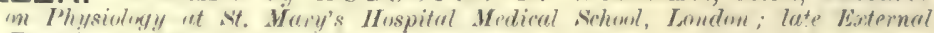
Evrminer at the Victorian Unicersity.

AN INTRODUCTION TO HUMAN PHYSIOLOGY. Third Edition, Revised. With 314 Illustrations. 8vo, 18s.

LECTURES ON PHYSIOLOGY.

First Serins.-On Animal Electricity. 8vo, 5s, net.

\section{eqeterinary atledirime, etr.}

FITZWYGRAM. HORSES AND STABLES. By Lieutenant(ieneral Sir F. FIT\%WYGRAM, Bart. With 56 pages of Illustrations. $8 \mathrm{vo}, 3 s$. net.

STEEL. WORK' by JOHN HENRY STEEL, F.R.C.V.S., F.Z.S.,

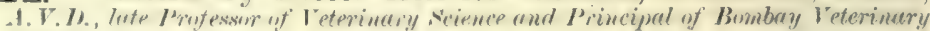
Cinllege.

A TREATISE ON THE DISEASES OF THE DOG; being a Manual of Canine Pathology. Especially adapted for the use of Veterinary Practitioners and Students. With 88 Illustrations. 8vo, 10s. 6 d.

A TREATISE ON THE DISEASES OF THE OX; being a Manual of Bovine Pathology. E'specially adapted for the use of Veterinary Practitioners and Students. With 2 Plates and 117 Woodcuts. 8vo, 15s.

A TREATISE ON THE DISEASES OF THE SHEEP; being a Manual of Ovine Pathology for the use of Veterinary Practitioners and Students. With Coloured Plate and 99 Woodeuts. 8vo, 12 s.

YOUATT. - WORKS l, WILLIAM YOLATT.

THE HORSE. Revised and Enlarged by W. WATSON, M.R.C.V.S. With 52 Wood Engravings. 8vo, $6 s$.

THE DO(i. Rerised and Enlarged. With 393 Wood Engravings. 8vo, 6s. 


\section{Genexal scientific colorts.}

ARRHENIUS. A TEXT-BOOK OF ELECTRO-CHEMISTRY. Py SVANTE ARRHENIL'S. Professor of Physics at the I'niversity of Stockholm. Translated from the German Edition br JOHX MCCRAE, Ph.D. With 58 Illustrations. 8vo, 98,6d. net.

BEDDARD. THE STRUCTURE AND CLASSIFICATION OF BIRDS. By FRANK E. BEDDARD, M.A., F.R.S., I'rosector and Vice-Secretary of the Zoological Society of London. With 25.2 Illustrations. 8vo, 21s. net.

BENNETT AND MURRAY. A HANDBOOH OF CRYPTOGAMIC BOTANY. By A. W. BENNETT, M.A., B.SC.. F.L.S., and GEORGE R. MIL.NE MURRAY. F.L... With 3Tis Illustrations. 8 vo, 16 .

BOSE. RESPONSE IN THE LIVING AND NON-LIVING. By JAGADIS CHIXNDER BOSE. M.A., Cantab., D.sic. Lond., Professor. Presidency College, Calcutta. With 117 Hlustrations. Sro, 10s. Gal.

***This volume ileserilve- experimental investigations on animal, vegetable, and inorganir suhstances regariling their response to stimulus. These rmsearehes show that the effeets of fatigue. stimulants, depressants, and puisoms are alike in the organie and inorganic. and demonstrate that the response phenomena in the "living" have been foreshadowed in the "non-living".

CHAPMAN. THE FORAMINIFERA: AN INTRODLCTION TO THE STCDY OF PROTOZOA. By FREDERICK CHAP. MAN, A.L.S.. F.R.M.S., formeriy Assistant in the Geulogical I.ahoratory of the Royal College of Sience: Palaontologint to the National Museum. Irelbourne. With $1 \pm$ Plates and 42 Illustrations in the Text. Rro, 9s. net.

CROOKES. SELECT METHODS IN CHEMICAL ANALYSIS (chiefly inorganic). By Sir W. CROOKES, F.R.S.. V.P.C.S. Editor of "The Chemical News". Third Edition, re-written and enlarged. Illustrated with 67 Woodcuts. 8vo, 21s. net.

CURTIS. A TEXT-BOOK OF GENERAL BOTANY. BY CARLTON C. Cl'RTIS, A.M., Ph.D. Tutor in Botany in Columbia Cuiversity. With 87 Illustrations. Royal 8ro, 12s, net.

DRUDE. THE THEORY OF OPTICS. BY PACL, DRUIDE, Profesior of Physics at the Cniversity of Giessen. Tramslated from the German by C. RIBORG MANN and ROBERT A. MILIILAN, Assistant Professors of Physics at the Cniversity of Chicago. With 110 Diagrans. 8vo, 15s. net.

FRANKLAND. MICRO-ORGANISMS IN WATER, THEIR SIGNIFICANCE, IDENTIFICATION AND REMOVAL. Together with an Account of the Bacteriological Methods Involved in their Investigation. Specially Desigued for the I'se of those connected with the Sanitary Aspects of Water Supply. By Professor PERCY FRANKIAND, Ph.D., B.Sc. Lond., F.R.S., Fellow of the Chemical Society; and Mrs. PERCY FRANKLAND, Joint Author of "Studies on Some Yew MicroUrganisms Obtained from Air". With 2 Plates and numerous Diagrams. 8 vo, $16 s$, net.

FRANKLAND. BACTERIA IN DAILY LIFl. BY MN. PERCY FRANKLAND, F.R.M.S. Crown 8vo, 5s. net. 
HELMHOLTZ.- WORKS by HERMANN L. F. HEL,WHOLTZ, M.D., late Professer of I'hysics in the University of Berlin.

ON THE SENSATIONS OF TONE AS A PHYSIOLOGICAL BASIS FOR THE THEORY OF MUSIC. Second English Edition; with numerous additional notes and a new Additional Appendix. bringing down information to 1885 , and specially adapted to the use of Musical Students. By ALEXANDER J. ELLIS, B.A., F.R.S., F.S.A., etc., formerly Scholar of Trinity College, Cambridge. With 68 Figures engraved on Wood, and 42 Passages in Musical Notes. Royal Svo, 28s.

POPULAR LECTURES ON SCIFNTIFIC SUBJECTS. With 68 Woodcuts. 2 vols. Crown 8 vo, $3 s .6 d$, each.

HERSCHEL. OUTLINES OF ASTRONOMY. By Sir JUHN F. W. HERSCHEL, Bart., K.H., etc., Member of the Institute of France. Twelth Fdition, with 9 Plates, and numerous Diagrams. 8vo, 12s.

HOFF. THE ARRANGEMENT OF ATUMS IN SPACE. Ry J. H. VAN 'T HOFF. Second, Revised and Enlarged Edition. With a Preface by JOHANNES WISLICENUS, Professor of Chemistry at the Iniversity of Leipzig ; and an Appendix, "Stereochemistry among Inorganic Substances," by ALFRED WERNER, Professor of Chemistry at the University of Ziurich. Translated and Edited by ARNOLD EILOART. Crown 8vo, 6s, $6 d$.

HUDSON AND GOSSE. THE ROTIFERA OR "WHEEL INIMALCULES". By C. T. HUDSON, LL.D., and P. H. GOSSE, F.R.S. With 30 Coloured and 4 Uncoloured Plates. In 6 Parts. 4to, price 10s. 6d. each; Supplement. 12s. 6r. Complete in Two Volumes, with Supplement, 4to, $£ 44 s$.

** The Plates in the Supplement contain figures of almost all the Foreign species, as well as of the British Species, that have been discovered since the original publication of Vols. I. and II.

JOUBERT. ELEMLNTARY TREATISE ON ELECTRICITY ANI) MAGNETISM. Founded on JouBERT"s "Traiti Filimentaire "'Flectricite". By G. C. FOSTER, F.R.S., Quain Professor of Physics in University College, Londou; and E. ATKINSON, Ph.D., formerly Professor of Experimental Science in the Staff College. With Illustrations. Crown 8 vo.

[New Edition in the Press.

KLÖCKER. FERMENTATION ORGANISMS IX THE THEORY AND PRACTICE OF THE ALCOHOLIC FERMENTATION INDUSTRY, with special reference to the Construction and Work of laboratories for the Physiology and Technolugy of Fermentation. By ALB. KLOCKRER, Assistant in the Carlsberg Laboratory, Copenhagen. Translated from the (ierman by G. F. ALLAN, B.s.e, Lecturer in the Lniversity of Birmingham, and J. H. MITIIAIR, F.I.C., formerly Leeturer in the British school of Malting and Brewing, and revised hy the Author. With 146 Illustrations in the Text. 8vo. 
LINDLEY AND MOORE. THE TREASLRY OF BOTANY, OR POPLLAR DICTIONARY OF THE VEGETABLE KINGDOM : with which is incorporated a Glossary of Botanical Terms. Edited by J. LINILEY, M.D., F.R.S., and T. MIOORE, F.L.S. With 20 Steel Plates and numerous Woodcuts. 22 Parts. Fcap. Sro, 12s.

LOWELL. MARS. BY PFRCIVAL LOWELL. Fellow American Academy, Member Roval Asiatic Society, Great Britain and Ireland, etc. With 24 Plates. 8vo, 12s. 6d.

*** The book is written in a style suitable for the general reader. and the inost recent sperculations as to the planet heing inhabited. the possible canals, oases, etc., are discussed.

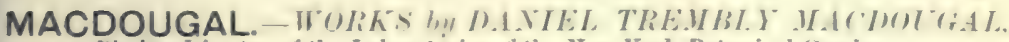

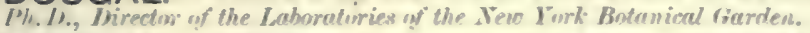

PRACTICAL TEXT-BOOK OF PLANT PHYSIOLOGY. With 159 Illustrations. 8vo, 7s. 6d. net.

ELEMENTARY PLANT PHYSIOLOGY. With 10s Illustrations. Crown $8 v 0,3 s$.

MELLOR. HIGHER MATHEMATICS FOR STCDENTS OF CHEMITRY AND PHYSICS. With special Reference to Practieal Work. By J. W. ME.I.LOR. D.Sc.. late senior scholar. and 1851 Fxhibition Scholar. New Zealand Lniversity: Honorary Research Fellow. the Owens College. Manchester. With 142 Diagrams. Sso, 12s. fol. net.

MENDELÉEFF。 THE PRINCIPLES OF ('HEMISTRY. Bv D. MFXDELEEFF. Translated from the Rusian (Sixth Edition) by GEORGE KAMENSKY.A.R.A.M., of the Imperial Mint. St. Petersburg, and Edited by T. A. LAWSON. B.Sc.. Ph.D.. Fellow of the Institute of Chemistry. With 96 Diagrams and Illustrations. 2 vols. 8vo, 36s.

MEYER. (OTTLINES OF THEORETICAL CHEMISTRY. By LoTHAR MEIFI, Professor of Chemistry in the Lniversity of Tuibingen. Translatel by Professors P. PHILI.IPS BEINON, D.se., and W. CARLETON WILLIAMS, B.Sc. 8vo, 9 .

MEYER. THE KINETIC THEORY OF G.ASES. Elementary Treatise with Mathematical Appeniices. By Dr. OSKAR FMIL MEYER. Professor of Physics at the University of Breslau. Second Revised Edition. Translated br ROBERT E. BAYNES. M.A., Student of Christ Church, ()xford, and Dr. Lee's Reader in Physics. Svo, 15: net.

MORGAN. ANIMAL BIOLOGY. An Elementary Text-Buok. By C. LLOYD MORGAX, F.R.S., Principal of Unirersity College, Bristol. With uumerous Illustrations. Crown svo, 8s. 6rl.

OSTWALD. SOLLTIONS. By W. OSTWALD, Professor of Chemistry in the L"niversity of Leipzig. Being the Fourth Book. with some adiditions, of the Second Edition of Ostwald's "Lehrbuch der Allgemeinen Chemie". Translated by M. M. PATTISON ML IR. Professor of Gonville and Caius College, Cambridge. $8 v o, 10 s .6 d$.

PLIMMER. THE CHEMICAL CHANGES AND PRODUCTS RESULTING FROM FERMENTATION. BN R. H. ADERS

PLIMMER, D.Se. Lond. 


\section{PROCTOR. - WORKS by RICHARD A. IROCTOR.}

LIGHT SCIENCE FOR LEISURE HOURS ; Familiar Essays on Scientific Subjects, Natural Phenomena, etc. Crown 8vo, 3s. 6d.

THE ORBS AROUND US ; a Series of Essays on the Moon and Planets, Meteors and Comets. With Chart and Diagrams. Orown 8vo, 3s. 6d.

OTHER WORLDS THAN OURS : The Plurality of Worlds Studied under the Light of Recent Scientific Researches. With 14 Illustrations. Crown 8vo, 3s. $6 d$.

THE MOON; her Motions, Aspects, Scenery and Physical Condition. With Plates, Charts, Woodcuts and Lunar Photographs. Crown 8 vo, 3s. $6 d$.

LARGER STAR ATLAS for the Library, in 12 Circular Maps, with Introduction and 2 Index Pages. Folio, 15s., or Maps only, 12s. $6 d$.

NEW STAR ATLAS for the Library, the School and the Observatory, in 12 Circular Maps (with 2 Index Plates). Crown 8vo, $5 s$.

OTHER SUNS THAN OURS : a Series of Essays on Suns-Old, Young and Dead. With other Science Gleanings, Two Essays on Whist, and Correspondence with Sir John Herschel. With 9 Star-Maps and Diagrams. Crown 8vo, 3s. 6d.

HALF-HOURS WITH THE TELESCOPE : a Popular Guide to the Use of the Telescope as a Means of Amusement and Instruction. With 7 Plates. Fcap. 8vo, 2s. $6 d$.

THE EXPANSE OF HEAVEN. Essays on the Wonders of the Firmament. Crown 8vo, 3s. 6d.

PLEASANT WAYS IN SCIENCE. Crown 8vo, 3s. 6d.
THE SOUTHERN SKIES : a Plain and Easy Guide to the Constellations of the Southern Hemisphere. Showing in 12 Maps the Position of the principal Star-Groups night after night throughout the yeax. With an Introduction and a separate Explanation of each Map. True for every Year. 4to, 5 s.

MYTHS AND MARVELS OF ASTRONOMY. Crown 8vo, 3s. $6 d$.

HALF - HOURS WITH THE STARS : a Plain and Easy Guide to the Knowledge of the Constellations. Showing in 12 Maps the position of the principal Star-Groups night after night throughout the $Y$ ear. With Introduction and a separate Explanation of each Map. True for every Year. 4to, 3s, net.

THE STARS IN THEIR SEASONS. An Easy Guide to a Knowledge of the Star Groups, in 12 large Maps. Imperial $8 \mathrm{vo}, 5 s$.

OLR PLACE AMONG INFINITIES : a Series of Essays contrasting our Little Abode in Space and Time with the Infinities around Us. Crown 8 vo, $3 \dot{s}, 6 d$.

ROUGH WAYS MADE SMOOTH. Familiar Essays on Scientifie Subjects. Crown 8vo, 3s. $6 d$.

NATURE STUDIES. By Grant Allen, A. Wilson, T. Foster, E. Clodd and R. A. Procton. Crown 8vo, 3s. 6d.

LEISURE READINGS. By E. Clodd, A. Wilson, T. Fosthir, A. C. Runyard and R. A. Proctor. Crown 8 vo, $3 s .6 d$.

STRENGTH : How to get Strong and keep Strong, with Chapters on Rowing and Swimming, Fat, Age and the Waist. With 9 Illustrations. Crown 8 vo, $2 s$.

REYNOLDS. EXPERIMENTAL CHEMISTRY for Junior Students. By J. EMHRSON REYNOLDS, M.I)., F.R.S., Professor of Chemistry, Univ, of Dublin. Feap. 8vo, with numerous Woodcuts.

PAlew I.-Introductory, 1s.6d. PART III.-Metals and Allied Bodies, 3s.6d.

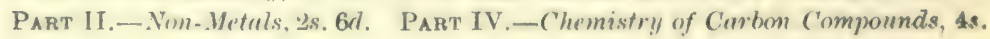


ROMANES.-WURKS by GEORGE JOHY ROMANES M.A., LL.D., F.R.S.

DARWIN, AND AFTER DARWIN : an Exposition on the Darwinian Theory, and a Discussion on Post-Darwinian Questions. Part I. THE. Darwinian Theorr. With Portrait of Darwin and 125 Illustrations. Crown 8vo, 10s. 6d. Part II. Post-Darwisian Qcestross: Heredity and Vtility. With Portrait of the Author and 5 Illustrations. ('rown 8ro. 10s. 6d. Part III. Post-Darwivias Qeestions: Isolation axp PhysioLogical Selection. Crown 8vo, 5 s.

\section{AN EXAMINATION OF WEISMANNISM. Crown sro, 6.}

ESSAYS. Edited by C. LLOYD MORGAN, F.R.S., Principal of I!nirersity College, Bristol. Crown 8vo, 6s.

Costerts: Primitive Natural History-The Darwinian Theory of Instinct-Man and Brute-Mind in Men and Animals-Origin of Human Faculty-Mental Differences between Meu and Women-What is the Object of Life? - Recreation-- Hypnotism -Hydrophohia and the Muzzling Order.

SLINGO AND BROOKER. ELECTRICAL ENGINEERING FOR ELECTRIC-LIGHT ARTISANS AND STLDENTS. (Embracing those branches prescribed in the syllabus issued by the City and Guilds Technical Institute.) Br W. SIIXio and A. BRoOKER.

With 371 Illustrations. Crown 8vo, $12 s$.

SORAUER. A POPULAR TREATISE ON THE PHYSIOLOGY OF PLANTS. For the tse of Gardeners or for Students of Hortieulture and of Agriculture. By Dr. PALL SORALER, Direetor of the Experimental Station at the Koyal Pomologieal Institute in Pronkau (Silesia). Tran-lated by F. E. WEISS. B.Sc., F.L.S.. Professor of Bota:y at the Oweus College, MIanchester. With 33 Illustrations. 8vo, 9.s. net.

THORPE. A DICTIONARY OF APPLIED CHEMISTRY. By T. E. THORPE, C.B., B.Se. Vict., Ph.D., F.R.S., Treas. C.... Director of Government Lahoratories, London. Assisted by Eminent Contributors. To be published in 3 vols. swo. Vols. I. and 1I.. $1222 \mathrm{~s}$. each; Vol. III., £3 3 s.

TILDEN. A SHORT HISTORY OF THE PROGRESS UF SCIENTIFIC CHEMISTRY IN OUR OWN TIMES. By WILLIAII A. TILDEN, D.Sc. Lond.. D.Sc. Dub., F.R.S., Fellow of the University of London, Professor of Chemistry in the Royal College of Seience, London. Crown $8 v 0,5 s$. net.

TUBEUF. DISEASES OF PLANTS DUE TO CRYPTOGAMIC PARASITES. Translated from the German of Dr. CARL FREIHERR VON TUBEUF, of the University of Munich, by WILLIAM G. SMITH. B.Sc., Ph.D., Lecturer on Plant Physiology to the University of Fdinburgh With 350 Illustrations. Royal 8vo, 18s. net. 
TYNDALL. - WORKS' by JOHN TYNDALI, F.R.S., ete. FRAGMENTS OF SCIENCE. 2 Vols. Crown 8vo, 16.

NEW FRAGMENTS. Crown 8vo, 10s. 6d.

HEAT A MODE OF MOTION. Crown 8vo, 12.

SOUND. With 204 Woodeuts. Crown 8vo, 10s. $6 d$.

RESEARCHES ON DIAMAGNETISM AND MAGNECRYSTALLIC ACTION, including the question of Diamagnetic Polarity. Crown 8vo, 12s.

ESSAYS ON THE FLOATING MATTER OF THE AIR in relation to Putrefaction and Infection. With 24 Woodeuts. Crown $8 \mathrm{vo}, 7 s, 6 d$.

LECTLRES ON LIGHT, delivered in America in 1872 and 1873. With 57 Diagrams. Crown 8vo, $5 s$.

LESSONS IN ELECTRICITY AT THE ROYAL INSTITU. TION, 1875-76. With 58 Woodeuts. Crown 8vo, 2s. 6d.

NOTES OF A COURSE OF SEVEN LECTLRES ON ELECTRICAL PHENOMENA AND THEORIES, delivered at the Royal Institution. Crown 8vo, 1s. 6d.

NOTES OE A COURSE OF NINE LECTURES ON LIGHT, delivered at the Royal Institution. Crown 8vo, 1s. $6 d$.

FARADAY AS A DISCOVERER. Crown 8vo, 3s. Grl.

THE GLACIERS OF THE ALPS : leing a Narrative of Excursions and Ascents. An Account of the Origin and Phenomena of (ilaciers and an Exposition of the Physical Principles to which they are related. With 61 Illustrations. Crown 8 vo, $6 s$. $6 d$. net.

WATTS $\left(H_{1}\right)$. DICTIONARY OF CHEMISTRY. Revised and entirely Re-written by H. FORSTER MORLEY, M.A., D.Sc., Fellow of, and lately Assistant-Professor of Chemistry in, University College, London; and II. M. PATTISON MLIR, M.A., F.R.S.E., Fellow and Prelector in Chemistry of (ionville and Caius College, Cambridge. Assisted by Eminent Contributors. 4 vols. 8 vo, $£ 5$ net.

WEBB. CELESTIAL OBJECTS FOR COMMON TELHSCOPES. By the Rev. T. W. WEBB, M.A., F.R.A.S., late Vicar of Hardwick, Herefordshire. Fifth Edition, Revised and greatly Enlarged by the Rev. T. E. ESPIN, M.A., F.R.A.S. (Two Volumes.)

Voc. 1. With Portrait and a Reminiscence of the Author, 2 Plates and numerous Illustrations. Crown $8 v 0,6 s$.

lou. II. With Illustratious and Map of Star Spectra. Crown 8vo, fis. fid.

WRIGHT. OPTICAL PROJHCTION: A Treatise on the Use of the Lantern in Exhibition and Scientific Demonstration. By LEWIS WRI(iH'T', Author of "Light: a Course of Experimental Optics". With 232 Illustrations. Crown 8 vo, 6 s. 





\section{PLEASE DO NOT REMOVE \\ CARDS OR SLIPS FROM THIS POCKET}

\section{UNIVERSITY OF TORONTO LIBRARY}

QP

514

H3

1901

Biological

\& Medical
Halliburton, William Dobinson The essentials of chemical physiology. 4th ed. 
